\title{
Discrete Wavelet Transform Analysis of Surface Electromyography for the Objective Assessment of Neck and Shoulder Muscle Fatigue
}

\author{
Suman Kanti Chowdhury \\ West Virginia University
}

Follow this and additional works at: https://researchrepository.wvu.edu/etd

\section{Recommended Citation}

Chowdhury, Suman Kanti, "Discrete Wavelet Transform Analysis of Surface Electromyography for the Objective Assessment of Neck and Shoulder Muscle Fatigue" (2012). Graduate Theses, Dissertations, and Problem Reports. 4841.

https://researchrepository.wvu.edu/etd/4841

This Thesis is protected by copyright and/or related rights. It has been brought to you by the The Research Repository @ WVU with permission from the rights-holder(s). You are free to use this Thesis in any way that is permitted by the copyright and related rights legislation that applies to your use. For other uses you must obtain permission from the rights-holder(s) directly, unless additional rights are indicated by a Creative Commons license in the record and/ or on the work itself. This Thesis has been accepted for inclusion in WVU Graduate Theses, Dissertations, and Problem Reports collection by an authorized administrator of The Research Repository @ WVU. For more information, please contact researchrepository@mail.wvu.edu. 


\title{
Discrete Wavelet Transform Analysis of Surface Electromyography for the Objective Assessment of Neck and Shoulder Muscle Fatigue
}

\author{
Suman Kanti Chowdhury \\ Thesis submitted to the Benjamin M. Statler College of \\ Engineering and Mineral Resources at \\ West Virginia University in partial fulfillment \\ of the requirement for the degree of \\ Master of Science \\ in \\ Industrial Engineering
}

Ashish D. Nimbarte, Ph.D., Chairn

Robert C. Creese, Ph.D., P.E.

Majid Jaridi, Ph.D.

Department of Industrial and Management Systems Engineering

Morgantown, West Virginia

2012

Keywords: Neuromuscular Fatigue; Surface Electromyography; Discrete Wavelet Transform; Neck; Shoulder; Musculoskeletal Disorders

Copyright 2012 Suman K. Chowdhury 


\begin{abstract}
Discrete Wavelet Transform Analysis of Surface Electromyography for the Objective Assessment of Neck and Shoulder Muscle Fatigue
\end{abstract}

\title{
Suman Kanti Chowdhury
}

Objective assessment of neuromuscular fatigue caused by sub-maximal repetitive exertions is essential for the early detection and prevention of risks of neck and shoulder musculoskeletal disorders. In recent years, discrete wavelet transforms (DWT) of surface electromyography (SEMG) has been used to evaluate muscle fatigue, especially during dynamic contractions when the SEMG signal is non-stationary. However, its application to neck muscle fatigue assessment is not well established. Therefore, the purpose of this study was to establish DWT analysis as a suitable method to conduct quantitative assessment of neck muscle fatigue caused by dynamic exertions. Ten human participants performed 40 minutes of fatiguing repetitive arm and neck exertions. SEMG data from the upper trapezius and sternocleidomastoid muscles were recorded. Ten most commonly used orthogonal wavelet functions were used to conduct DWT analysis. A significant increase in the power was observed at lower frequency bands of $6-12 \mathrm{~Hz}, 12-23 \mathrm{~Hz}$, and $23-46 \mathrm{~Hz}$ with the onset and development of fatigue for most of the wavelet functions. Among ten wavelet function, a relatively higher power estimation, consistent statistical trend and better power contrast with the onset and development of fatigue was observed for the Rbio3.1 wavelet function. The results of this study will assist Professional Ergonomists to automate the process of localized muscle fatigue estimation, which could have applications related to improving working environment. 


\section{Dedications}

This thesis is dedicated to my father who taught me that the best kind of knowledge to have is that which is learned for its own sake. It is also dedicated to my mother, who taught me that even the largest task can be accomplished if it is done one step at a time.

Also, this thesis is dedicated to my wife who has been a great source of motivation and inspiration.

Finally, this thesis is dedicated to all those who believe in the richness of learning. 


\section{Acknowledgements}

I would like to wholeheartedly thank my advisor Dr. Ashish Nimbarte for his continued support, guidance and encouragement throughout this study, and especially for his confidence in me. I would also like to thank Dr. Majid Jaridi and Dr. Robert Creese for their valuable advice and support.

Above all, I wish to thank my parents, and all my friends for their constant support and blessings for enabling my success and happiness in all my pursuits and endeavors in life. 


\section{Table of Contents}

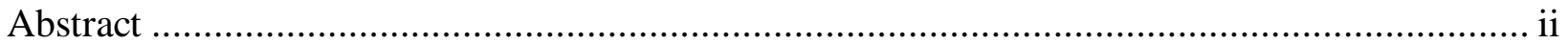

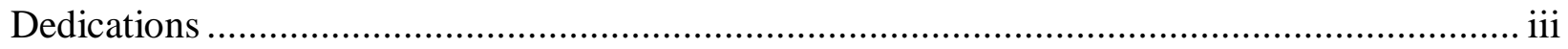

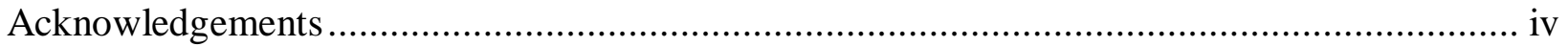

Table of Contents ........................................................................................................

List of Tables ........................................................................................................ vii

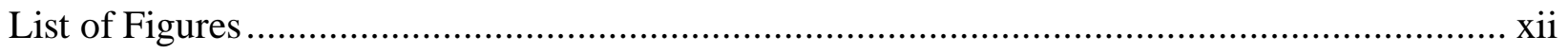

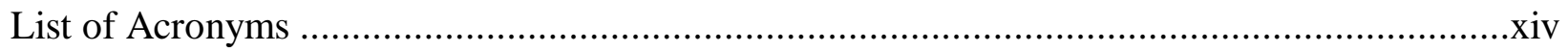

Chapter 1: Introduction ...........................................................................................

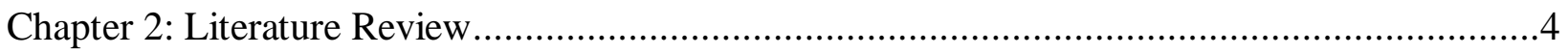

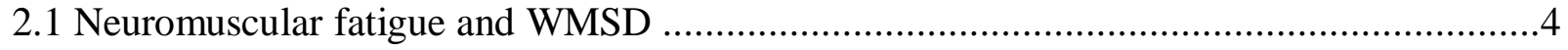

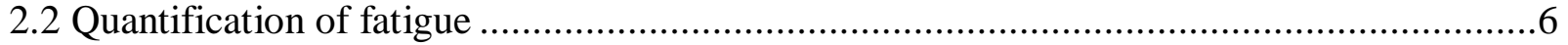

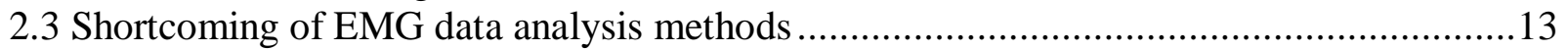

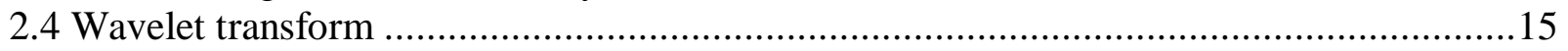

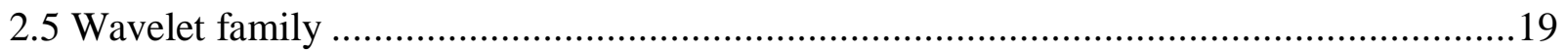

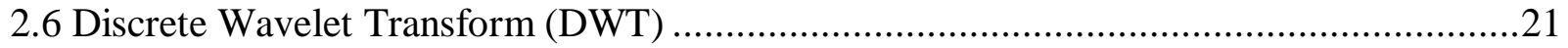

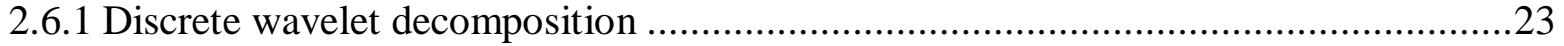

2.6.2 Discrete wavelet reconstruction ...................................................................26

2.7 Previous studies of DWT and neuromuscular fatigue .............................................22

2.7.1 DWT as a better tool for neuromuscular fatigue determination .............................27

2.7.2 Appropriate mother wavelet selection for DWT ............................................. 30

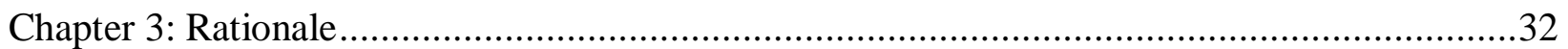

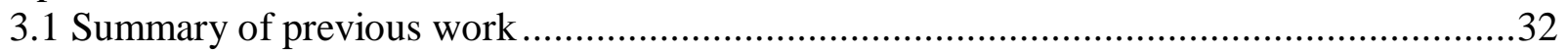

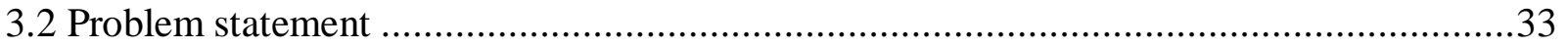

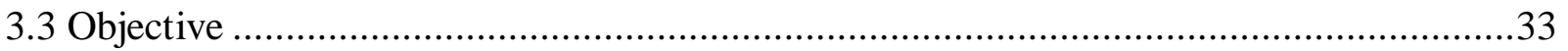

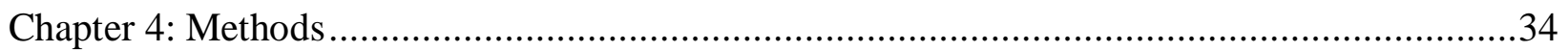

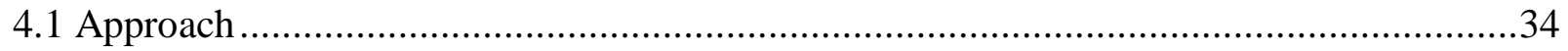

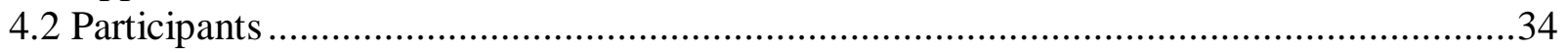

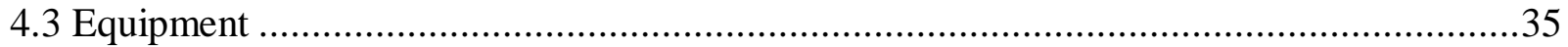

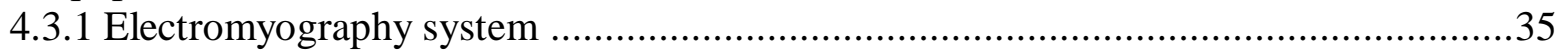

4.3.2 Custom-built manual handling workstation.................................................... 37

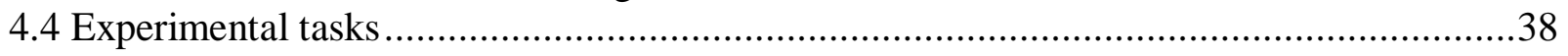

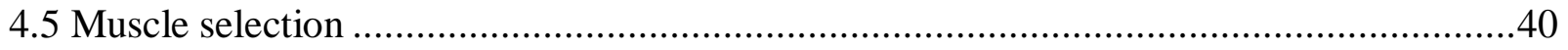




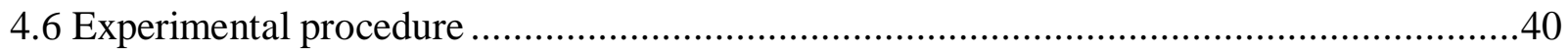

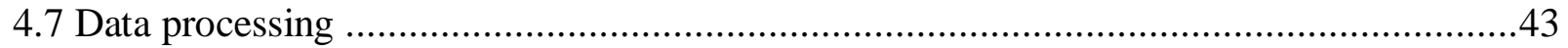

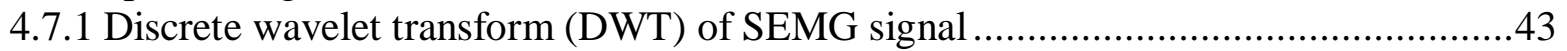

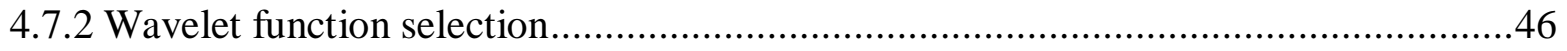

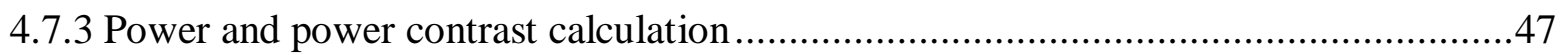

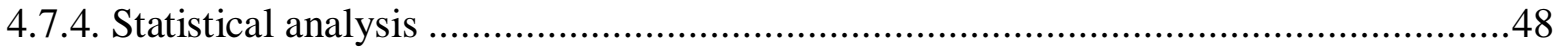

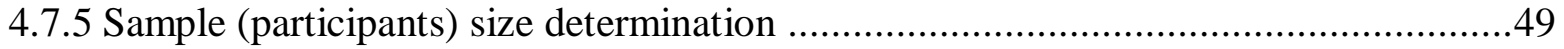

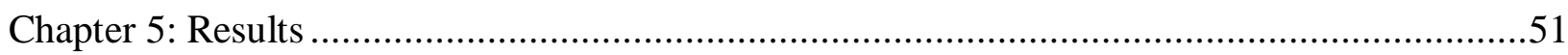

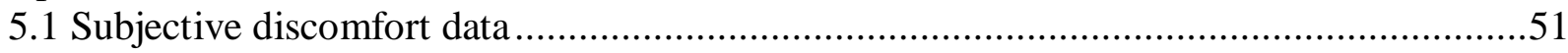

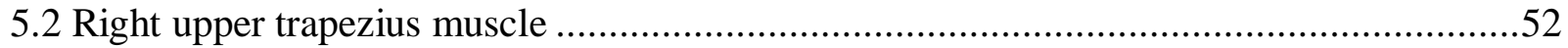

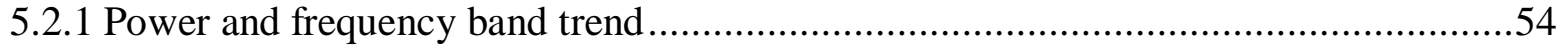

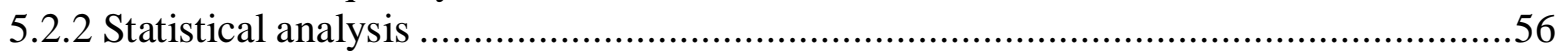

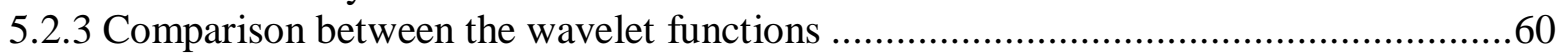

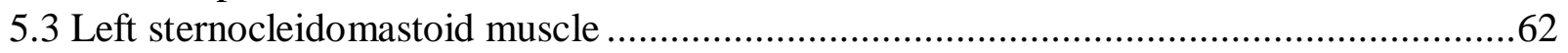

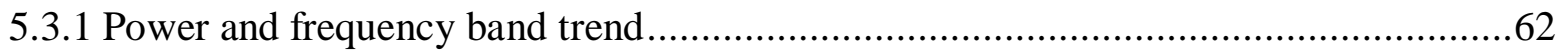

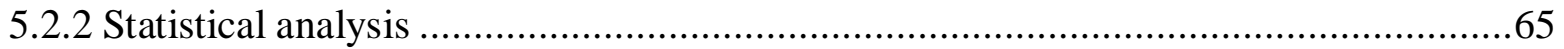

5.2.3 Comparison between the wavelet functions ..........................................................68

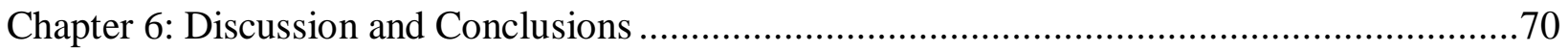

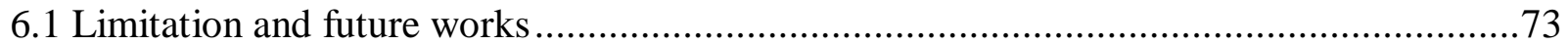

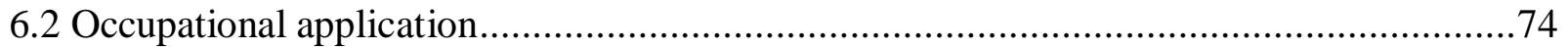

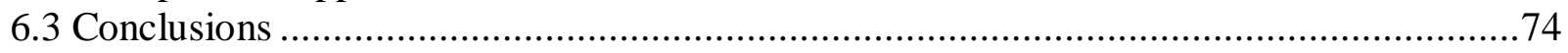

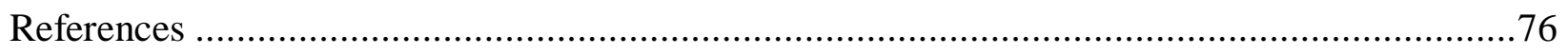

Appendix A: Physical Activity Readiness Questionnaire (PAR-Q) .......................................90

Appendix B: Institutional Review Board (IRB) approval form …….....................................

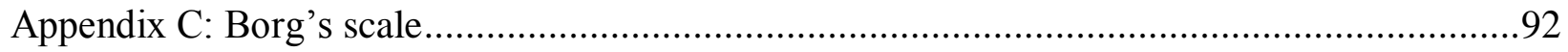

Appendix D: Matlab codes for discrete wavelet transform (DWT) ………………….............93

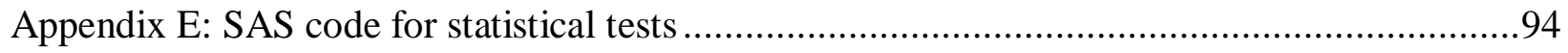

Appendix F: Participants demographic and anthropometric data..........................................95

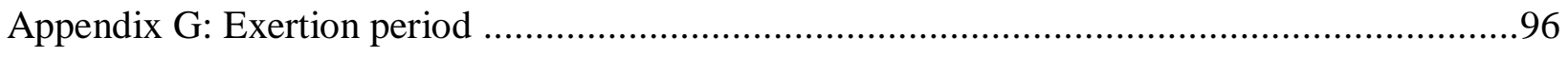

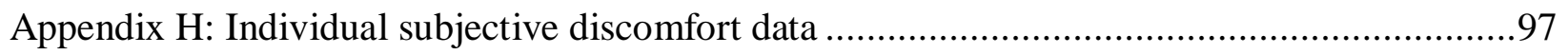

Appendix I: Power data $\left(\mathrm{mV}^{2}\right)$ for individual participants ……..........................................98

Appendix J: Mean ( \pm standard deviation) of power (in $\mathrm{mV}^{2}$ ) calculated using ten wavelet for right

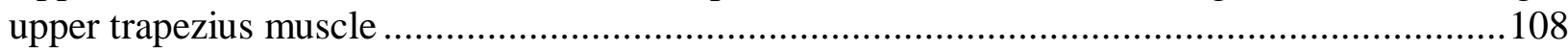


Appendix K: Output of Turkey's test of multiple comparisons for right upper trapezius muscle

Appendix L: Mean ( \pm standard deviation) of power (in $\mathrm{mV}^{2}$ ) using ten wavelet functions for left sternocleidomastoid muscle. 126

Appendix M: Output of Turkey's test of multiple comparisons for left sternocleidomastoid

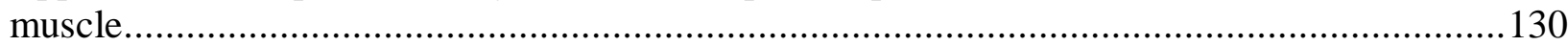




\section{List of Tables}

Table 4.1: Frequency bands for the seven levels of decomposition ...................................43

Table 4.2: Selected wavelet functions or mother wavelets in this study ...............................47

Table 4.3 : Power values for chosen number of participants................................................50

Table 5.1: P-values of the Levene's test for equality of variance of the mixed models for the

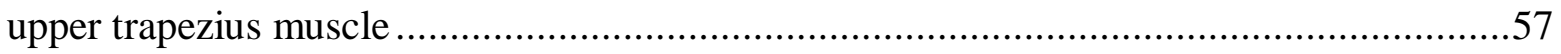

Table 5.2: P-values for the effect of time on the power of SEMG signal from the right upper trapezius muscle for different wavelet functions at various frequency bands. Values marked with asterisks $(*)$ are statistically significant........................................................5

Table 5.3: P-values of Tukey's multiple comparison tests for the effect of time on the power of SEMG signals from right upper trapezius muscle at lower frequency bands for different wavelet functions. Different times instances, $\mathrm{T}_{0}, \mathrm{~T}_{20}, \mathrm{~T}_{25}$ and $\mathrm{T}_{45}$ are symbolized as ' 1 ', '2', '3' and '4', respectively. Values marked with asterisks (*) are statistically significant ..59

Table 5.4: Rank and scores based on the P-values of Turkey's multiple comparison and mixed model for the right upper trapezius muscle. P-values of mixed model are denoted by 'Mixed'. Different times instances, $\mathrm{T}_{0}, \mathrm{~T}_{20}, \mathrm{~T}_{25}$ and $\mathrm{T}_{45}$ are symbolized as ' 1 ', '2', ‘3' and '4', respectively

Table 5.5: Power contrast (\%) at the lower frequency bands: $6-12 \mathrm{~Hz}, 12-23 \mathrm{~Hz}$ and $23-46 \mathrm{~Hz}$ for the top 3 wavelet function for right upper trapezius muscle. Different times instances, $\mathrm{T}_{0}$, $\mathrm{T}_{20}, \mathrm{~T}_{25}$ and $\mathrm{T}_{45}$ are symbolized as ' 1 ', '2', '3' and '4', respectively

Table 5.6: P-values of the Levene's test for equality of variance of the mixed models for left sternocleidomastoid muscle.

Table 5.7: P-values for the effect of time on the power of SEMG signals from the left sternocleidomastoid muscle for different wavelet functions at various frequency bands.

Values marked with asterisks $(*)$ are statistically significant .66

Table 5.8: P-values of Tukey's multiple comparison tests for the effect of time on the power of SEMG signal from the left sternocleidomastoid muscle at lower frequency bands for 
different wavelet functions. Different times instances, $\mathrm{T}_{0}, \mathrm{~T}_{20}, \mathrm{~T}_{25}$ and $\mathrm{T}_{45}$ are symbolized as '1', '2', '3' and '4', respectively. Values marked with asterisks (*) are statistically significant

Table 5.9: Rank and scores based on the P-values of Turkey's multiple comparison and mixed model for the left sternocleidomastoid muscle. P-values of mixed model are denoted by 'Mixed'. Different times instances, $\mathrm{T}_{0}, \mathrm{~T}_{20}, \mathrm{~T}_{25}$ and $\mathrm{T}_{45}$ are symbolized as '1', '2', ‘3' and '4', respectively

Table 5.10: Power contrast (\%) at the lower frequency bands: $6-12 \mathrm{~Hz}, 12-23 \mathrm{~Hz}$ and $23-46 \mathrm{~Hz}$ for the top 3 wavelet function for left sternocleidomastoid muscle. Different times instances, $\mathrm{T}_{0}$, $\mathrm{T}_{20}, \mathrm{~T}_{25}$ and $\mathrm{T}_{45}$ are symbolized as ' 1 ', '2', '3' and '4', respectively 69

Table C.1: Borg's scale of subjective discomfort rating ...............................................92

Table F.1: Demographic and anthropometric data of the participants.... .95

Table G.1: Task completion durations and total number of cycles for the individual participants 96

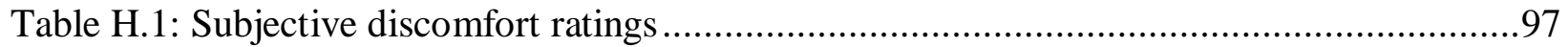

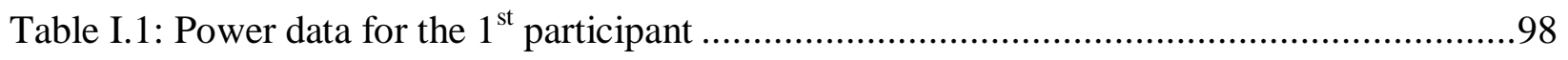

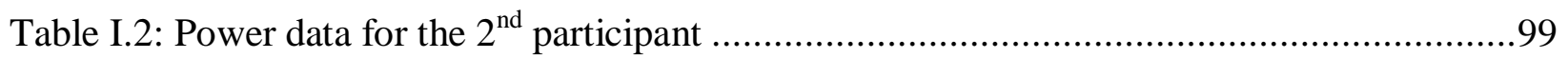

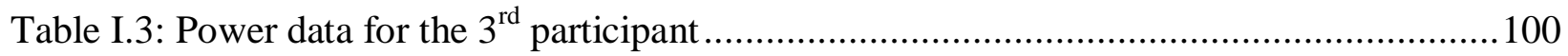

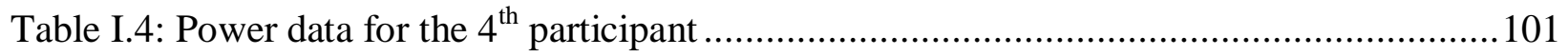

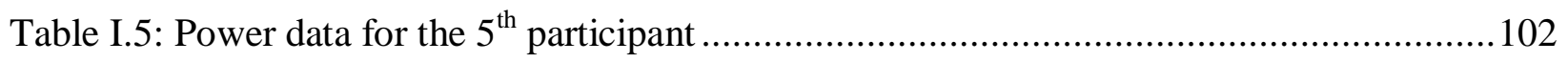

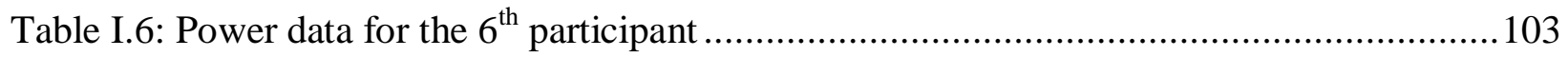

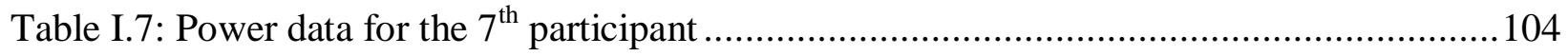

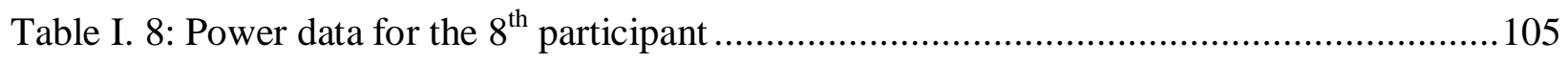

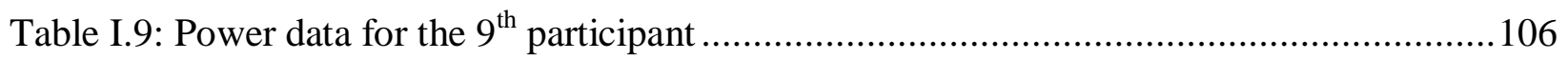

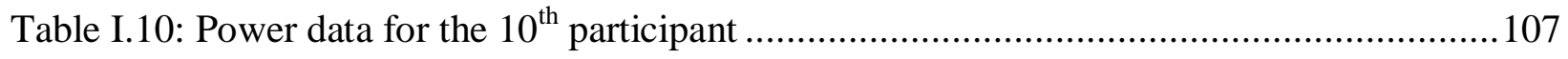

Table J.1: Power estimated using Bior1.5 wavelet function as an effect of time for right upper

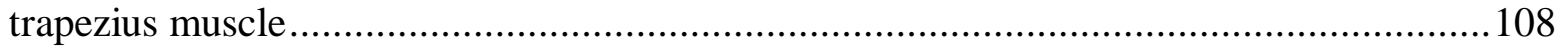

Table J.2: Power estimated using Bior3.1 wavelet function as an effect of time for right upper trapezius muscle 108

Table J.3: Power estimated using Rbio3.1 wavelet function as an effect of time for right upper trapezius muscle 
Table J.4: Power estimated using Coif5 wavelet function as an effect of time for right upper trapezius muscle.

Table J.5: Power estimated using Db2 wavelet function as an effect of time for right upper trapezius muscle.

Table J.6: Power estimated using Db5 wavelet function as an effect of time for right upper trapezius muscle.

Table J.7: Power estimated using Db45 wavelet function as an effect of time for right upper trapezius muscle.

Table J.8: Power estimated using Haar wavelet function as an effect of time for right upper trapezius muscle

Table J.9: Power estimated using Sym4 wavelet function as an effect of time for right upper trapezius muscle.

Table J.10: Power estimated using Sym5 wavelet function as an effect of time for right upper trapezius muscle.

Table L.1: Power estimated using Bior1.5 wavelet function as an effect of time for left sternocleidomastoid muscle.

Table L.2: Power estimated using Bior3.1 wavelet function as an effect of time for left sternocleidomastoid muscle.

Table L.3: Power estimated using Rbio3.1 wavelet function as an effect of time for left sternocleidomastoid muscle.

Table L.4: Power estimated using Coif5 wavelet function as an effect of time for left sternocleidomastoid muscle.

Table L.5: Power estimated using Db2 wavelet function as an effect of time for left sternocleidomastoid muscle.

Table L.6: Power estimated using Db5 wavelet function as an effect of time for left sternocleidomastoid muscle.

Table L.7: Power estimated using Db45 wavelet function as an effect of time for left sternocleidomastoid muscle.

Table L.8: Power estimated using Haar wavelet function as an effect of time for left sternocleidomastoid muscle. 
Table L.9: Power estimated using Sym4 wavelet function as an effect of time for left

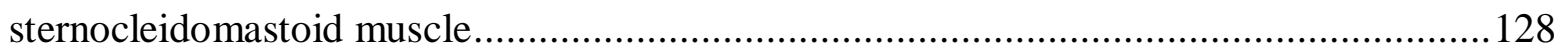

Table L.10: Power estimated using Sym5 wavelet function as an effect of time for left sternocleidomastoid muscle...... 


\section{List of Figures}

Figure 2.1: Transformation of EMG signal from time domain to frequency domain using FFT..10

Figure 2.2: Power spectrum of a FFT transformed EMG signal

Figure 2.3: Wavelet coefficients for large- and small-scale wavelets plotted as a function of translation in time 16

Figure 2.4: Commonly used wavelet functions ........................................................... 17

Figure 2.5: Shrinking and dilation of a simple wavelet .................................................18

Figure 2.6: Scalogram of DWT of SEMG signal using db2 wavelet function.........................19

Figure 2.7: Discrete wavelet decomposition process ...............................................24

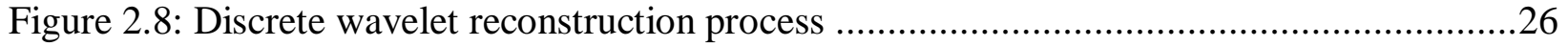

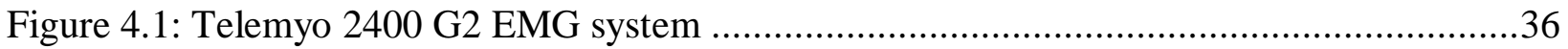

Figure 4.2: Pre-amplified lead wire and snap electrode...............................................36

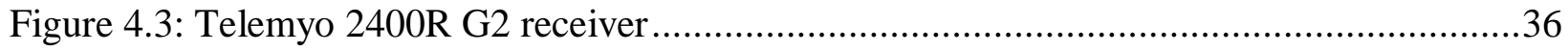

Figure 4.4: Bipolar Ag/AgCl pre-gelled surface electrodes ............................................37

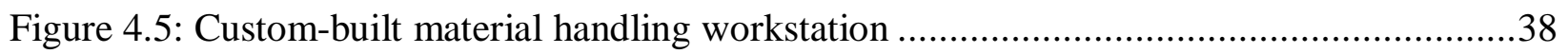

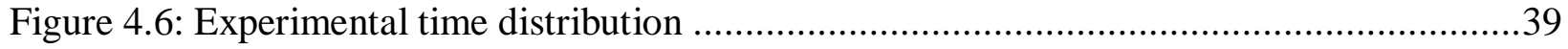

Figure 4.7: A picture from a grocery store showing the height of the top shelves ....................40

Figure 4.8: Location of electrode on the left sternocleidomastoid muscle. ............................41

Figure 4.9: Location of electrode on the right upper Trapezius muscle. ..............................42

Figure 4.10: Seven level decomposition algorithm of DWT used in this study......................44

Figure 4.11: Reconstruction algorithm of DWT used in this study ...................................45

Figure 5.1: Subjective discomfort scores at different time instances .................................52

Figure 5.2: Illustration of the raw SEMG signal and corresponding intensity pattern computed using DWT with Rbio3.1 wavelet function. Horizontal axis represents time scale in milliseconds. Blue bars separate signals collected at different time instances..... 
Figure 5.3: The graphical representation of power $\left(\mathrm{mV}^{2}\right)$ as a function of time for the following wavelet functions: (a) Bior1.5, (b) Bior3.1, (c) Rbio3.1, (d) Coif5, (e) Db2, and (f) Db5 for the right upper trapezius muscle

Figure 5.4 : The graphical representation of power $\left(\mathrm{mV}^{2}\right)$ as a function of time for ten wavelet functions: (g) Db45, (h) Haar (i), Sym4, and (j) Sym5 for the right upper trapezius muscle 56 Figure 5.5: Power of SEMG signal recorded from the right upper trapezius muscle at different time instances for the following frequency bands: (a) 6-12 Hz (b) $12-23 \mathrm{~Hz}$ and (c) 23-46 Hz. Behavior of Rbio3.1 and Bior3.1 wavelets were plotted using a secondary axis .58

Figure 5.6: The graphical representation of power $(\mathrm{mV} 2)$ as a function of time for following wavelet functions: (a) Bior1.5, (b) Bior3.1, (c) Rbio3.1, (d) Coif5, (e) Db2, and (f) Db5 for the left sternocleidomastoid muscle. .63

Figure 5.7: The graphical representation of power $\left(\mathrm{mV}^{2}\right)$ as a function of time for following wavelet functions: (g) Db45, (h) Haar (i), Sym4, and (j) Sym5 for the left sternocleidomastoid muscle.

Figure 5.8: Power of SEMG signal recorded from the left sternocleidomastoid muscle at different time instances for the following frequency bands: (a) 6-12 Hz (b) $12-23 \mathrm{~Hz}$ and (c) 23-46 Hz. Behavior of Rbio3.1 and Bior3.1 wavelets were plotted using a secondary axis .66

Figure A.1: Physical Activity Readiness Questionnaire (PAR-Q) of British Columbia Ministry of Health .90

Figure B.1: Snap shot of Institutional Review Board (IRB) approval of this study .... .91 


\section{List of Acronyms}

\begin{tabular}{|c|c|}
\hline $\mathrm{A}(\mathrm{n})$ & Approximation Vector at 'n' level \\
\hline ANOVA & Analysis of Variance \\
\hline Bior & Biorthogonal Splines \\
\hline Bior1.5 & Biorthogonal wavelet function with scale of 1.5 \\
\hline Bior3.1 & Biorthogonal wavelet function with scale of 3.1 \\
\hline $\mathrm{CA}$ & Coefficients of Approximate level \\
\hline $\mathrm{CD}$ & Coefficients of Details level \\
\hline $\mathrm{cm}$ & Centimeter \\
\hline Coif & Coiflet \\
\hline Coif5 & Coiflet wavelet function with scale of 5 \\
\hline $\mathrm{D}(\mathrm{n})$ & Detail Vector at 'n' level \\
\hline $\mathrm{Db}$ & Daubechies \\
\hline $\mathrm{Db} 2$ & Debauchee wavelet function with scale of 2 \\
\hline Db5 & Debauchee wavelet function with scale of 5 \\
\hline Dmey & Discrete Meyers \\
\hline DOF & Degree of Freedom \\
\hline DWT & Discrete Wavelet Transform \\
\hline EMG & Electromyography \\
\hline FFT & Fast Fourier Transform \\
\hline $\mathrm{FMF}$ & Fast Fatigable Muscle Fiber \\
\hline
\end{tabular}




\begin{tabular}{ll} 
Haar & Haar Wavelet function \\
Hz & Hertz \\
JASA & Joint analysis of EMG spectrum and amplitude \\
Kg & Kilogram \\
MAV & Mean Absolute Value \\
MPD & Myophosphorylase Deficiency \\
MSD & Musculoskeletal Disorders \\
MSE & Mean Squared Error \\
PAR-Q & Physical Activity Readiness Questionnaire \\
Rbio & Reverse Biorthogonal Splines \\
Rbio3.1 & Reverse Biorthogonal wavelet function with scale of 3.1 \\
RMS & Root Mean Square \\
SCM & Sternocleidomastoid \\
STD & Standard Deviation \\
SEMG & Surface Electromyography \\
SMG & Slow Fatigable Muscle Fiber \\
STFT & Short Time Fourier Transform \\
Sym & Symlet \\
Sym4 & Symlet Wavelet function with scale of 4 \\
Sym5 & Symlet Wavelet function with scale of 5 \\
WMSD & Work-Related Musculoskeletal Disorder \\
WT & Wavelet Transform \\
ZCro Crossing Rates \\
\hline M
\end{tabular}




\section{Chapter 1: Introduction}

Work-related Musculoskeletal disorder (WMSD) are defined as the injuries or disorders of the muscles, nerves, tendons, joints, cartilage, or spinal discs (disorders caused by slips, trips, falls, motor vehicle accidents or similar accidents are not included) [1]. The overall impact of WMSDs is enormous in terms of individual health and corporate economics. According to U.S. Bureau of Labor Statistics [1], there were 335,390 cases of WMSDs in 2007 that accounted for $29 \%$ of all workplace injuries requiring days away from work. The WMSDs of neck and shoulder accounted for approximately $10 \%$ of these cases [1]. In the recent data published by the Bone and Joint Decade on Neck Pain Task Force, an annual prevalence of 30\% to 50\% for neck pain among the general adult population was reported. Among the working population, nearly $11 \%$ to $14.1 \%$ of workers were found to suffer from disabling neck pain symptoms, i.e., they are limited in their activities because of neck pain [2]. In another study by Washington State Department of Labor and Industries, it was reported that on an annual basis more than 50,000 workers' compensation claims were filed for WMSDs of the neck, back and upper extremity for a period between 1996 and 2004. On average, 37.5\% of those claims involved WMSDs of upper extremity, neck and shoulder with an average cost of $\$ 11,334$ per claim, costing approximately $\$ 3.8$ billion in direct costs. [3].

Different types of physical exertion were deemed to be the causal factors of work-related neck and shoulder pain in the epidemiological studies. Physical exertions that demand low levels of prolonged and/or repetitive movement are associated with inflammatory-type neck pain syndromes such as trapezius myalgia, cervicalgia, etc. [4]. Whereas forceful arm exertion required in physically demanding activities are identified as the risk factors for disc specific 
diseases, such as herniated/protruded discs. In the recent years, evidence for a causal relationship between work-activities that demand sustained, sub-maximal repetitive exertions and neck and shoulder WMSDs is mounting in the literature [2, 5-7]. Such exertions performed over sustained period of time cause overuse of muscles, nerve, and joints leading to neuromuscular fatigue, which is believed to be the precursor of WMSDs. Therefore, quantitative assessment of muscle fatigue is essential for early detection and prevention of risks of WMSD [8]. An accurate assessment of fatigue caused by different types of exertions could also facilitate development of intervention strategies to mitigate risks of WMSDs.

There are a number of techniques that can be used for the objective assessment of fatigue. Some of these techniques/methods involve measurement of maximum voluntary contraction, endurance time, power output, etc. A few studies have also used subjective methods such as measurement of perceived effort, discomfort ratings, etc. for the evaluation of fatigue. Most of these methods are more sensitive to the changes that are more representative of fatigue caused by high force or static sustained exertions and are not receptive to the subtle physiological changes caused by the sub-maximal repetitive exertions. Surface electromyography (SEMG) is a noninvasive and fairly accurate tool for continuous monitoring of muscle fatigue during a physical activity [9-11]. Most popular method used for evaluating muscle fatigue using SEMG is the study of median frequency pattern. A drop in the median frequency is known as the one of the biomarkers of muscle fatigue. Calculation of median frequency is based on the Fast Fourier Transform (FFT), which identifies frequency content of a signal but is unable to determine when a particular frequency component of the signal takes place in time. For a stationary signal (all frequency components exist at all times) timing information is irrelevant and shift in the power spectrum frequencies provide valuable information about the muscle fatigue. Isometric constant 
force contraction was treated as a stationary signal for fatigue assessment using FFT in previous studies [12]. However, under dynamic conditions the surface electromyography signal is nonstationary and fatigue assessment using FFT may not provide accurate assessment [7, 9, 13]. Short Term Fourier Transform (STFT) provides a possible solution to this problem [12], however it cannot solve time and frequency resolution issues. A short window size in STFT provides better time resolution, but poor frequency resolution; while a relatively long window provides better frequency resolution but poor time resolution [12].

The Discrete Wavelet Transform (DWT) analysis provides a potential solution to this dilemma of resolution and is becoming a more common digital signal processing method for analyzing SEMG signals. It acts as a "mathematical microscope" in which one can observe different parts of the signal by just adjusting the focus. This allows the detection of short-lived time components of signals. Another advantage of DWT is the availability of various orthogonal wavelet functions that allow the most appropriate to be chosen for the signal under investigation [14]. In recent years although a number of researchers have used DWT for evaluating muscle fatigue using surface electromyography [13-19], its application to neck and shoulder muscle fatigue is not well established. In this study, DWT analysis was established as a suitable method to conduct quantitative assessment of neck and shoulder muscle fatigue caused by repetitive exertions. 


\section{Chapter 2: Literature Review}

\subsection{Neuromuscular fatigue and WMSD}

The major risk factors that are typically associated with the WMSDs of neck and shoulder include genetic, morphological, psychosocial, and biomechanical factors [20]. Among these factors, genetic and morphological factors play important role in understanding the prevalence of WMSDs. The biomechanical factors are critical in determining effective control strategies. Biomechanical factors that are most frequently associated with WMSDs of neck and shoulder includes work activities that demands low levels of prolonged exertions, repetitive arm exertions, or forceful arm exertions. Exertions that demand low levels of prolonged and/or repetitive exertions are frequently performed by office workers, sewing machine operators, dental hygienists, and surgeons [21-26]. Whereas forceful arm exertions are commonly performed by the workers in occupations such as health care, construction work, farm work, and manual material handling industries [27-32]. Low levels of sustained exertions and/or sub maximal repetitive exertions were typically associated with inflammatory-type neck pain syndromes such as trapezius myalgia, cervicalgia, etc. [4]. Whereas heavy exertions are identified as the risk factors for the disorders such as tension neck syndrome and disc specific diseases such as herniated/protruded discs.

In the recent years, the incidence rate of inflammatory-type neck and shoulder pain syndromes among working population in the USA has shown an increasing trend [2, 5-6]. Overuse of muscles, nerves, and/or joints caused by repetitive movements leads to muscle fatigue which is believed to be the precursor of most of the inflammatory-type neck and shoulder 
musculoskeletal disorders. Therefore, quantitative assessment of muscle fatigue is essential for early detection and prevention of risks of WMSDs [8]. An accurate assessment of fatigue caused by different types of exertions could also facilitate development of intervention strategies to mitigate risks of WMSDs. In an early fatigue study, Rohmert [33] stated that static contractions performed above $30 \%$ of maximal voluntary contraction (MVC) may result in early fatigue increasing the risk of WMSDs. He suggested that static contractions below this level represent a safe limit for muscle load and may reduce risk of WMSDs.

Chaffin [34] performed a study to evaluate postural risk factors for WMSDs of the neck using subjective and objective assessments of muscular fatigue. He found that tilting the head/neck forward more than $30^{\circ}$ greatly increases the neck extensor fatigue and recommended work-place design changes such that the tilting angle can be reduced to $15^{\circ}$ or less to prevent fatigue and, subsequently, the risk of neck WMSDs. In a study of fish processing workers in Taiwan, Chiang et al., [35] studied the relationship between workplace factors and shoulder girdle pain using fatigue estimates. Shoulder girdle pain was defined as self-assessed symptoms of pain in the neck, shoulder or upper arms, and signs of muscle tender points or palpable hardenings upon physical examination. Fatigue caused by different types of exposure outcomes in terms of force and repetitiveness was evaluated using surface electromyography. Using multiple logistic regression analysis with age, gender, and force as co-variants, the authors determined that highly repetitive upper extremity movements generated fatigue that was associated with shoulder girdle pain.

Neuromuscular fatigue has also been used by a number of scientific committees to setup workplace guidelines. In a report published by National Research Council in 1999 it was stated that "Scientists with experience of policy setting affirmed their belief that it was prudent to 
consider fatigue as a potential precursor to some of the disorders under consideration" [36]. In the Annex of Council Directive set up by the European Directives and Standard to establish safety and health requirements for the computer users in recognition of the importance of fatigue with respect to keyboard use, it was stated that: "(c) Keyboard: The keyboard shall be tilt-able and separate from the screen so as to allow the worker to find a comfortable working position avoiding fatigue in the arms or hands" [37]. In the European WMSD standards on Machinery Directive (prEN 1005-3) estimates of force limits for machinery operation were primarily derived on the basis of decreasing fatigue during work to reduce WMSDs [37].

\subsection{Quantification of fatigue}

In ergonomics literature, the terms muscle fatigue and neuromuscular fatigue have been used interchangeably [34]. Muscle Fatigue has generally been defined as an acute impairment of mental or physical performance as a result of an increase in the perceived effort necessary to exert force, regardless of whether a subject can still perform the task successfully or not [38-39]. Vollestad [40] defined neuromuscular fatigue as the reduction of force generating capacity of the muscular system, usually seen as a failure to maintain or develop a certain expected force or power. In the scientific literature, researchers have used the following five assessment methods to quantify neuromuscular fatigue.

1) Changes in the Maximum Voluntary Contraction (MVC): MVCs are executed by instructing the participants to produce the highest possible force, in a setting where the length changes are restricted to the initial tightening up of the muscle-tendon unit (isometric exertion). The changes in recorded force before and after a bout of exertions are used to estimate muscle fatigue. A significant decrease in the force exertion during the MVC contraction indicates the sign of fatigue. In a study, Newham et al., [41] examined the force generating capacity 
during the MVC exertions before and after $4 \mathrm{~min}$ of knee extension activities. Authors observed $80 \%$ decreases in the force exertion during the MVC exertions after 4 minutes of knee extension activities.

2) Changes in the endurance time: In many studies, fatigability is examined by assessing the endurance time. This approach is based on a presumption that there is an association between the decline in maximal force generating capacity and the time to exhaustion. Garg et al., [42] studied the fatigue of shoulder girdle musculature by using isometric contraction performed at different shoulder postures under different weight conditions. The weights used by the participants were $5 \%, 15 \%, 30 \%, 45 \%, 60 \%, 75 \%$, and $90 \%$ of the MVC at each of the shoulder postures. With an increase in the weight, the endurance time decreased significantly. The decrease in endurance time followed a non-linear trend and corresponded very well with the subjective assessment measures of fatigue and pain ratings.

3) Changes in the metabolite concentration: There are a number of metabolic changes that occur concurrently with muscular fatigue. The relationship between intracellular metabolites and the force exertion during fatigue has been examined in a number of studies [43-45]. Most of these studies indicated that the normal participant's intracellular $\mathrm{pH}$ value decreases as the muscle is fatigued. Cady et al., [44] studied the first dorsal interosseous muscle of the hand by fatiguing the muscle with three bouts of maximal voluntary contraction. The intracellular phosphorus metabolites were measured by nuclear magnetic resonance during the intervals between the fatiguing contractions. The relationships between loss of force and change in metabolite concentrations were obtained from four normal participants and one subject with myophosphorylase deficiency (MPD) who could not utilize muscle glycogen and therefore produced no hydrogen ion from glycolysis. For both the MPD and normal participants the 
relationship between relative force loss and inorganic phosphate concentration was found to be curvilinear.

4) Near-infrared spectroscopy: This technique utilizes oxygenation properties of skeletal muscle to estimate muscle fatigue [46]. A muscle shows significant changes in the hemoglobin oxygenation and blood volume during fatiguing contracting [46-48]. Yoshitake et al., [47] used near-infrared spectroscopy to investigate the etiology of lower-back fatigue. They compared isometric back extensions for a period of 60 seconds performed at an angle of $15^{\circ}$ with $0^{\circ}$ horizontal plane. It was observed that oxygenation and the blood volume of the lower back muscles decreased significantly throughout the exertions performed at $15^{\circ}$ compared to those performed at $0^{\circ}$.

5) Electromyography (EMG): This is probably one of the most widely used methods in fatigue quantification in the occupational settings. EMG has been extensively used to study the patterns of activation or tension developed in the muscles during a variety of occupational tasks. There are two types of EMG data recording techniques: intramuscular EMG (needle of fine-wire) and surface EMG (SEMG). Intramuscular EMG involves inserting needle or fine-wire electrodes directly into the muscle through the skin and is invasive in nature. In SEMG, surface electrodes are placed on the muscle of interest over the skin to record the muscle activity [49]. Surface electrodes pick up changes in the muscle activation resulting from either a changed number of active muscle fibers or excitation rates [50]. Electrical activity picked up by the surface electrodes reflects a summary of active motor unit action potential, which reflects a chemical- electrical process in several muscles' fibers and motor units [51]. The EMG data can be processed using time domain or frequency domain analysis. Time domain analysis typically deals with amplitude estimation, while frequency domain 
analysis deals with the trends in the different frequencies in the signal. The following methods are commonly used by the researchers to evaluate EMG signal for the objective assessments of fatigue:

I. Change in the EMG amplitude: There are two methods that are most commonly used to estimate changes in the amplitude of the EMG signal: mean absolute value (MAV) [52] and root-mean-square (RMS) value [53]. The equations used for computation of these values are as follows [54]:

$$
\begin{aligned}
& M A V=\frac{1}{N} \sum_{i=1}^{N}\left|X_{i}\right| \\
& R M S=\frac{1}{N} \sum_{i=1}^{N} X_{i}^{2}
\end{aligned}
$$

Where,

$$
\begin{aligned}
& X_{i} \text { is the } i^{\text {th }} \text { sample of the signal } \\
& \mathrm{N} \text { number of samples in the signal }
\end{aligned}
$$

In previous studies, it was shown that EMG amplitude increases with fatigue due to additional recruitment of motor units during the exertions that are physically demanding, such as maximal or near maximal exertions [55-56].

II. Change in the Zero-crossing rate (ZCR) of the signal: Zero-crossing rate (ZCR) is defined as half the number of zero crossing of EMG signal ( $\mathrm{S}(\mathrm{t}))$ per second [57]. If both the first derivative $\mathrm{S}_{0}(\mathrm{t})$ and signal $\mathrm{S}(\mathrm{t})$ have a Gaussian amplitude, the distribution of the expected zero-crossing rate $\mathrm{Z}$ can be calculated as [58] -

$$
Z=2\left[\frac{\int_{0}^{\frac{f_{s}}{2}} f^{2} s(f) d f}{\int_{0}^{\frac{f_{S}}{2}} S(f) d f}\right]
$$


Where, $\mathrm{S}$ (f) is the Power Spectral Density (PSD) of the signal and $\mathrm{f}_{\mathrm{s}}$ is the sampling frequency. Inbar et al., [57] showed that the ZCR can be used to monitor the spectral changes of EMG signal. Authors observed that zero crossing of the raw EMG signal shifts to lower values as an indicator of muscle fatigue.

III. Changes in the frequency spectrum variables: To estimate changes in the frequency content of the EMG signal, the raw EMG signal is transformed from the time domain to the frequency domain (Figure 2.1). Fast Fourier transform (FFT) is the most frequently used method for conducting this transformation. By using FFT, the frequency spectrum of EMG signals are clarified and recognized by breaking down the signal into its corresponding sinusoidal of different frequencies [59]. Three variables based on the FFT transformed data that are often used to estimate muscle fatigue are (Figure 2.2):
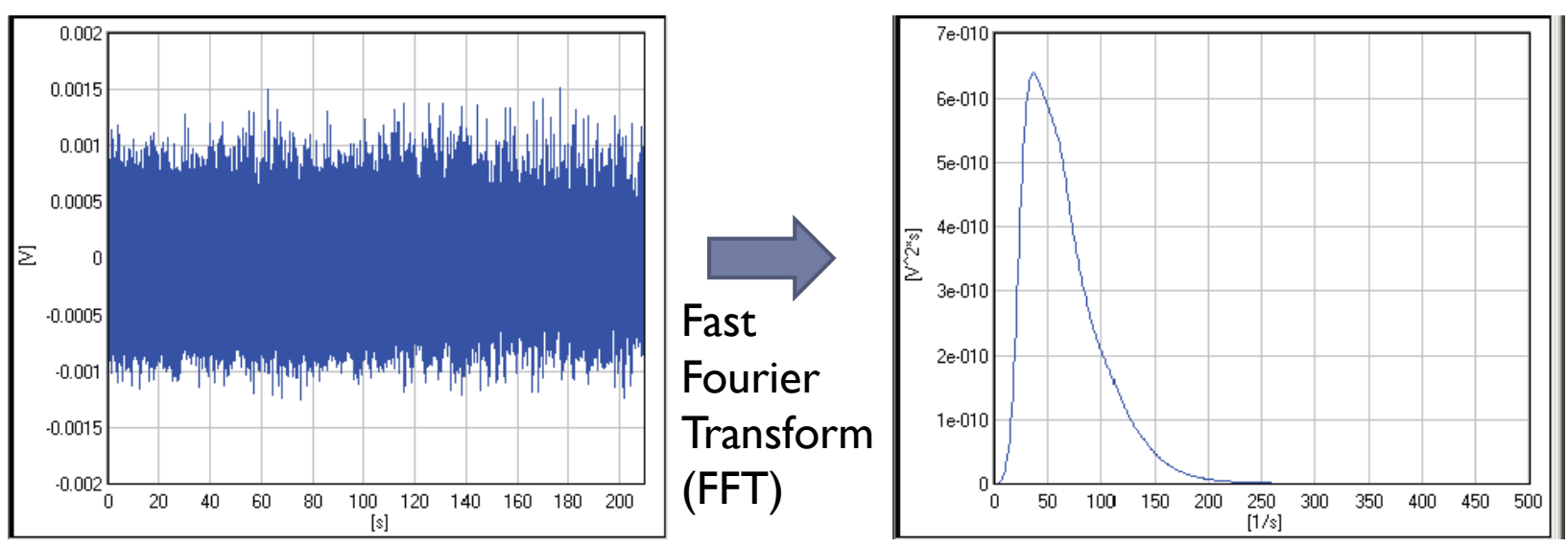

Figure 2.1: Transformation of EMG signal from time domain to frequency domain using FFT

(1) Mean frequency: the mathematical mean of the spectrum curve

(2) Median frequency: the parameter that divides the total power area into two equal parts

(3) Total power: The integral of the spectrum curve (Figure 2.2). 


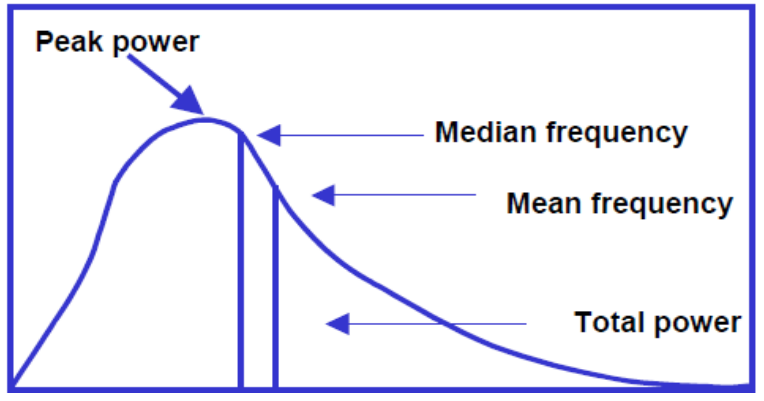

Figure 2.2: Power spectrum of a FFT transformed EMG signal

A number of previous studies have used changes in the median frequencies of EMG data to evaluate muscle fatigue [56]. A shift in the median frequencies to lower values has been identified as the indicator of neuromuscular fatigue in most of these studies. For example, in a study conducted by Potvin et al., [56] behavior of the bicep brachii muscle was evaluated using changes in the median frequencies of the EMG signal during fatiguing contractions. The authors found that muscle fatigue resulted in the drop of median frequencies. In another study by Georgakis et al., [60] fatiguing behavior of knee extensors was studied during the isometric knee extension. A consistent decrease in the median frequencies of knee extensor muscles, vastus medialis, vastus lateralis, and rectus femoris muscles, was reported by the authors. A drop in the mean frequency has also been used as the biomarker of fatigue in a few studies. However, a relatively lower coefficient of variation for the mean frequency was reported than the median frequency. In terms of power, an increase in the power of the low frequency components of the EMG and a decrease in the power of high frequency components were reported by a number of authors for various muscles in the human body with the onset of fatigue $[50,56,59,61-62]$. 
IV. Joint analysis of EMG spectrum and amplitude (JASA): In non-isometric contractions, sometimes it is very difficult to interpret changes in the spectrum and amplitude of the surface EMG signal independently [54]. At such instances, simultaneous consideration of amplitude and spectrum related variables of EMG signal is essential to provide information on whether EMG changes are fatigue-induced or force-related. JASA uses the following four criteria to distinguish fatigue-induced or force-related changes caused by a dynamic exertion [63]:

(1) If the EMG amplitude increases and EMG spectrum shifts to the right, muscle force increase is the probable cause.

[37](2) If the EMG amplitude decreases and EMG spectrum shifts to the left, muscle force decrease is the probable cause

(3) If the EMG amplitude increases and EMG spectrum shifts to the left, this is considered to be result of muscle fatigue

(4) If the EMG amplitude decreases and the EMG spectrum shift to the right, this is considered to be recovery from previous muscle fatigue.

V. Short-time Fourier transform: Isometric muscle contractions can be easily analyzed for muscle fatigue by using either of the above mentioned time or frequency domain analysis method. Evaluation of fatigue caused by dynamic contraction is rather problematic because of its time variant nature. For such signal, variations of the EMG signal spectrum cannot be analyzed by simply applying Fourier transform, since information about time would be lost. Also, generally speaking, EMG signals do not conform to the stationary requirement of the Fourier transform. One way to satisfy this requirement is to apply Fourier transform only to signal segments that are short enough 
to fulfill this requirement. Short-time Fourier transform (STFT) provides the potential solution to this problem, where the EMG signal is divided into short time windows and Fourier transform is applied to each window. STFT also provides an insight into variations of the spectrum as a function of time. It is defined as [12]

$$
\operatorname{STFT}(\tau, f)=\int x(t) w(t-\tau) e^{-j 2 \Pi f t} d t
$$

Where $f$ is the sinusoidal frequency, $\mathrm{t}$ is the time and $w(t-\tau)$ is the normalized window. STFT analyzes the signal $x(t)$ through a short-time window $w(t): x(t) w(t-\tau)$, and then a Fourier transform is performed on this product. Previously, STFT was used by Sparto et al., [64] to study fatigue of low back muscles caused by isokinetic exertions. The authors used a window size of 1 second to compute the Fourier transform. A significant decline in the median frequency was reported by the authors in this study.

\subsection{Shortcoming of EMG data analysis methods}

Amplitude analysis in time domain is a simple data reduction technique of an EMG signal that provides a crude estimation of the exposure level. However this method does not provide detailed information regarding exposure dynamics. Amplitude increases with force as well as fatigue, so it is difficult to interpret whether the amplitude modification represents a fatigue or force change [63]. Moreover, in the presence of additive noise, amplitude based methods are subjected to overestimation errors [65]. ZCR provide a reliable estimate of spectral changes, but it is highly dependent on signal-to-noise ratio (SNR) of the analyzed EMG signal. Moreover, ZCR is also very sensitive to the deviations of the amplitude distribution from Gaussian one [66-67]. The JASA considers simultaneous discrimination between fatigue-induced 
and force-related changes with time in the EMG signal $[63,68]$. The dependencies of spectral variables on force can neither be fully explained nor be clearly understood, hence it is questionable to reach a precise conclusion of muscle fatigue based on the four possible case algorithm presented by JASA during non-isometric contractions [68].

Algorithms based on the Fourier transform (FT) are the most widely used methods to describe the spectral content (power spectral density (PSD) of EMG signal [69]. FFT based analyses identify frequency content of a signal but do not determine when a particular frequency component of the signal takes place in time. For a stationary signal (all frequency components exist at all times) timing information is irrelevant and shift in the power spectrum frequencies provide valuable information about the muscle fatigue. In the real world, force level and body posture do not remain constant during physical activities. During such exertions, the level of force application changes continuously. The SEMG signal recorded during such exertions is nonstationary in nature i.e. all frequency components are not present at all the times. [62]. The FFT analysis of such non-stationary signals could only provide spectral information of different frequencies without providing sufficient information regarding when a particular frequency content of the signal takes place in time [70].

Short-Time Fourier Transform (STFT) provides a possible solution to this problem, however, it presents time and frequency resolution issues [12]. A short window size in STFT provides better time resolution, but poor frequency resolution and relatively longer window provides better frequency resolution but poor time resolution. In some applications this can be a rather irrelevant, yet in others it may be a limitation. For example, if the analyzed signal is a mixture of short-duration high-frequency events that are closely spaced in time and long-duration low frequency components that are closely spaced in frequency, STFT cannot provide 
appropriate time resolution for distinguishing high-frequency events along with adequate frequency resolution for distinguishing low frequency components [54, 67].

The wavelet transform (WT) analysis provide a potential solution to this dilemma of resolution and is becoming a more common digital signal processing method for analyzing EMG signals. Discrete Wavelet Transform (DWT) acts as a bank of low-pass and high-pass filters that decompose a signal into multiple signal bands. It separates and retains the signal features in one or a few sub-bands and presents a method for analyzing the temporal occurrence of frequency alterations in a signal [71]. In the following section a detailed description of how wavelet transforms works is provided.

\subsection{Wavelet transform}

Just as STFT is based on a family of sinusoids used to decompose EMG signal within successive windows of time, wavelet transform (WT) implements a set of time scaled and time translated versions of a basic wavelet function. Just as the original signal can be built back up from its Fourier components by adding those components all together in the right proportions and with the right phase lags, the original waveform can be built back up from its wavelet components by adding those wavelet components all up in the correct proportions and with the correct time translations. Computationally, the WT uses wavelets to break down EMG signal in much the same way that the STFT uses windowed sine and cosine waves. Figure 2.3 provides a simplified illustration of the WT of an EMG signal for two of the many possible different scales of waveform structure, a large scale and a small scale. At the large scale, the wavelet is aligned with the beginning of the neuroelectric waveform and the correlation of the wavelet shape with the shape of the neuroelectric waveform at that position is computed. This correlation, known as a wavelet coefficient, measures how much of the wavelet at that scale and position is included in 
the neuroelectric waveform. The same wavelet is then translated (moved) a small amount to a later position in time, bringing a slightly different portion of the neuroelectric waveform into the "view" of the wavelet and a new wavelet coefficient is computed. This process continues until all possible translations of the wavelet at the large scale have been exhausted and their corresponding wavelet coefficients have been computed [71].

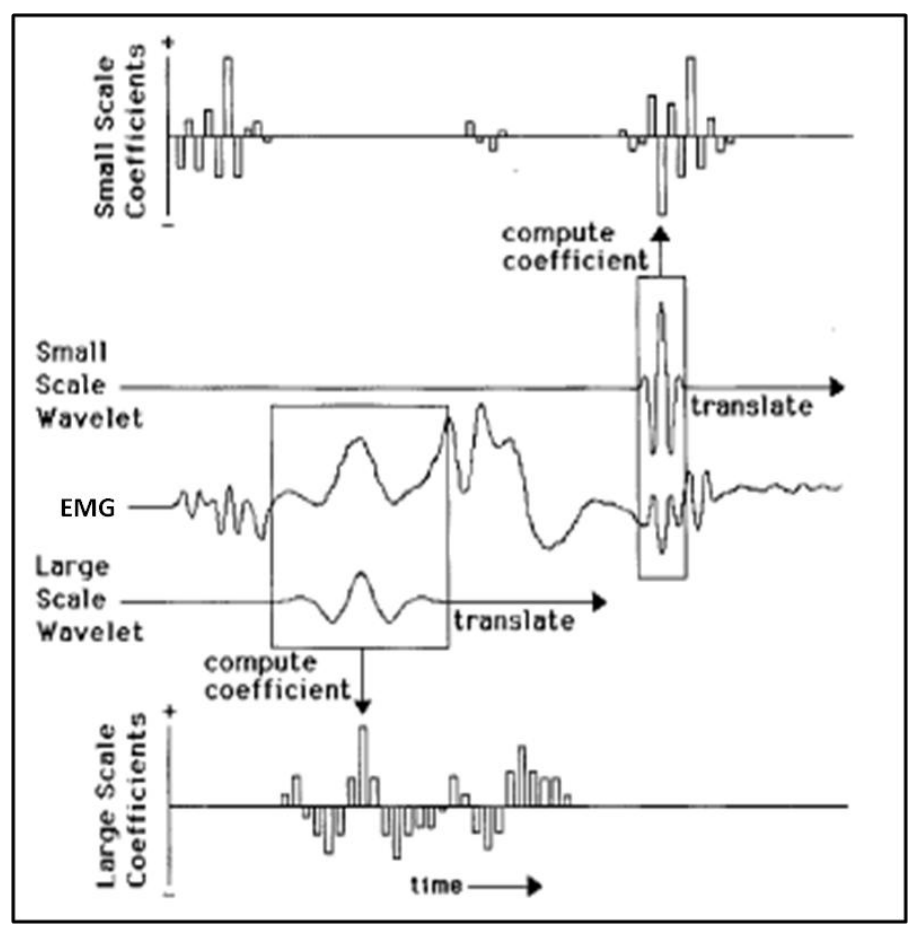

Figure 2.3: Wavelet coefficients for large- and small-scale wavelets plotted as a function of translation in time [77]

The coefficient plot at the bottom of Figure 2.3 illustrates the wavelet coefficients that correspond to each position of the large-scale wavelet as it moves along the signal in time. The large-scale wavelet is frozen in time at a position where it closely correlates with the local shape of the signal. Generally, whenever the wavelet shape matches the overall shape of the signal, a large wavelet coefficient is computed, with positive amplitude if the match is normal and negative amplitude if the match has inverted polarity. Conversely, when the shape match is poor, a small or zero wavelet coefficients is computed. Hence, the core of a wavelet transform is the 
appropriate selection of the mother wavelet. It is this wavelet that is used to form the first and subsequent detail functions. If the mother wavelet shape is better matched with the EMG waveform, it can localize high time and frequency information [72-73].
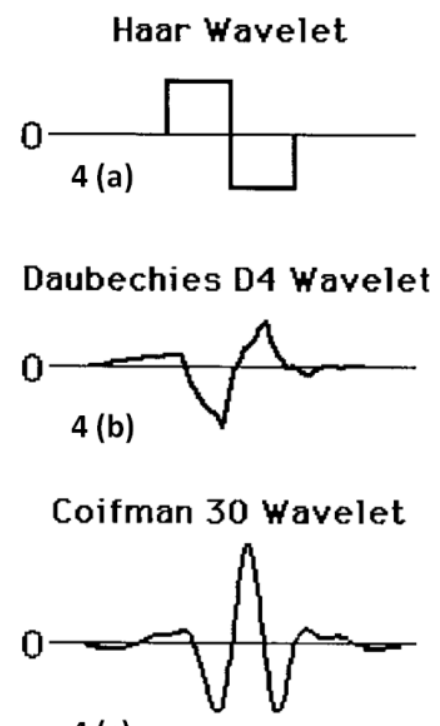

4 (c)

Figure 2.4: Commonly used wavelet functions [71]

Mother wavelets with wide variety of shapes are available for conducting WT. Some commonly used wavelet functions, like the Haar, Daubechies, and Coifman 30 wavelet functions are shown in Figure 2.4. Wavelet functions can be scaled in time by stretching or shrinking them and can be moved (translated) to different time positions at any scale without changing their basic shape. Scaling and translation are the two basic parameters of wavelet representations. Higher scale is proportional to lower frequency and higher frequency is proportional to lower scale. The set of all scaled and translated wavelets of the same basic wavelet shape forms a wavelet family. There are an infinite number of wavelet functions in a wavelet family because there are, in principle, an infinite number of scales and an infinite number of time translations for any wavelet [71-74]. Stretching a wavelet to a larger scale makes it less localized in time (more 
spread out), and its spectrum (Figure 2.5) consequently shifts to lower frequencies and concentrates more over a smaller bandwidth. That is, it becomes more localized in frequency. Conversely, shrinking a wavelet to a smaller scale makes it more localized in time, and its spectrum shifts to higher frequencies and spreads out more over a larger bandwidth. That is, it becomes less localized in frequency.

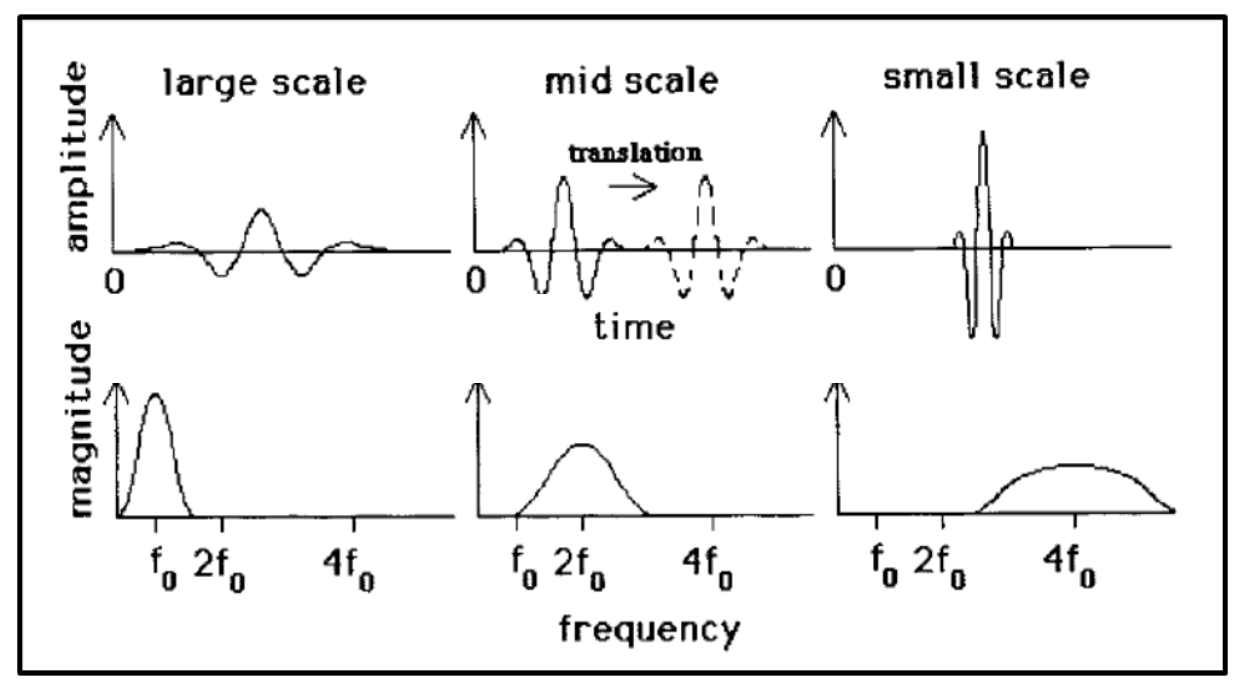

\section{Figure 2.5: Shrinking and dilation of a simple wavelet [77]}

Figure 2.6 shows a DWT transform of a signal into seven decomposition levels and how each level (scales) has both localized corresponding time and localized frequency information. The bright (minimum to maximum) spots represent the highest localized content of those frequency band (scales) in that particular time period [73]. Thus, wavelets obey a fundamental uncertainty principle, the Heisenberg Uncertainty Principle, which states that time localization trades off against frequency localization as wavelets are stretched or shrunk. 


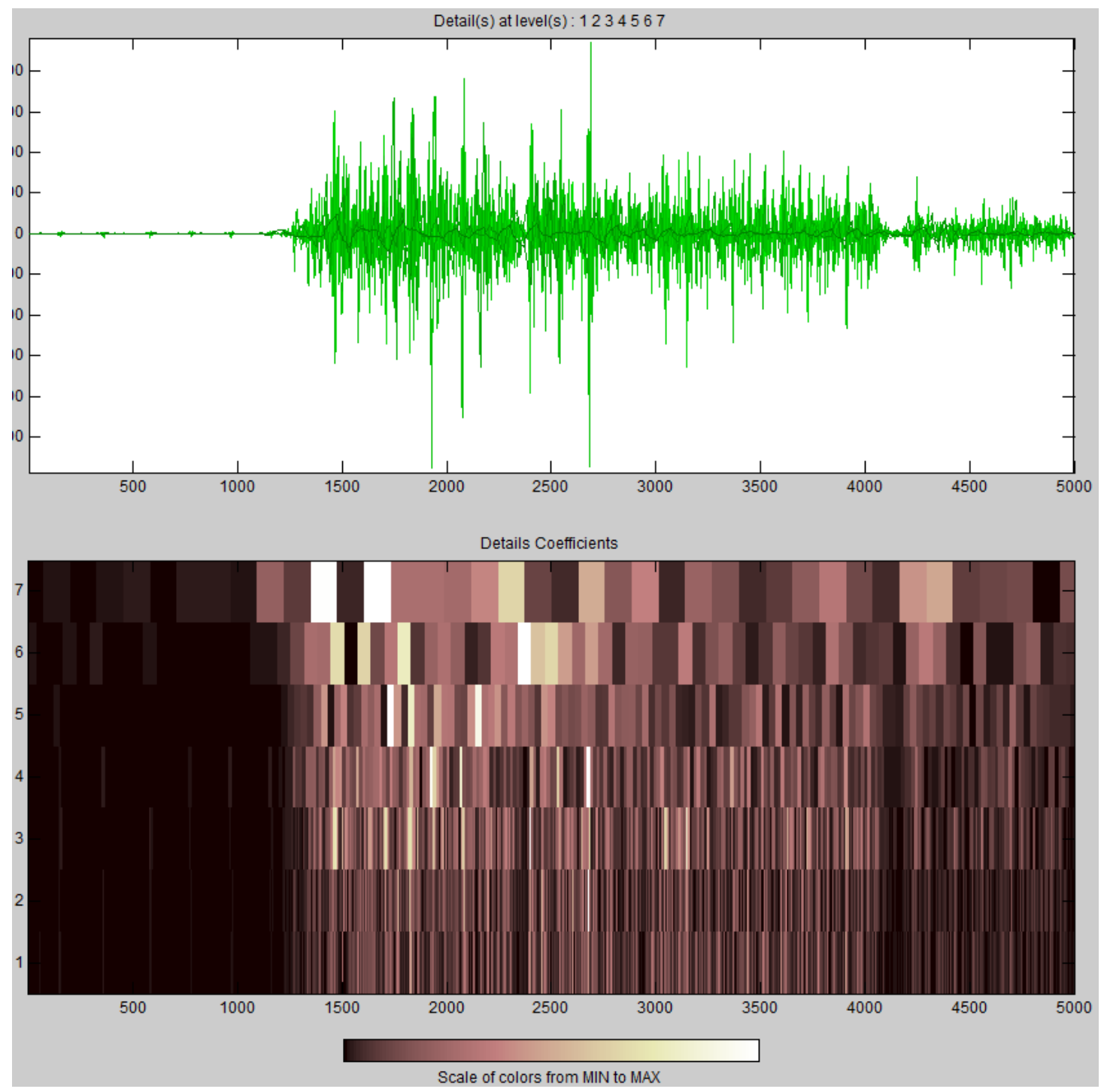

Figure 2.6: Scalogram of DWT of SEMG signal using db2 wavelet function

\subsection{Wavelet family}

The mother wavelet produces all wavelet functions used in the transformation through translation and scaling and therefore it determines the characteristics of the resulting wavelet transform. The wavelet functions are chosen based on their shape and their ability to process the signal in a particular application [17]. The following orthogonal mother wavelets are available for conducting wavelet transform [73]: 
1) Haar wavelet family: This is the oldest and the simplest wavelet family. Its filter has only one vanishing moment, perfect reconstruction and aliasing cancelation capability. With a basic filter length of only 2 points it has excellent time resolution but poor frequency resolution. Generally Haar wavelet families are good for edge detection, for matching binary pulses, and for very short phenomenon [73].

2) Daubechies wavelet family: These wavelet functions (filters) are robust, fast, and adaptable. They are in wide use for identifying signals with both time and frequency characteristics. Being non-symmetric, Daubechies wavelet functions may be passed by in favor of some symmetric wavelets for image processing because the human eye is more tolerant of symmetric errors [73].

3) Symlet wavelet family: Symlet wavelet family is compactly supported wavelets with the least asymmetry and highest number of vanishing moments for a given support width. It is more symmetrical than the Daubechies. Being nearly symmetrical, the larger Symlet function (Sym 12, Sym16, etc.) also have a nearly linear phase. Other than the symmetry and phase, Symlets share the same properties as the Daubechies wavelet family. They become more regular with larger $\mathrm{N}$ ("SymN"). They have the same compact support as the Daubechies for a given $\mathrm{N}$, they have the same number of vanishing moments as the $\mathrm{DbN}$ family, and they have the perfect reconstruction and alias cancellation capability [73].

4) Coiflet wavelet family: Coiflet wavelet family is compactly supported wavelet function with the highest number of vanishing moments for both phi and psi for a given support width. It was developed by Ingrid Daubechies at the request of wavelets pioneer Ronald Coifman to invent an orthogonal wavelet (filter set) that had vanishing moment capabilities for both the high pass and low pass filters. These Coiflet wavelet function have the same 
orthogonality relationships as the Daubechies Wavelets and the Symlet filters and also possesses alias cancellation and perfect reconstruction capabilities [73].

5) Discrete Meyer wavelet family: The continuous Meyer Wavelet is originated in the frequency domain, which produce excellent frequency characteristics. The discrete Meyer wavelet functions satisfy the orthogonality conditions and they also have perfect reconstruction capability. These wavelets do not have vanishing moments; however, they have nearly perfect symmetry and linear phase [73].

6) Biorthogonal wavelet family: BioSpline or Biorthogonal wavelet functions have vanishing moments and perfect reconstructions capability. The most useful property of it is symmetry with FIR filters, while the main difficulty is its lost orthogonality. Biorthogonal Wavelets are in wide use in image processing because of their perfect symmetry. Image compression and denoising can be accomplished efficiently using the biorthogonal filters [73].

7) Reverse Biorthogonal wavelet family: These are compactly supported biorthogonal spline wavelet functions with symmetry and perfect reconstruction capability [73].

\subsection{Discrete Wavelet Transform (DWT)}

Most of the time, signals are sampled at discrete time points with limited resolution and one must use a very limited number of discrete incremental scales and time translations if they are going to produce an answer in a reasonable amount of time. The discrete wavelet transform (DWT) technique was introduced by Mallat [72]. The DWT provides highly efficient wavelet representation that can be implemented with a simple recursive filter scheme, but provides no redundancy. Moreover, it only produces as many coefficients as there are sampled within the original signal, without the loss of any information at all. Consequently, the DWT permits 
perfect reconstruction of the original waveform by an inverse filtering operation. In general, the discrete wavelet tools have capabilities for both signal analysis and signal processing, such as noise reduction, data compression, peak detection and so on [71]. A number of studies employed discrete wavelet transform to study Electromyography signal [13-19].

The DWT coefficients are usually sampled on a dyadic grid. Given that the signal is a discrete time function and interchangeable sequence is denoted by $\mathrm{X}[\mathrm{n}]$, where $\mathrm{n}$ is an integer. The DWT is computed by successive low pass and high pass filtering of the discrete time domain signal. First of all, the signal (sequence) will pass through a half band digital low pass filter with impulse response $\mathrm{P}[\mathrm{n}]$ and filter the signal by convoluting the signal with the impulse response of the filter. The convolution operation in discrete time is defined as follows [17]:

$X[n] * P[n]=\sum_{k=-\infty}^{\infty} X[k] * P[n-k]$

To understand the DWT it is necessary to understand a remarkable property of wavelets. It is possible for wavelets to be orthogonal, meaning that a subset of a given wavelet family can be chosen from specially selected scales and translations in such a way that none of the scaled and translated wavelets in the subset correlate with each other at all. Such subsets are said to form an orthogonal basis for representing real functions. That is, any EMG waveform can be perfectly constructed by adding together point-for-point in time all of the orthogonal wavelets in the subset after correctly setting their individual magnitudes. Hence, the DWT algorithm consists of two phases, the decomposition phase and the reconstruction phase. In 1988, Mallat produced a fast wavelet decomposition and reconstruction algorithm [72]. 


\subsubsection{Discrete wavelet decomposition}

The DWT analyzes the signal at different frequency bands with different resolutions by decomposing the signal into a coarse approximation and detail information. DWT employs two sets of functions, called scaling functions and wavelet functions, which are associated with low pass and high pass filters, respectively. The procedure of decomposition starts with passing the signal $\mathrm{X}[\mathrm{n}]$ through a series of half band high pass filters $\mathrm{H}[\mathrm{n}]$ to analyze the high frequencies, and passing through a series of half band low pass $\mathrm{L}[\mathrm{n}]$ filters to analyze the low frequencies. The coefficients resulting from the high pass filter band are known as 'details coefficients' and the coefficients found in low pass filter band are known as 'approximate coefficients'. To obtain additional scales of waveform information, the first detail function is set aside and the approximate coefficients for the low resolution signal after the first filtering operation are fed back through the two filters simultaneously, giving a second set of small-scale wavelet coefficients and a new set of coefficients for the low resolution signal. This procedure can mathematically be expressed as

$$
\begin{aligned}
& Y_{\text {low }}[k]=\sum_{n} X[n] * L[2 k-n] \\
& Y_{\text {high }}[k]=\sum_{n} X[n] * H[2 k-n]
\end{aligned}
$$

In equation (2.6) and (2.7), $\mathrm{Y}_{\text {high }}[\mathrm{k}]$ and $\mathrm{Y}_{\text {low }}[\mathrm{k}]$ are the outputs of the high pass and low pass filters respectively, after down sampling by 2 . The above procedure, known as the sub band coding, can be repeated for further decomposition. At every level, the filtering and sub sampling will result in half the number of samples (and hence half the time resolution) and half the frequency band spanned (and hence doubles the frequency resolution) [17, 71]. 
To illustrate with an example, it is assumed that the signals have ' $\mathrm{n}$ ' points and ' $\mathrm{f}$ ' highest frequency and run through high pass filter, $H_{0}$, and low pass filter, $L_{0}$ whose filter coefficients are uniquely determined by the particular wavelet shape that is to be used in the analysis. Different wavelet shapes are associated with different filter coefficient sequences. The filtering operation can eliminate half of the samples according to Nyquist's rule. The output of each filter is a series of $n$ wavelet coefficients. Every other coefficient is discarded from the series, leaving $n / 2$ coefficients for each filter output. This process of discarding alternate coefficients is known as down sampling and is indicated by the downward pointing arrow and adjacent " 2 "' symbol (Figure 2.7). The signal now has a highest frequency of $\mathrm{f} / 2$ radians instead of $\mathrm{f}$. The low pass filter output captures all of the low frequency energy of the waveform $(0-f / 2)$ and the high pass filter output captures all of the high frequency energy of the waveform $(f / 2-f)$. This constitutes one level of decomposition.

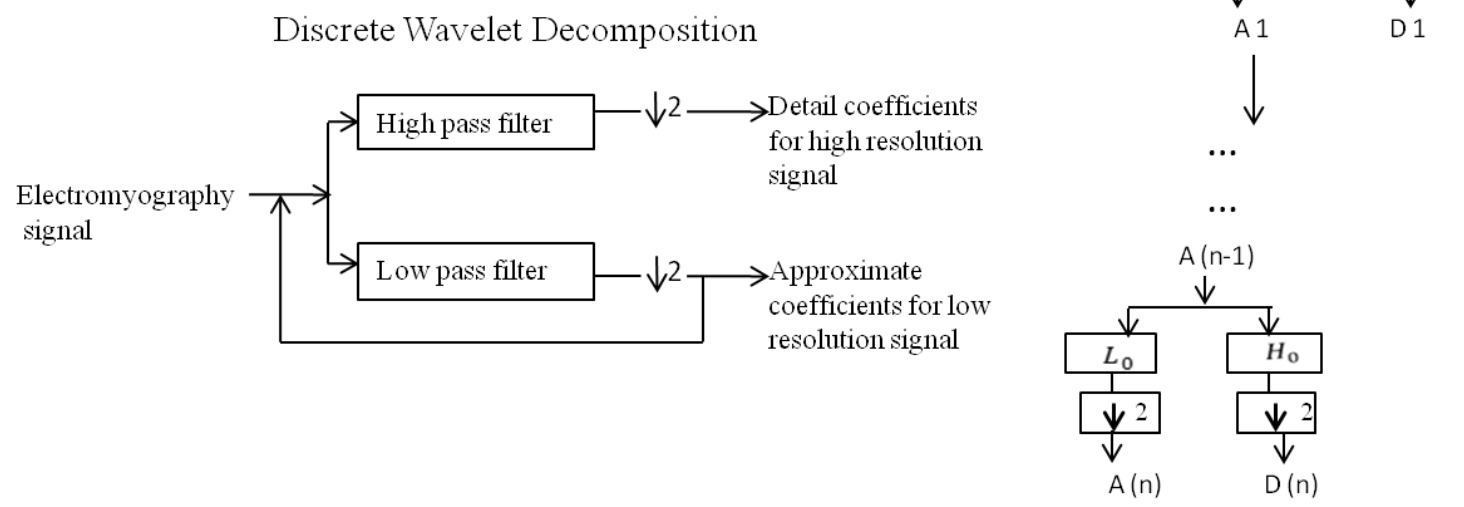

Figure 2.7: Discrete wavelet decomposition process [77]

This signal is then passed through the same low pass and high pass filters for further decomposition. This process continues until two samples are left. The maximum level of 
decomposition depends on the signal length. If the signal has ' $N$ ' number of data points, the maximum level of decomposition will be

$\mathrm{Q}=\log _{2} N$

Equation (2.8) can also be expressed as -

$\mathrm{N}=2^{Q}$.

The maximum level of decomposition is also known as full decomposition. A neuroelectric signal can be decomposed at any level within the maximum level of decomposition, depending on the choice of frequency bands. Each of these wavelet levels correspond to a frequency band. The maximum frequency that can be measured is given by the Nyquist theory as

$f_{\max }=\frac{f_{s}}{2}$

Here $f_{\max }$ is the maximum frequency band of the signal if the sampling frequency of the signal is $f_{S}[75]$.

In Figure 2.7, each successive detail function- D1, D2, D3, .. D (n) and approximate function - A1, A2, A3, . A (n) has a spectrum with a center frequency $(f)$ and bandwidth $(\Delta f)$ that is half those of the previous detail function and approximate function. As an example, the frequency of the first level details is $\frac{f_{\max }}{2}$ to $f_{\max }$ and the frequency of the first level approximation is 0 to $f_{\max }$. Thus, frequency resolution improves by a factor of 2 for each successively larger scale in a DWT while time resolution correspondingly decreases by a factor of 2. Conversely, time resolution improves by a factor of 2 at successively smaller scales and frequency resolution correspondingly decreases by a factor of 2 . The corresponding frequency band of each level will appear as high amplitudes in that region if these are prominent frequencies in the original signal. On the contrary, the frequency bands that are not very 
prominent in the original signal will have very low amplitudes, and that part of the DWT signal can be discarded without any major loss of information.

\subsubsection{Discrete wavelet reconstruction}

Since the wavelet transform is a band pass filter with a known response function (the wavelet function), it is possible to reconstruct the original time series using either deconvolution or the inverse filter. This is straight-forward for the orthogonal wavelet transform (which has an orthogonal basis), but for the continuous wavelet transform it is complicated by the redundancy in time and scale. The original EMG signal can be built back up from its wavelet components by adding those wavelet components all up in the correct proportions and with the correct time translations [76-77]. The signal reconstruction procedure follows the reverse order of the signal decomposition. Figure 2.8 represents the schematic diagram of the signal reconstruction where the signals at every level are up-sampled by two, and passed through the synthesis filters $\mathrm{L}^{\prime}[\mathrm{n}]$, and $H^{\prime}[n]$ (low pass and high pass, respectively), and then added.
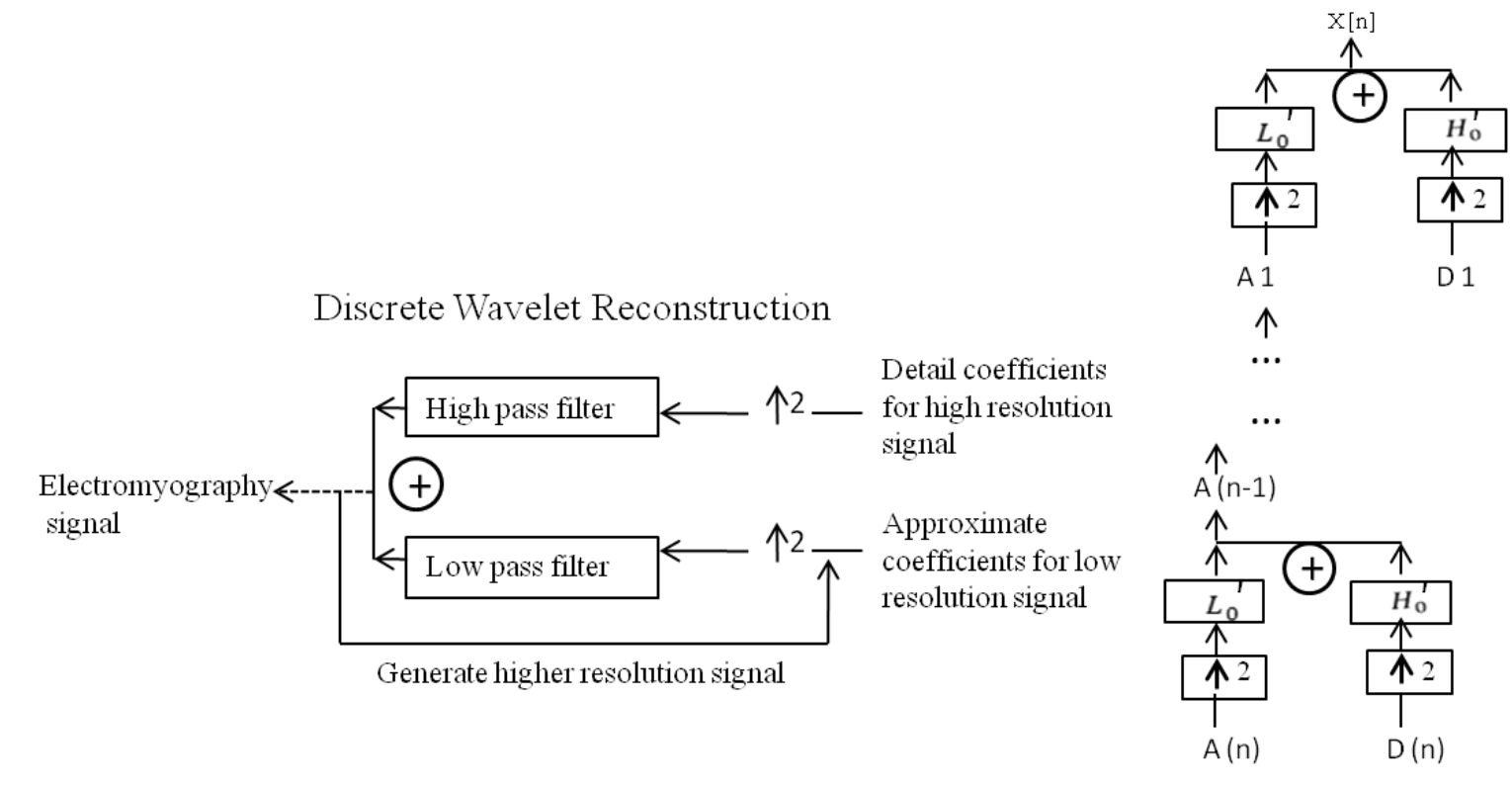

Figure 2.8: Discrete wavelet reconstruction process [77] 
Both the analysis and synthesis filters are identical to each other, except for a time reversal. Therefore, the reconstruction formula for each level can be written as

$X[n]=\sum_{k=-\infty}^{\infty}\left(Y_{\text {high }}[k] . H[-n+2 k]\right)+\left(Y_{\text {low }}[k] \cdot L[-n+2 k]\right)$

Regardless of the number of detail functions generated, the total number of wavelet and scaling function coefficients necessary to exactly reconstruct the original waveform always equals the number of original waveform samples. However, if the filters are not ideal half band, then perfect reconstruction cannot be achieved. Although it is not possible to realize ideal filters, under certain conditions it is possible to find filters that provide perfect reconstruction. Hence, the best wavelet function selection is a very crucial issue in DWT analysis [77].

\subsection{Previous studies of DWT and neuromuscular fatigue}

\subsubsection{DWT as a better tool for neuromuscular fatigue determination}

Discrete wavelet transform in SEMG signal analysis lays a foundation for studying the muscle fatigue in a variety of muscle contraction modes. The quantification of the amount of neuromuscular fatigue of the back during repetitive exertions has been performed by using DWT in SEMG signal processing. For this purpose, Sparto et al., [64] used filter banks and wavelets to determine additional insights into the fatigue process during repetitive isokinetic trunk extension tasks. They also decided which measures were more highly correlated with the decline in maximal trunk extension torque. Trunk muscle electromyograms were collected from 16 healthy men performing repetitive isokinetic trunk extension endurance tests over a four week period. The test was controlled at $35 \%$ and $70 \%$ of the participants' maximal voluntary contraction while they exerted at 5 and 10 repetitions per minute to induce different rates of fatigue. SEMG data were analyzed using the wavelet and the traditional Short Time Fourier methods. Linear 
regression quantified the rate of change in Fourier and wavelet measures caused by fatigue, whereas Pearson's correlation coefficient determined their association with the decline in maximum torque. Six scales of Daubechies wavelet were selected that resulted in adequate coverage of the frequency range expected for SEMG signals (i.e., 5-300 Hz). Wavelet coefficients were computed for each wavelet function and scale during each exertion. The rootmean-square value was calculated for the 1 second of data corresponding to the trunk range of motion between $25^{\circ}$ and $10^{\circ}$. RMS torque in the STFT and wavelet measures were quantified using simple linear regression. The statistical analysis of regression reflected that repetition rate is a significant factor that affects the decline in maximal torque. There was a significant decrease in the scale 4 coefficients $(209-349 \mathrm{~Hz})$ and a significant increase in scale 32 coefficients $(26-44 \mathrm{~Hz})$ and scale 64 coefficients $(13-22 \mathrm{~Hz})$ for 10 repetitions. Only $69 \%$ of the coefficients at the same scale were significantly increased during the trials of 5 repetitions per minute. The same trends were also observed during STFT. In addition, the decline in maximal torque output was significantly affected by exertion magnitude. The correlations between the rate of change in the RMS value of Daubechies wavelet coefficient and the maximum torque output decline were positive for scale 4 (the high-frequency range) and negative for the other scales. Hence they showed that DWT is a validated tool for quantifying and detecting back muscle fatigue.

The most commonly used parameters describing the spectral content of SEMG, such as Fourier-based mean and median power frequencies, are routinely used to characterize muscle activity and fatigue in many physiologic and pathologic circumstances. The application of the Fourier transform to a data stream is only limited for stationary signal, but for the cases where repetitive or non-constant muscular activity is considered, stationary constraints are violated. 
Hence the researchers proposed the use of multi-resolution wavelet analysis which provides both temporal and frequency resolution of a signal [78]. In order to determine the ability of this method, T. Vukova [79] investigated fatigue-induced changes in the spectral parameters of slow (SMF) and fast fatigable muscle fiber (FMF) action potentials using DWT and FFT. Intracellular potentials were recorded during repetitive stimulation of isolated muscle fibers immersed in $\mathrm{Ca}^{2+}$-enriched medium, while extracellular potentials were obtained from muscle fibers preexposed to electromagnetic microwaves. The changes in the frequency distribution of the action potentials during the period of uninterrupted fiber activity were used as criteria for fatigue assessment. The results showed a fatigue-induced decrease of potential high frequencies (SMF: 59\% vs. 96\%, MMW vs. control; FMF: $30 \%$ vs. 92\%, respectively), and an increase of low frequencies (SMF: $200 \%$ vs. $207 \%$, MMW vs. control; FMF: $93 \%$ vs. $314 \%$, respectively). They further observed that DWT provides a reliable method for estimation of muscle fatigue onset and progression from data analysis of RMS analysis of the wavelet coefficients.

The frequency characteristics of random signals like SEMG can be studied by power spectrum analysis by using wavelet transform function. Changes in the SEMG power spectrum are used as an indicator of changes in muscle contraction and muscle fatigue for ergonomic purposes [80]. These SEMG power spectrums are also varied when different wavelet functions are used and it is not clear which wavelet function offer appropriate results. In a gait analysis using various wavelet functions, Reaz and Hussain [81] analyzed SEMG power spectral parameters and compared different wavelet families. In this research, SEMG were decomposed using Discrete Wavelet Transform (DWT) with various wavelet families (WFs) - Haar, Daubechies (db2, db3, db4, db5, db45) and Symlet (sym4, sym5) at Matlab environment. The authors collected 11 separate EMG data files for the 9 trial walks, muscle at rest level, and 
muscle at maximum contraction level. The power spectrum properties (mean frequency and median frequency) were calculated by using FFT to estimate the muscle contraction at various walking trials. The difference of mean and median frequency is used to analyze the EMG signal to understand the muscle contractions. It was observed that changes in the mean and median frequencies are most significant in $\mathrm{db} 45$ to indicate muscle contraction compared to the other seven wavelet functions. The results also indicate a significant increase in SEMG amplitude and mean power frequency during with the increase in the force. On the other hand, during muscle fatigue, the power spectrum of SEMG shows a shift to lower frequencies. The power spectrum analysis of mean and median frequency verified that wavelet function db45 most significantly presents variation on the power spectrum.

\subsubsection{Appropriate mother wavelet selection for DWT}

The selection of an appropriate mother wavelet for SEMG signal analysis is very complicated. One mother wavelet may be better than another for a specific signal or for the same type of signal collected on different participants or in different experimental sessions. There is no universal wavelet function to achieve optimal performance in electromyography signal processing because the firing rates of different muscles are significantly different from each other. The spectrum of the surface electromyography of un-fatigued muscles is different from the fatigued muscles. Kumar et al., [18] observed the contrast between the fatigued and un-fatigued muscle pulses by decomposing the signal with various wavelet functions. The output power of the transform domain was calculated and used as the deciding parameter in choosing the wavelet function that provided the best contrast in general between non-fatigue and fatigue SEMG cases.

They recorded SEMG signal from the right arm biceps-brachii muscle of three healthy males volunteer. The recorded SEMG signals were grouped into two groups: non-fatigue and fatigue 
signals. These SEMG signals were decomposed using discrete wavelet transform (DWT) with five different wavelet functions (Haar, $d b 2, d b 3, d b 4$, and Sym4). The results showed that the differences between the EMG corresponding to fatigued muscles and non-fatigued muscles is highlighted in the power of the wavelet coefficients when using wavelet functions sym 4 and sym5 for all cases. The largest contrast of power of wavelet coefficients between fatigue and non-fatigue SEMG cases occurred at decomposition level of 6-12 Hz and 12-23 Hz frequency band. 


\section{Chapter 3: Rationale}

\subsection{Summary of previous work}

Evidence for a causal relationship between highly repetitive work and neck/shoulder WMSDs is mounting in the literature $[2,5-6]$. Repetitive arm and neck movement constitute a major facet of workplace tasks in several industries including fishing, food processing, wholesale and retail industry, agriculture, transportation and warehousing, assembly line, service etc. Repetitive motion disorders such as cervicalgia, tension neck syndrome, etc. are the common pathologies associated with the repetitive movements. Overuse of muscles, nerves, and/or joints caused by the repetitive movement leads to muscle fatigue, which is believed to be the precursor of musculoskeletal disorders and therefore quantitative assessment of muscle fatigue is essential for early detection and prevention of risks of WMSD. Most of the objective and subjective methods account for changes that are more representative of fatigue caused by high force or static sustained exertions and are not receptive to the subtle physiological changes caused by the sub-maximal repetitive exertions. SEMG is a non-invasive and fairly accurate tool for continuous monitoring of muscle fatigue during a physical activity. However, traditional methods for evaluating muscle fatigue using SEMG signals have typically relied on metrics such as changes in the mean/median frequencies present in the signal. While these methods are applicable for fatigue detection under heavy and sustained static contraction, they are unable to capture interesting artifacts occurring in distinct frequency ranges of the SEMG signal and are also unable to localize the timing of interesting events in the signal. As a result, these traditional methods cannot be used to predict muscle fatigue accurately under dynamic conditions involving multiple repetitive movements which result in the SEMG signal being non-stationary. Analysis

using the discrete wavelet transform (DWT) provides a potential solution to this issue. Of several 
time-frequency analysis tools that are available (including a variant of FFT, namely short-time frequency transform), the DWT is valuable because of its ability to simultaneously elucidate local spectral and temporal information from a signal in a more flexible way by employing a window of variable width. Another key advantage of wavelet techniques is the variety of wavelet functions available, thus allowing the most appropriate to be chosen for the signal under investigation. This is in contrast to Fourier analysis which is restricted to one feature morphology: the sinusoid. Although, in recent years a number of researchers have used DWT for evaluating muscle fatigue using SEMG [18, 64, 82-84], its application to neck and shoulder muscle fatigue is not well established.

\subsection{Problem statement}

Establish DWT analysis as a suitable method to conduct quantitative assessment of neck and shoulder muscle fatigue caused by repetitive exertions.

\subsection{Objective}

The two objectives used to establish wavelet analysis as a suitable method for the quantitative assessment of neck and shoulder muscle fatigue are as follows:

1) Identify appropriate mother wavelet functions for analyzing neuromuscular fatigue of neck and shoulder muscles caused by repetitive exertions

2) Identify frequency bands that show characteristic changes with the onset and development of fatigue 


\section{Chapter 4: Methods}

\subsection{Approach}

Human participants performed fatiguing repetitive arm exertions for sustained duration. SEMG data from the major neck and shoulder muscles were analyzed using discrete wavelet transforms. Parameters such as power trend, power contrast between SEMG signals from fatigued and non-fatigue muscles as well as statistical tests were performed to understand fatigue induced changes in SEMG signals. These parameters were also used to identify appropriate mother wavelet function. In order to generate fatigue in the neck and shoulder muscles, tasks of stock clerk or grocery clerk, who works at super market or warehouse super store, were simulated in the laboratory setting. The tasks of these workers include stocking or un-stocking various grocery or other items at shelves, racks, cases, bins, and tables located at various locations. These operations involve repetitive arm as well as neck motions. The experimental task and the material handling work station used for simulating stocking or un-stocking operations are described in a later section.

\subsection{Participants}

Most of the stock clerks are primarily men; therefore, male participants between ages of 18 to 40 years were recruited for data collection in this study. All the participants were free of musculoskeletal disorders or deformities. The Physical Activity Readiness Questionnaire (PARQ) of British Columbia Ministry of Health [85] was used to screen participants for cardiac and other health problems (e.g., dizziness, chest pain, heart trouble) (Appendix A). Participants who answered 'yes' to any of the questions on the PAR-Q form were excluded. 
All the participants were graduate students in the college of Engineering at West Virginia University. Before the data collection, the following information was explained to the participants in lay language - 1) Experimental protocol; 2) Equipment used and their purpose; 3) Demands of testing 4) Probable discomfort and potential benefits. Moreover, participants were also notified about their right to stop and withdraw from the experiment anytime during the data collection procedure if they felt uncomfortable with any data collection methods. Subsequent to above verbal explanation participants were given the informed consent form to read and were encouraged to ask questions about the study. All participants signed the consent form approved by Institutional Review Board (IRB) at West Virginia University before the actual data collection (Appendix B).

\subsection{Equipment}

Equipment in this research included an electromyography system and custom-built material handling work station.

\subsubsection{Electromyography system}

The EMG signal is a biomedical signal that measures electrical currents generated by a contracting muscle. It has been extensively used to study the patterns of muscle activation [86]. Usually, the EMG system picks up the desired signal by an electrode placed on intended muscle. There are two types of EMG electrodes: needle or wire electrode and surface electrode (described in detail in Section 2.2). In this study, surface electrodes were used to record EMG of the neck -shoulder musculature. The Telemyo 2400 T G2 EMG system used in this study is the latest generation of surface telemetric EMG system that can send real-time SEMG signals up to 300 feet (100 meters) by wireless transmission to a desktop computer or notebook. It combines 
high-quality, scientifically reliable data with mobility, flexibility and ease-of-use for researchers [87].

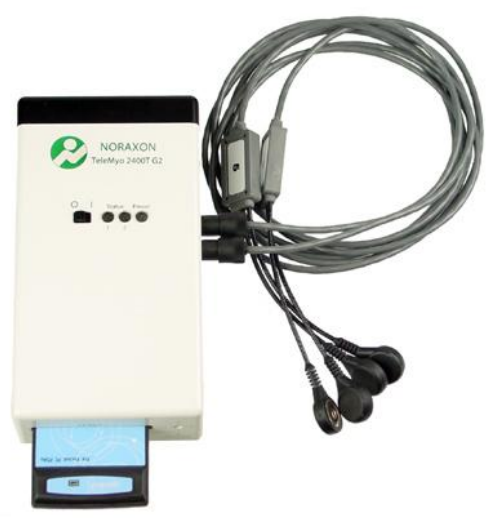

Figure 4.1: Telemyo 2400 G2 EMG system [87]

Preamplifier lead

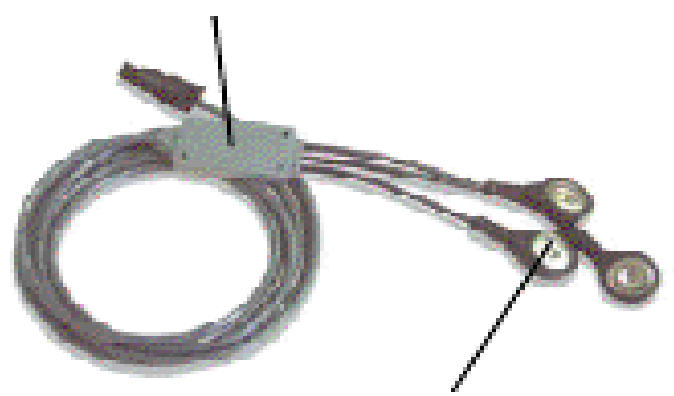

Snaps of the electrode pair,

Figure 4.2: Pre-amplified lead wire and snap electrode [87]

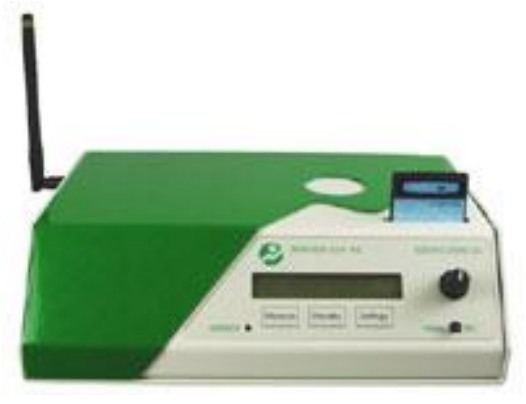

Figure 4.3: Telemyo 2400R G2 receiver [87] 


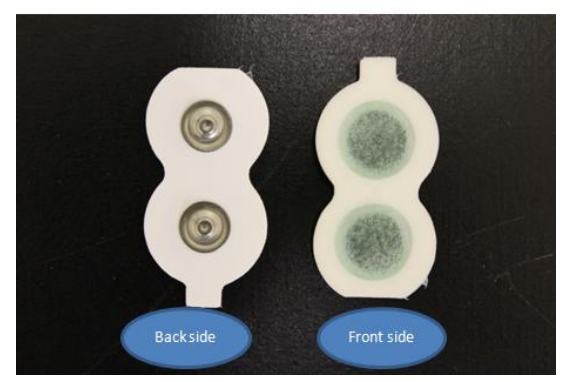

Figure 4.4: Bipolar Ag/AgCl pre-gelled surface electrodes [87]

A 16 channel telemetry SEMG system used in this study consist of Telemyo 2400T G2 transmitter (Figure 4.1), Telemyo 2400R G2 receiver (Figure 4.3), pre-amplified lead wires (Figure 4.2), and disposable, self-adhesive $\mathrm{Ag} / \mathrm{AgCl}$ snap electrodes (Figure 4.4). The bipolar $\mathrm{Ag} / \mathrm{AgCl}$ pre-gelled surface electrodes are of $1 \mathrm{~cm}$ diameter with inter-electrode distance of 2 cm. Pre-amplified lead wires act as differential amplifiers and reject or eliminate motion artifacts. It also detect the potential differences between the electrodes and cancels external interferences [87]. It had a common mode rejection ratio $(\mathrm{CMRR})>100 \mathrm{~dB}$, Input Impedance >100 MOhm. CMMR represented the relationship between differential and common mode gain and was therefore a criteria for the quality of the chosen amplification technique. The electrodes were attached to pre-amplified lead wires, which were then connected to Telemyo 2400T G2 transmitter. The Telemyo 2400T G2 transmitter could be mounted on the participants using a pouch and belt clip, and transmitted the data wirelessly to the Telemyo 2400R G2 receiver, which was connected to the host computer. The sampling frequency of EMG data acquisition was set at $1500 \mathrm{~Hz}$.

\subsubsection{Custom-built manual handling workstation}

To simulate repetitive sub-maximal arm and neck motions, a standing workstation was designed. This workstation was consisted of two adjustable work surfaces (Figure 4.5). Surface 1, was placed directly in front of the participant with height adjustability range to approximately 
standing fingertip height of the participant. Surface 2 was placed to the right of the participant making an angle of 90 degrees with surface 1, approximately along the standing eye height of the participant. To make the simulation, participants was in standing posture performing manual handling (both lifting and lowering) of 30 small cylindrical boxes (diameter $=1.25$ inch; height= 2 inch; weight $=50$ grams) from cart to shelf and shelf to cart.

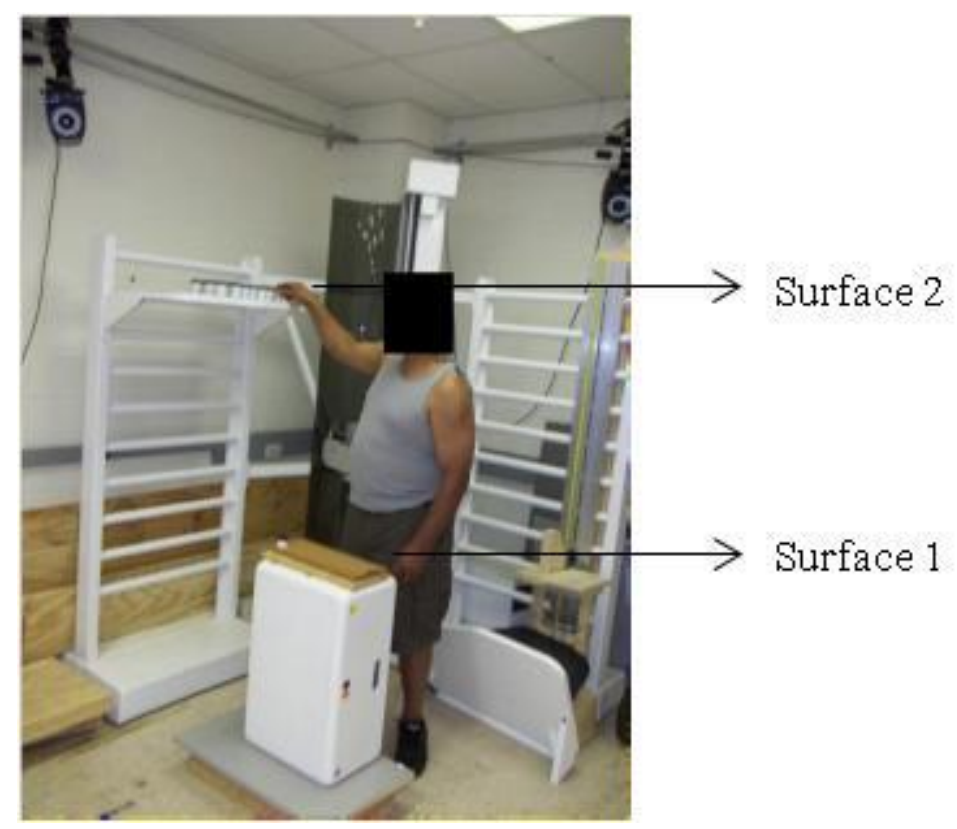

Figure 4.5: Custom-built material handling workstation

\subsection{Experimental tasks}

Each participant participated in two experimental sessions. During each session participant performed repetitive right arm exertions simulating material stocking and un-stocking operations. The purpose of performing monotonous repetitive exertions during the two sessions was to generate fatigue in the shoulder and neck muscles. During stocking operation, participant stood normal with his feet placed shoulder width apart. A stand with 30 small cylindrical boxes was placed directly in front of the participant, approximately at his figure tip height. Participants 
grabbed one box at a time and placed it on the shelf to his right. The height of shelf was adjusted to participant's eye height (Figure 4.5). The location of the shelf was such that participant has to twist his neck approximately 60 to 90 degrees to place the box on it. Upon transferring all the boxes from the stand to shelf, participant began the un-stocking operation. During un-stocking operation, participant transferred the boxes from shelf to stand. Participant continued stocking and un-stocking operations for twenty minutes during first session followed by a rest period of 5 minutes. After the rest period participant again performed the similar stocking and un-stocking operations for another 20 minutes (Figure 4.6). During both the sessions muscle activity was recorded continuously using SEMG. In addition, duration of stocking and un-stocking cycles was also recorded. At $19^{\text {th }}$ minute a participant was instructed to finish their current cycle. Most of the participants completed the cycle at exactly 20 minute. But few participants completed the cycle few seconds before or after twenty minute.

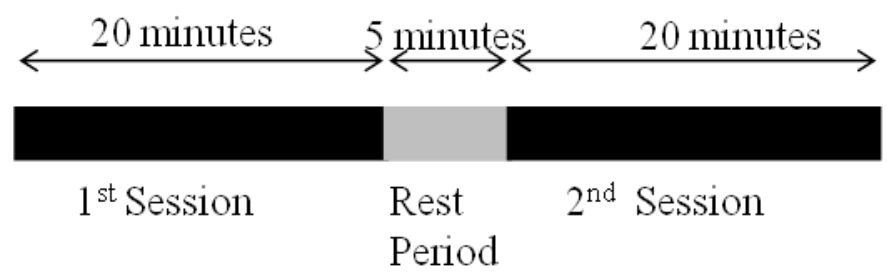

Figure 4.6: Experimental time distribution

The height of the shelf and the weight of the boxes used in this study are based on the real grocery shop environment. The top shelve in most of these shops is at the approximate eye height of the user. Mostly light weight goods are stored in these shelve with the weight ranging from 20-150 grams (Figure 4.7). 


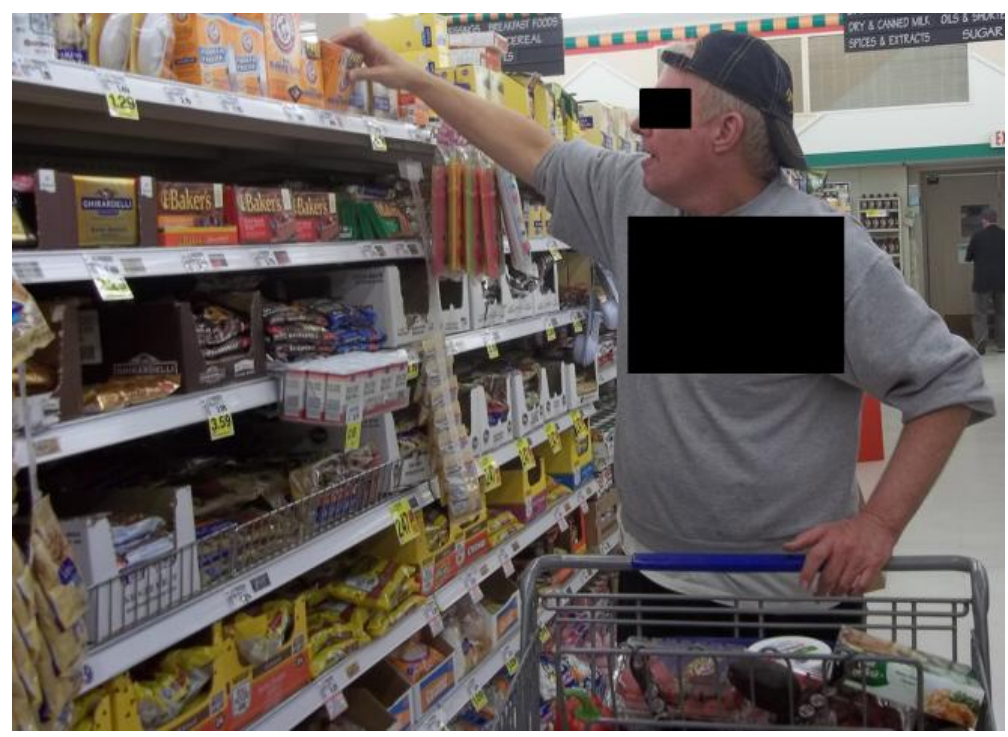

Figure 4.7: A picture from a grocery store showing the height of the top shelves

\subsection{Muscle selection}

It was very essential to select the appropriate muscles that were sensitive to the given occupational tasks. As the experimental task involved repetitive arm exertion and neck rotation to the right side, therefore, in this research right upper trapezius muscle and left sternocleidomastoid muscle were considered as potential site of muscle activation.

\subsection{Experimental procedure}

The data collection procedures for each participant consisted of following four steps:

1) Participant orientation and anthropometric measurement: Each eligible participant was introduced to the equipment, data collection procedures, and specifics of the experimental tasks and subsequently signatures were obtained on the consent form. After obtaining consent, the demographics (age, height, and weight) and anthropometric measurements were recorded. The required anthropometric measurements were: distance between sternal notch and the mastoid process, distance between the acromion and $\mathrm{C} 7$ and $\mathrm{C} 6-\mathrm{C} 7$ distance. 
2) EMG data collection preparation: Participant was then prepared for SEMG data collection. The skin over the anatomical landmarks were shaved (if needed), abraded and cleaned with70\% alcohol prior to the placement of the SEMG electrodes. Electrode location for these muscles were as described below:

A. Left sternocleidomastoid muscle (SCM): The electrodes were placed along a line drawn from the sterna notch to the mastoid process of the sternocleidomastoid muscle, at $1 / 3$ the length of the line from the mastoid process (Figure 4.8) [88].

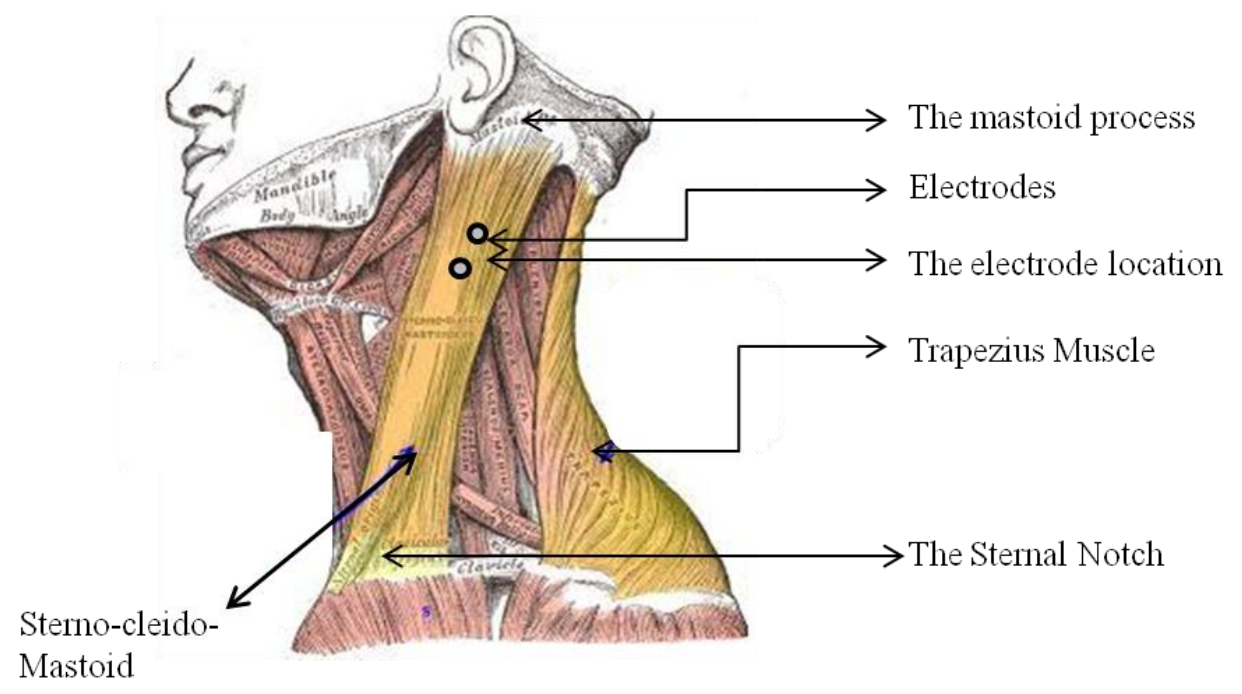

Figure 4.8: Location of electrode on the left sternocleidomastoid muscle [88].

B. Right upper trapezius muscle: The SEMG data were collected from the upper trapezius muscle in the shoulder region by placing an electrode along a line joining the acromion and C7, at $1 / 3$ the distance from the acromion process (Figure 4.9) [89]. 


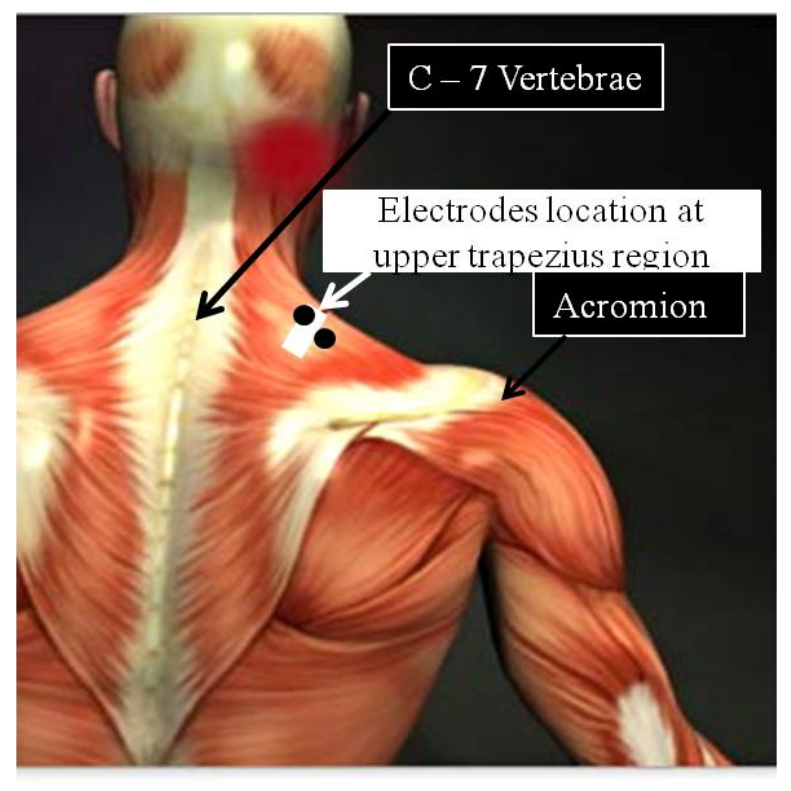

Figure 4.9: Location of electrode on the right upper Trapezius muscle [89].

The placement of the SEMG electrodes was checked for accuracy and cross talk. The sternocleidomastoid muscle electrode location was tested by a measurable SEMG signal during head rotation [90]. For upper trapezius muscle in shoulder region the action used for testing the electrode location was the movement of arm elevation with the arms abducted $90^{\circ}$ in the scapular plane [91]. The placements of all electrodes were outlined by a green marker to prevent error in the EMG data collection, so that, if any electrodes fell off while doing the tasks, it was easy to fix at the proper location.

3) Actual data collection: Heights of the surface 1 and 2 were adjusted to the fingertip and standing eye heights of the participant, respectively. Once the workstation parameters were set up, participant performed two experimental sessions. At the end of each session, participant was asked to report discomfort in the various regions of neck and shoulder using Borg's subjective rating scale (Appendix C). 


\subsection{Data processing}

\subsubsection{Discrete wavelet transform (DWT) of SEMG signal}

The SEMG data recorded at the beginning of session 1 was treated as the fresh or nonfatigued signal. Data obtained at the end sessions 1 and 2 were treated as the fatigued signal. In DWT, an optimal decomposition with $L$ levels is allowed under the condition that

$$
\mathrm{Q}=2^{L}
$$

Where, Q represents the length of the decomposed signal. During the signal decomposition by a wavelet, the signal is divided into different frequency bands at different levels. The bandwidth of frequency bands at different levels in DWT is defined based on the sampling frequency [71]. Based on the sampling frequency of $1500 \mathrm{~Hz}$, the relationship between number of levels $\mathrm{L}$ and sampling frequency is given by following equation:

$$
B=\frac{1500}{2^{L+1}}
$$

Where, B represented different bandwidths corresponded to different level (L) of decomposition. Previous studies evaluated lower frequency bands of $5-30 \mathrm{~Hz}$ as the fatigue frequency band $[18,75]$. Based on the sampling frequency of $1500 \mathrm{~Hz}$ used in this study, seven level of decomposition was enough to analyze these lower frequency bands according to the Nyquest rule (Table 4.1).

Table 4.1: Frequency bands for the seven levels of decomposition

\begin{tabular}{llllllll}
\hline Level & Level 1 & Level 2 & Level 3 & Level 4 & Level 5 & Level 6 & Level 7 \\
\hline Frequency Band, Hz & $375-750$ & $187-375$ & $93-187$ & $46-93$ & $23-46$ & $12-23$ & $6-12$ \\
\hline
\end{tabular}

Wavelet toolbox of Matlab was used to conduct the DWT analysis of SEMG signals (Appendix D). The DWT uses high-pass filter to obtain high frequency components so called as 
details coefficients (CD) and low-pass filters to obtain low frequency components so called as approximations coefficients (CA).

Let $\mathrm{X}$ was the SEMG signal of $\mathrm{N}$ samples which was decomposed to desired seven level, so the vector could be defined as $\mathrm{X}=(\mathrm{CA} 7, \mathrm{CD} 7, \mathrm{CD} 6, \mathrm{CD} 5, \mathrm{CD} 4, \mathrm{CD} 3, \mathrm{CD} 2, \mathrm{CD} 1)$

Where CA7 are the approximation coefficient vector at level seven and the detail coefficient vectors are named CD1 to CD for level 2 to 7, respectively (Figure 4.10).

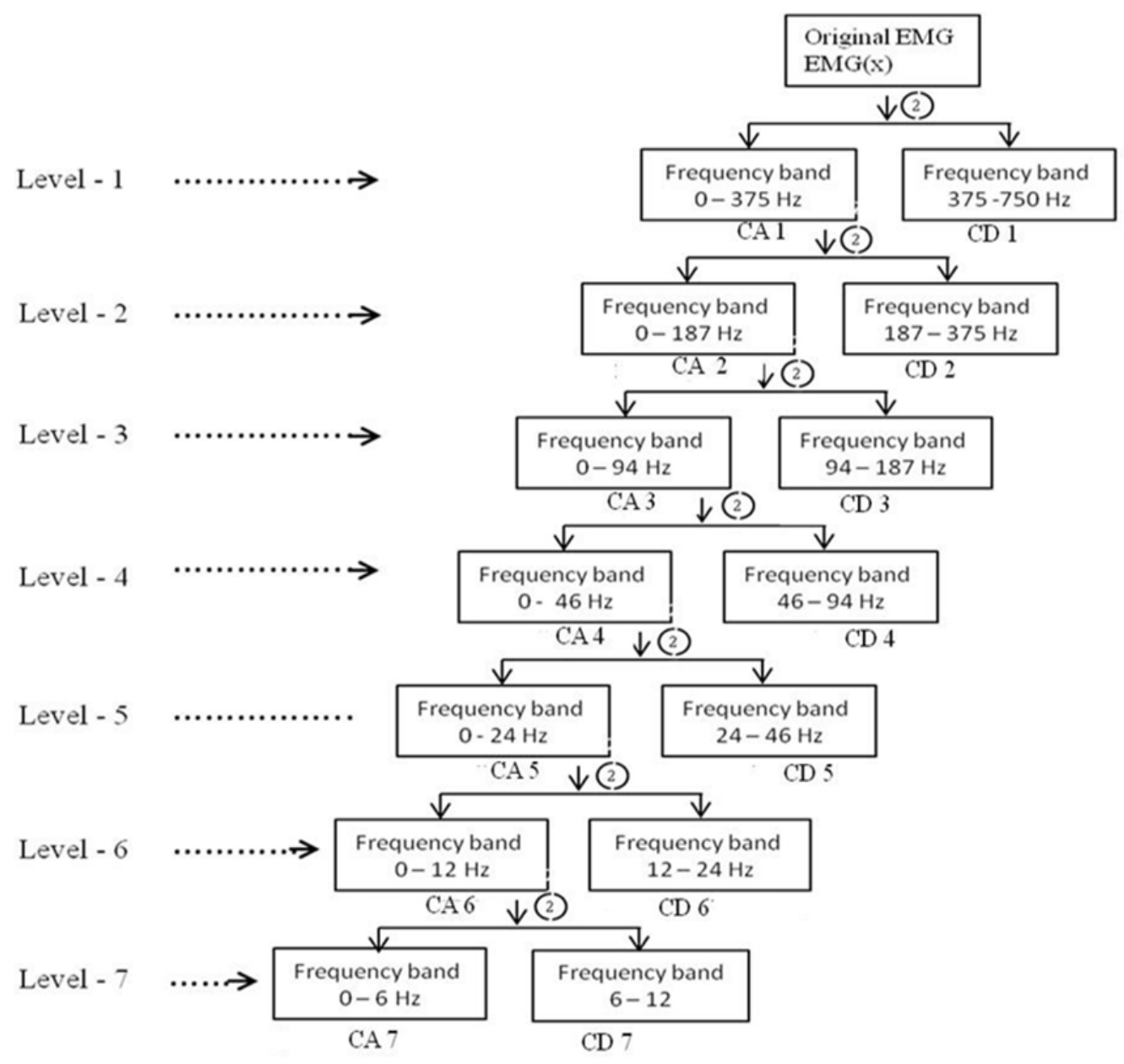

Figure 4.10: Seven level decomposition algorithm of DWT used in this study 
The raw SEMG signal was decomposed to get the detailed coefficients (CD1) and approximation coefficients (CA1) during the first level of decomposition. The detail coefficients CD1 were stored and the approximation coefficients CA1 was further decomposed into the second-level of detail and approximation coefficients. The process was continued further to get detail coefficient CD7 and approximate coefficient CA7 at seventh level of decomposition. The seventh level of decomposition produced CD7, CD6, CD5, CD4, CD3, CD2, and CD1 detail coefficients and CA7 approximation coefficients.

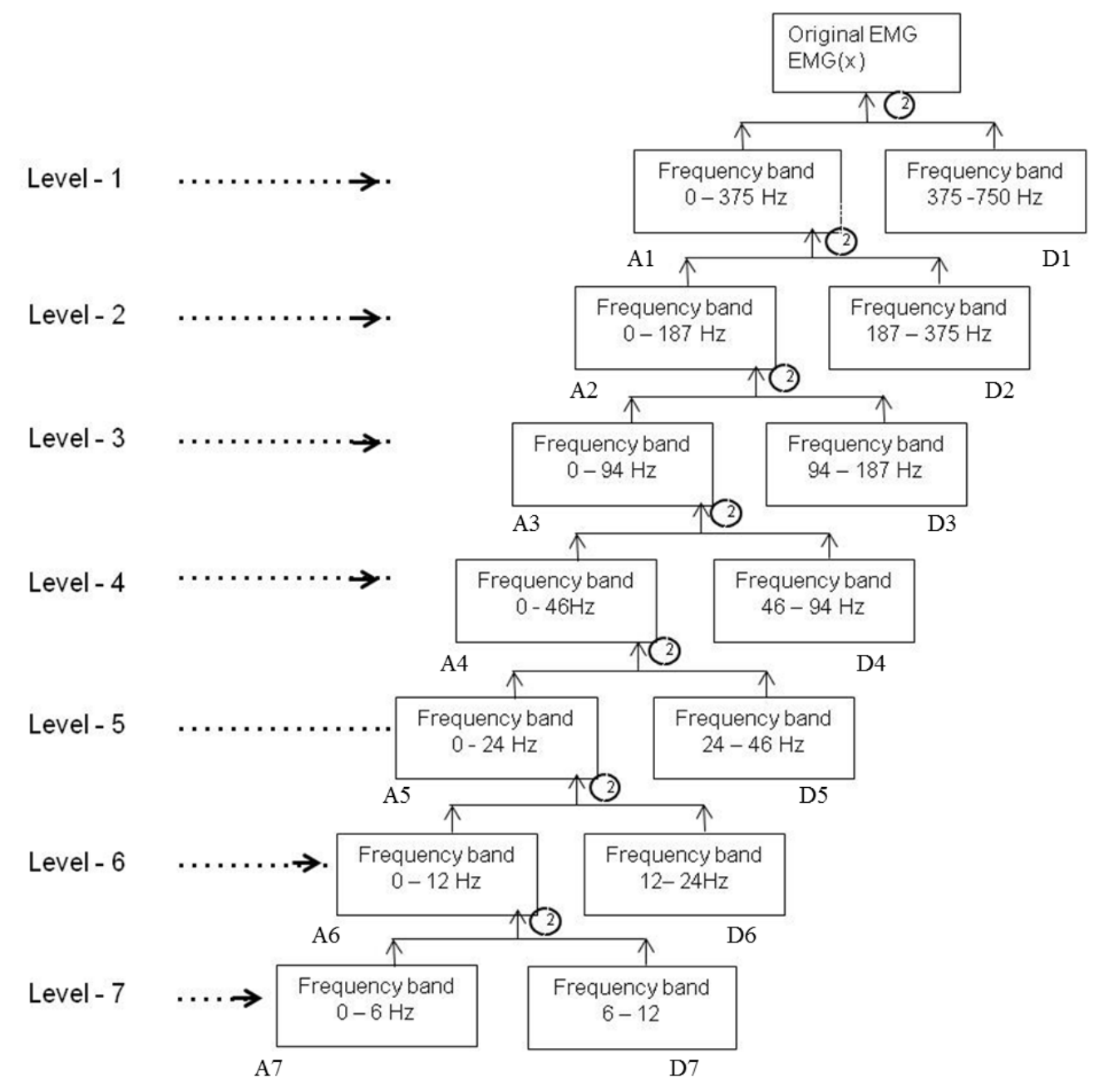

Figure 4.11: Reconstruction algorithm of DWT used in this study 
The decomposed signal $\mathrm{X}$ was reconstructed through synthesis filters, so the reconstructed SEMG signal was the summation of $\mathrm{A}_{7}$ and $\sum_{j=1}^{7} \mathrm{D}$ levels. The equality is $X^{\prime}=A_{7}+\sum_{j=1}^{7} \mathrm{D}$

The vector can be defined as: $X^{\prime}=\left(A_{7}, D_{7}, D_{6}, D_{5}, D_{4}, D_{3}, D_{2}, D_{1}\right)$

Here, $X^{/}$was the reconstructed signal which was sum of its approximation $A_{7}$ and of its fine details, $D_{7}$ to $D_{1}$ (Figure 4.11)

\subsubsection{Wavelet function selection}

The aforementioned decomposition and reconstruction was conducted using a total of 10 wavelet functions of five orthogonal wavelet families (Table 4.2). A list of previous studies that used similar wavelet functions is as follows:

1) Kumar et al., [18] found significant differences between the power of fatigued and non-fatigued SEMG signal using sym4 and sym5 wavelet functions.

2) Reaz et al., [92] found that db45 wavelet function most significantly presented the change in the power spectrum properties of resting and maximum contraction stage of walking exertions.

3) Khezri and Jahed [93] recommended bior 1.5 as the best denoising estimation of SEMG signals.

4) Ren et al., [94] used wavelet function db5 to denoise SEMG signals in their research.

5) Hussein et al., [95] found $\mathrm{db} 2$ as the best choice among other wavelets to denoise SEMG signals.

6) Bousbia-Salah et al., [96] recommended bior3.1 as the best among biorthogonal family for biosignal compression. 
7) In a DWT analysis of SEMG, Balasubramanian et al., [84] used db5 to decompose the signal to understand muscle fatigue during driving.

8) Coif5 provided the best reconstruction of SEMG signal in a study performed by Phinyomark [19].

9) Haar was used by Lauer et al., [97] for SEMG decomposition to quantify onset and offset of muscle activity in a human gait study.

10) Rbio3.1 was used in few studies along with other wavelet functions to extract muscle activity features and denoise the SEMG signals [19, 98-99].

Table 4.2: Selected wavelet functions or mother wavelets in this study

\begin{tabular}{llllllllll}
\hline 1 & 2 & 3 & 4 & 5 & 6 & 7 & 8 & 9 & 10 \\
\hline Bior 1.5 & Bior 3.1 & Rbio 3.1 & coif 5 & db 2 & db 5 & db 45 & Haar & sym 4 & sym 5 \\
\hline
\end{tabular}

\subsubsection{Power and power contrast calculation}

At each level, the power of that sub-band was estimated using following equation:

Power $=\sum_{i=1}^{i=n}\left(c_{1}+c_{2}+\cdots+c_{n-1}+c_{n}\right)^{2}$

Where, $c_{1}$ to $c_{n}$ are the approximate or detailed coefficients at a particular level of decomposition. Power computation was performed using Matlab (Appendix D).

Power contrast was determined by comparing power of fatigued signal with the power of non-fatigued signal at the corresponding levels using the following equation:

Power Contrast $=\left(\frac{\text { Power }_{\text {fat }}-\text { Power }_{f}}{\text { Power }_{f}}\right) \times 100 \%$

Where, Power $_{f}$ represented powers of non-fatigue signal at a level of decomposition and Power $_{\text {fat }}$ represented the power of the fatigued signal at the same level of decomposition. 


\subsubsection{Statistical analysis}

'Time' and 'subject' were the independent variables, and the calculated power was the dependent or response variable in this study. 'Subject' was treated as a randomized blocking variable. 'Time' had four different levels: exertions at first $\left(\mathrm{T}_{0}\right)$ and $20^{\text {th }}\left(\mathrm{T}_{20}\right)$ minute of the first session and exertions at $25^{\text {th }}\left(\mathrm{T}_{25}\right)$ and $45^{\text {th }}\left(\mathrm{T}_{45}\right)$ minute of the second session for each muscle group. The statistical analysis was performed for all selected ten wavelet functions and for all decomposed levels.

A mixed model statistical analysis was chosen for the statistical analysis. A total of 70 mixed model ANOVAs were performed SAS (version 9.2) software for each muscle. The SAS codes are reported in Appendix E.

$Y_{i j}=\mu+\alpha_{i}+\tau_{j}+\epsilon_{i j} \quad\left\{\begin{array}{l}i=1, \ldots, a \\ j=1, \ldots, c\end{array}\right.$

Where,

$Y_{i j}$ represent power value

$\mu$ is the overall mean

$\alpha_{i}$ is the fixed effect of time, $i=1,2,3,4$.

$\tau_{j}$ is the effect of blocking factor - participants, $\mathrm{j}=1,2, \ldots, 10$.

$\epsilon_{i j}$ is the random error term.

The hypothesis was tested for the effect of time.

$H_{0}: \alpha_{1}=\cdots .=\alpha_{4}$

In the model, the Type I error $\alpha=0.05$ and power of the test $(1-\beta)$, which equals 0.95 , were chosen for the hypothesis test and sample size determination. The confidence level of this study was $95 \%$. If the null hypothesis was rejected, the analysis of variance indicated that mean 
power at the four time instances was different. Then the next procedure was to make comparisons between different time instances. If the effect of time was significant for any band, Tukey's test was performed for all wavelet functions to find specific differences between different time instances. The equality of variance assumption of F-test was also assessed.

\subsubsection{Sample (participants) size determination}

Statistical methods required that the observations (or errors) be independently distributed random variables. By properly randomizing the experiment, i.e., by randomly selecting the study participants, the effects of extraneous factors that might be present were mitigated.

Operating characteristics curves (OC curves), a graph of $\beta$ (type II error probability) versus the true difference in means, play an important role in the choice of sample size in experimental design problems. Therefore, the OC curves were used to do a statistical power analysis and to determine the number of participants for the mixed model. The $\lambda$ parameter was calculated using the following equation-

$\lambda=\sqrt{1+\frac{\mathrm{an} \sigma_{\beta}{ }^{2}}{\sigma^{2}}}$

Where,

' $a$ ' is the number of levels of fixed effect variable 'time'

' $\mathrm{n}$ ' is the number of repetition

$\sigma_{\beta}^{2}$ is the variance component of the random factor

$\sigma^{2}$ is the error variance component of the model

The $\sigma_{\beta}{ }^{2}$ is calculated from the expected mean square table -

$\sigma_{\beta}^{2}=\frac{\ddot{\sigma}_{\beta}^{2}-\sigma^{2}}{a n}$ 


$$
\ddot{\sigma}_{\beta}^{2}=\text { EMS of time, } \sigma^{2}=\text { Expected MSE } .
$$

Most of the previous studies used data from two or three participants for this type of analysis. In the preliminary study, the power values of a lower frequency band $(12-23 \mathrm{~Hz}) \mathrm{using}$ $\mathrm{db} 2$ wavelet function were calculated for SEMG signals from right upper trapezius muscle. Four participants $(b=4)$ participated in the preliminary study. Value of $\lambda$ was calculated using equation 4.10 and 4.11. From the operating characteristic chart for random effect, power of the test was calculated (Table 4.3). No repetition was considered therefore $n=1$. The degrees of freedom for random effect were 3 (4-1) and for the fixed effect of time were 3 (4-1). So, the DOF related to the error of the ANOVAs were $16(4 * 4)$. The significance level was set at $\alpha=$ 0.05. From the OC curve for random effect, from the values of $\lambda, v 1$, and v2, probability of accepting the hypothesis was determined and power of the test was estimated to be 0.70 (Table 4.3).

Table 4.3 : Power values for chosen number of participants

\begin{tabular}{lllll}
\hline$\lambda$ & Numerator DOF, v1 & Denominator DOF, v2 & $\beta$ & Power $(1-\beta)$ \\
\hline 2.84 & 3 & 16 & 0.30 & 0.70 \\
\hline
\end{tabular}

Therefore, 4 participants were not sufficient to achieve the required power. Using $\lambda=$ 2.84 , power of $95 \%$ could be achieved for $v 1=6$ and $v 2=24$, i.e., 7 subjects were sufficient to achieve the power of greater than $95 \%$. However, we slightly increased the sample size to ten subjects to guard against the possibility that the prior estimate of error variance was too conservative. 


\section{Chapter 5: Results}

Ten healthy male participants were recruited for data collection. The average weight, height and age of the participants were $71.12( \pm 9.30) \mathrm{Kg}, 170.2( \pm 11.1) \mathrm{cm}$, and $27( \pm 4.8)$ years, respectively (Appendix F). During first session, participants completed an average of $19.5( \pm$ 0.71) loading and unloading trials. During second session, on an average $19.8( \pm 0.79)$ loading and unloading trials were completed. Task completion time data for individual participants are shown in Table F (Appendix G). Average durations of loading and unloading trials during first and second sessions were $61.61( \pm 2.32)$ and $60.69( \pm 2.39)$ seconds, respectively. During a trial, 30 small boxes were transferred from the cart to the shelve (loading) and from shelve back to the cart (unloading). Therefore, average duration of an actual loading or unloading exertion was 2.03 $( \pm 0.08)$ seconds.

\subsection{Subjective discomfort data}

The individual subjective discomfort rating data are tabulated in Appendix H. The mean of subjective discomfort scores in the right posterior and the left anterior regions of neck showed increasing trend towards the end of session 1 and session 2 (Figure 5.1). Right upper trapezius muscle is located in the right posterior region of the neck and left sternocleidomastoid muscle is located in the left anterior region of the neck. For both these muscles, the participants rated higher discomforts due to continuous dynamic contractions. A baseline discomfort of 1 (= nothing at all) was recorded at the beginning of the first session $\left(\mathrm{T}_{0}\right)$. After twenty minutes of loading and unloading tasks $\left(\mathrm{T}_{20}\right)$, a mean discomfort of 5 (= moderate discomfort) was reported in the right posterior region of the neck. A mean discomfort of 4 (= slight discomfort) was reported in the left anterior region of the neck. At the end of forty minutes of monotonous cyclic 
loading and unloading tasks $\left(\mathrm{T}_{45}\right)$, a mean subjective discomfort of 7 (= some complicated discomfort) was reported in the right posterior region of the neck. In the left anterior region, the corresponding value of subjective discomfort was 5 (= moderate discomfort).

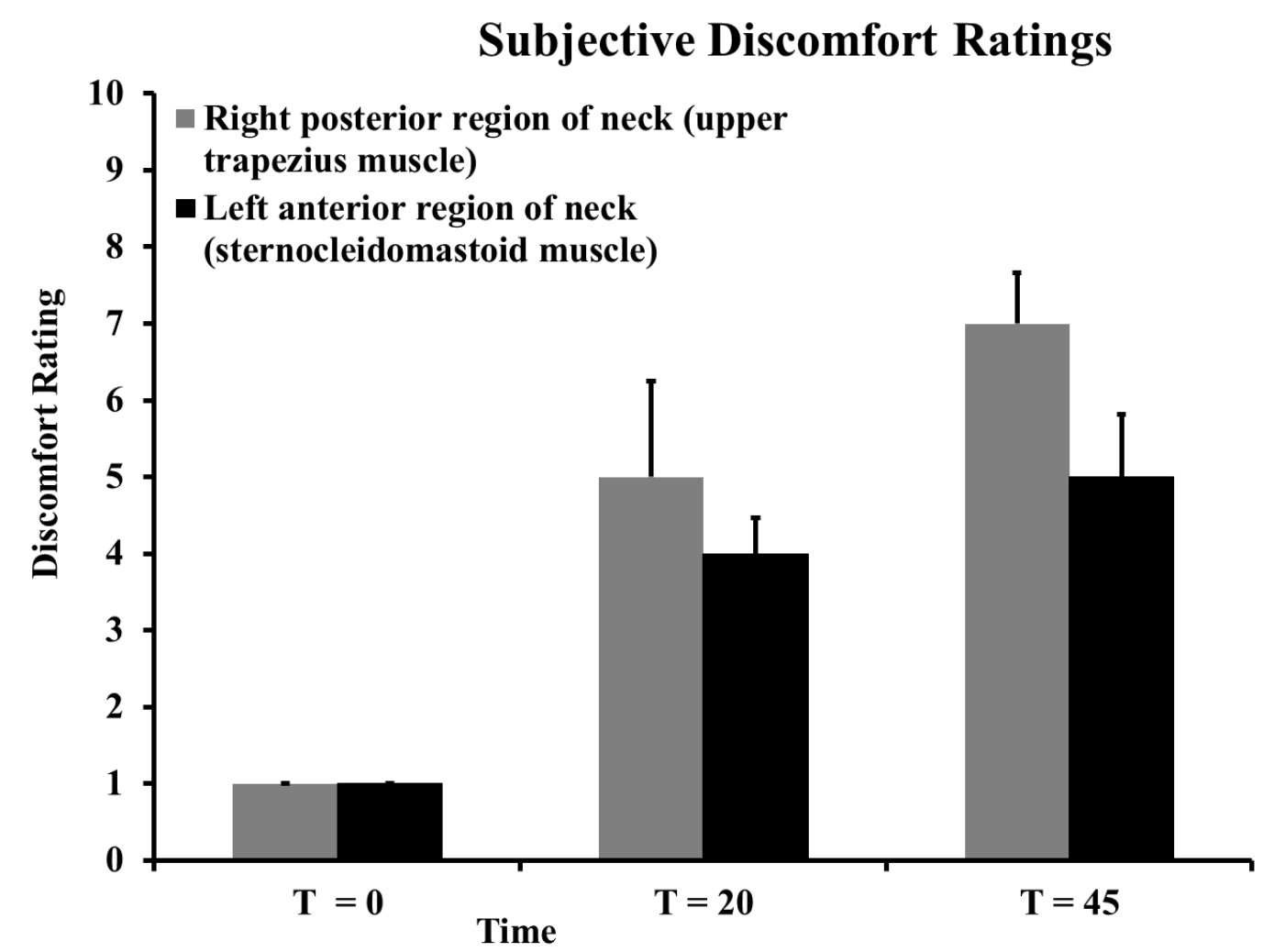

Figure 5.1: Subjective discomfort scores at different time instances

\subsection{Right upper trapezius muscle}

Raw SEMG data recorded from the right upper trapezius muscle for one of the participants during loading and unloading exertion are shown in Figure 5.2. Based on the sampling frequency of $1500 \mathrm{~Hz}, 3000$ data points showed the muscle activation pattern during a loading and unloading exertion of two seconds (Figure 5.2 a). Results of DWT using Rbio3.1 wavelet function were plotted using scalogram (Figure 5.2 b). Scalogram represents the 
percentage of energy based on the detail coefficients at different levels of decomposition. At $5^{\text {th }}$, $6^{\text {th }}$, and $7^{\text {th }}$ decomposition level, more number of darker bands were observed for exertions performed at $T_{20}$ and $T_{45}$ than at $T_{0}$ and $T_{25}$. This indicated higher amount of the energy for lower frequency bands towards the end of the sessions 1 and 2. A substantial increase in the number of darker bands was observed at $T_{45}$ compared to $T_{25}$ further indicating higher increase in the amount of the energy for exertions performed at the end of session 2 than 1.

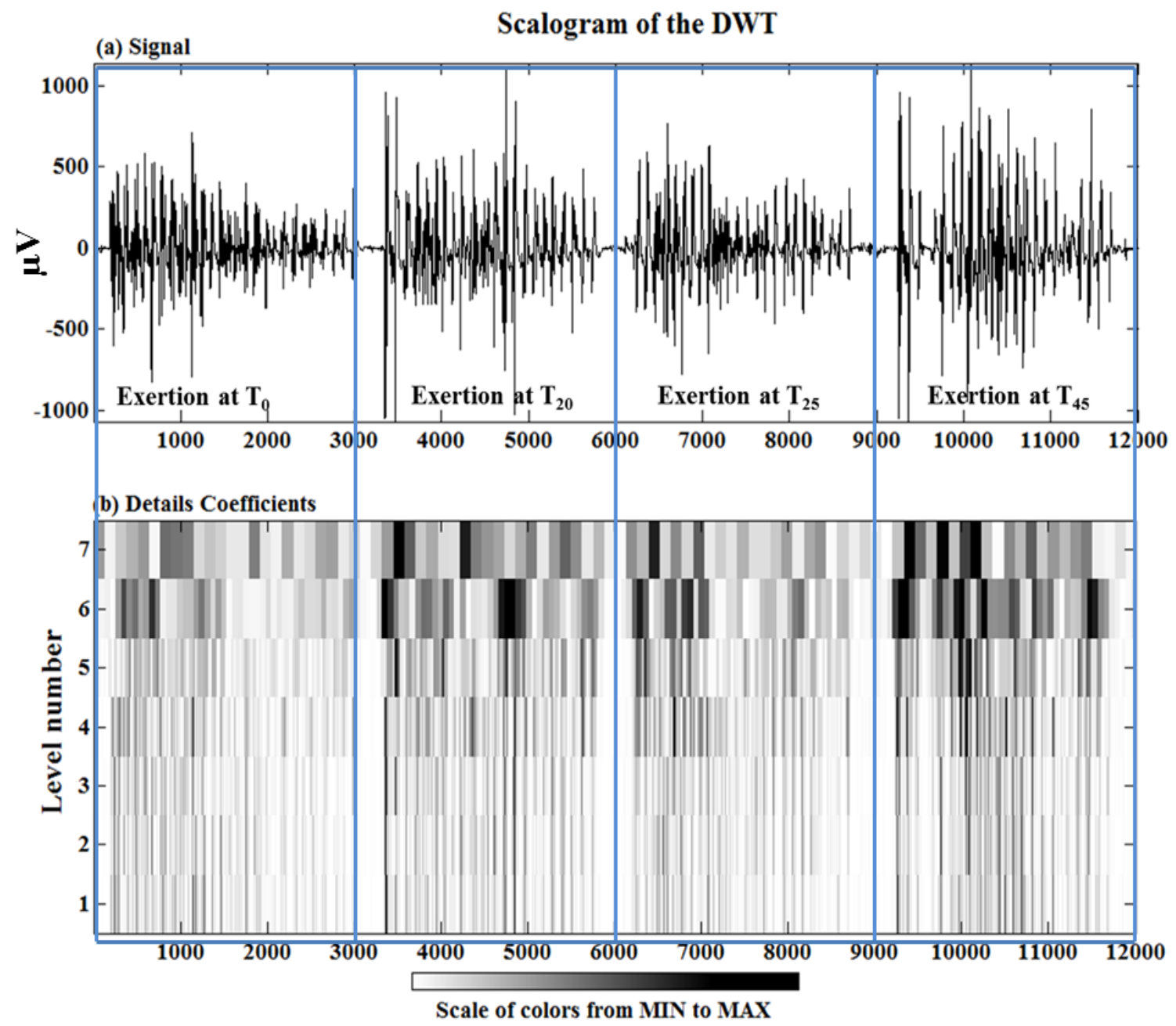

Figure 5.2: Illustration of the raw SEMG signal and corresponding intensity pattern computed using DWT with Rbio3.1 wavelet function. Horizontal axis represents time scale in milliseconds. Blue bars separate signals collected at different time instances 


\subsubsection{Power and frequency band trend}

Based on the subjective discomfort data it is evident that the participants experienced progressively higher levels of fatigue towards the end of sessions 1 and 2 . The raw power data of right upper trapezius muscles at four different time instances for each individual subject is tabulated in Appendix I. The mean and standard deviation of power at different frequency bands computed using ten wavelet functions are tabulated in appendix J. The power of the SEMG signal at different time instances marked with different levels of muscle fatigue showed variable magnitudes at different frequency bands (Figure 5.3 and Figure 5.4). It was observed that for most of the wavelets, mean power was relatively very low at the frequency bands of $375-750$ $\mathrm{Hz}, 187-375 \mathrm{~Hz}$ and 6-12 Hz. Furthermore, at $375-750 \mathrm{~Hz}$ and $187-375 \mathrm{~Hz}$ frequency bands, trend in the power with respect to different time instances was inconsistent for all the wavelet functions used in this study. For the frequency bands of $93-187 \mathrm{~Hz}$ and $46-93 \mathrm{~Hz}$, a relatively high power was observed for most of the wavelet functions. In case of Rbio3.1 and Bior3.1 wavelet functions, the highest power was observed for the frequency bands of $23-46 \mathrm{~Hz}$ and 6-12 $\mathrm{Hz}$, respectively (Figure $5.3 \mathrm{c}$ ). A general trend in the power of different frequency bands showed an increase from $T_{0}$ to $T_{20}$ corresponding to the sustained repetitive loading and unloading exertions. A decline in power due to rest period was observed from $T_{20}$ to $T_{25}$. From $\mathrm{T}_{25}$ to $\mathrm{T}_{45}$, further increase in the power was observed with the continued loading and unloading exertions. However, these power trends with respect to different time instances were relatively more consistent at the three lower frequency bands, i.e., $23-46 \mathrm{~Hz} .12-23 \mathrm{~Hz}$, and 6-12 Hz (Figure 5.3 and Figure 5.4). 

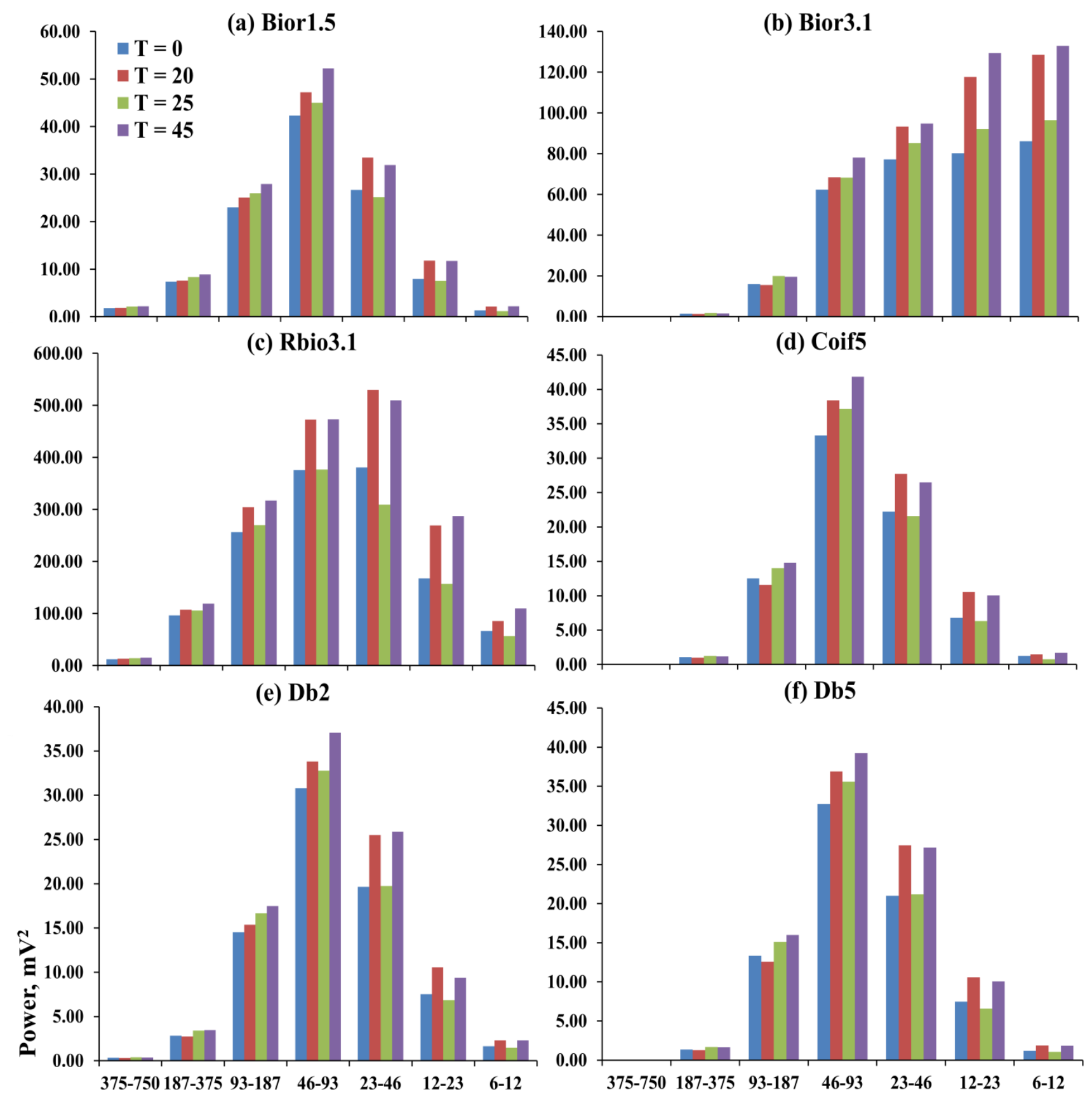

Frequency Band, $\mathrm{Hz}$

Figure 5.3: The graphical representation of power $\left(\mathrm{mV}^{2}\right)$ as a function of time for the following wavelet functions: (a) Bior1.5, (b) Bior3.1, (c) Rbio3.1, (d) Coif5, (e) Db2, and (f) Db5 for the right upper trapezius muscle 

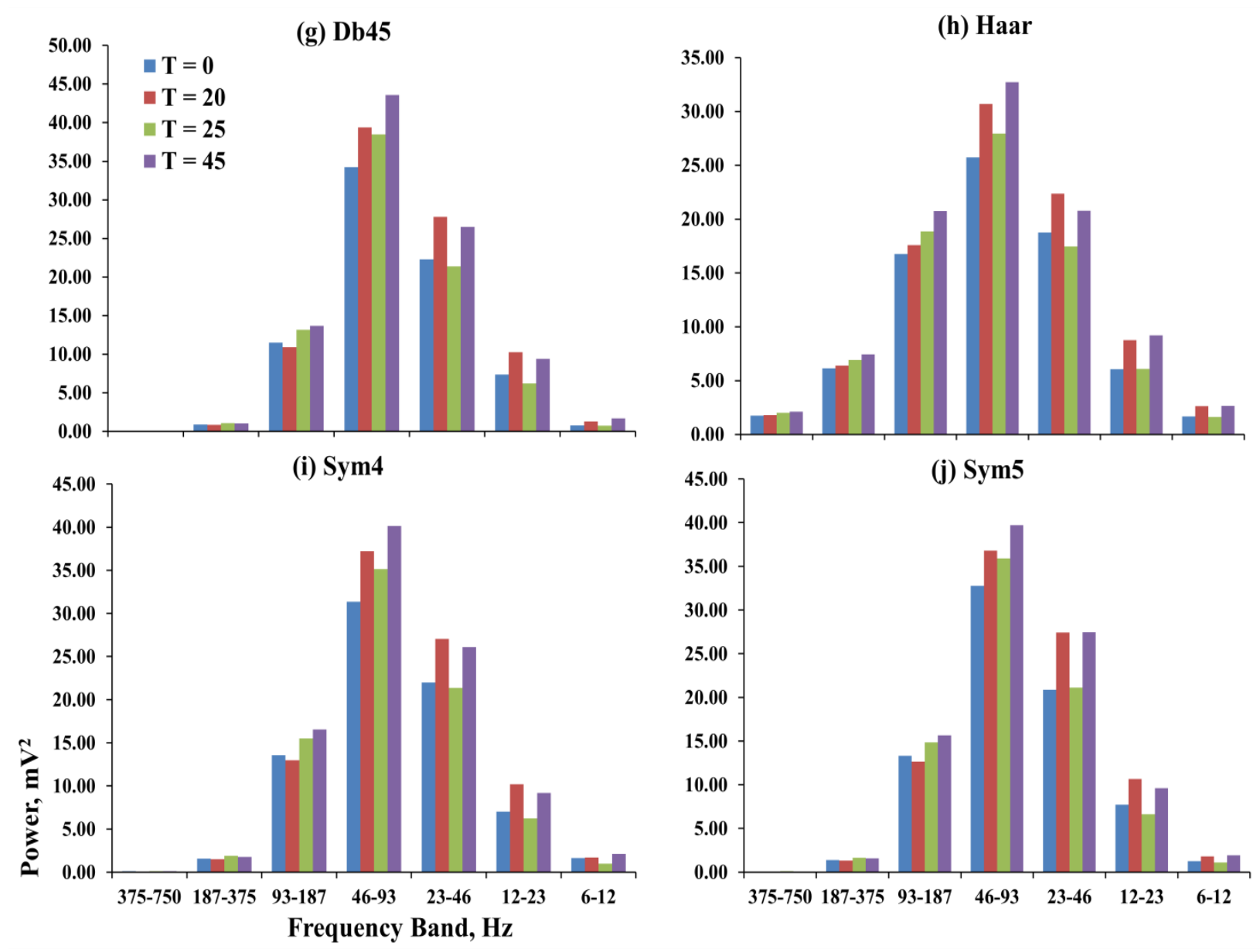

Figure 5.4 : The graphical representation of power $\left(\mathrm{mV}^{2}\right)$ as a function of time for ten wavelet functions: (g) Db45, (h) Haar (i), Sym4, and (j) Sym5 for the right upper trapezius muscle

\subsubsection{Statistical analysis}

The effect of time on the power of SEMG signal was studied using a mixed model ANOVA. The equality of variance test $(\mathrm{P}>0.05)$ showed that the assumption of the homoscedasticity condition was true (Table 5.1). 
Table 5.1: P-values of the Levene's test for equality of variance of the mixed models for the upper trapezius muscle

\begin{tabular}{lllllllllll}
\hline $\begin{array}{l}\text { Frequency } \\
\text { Band, Hz }\end{array}$ & Bio 1.5 & Bior3.1 & Rbio3.1 & Coif5 & Db2 & Db5 & Db45 & Haar & Sym4 & Sym5 \\
\hline $375-750$ & 0.44 & 0.50 & 0.46 & 0.71 & 0.40 & 0.50 & 0.78 & 0.44 & 0.45 & 0.47 \\
$187-375$ & 0.45 & 0.42 & 0.54 & 0.45 & 0.40 & 0.38 & 0.45 & 0.46 & 0.41 & 0.43 \\
$93-187$ & 0.53 & 0.41 & 0.66 & 0.42 & 0.53 & 0.43 & 0.43 & 0.44 & 0.43 & 0.45 \\
$46-93$ & 0.60 & 0.56 & 0.46 & 0.64 & 0.62 & 0.71 & 0.63 & 0.62 & 0.62 & 0.65 \\
$23-46$ & 0.64 & 0.60 & 0.35 & 0.58 & 0.48 & 0.51 & 0.63 & 0.58 & 0.53 & 0.47 \\
$12-23$ & 0.18 & 0.37 & 0.29 & 0.31 & 0.17 & 0.25 & 0.58 & 0.13 & 0.39 & 0.33 \\
$6-12$ & 0.64 & 0.18 & 0.31 & 0.35 & 0.59 & 0.74 & 0.33 & 0.69 & 0.35 & 0.50 \\
\hline
\end{tabular}

For the frequency bands of 46-93 Hz, 93-187 Hz, 187-375 Hz and $375-750 \mathrm{~Hz}$, the effect of time were statistically not significant for any of ten wavelet functions used in this study. The effect of time was statistically significant for most of the wavelets at lower frequency bands of 6$12 \mathrm{~Hz}, 12-23 \mathrm{~Hz}$ and 23-46 Hz (Table 5.2). For 6-12 Hz frequency band, statistical significance was observed for Bior1.5, Bior3.1, Rbio3.1, Coif5, Db5, Db45, Haar, and Sym4 wavelet functions. For 12-23 Hz frequency band, statistical significance was observed for all wavelet functions. For 23-46 Hz frequency band, statistical significance was observed for five wavelet functions: Bior1.5, Rbio3.1, Db2, Db5, and Sym5 (Table 5.2). A comparison of wavelets at these three frequency bands is shown in Figure 5.5. 
(a) Details Level 7 (6-12 Hz)

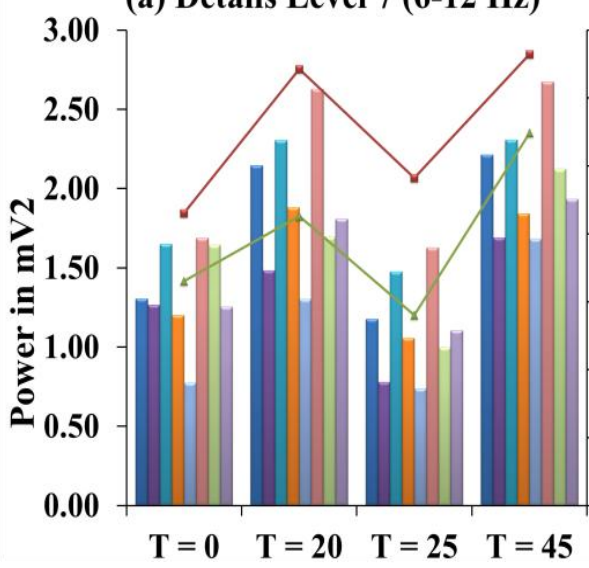

(b) Details Level $6(12-23 \mathrm{~Hz})$

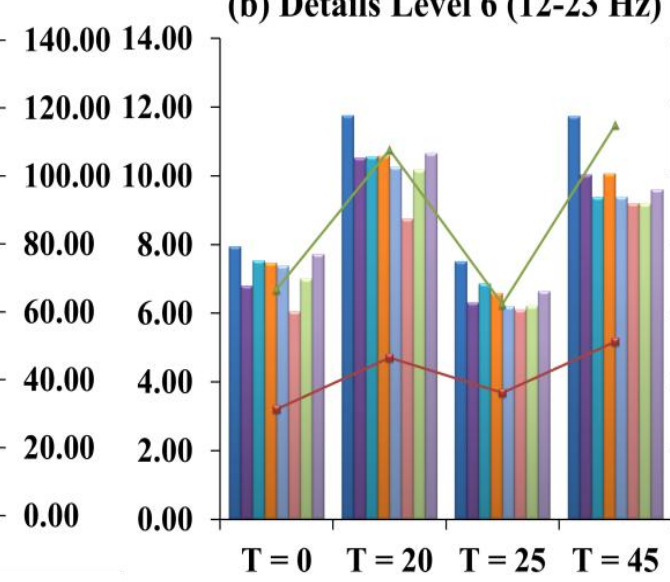

(c) Details Level $5(23-46 \mathrm{~Hz})$

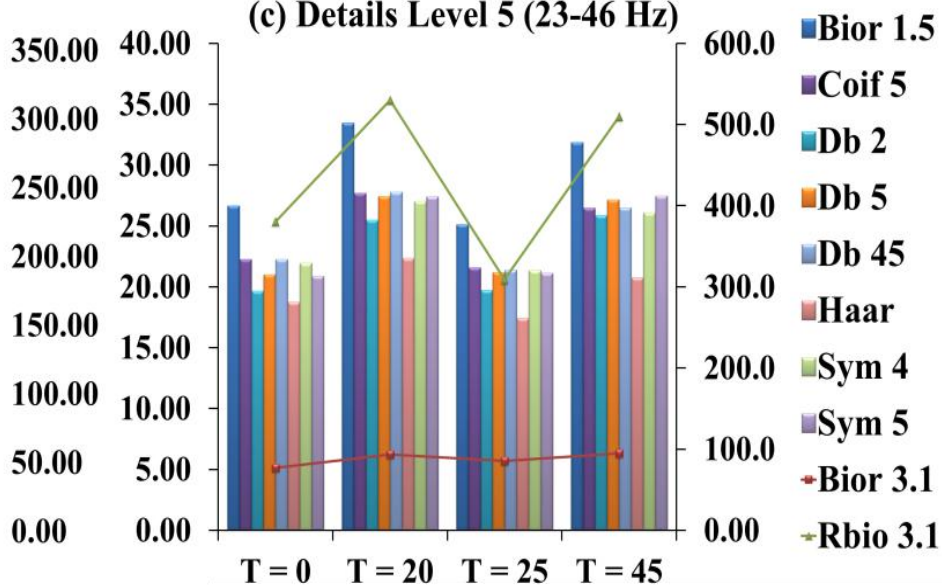

Figure 5.5: Power of SEMG signal recorded from the right upper trapezius muscle at different time instances for the following frequency bands: (a) 6-12 Hz (b) 12-23 Hz and (c) 23-46 Hz. Behavior of Rbio3.1 and Bior3.1 wavelets were plotted using a secondary axis

Table 5.2: P-values for the effect of time on the power of SEMG signal from the right upper trapezius muscle for different wavelet functions at various frequency bands. Values marked with asterisks $(*)$ are statistically significant

\begin{tabular}{lllllllllll}
\hline $\begin{array}{l}\text { Frequency } \\
\text { Band, Hz }\end{array}$ & Bior1.5 & Bior3.1 & Rbio3.1 & Coif5 & Db2 & Db5 & Db45 & Haar & Sym4 & Sym5 \\
\hline $375-750$ & 0.69 & 0.65 & 0.67 & 0.49 & 0.63 & 0.65 & 0.26 & 0.69 & 0.56 & 0.44 \\
$187-375$ & 0.69 & 0.6 & 0.56 & 0.68 & 0.6 & 0.58 & 0.64 & 0.69 & 0.65 & 0.71 \\
$93-187$ & 0.64 & 0.61 & 0.29 & 0.69 & 0.67 & 0.68 & 0.72 & 0.65 & 0.67 & 0.68 \\
$46-93$ & 0.54 & 0.52 & 0.12 & 0.44 & 0.66 & 0.59 & 0.37 & 0.22 & 0.28 & 0.63 \\
$23-46$ & $0.04 *$ & 0.42 & $0.03 *$ & 0.13 & $0.04 *$ & $0.04 *$ & 0.13 & 0.19 & 0.2 & $0.04 *$ \\
$12-23$ & $0.03 *$ & $0.02 *$ & $0.03 *$ & $0.02 *$ & $0.03 *$ & $0.03 *$ & $0.04 *$ & $0.04 *$ & $0.03 *$ & $0.02 *$ \\
$6-12$ & $0.02 *$ & $0.03 *$ & $0.04 *$ & $0.03 *$ & 0.1 & $0.04 *$ & $0.03 *$ & $0.01 *$ & $0.05 *$ & 0.08 \\
\hline
\end{tabular}


Multiple comparisons based on the Tukey's test were performed for statistically significant frequency bands. Results of Tukey's test are shown in Appendix K. A distinct pattern of statistical significance between the time instances was observed for different wavelet functions (Table 5.3).

Table 5.3: P-values of Tukey's multiple comparison tests for the effect of time on the power of SEMG signals from right upper trapezius muscle at lower frequency bands for different wavelet functions. Different times instances, $T_{0}, T_{20}, T_{25}$ and $T_{45}$ are symbolized as ' 1 ', ' 2 ', '3' and ' 4 ', respectively. Values marked with asterisks $(*)$ are statistically significant

\begin{tabular}{|c|c|c|c|c|c|c|c|c|c|c|c|}
\hline $\begin{array}{l}\text { Frequency } \\
\text { Band }(\mathrm{Hz})\end{array}$ & & Bior1.5 & Bior3.1 & Rbio3.1 & Coif5 & $\mathrm{Db} 2$ & Db5 & $\mathrm{Db} 45$ & Haar & Sym4 & Sym5 \\
\hline \multirow[t]{6}{*}{$6-12$} & 1 vs 2 & $0.04 *$ & $0.03^{*}$ & 0.48 & 0.47 & 0.12 & 0.06 & 0.13 & $0.02 *$ & 0.89 & 0.14 \\
\hline & 1 vs 3 & 0.75 & 0.47 & 0.61 & 0.11 & 0.67 & 0.68 & 0.92 & 0.87 & 0.1 & 0.69 \\
\hline & 1 vs 4 & $0.03 *$ & $0.02 *$ & $0.01 *$ & 0.16 & 0.12 & 0.08 & $0.01 *$ & $0.01 *$ & 0.22 & 0.07 \\
\hline & 2 vs 3 & $0.02 *$ & 0.13 & $0.04 *$ & $0.02 *$ & $0.04 *$ & $0.03 *$ & 0.11 & $0.01 *$ & 0.08 & 0.06 \\
\hline & 2 vs 4 & 0.87 & 0.76 & 0.18 & 0.49 & 1 & 0.91 & 0.27 & 0.9 & 0.27 & 0.73 \\
\hline & 3 vs 4 & $0.02 *$ & $0.03 *$ & $0.01 *$ & $0 * *$ & $0.04 *$ & $0.03 *$ & $0.01 *$ & $0.01 *$ & $0.01 *$ & $0.03 *$ \\
\hline \multirow[t]{6}{*}{$12-23$} & 1 vs 2 & $0.04 *$ & $0.02 *$ & $0.01 *$ & $0.03^{*}$ & $0.02 *$ & $0.04 *$ & 0.06 & 0.07 & $0.03^{*}$ & $0.03 *$ \\
\hline & 1 vs 3 & 0.81 & 0.39 & 0.79 & 0.76 & 0.6 & 0.55 & 0.41 & 0.97 & 0.57 & 0.42 \\
\hline & 1 vs 4 & $0.04 *$ & $0.01 *$ & $0.02 *$ & $0.04 *$ & 0.16 & 0.08 & 0.18 & $0.03^{*}$ & 0.12 & 0.16 \\
\hline & 2 vs 3 & $0.02 *$ & $0.04 *$ & $0.03^{*}$ & $0.01 *$ & $0.01 *$ & $0.01 *$ & $0.01 *$ & 0.07 & $0.01 *$ & $0 * *$ \\
\hline & 2 vs 4 & 0.99 & 0.4 & 0.7 & 0.76 & 0.36 & 0.72 & 0.55 & 0.75 & 0.48 & 0.43 \\
\hline & 3 vs 4 & $0.03 *$ & $0.02 *$ & $0.02 *$ & $0.03^{*}$ & 0.06 & $0.02 *$ & $0.04 *$ & $0.04 *$ & $0.04 *$ & $0.03^{*}$ \\
\hline \multirow[t]{6}{*}{$23-46$} & 1 vs 2 & 0.06 & 0.18 & $0.04 *$ & $0.08 *$ & $0.04 *$ & $0.04 *$ & 0.08 & 0.14 & 0.12 & $0.04 *$ \\
\hline & 1 vs 3 & 0.65 & 0.49 & 0.17 & 0.82 & 0.98 & 0.95 & 0.77 & 0.58 & 0.85 & 0.93 \\
\hline & 1 vs 4 & 0.13 & 0.14 & $0.04 *$ & 0.17 & $0.03^{*}$ & $0.04 *$ & 0.18 & 0.4 & 0.2 & $0.04 *$ \\
\hline & 2 vs 3 & $0.02 *$ & 0.5 & $0.01 *$ & $0.05^{*}$ & $0.04 *$ & $0.04 *$ & $0.04 *$ & $0.04 *$ & 0.08 & $0.04 *$ \\
\hline & 2 vs 4 & 0.63 & 0.9 & 0.52 & 0.69 & 0.89 & 0.92 & 0.68 & 0.5 & 0.77 & 0.99 \\
\hline & 3 vs 4 & $0.05^{*}$ & 0.43 & $0.02 *$ & 0.11 & $0.03^{*}$ & $0.03 *$ & 0.11 & 0.17 & 0.14 & $0.04 *$ \\
\hline
\end{tabular}

The power differences between $\mathrm{T}_{0}$ and $\mathrm{T}_{25}, \mathrm{~T}_{20}$ and $\mathrm{T}_{45}$ were not significant for any of the lower frequency bands. At $23-46 \mathrm{~Hz}$ frequency band, power at $\mathrm{T}_{20}$ was significantly different than at $\mathrm{T}_{0}$, for Rbio3.1, Coif5, Db2, Db5, and Sym5 wavelet function. Significant decline in the power from $\mathrm{T}_{20}$ to $\mathrm{T}_{25}$ was observed for Bior1.5, Rbio3.1, Coif5, Db2, Db5, Db45, Haar, and Sym5 wavelet function. From $\mathrm{T}_{25}$ to $\mathrm{T}_{45}$, significant increase in the power was observed for Bior1.5, Rbio3.1, Db2, Db5, and Sym5 wavelet functions. Power at $\mathrm{T}_{45}$ was significantly higher than at $\mathrm{T}_{0}$ for Rbio3.1, Db2, Db5, and Sym5 wavelet functions (Table 5.3 and Figure $5.5 \mathrm{c}$ ). At $12-23 \mathrm{~Hz}$ frequency band, power at $\mathrm{T}_{20}$ was significantly higher than at $\mathrm{T}_{0}$, for Bior1.5, Bior3.1, 
Rbio3.1, Coif5, Db2, Db5, Sym4 and Sym5 wavelet functions. Significant difference in the power at $\mathrm{T}_{25}$ than at $\mathrm{T}_{20}$ was observed for Bior1.5, Bior3.1, Rbio3.1, Coif5, Db2, Db5, Db45, Sym4 and Sym5 wavelet function. From $T_{25}$ to $T_{45}$, significant increase in the power was observed for, Bior1.5, Bior3.1, Rbio3.1, Coif5, Db5, Db45, Haar, Sym4 and Sym5 wavelet functions. Power at $\mathrm{T}_{45}$ was significantly higher than at $\mathrm{T}_{0}$ for Bior1.5, Bior3.1, Rbio3.1, Coif5, Haar, and Sym5 wavelet functions (Table 5.3 and Figure 5.5 b). At $6-12 \mathrm{~Hz}$ frequency band, power at $\mathrm{T}_{20}$ was significantly different than at $\mathrm{T}_{0}$, for Bior1.5, Bior3.1, and Haar wavelet functions. Significant drop in the power from $\mathrm{T}_{20}$ and $\mathrm{T}_{25}$ was observed for Bior1.5, Rbio3.1, Coif5, Db2, Db5, and Haar wavelet function. From $\mathrm{T}_{25}$ to $\mathrm{T}_{45}$, all wavelet function showed significant power changes. Power at $\mathrm{T}_{45}$ was significantly higher than at $\mathrm{T}_{0}$ for Bior1.5, Bior3.1, Rbio3.1, Db45, and Haar wavelet functions (Table 5.3 and Figure 5.5 a).

\subsubsection{Comparison between the wavelet functions}

The performance of different wavelets in distinguishing power levels at different time instances, characterized by different levels of fatigue, was compared using a scoring system based on the P-values of Turkey's multiple comparison tests. A statistical significant of $\mathrm{P}<=0.05$ was assigned a score of ' 1 '. A score of ' 0 ' was assigned to statistically not significant $(\mathrm{P}>0.05)$ comparison. Summation of scores was used to rank the wavelets. Top 3 wavelets based on the overall score were Rbio3.1, Bior1.5 and Db5 wavelet functions, respectively (Table 5.4). Among these wavelet functions, Bior1.5 and Rbio3.1 wavelet functions showed more consistent and similar trend at the frequency band of $12-23 \mathrm{~Hz}$ (Figure $5.5 \mathrm{~b}$ ). The Rbio3.1 wavelet function showed comparatively better increase and decline of power than Bior1.5 and Db5 wavelet functions at the frequency band of $23-46 \mathrm{~Hz}$ with respect to different time instances (Figure 5.5 c). On the other hand, $\mathrm{Db} 5$ and Bior 1.5 wavelet functions exhibited better increase and decline of 
power than Rbio3.1 wavelet function at the frequency band of 6-12 Hz (Figure $5.5 \mathrm{a}$ ). Overall,

Rbio3.1 wavelet function showed higher power throughout all frequency bands than Db5 and

Bior1.5 wavelet functions.

Table 5.4: Rank and scores based on the P-values of Turkey's multiple comparison and mixed model for the right upper trapezius muscle. P-values of mixed model are denoted by 'Mixed'. Different times instances, $T_{0}, T_{20}, T_{25}$ and $T_{45}$ are symbolized as ' 1 ', ' 2 ', ' 3 ' and ' 4 ', respectively

\begin{tabular}{|c|c|c|c|c|c|c|c|c|c|c|c|}
\hline $\begin{array}{l}\text { Frequency } \\
\text { Band }(\mathrm{Hz})\end{array}$ & & $\begin{array}{l}\text { Bior } \\
1.5\end{array}$ & Bior3.1 & Rbio3.1 & Coif5 & Db2 & Db5 & Db45 & Haar & Sym4 & Sym5 \\
\hline \multirow[t]{7}{*}{$6-12$} & Mixed & 1 & 1 & 1 & 1 & 0 & 1 & 1 & 1 & 1 & 0 \\
\hline & 1 vs 2 & 1 & 1 & 0 & 0 & 0 & 0 & 0 & 1 & 0 & 0 \\
\hline & 1 vs 3 & 0 & 0 & 0 & 0 & 0 & 0 & 0 & 0 & 0 & 0 \\
\hline & 1 vs 4 & 1 & 1 & 1 & 0 & 0 & 0 & 1 & 1 & 0 & 0 \\
\hline & 2 vs 3 & 1 & 0 & 1 & 1 & 1 & 1 & 0 & 1 & 0 & 0 \\
\hline & 2 vs 4 & 0 & 0 & 0 & 0 & 0 & 0 & 0 & 0 & 0 & 0 \\
\hline & 3 vs 4 & 1 & 1 & 1 & 1 & 1 & 1 & 1 & 1 & 1 & 1 \\
\hline \multirow[t]{7}{*}{$12-23$} & Mixed & 1 & 1 & 1 & 1 & 1 & 1 & 1 & 0 & 1 & 1 \\
\hline & 1 vs 2 & 1 & 1 & 1 & 1 & 1 & 1 & 0 & 0 & 1 & 1 \\
\hline & 1 vs 3 & 0 & 0 & 0 & 0 & 0 & 0 & 0 & 0 & 0 & 0 \\
\hline & 1 vs 4 & 1 & 1 & 1 & 1 & 0 & 0 & 0 & 1 & 0 & 0 \\
\hline & 2 vs 3 & 1 & 1 & 1 & 1 & 1 & 1 & 1 & 0 & 1 & 1 \\
\hline & 2 vs 4 & 0 & 0 & 0 & 0 & 0 & 0 & 0 & 0 & 0 & 0 \\
\hline & 3 vs 4 & 1 & 1 & 1 & 1 & 0 & 1 & 1 & 1 & 1 & 1 \\
\hline \multirow[t]{9}{*}{$23-46$} & Mixed & 1 & 0 & 1 & 0 & 1 & 1 & 0 & 0 & 0 & 1 \\
\hline & 1 vs 2 & 0 & 0 & 1 & 0 & 1 & 1 & 0 & 0 & 0 & 1 \\
\hline & 1 vs 3 & 0 & 0 & 0 & 0 & 0 & 0 & 0 & 0 & 0 & 0 \\
\hline & 1 vs 4 & 0 & 0 & 1 & 0 & 1 & 1 & 0 & 0 & 0 & 1 \\
\hline & 2 vs 3 & 1 & 0 & 1 & 1 & 1 & 1 & 1 & 1 & 0 & 1 \\
\hline & 2 vs 4 & 0 & 0 & 0 & 0 & 0 & 0 & 0 & 0 & 0 & 0 \\
\hline & 3 vs 4 & 1 & 0 & 1 & 0 & 1 & 1 & 0 & 0 & 0 & 1 \\
\hline & Overall & 13 & 9 & 14 & 9 & 10 & 12 & 7 & 8 & 6 & 10 \\
\hline & Rank & 2 & 5 & 1 & 5 & 4 & 3 & 6 & 5 & 7 & 4 \\
\hline
\end{tabular}

The power contrasts (\%) among statistically significant time instances, were computed for the top three wavelet functions (Table 5.5). Progressively higher power contrasts were observed for lower frequency bands. Between $T_{0}$ and $T_{20}$ and $T_{20}$ and $T_{25}$ the highest power contrast was observed for Bior1.5 wavelet function at the frequency band of 6-12 Hz. The Rbio3.1 wavelet function showed the highest power contrast between, $\mathrm{T}_{25}$ and $\mathrm{T}_{45}$, and $\mathrm{T}_{0}$ and 
$\mathrm{T}_{45}$ at this band. Rbio3.1 wavelet function at the frequency bands of $12-23 \mathrm{~Hz}, 23-46 \mathrm{~Hz}$, respectively, showed the highest power contrast among all time instances comparison.

Table 5.5: Power contrast (\%) at the lower frequency bands: $6-12 \mathrm{~Hz}, 12-23 \mathrm{~Hz}$ and $23-46 \mathrm{~Hz}$ for the top 3 wavelet function for right upper trapezius muscle. Different times instances, $T_{0}, T_{20}, T_{25}$ and $\mathbf{T}_{45}$ are symbolized as ' 1 ', ' 2 ', '3' and '4', respectively

\begin{tabular}{l|lcccc}
\hline $\begin{array}{l}\text { Frequency Band } \\
(\mathrm{Hz})\end{array}$ & $\begin{array}{l}\text { Wavelet } \\
\text { Function }\end{array}$ & 1 vs 2 & 2 vs 3 & 3 vs 4 & 1 vs 4 \\
\hline $6-12$ & Bior1.5 & 64.54 & 45.15 & 87.98 & 69.65 \\
& Rbio3.1 & 28.96 & 34.12 & 95.51 & 66.09 \\
& Db5 & 56.48 & 43.82 & 74.43 & 53.34 \\
\hline $12-23$ & Bior1.5 & 48.04 & 36.15 & 56.28 & 47.73 \\
& Rbio3.1 & 60.71 & 41.76 & 83.27 & 71.54 \\
& Db5 & 41.76 & 37.78 & 52.9 & 34.86 \\
\hline $23-46$ & Bior1.5 & 25.54 & 24.93 & 26.83 & 19.53 \\
& Rbio3.1 & 39.33 & 41.62 & 64.80 & 34.04 \\
& Db5 & 30.67 & 22.81 & 28.15 & 29.26 \\
\hline
\end{tabular}

\subsection{Left sternocleidomastoid muscle}

\subsubsection{Power and frequency band trend}

The SEMG data at four time instances from left sternocleidomastoid muscle were analyzed using DWT. The raw power data of left sternocleidomastoid muscles at four different time instances for each individual subject is also tabulated in Appendix I. The mean and standard deviation of power at different frequency bands computed using ten wavelet functions are tabulated in Appendix L. The overall trend observed in the behavior of power of sternocleidomastoid muscle with respect to time and frequency bands was quite similar to the upper trapezius muscle. The power of the SEMG signals at different time instances, characterized with different levels of muscle fatigue, showed variable magnitudes at different frequency bands (Figure 5.6 and Figure 5.7). 

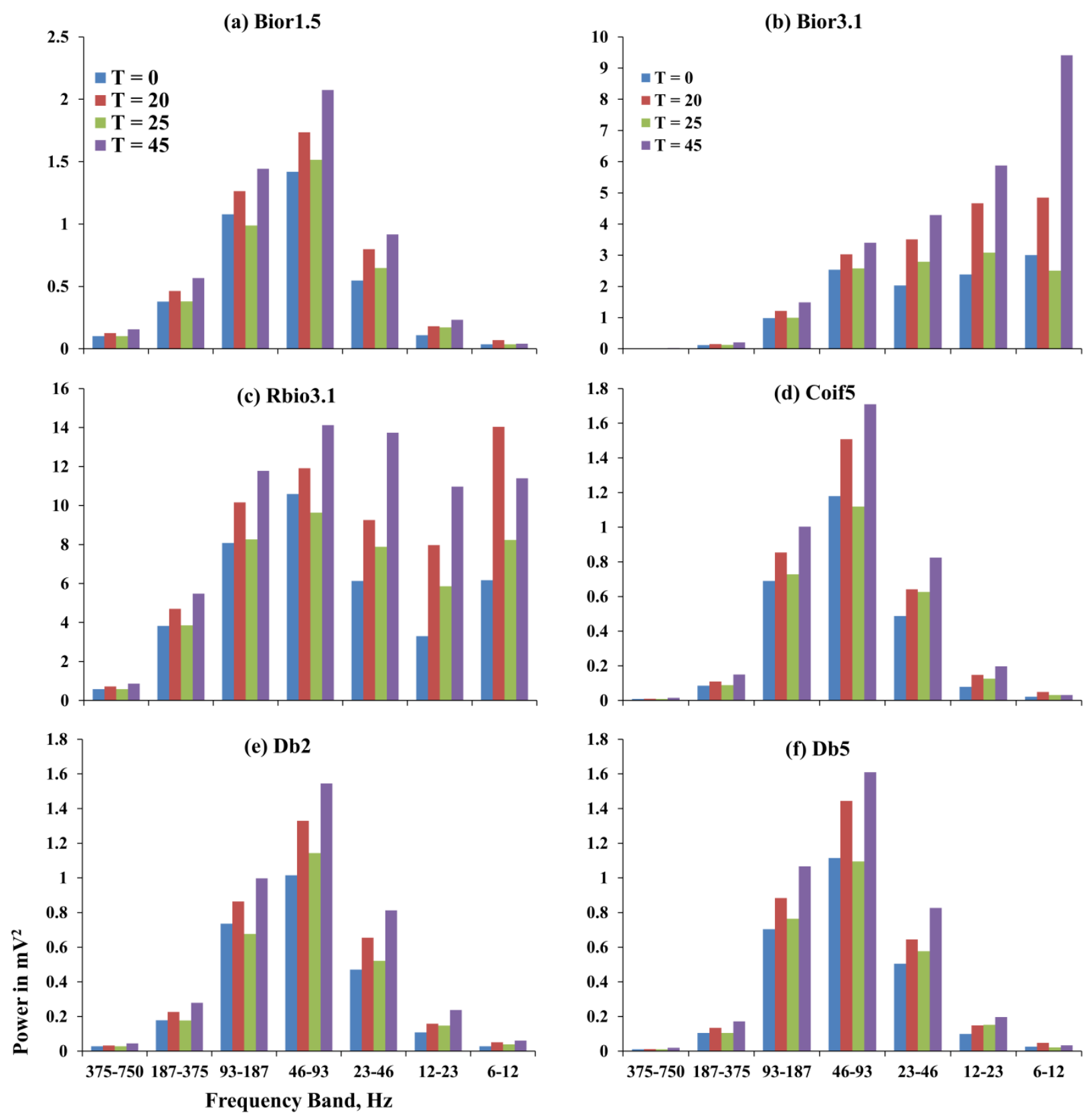

Figure 5.6: The graphical representation of power $(\mathrm{mV2})$ as a function of time for following wavelet functions: (a) Bior1.5, (b) Bior3.1, (c) Rbio3.1, (d) Coif5, (e) Db2, and (f) Db5 for the left sternocleidomastoid muscle 

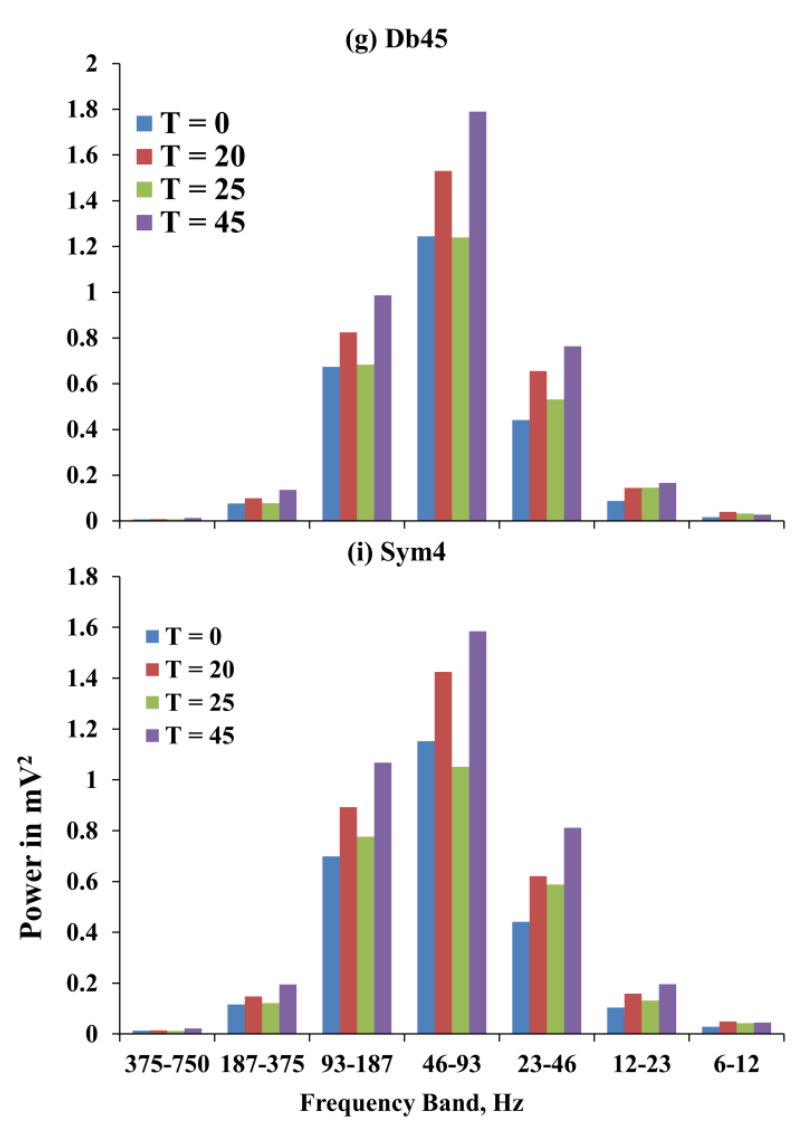

(h) Haar

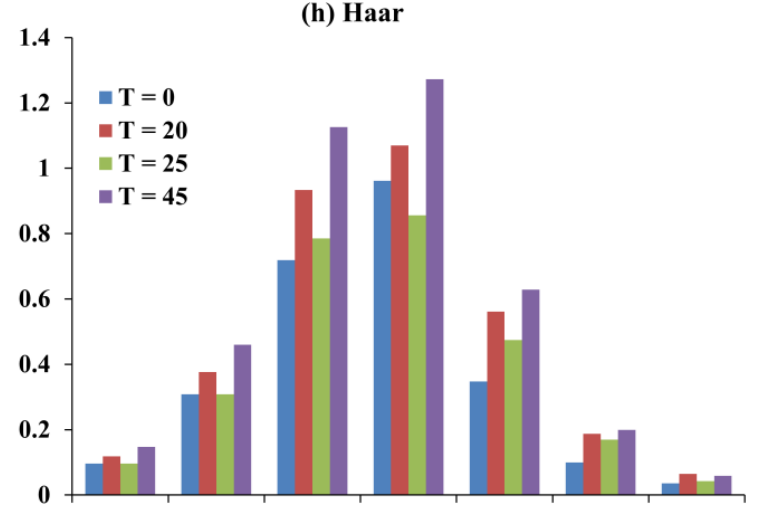

(j) Sym5

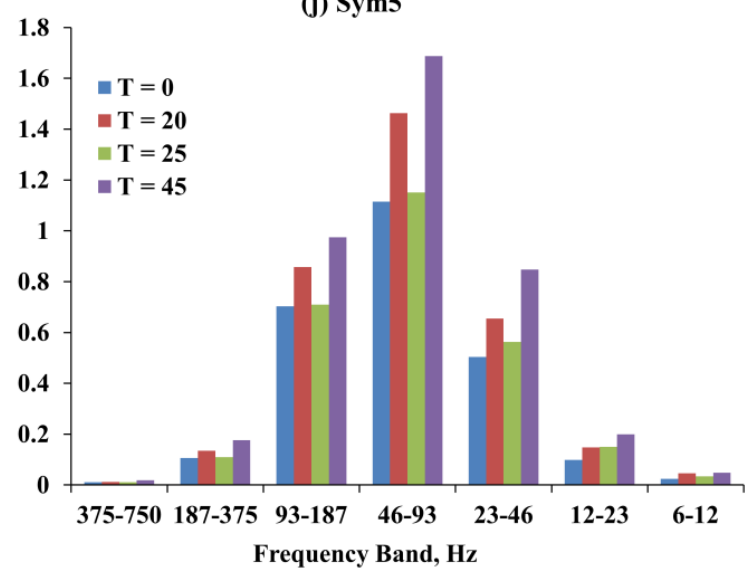

Figure 5.7: The graphical representation of power $\left(\mathrm{mV}^{2}\right)$ as a function of time for following wavelet functions: (g) Db45, (h) Haar (i), Sym4, and (j) Sym5 for the left sternocleidomastoid muscle

The mean power of Rbio3.1 wavelet function was comparatively higher for all frequency bands than other wavelet functions (Figure $5.6 \mathrm{c}$ ). It was also observed that for the most of the wavelet functions mean power was relatively very low at the frequency bands of $375-750 \mathrm{~Hz}$, 187-375 Hz and 6-12 Hz. But for Bior3.1 and Rbio3.1 wavelet functions, the power at the frequency bands of 6-12 Hz was relative high (Figure $5.6 \mathrm{~b}$ ). For the most of the wavelet functions, the highest power was observed at $46-93 \mathrm{~Hz}$ frequency band followed by the frequency band of $93-187 \mathrm{~Hz}$. A general trend in the power across various frequency bands showed an increase from $\mathrm{T}_{0}$ to $\mathrm{T}_{20}$ corresponding to the sustained repetitive loading and unloading exertions. A decline in power due to rest period was observed from $\mathrm{T}_{20}$ to $\mathrm{T}_{25}$, for the 
most of wavelet functions. From $\mathrm{T}_{25}$ to $\mathrm{T}_{45}$, further increase in the power was observed with the continued loading and unloading exertions (Figure 5.6 and Figure 5.7).

\subsubsection{Statistical analysis}

The effect of time on the power of SEMG signal was studied using a mixed ANOVA model. Levene's test for equality of variances showed no heteroscedasticity (Table 5.6).

Table 5.6: P-values of the Levene's test for equality of variance of the mixed models for left sternocleidomastoid muscle.

\begin{tabular}{lrrrrrrrrrr}
\hline $\begin{array}{l}\text { Frequency } \\
\text { Band, Hz }\end{array}$ & Bior1.5 & Bior3.1 & Rbio3.1 & Coif5 & Db2 & Db5 & Db45 & Haar & Sym4 & Sym5 \\
\hline $375-750$ & 0.54 & 0.42 & 0.66 & 0.36 & 0.44 & 0.95 & 0.84 & 0.81 & 0.90 & 0.80 \\
$187-375$ & 0.60 & 0.42 & 0.87 & 0.41 & 0.49 & 0.45 & 0.42 & 0.61 & 0.42 & 0.44 \\
$93-187$ & 0.92 & 0.58 & 0.95 & 0.69 & 0.86 & 0.62 & 0.63 & 0.62 & 0.62 & 0.81 \\
$46-93$ & 0.88 & 0.91 & 0.99 & 0.91 & 0.81 & 0.95 & 0.93 & 0.98 & 0.99 & 0.85 \\
$23-46$ & 0.82 & 0.67 & 0.81 & 0.63 & 0.94 & 0.78 & 0.85 & 0.66 & 0.68 & 0.87 \\
$12-23$ & 0.81 & 0.62 & 0.64 & 0.80 & 0.62 & 0.65 & 0.57 & 0.63 & 0.89 & 0.71 \\
$6-12$ & 0.25 & 0.29 & 0.55 & 0.45 & 0.55 & 0.08 & 0.46 & 0.79 & 0.65 & 0.64 \\
\hline
\end{tabular}

For the frequency bands of 23-46Hz, 46-93 Hz, 93-187 Hz, 187-375 Hz and $375-750 \mathrm{~Hz}$, the effect of time were statistically not significant for any of the ten wavelet functions used in this study (Table 5.7). The effect of time was statistically significant for most of the wavelets at lower frequency bands of $6-12 \mathrm{~Hz}$ and $12-23 \mathrm{~Hz}$. For $12-23 \mathrm{~Hz}$ frequency band, statistical significance was observed for Bior3.1, Rbio3.1, Coif5, Db2, and Sym4 wavelet functions. For 6$12 \mathrm{~Hz}$ frequency band, statistical significance was observed for only two wavelet functions: Bior3.1 and Rbio3.1. For 23-46 Hz frequency band, only Rbio3.1 showed statistically significant power changes over the course of time (Table 5.7). A comparison of wavelet functions at these three frequency bands is shown in Figure 5.8. Among the wavelet functions Rbio3.1 wavelet function showed more consistent and expected trend of positive and negative gradient of power for the lower frequency bands of 6-12 Hz, 12-23 Hz, and 23-46 Hz. 


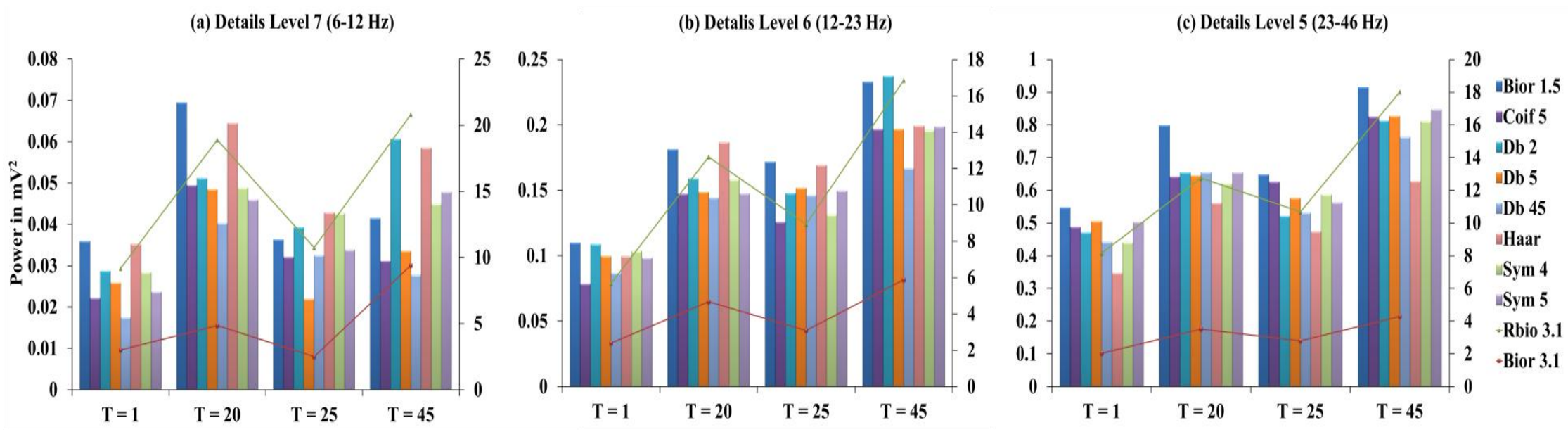

Figure 5.8: Power of SEMG signal recorded from the left sternocleidomastoid muscle at different time instances for the following frequency bands: (a) 6-12 $\mathrm{Hz}$ (b) 12-23 Hz and (c) 23-46 Hz. Behavior of Rbio3.1 and Bior3.1 wavelets were plotted using a secondary axis

Table 5.7: P-values for the effect of time on the power of SEMG signals from the left sternocleidomastoid muscle for different wavelet functions at various frequency bands. Values marked with asterisks (*) are statistically significant

\begin{tabular}{lllllllllll}
\hline $\begin{array}{l}\text { Frequency } \\
\text { Band, Hz }\end{array}$ & Bior1.5 & Bior3.1 & Rbio3.1 & Coif5 & Db2 & Db5 & Db45 & Haar & Sym4 & Sym5 \\
\hline $375-750$ & 0.5 & 0.43 & 0.55 & 0.32 & 0.47 & 0.64 & 0.64 & 0.59 & 0.7 & 0.5 \\
$187-375$ & 0.55 & 0.44 & 0.62 & 0.41 & 0.45 & 0.43 & 0.39 & 0.55 & 0.46 & 0.47 \\
$93-187$ & 0.6 & 0.51 & 0.59 & 0.66 & 0.59 & 0.63 & 0.57 & 0.56 & 0.63 & 0.69 \\
$46-93$ & 0.69 & 0.76 & 0.65 & 0.5 & 0.66 & 0.55 & 0.62 & 0.59 & 0.51 & 0.55 \\
$23-46$ & 0.42 & 0.37 & $0.03 *$ & 0.57 & 0.31 & 0.45 & 0.38 & 0.48 & 0.44 & 0.37 \\
$12-23$ & 0.15 & $0.03 *$ & $0.03 *$ & $0.04 *$ & $0.04 *$ & 0.17 & 0.3 & 0.18 & $0.04 *$ & 0.2 \\
$6-12$ & 0.13 & $0.01 *$ & $0.02 *$ & 0.23 & 0.42 & 0.09 & 0.34 & 0.16 & 0.61 & 0.4 \\
\hline
\end{tabular}


Multiple comparisons based on the Tukey's test were performed for statistically significant frequency bands. Results of Tukey's test are shown in Appendix M. A distinctive pattern of statistical significance between the time instances for different wavelet functions at lower frequency bands was observed (Table 5.8).

Table 5.8: P-values of Tukey's multiple comparison tests for the effect of time on the power of SEMG signal from the left sternocleidomastoid muscle at lower frequency bands for different wavelet functions. Different times instances, $T_{0}, T_{20}, T_{25}$ and $T_{45}$ are symbolized as '1', '2', '3' and '4', respectively. Values marked with asterisks (*) are statistically significant

\begin{tabular}{llllllllllll}
\hline $\begin{array}{l}\text { Frequency } \\
\text { Band (Hz) }\end{array}$ & & Bior1.5 & Bior3.1 & Rbio3.1 & Coif5 & Db2 & Db5 & Db45 & Haar & Sym4 & Sym5 \\
\hline $6-12$ & 1 vs 2 & $0.04^{*}$ & 0.57 & $0.04^{*}$ & $0.05^{*}$ & 0.32 & $0.04^{*}$ & 0.07 & 0.07 & 0.26 & 0.22 \\
& 1 vs 3 & 0.99 & 0.91 & 0.55 & 0.60 & 0.73 & 0.78 & 0.34 & 0.72 & 0.56 & 0.67 \\
& 1 vs 4 & 0.49 & $0.04^{*}$ & $0.01^{*}$ & 0.38 & 0.13 & 0.26 & 0.28 & 0.08 & 0.26 & 0.13 \\
& 2 vs 3 & 0.08 & 0.25 & 0.29 & 0.2 & 0.52 & $0.02^{*}$ & 0.38 & 0.15 & 0.58 & 0.42 \\
& 2 vs 4 & 0.25 & 0.18 & 0.28 & 0.35 & 0.58 & 0.33 & 0.46 & 0.96 & 1.00 & 0.77 \\
& 3 vs 4 & 0.5 & $0.04^{*}$ & $0.04^{*}$ & 0.72 & 0.23 & 0.16 & 0.89 & 0.16 & 0.58 & 0.27 \\
\hline $12-23$ & 1 vs 2 & 0.21 & $0.04^{*}$ & $0.04^{*}$ & 0.18 & 0.36 & 0.27 & 0.22 & 0.11 & 0.15 & 0.31 \\
& 1 vs 3 & 0.43 & 0.71 & 0.49 & 0.42 & 0.63 & 0.42 & 0.36 & 0.32 & 0.68 & 0.46 \\
& 1 vs 4 & $0.03^{*}$ & $0.01^{*}$ & $0.02^{*}$ & $0.01^{*}$ & $0.03^{*}$ & $0.03^{*}$ & 0.07 & $0.04^{*}$ & $0.04^{*}$ & $0.04^{*}$ \\
& 2 vs 3 & 0.64 & 0.35 & 0.4 & 0.58 & 0.66 & 0.77 & 0.76 & 0.51 & 0.45 & 0.77 \\
& 2 vs 4 & 0.29 & 0.18 & 0.36 & 0.20 & 0.17 & 0.25 & 0.51 & 0.62 & 0.35 & 0.26 \\
& 3 vs 4 & 0.13 & $0.03^{*}$ & $0.04^{*}$ & $0.04^{*}$ & $0.05^{*}$ & 0.15 & 0.33 & 0.25 & $0.04^{*}$ & 0.16 \\
\hline $23-46$ & 1 vs 2 & 0.29 & 0.27 & 0.36 & 0.52 & 0.35 & 0.5 & 0.28 & 0.26 & 0.43 & 0.46 \\
& 1 vs 3 & 0.67 & 0.56 & 0.61 & 0.56 & 0.80 & 0.73 & 0.64 & 0.50 & 0.52 & 0.77 \\
& 1 vs 4 & 0.13 & 0.1 & $0.03^{*}$ & 0.17 & 0.09 & 0.13 & 0.11 & 0.14 & 0.11 & 0.1 \\
& 2 vs 3 & 0.52 & 0.59 & 0.69 & 0.95 & 0.49 & 0.74 & 0.53 & 0.64 & 0.88 & 0.66 \\
& 2 vs 4 & 0.62 & 0.55 & 0.20 & 0.45 & 0.42 & 0.38 & 0.58 & 0.72 & 0.40 & 0.35 \\
& 3 vs 4 & 0.26 & 0.26 & $0.02^{*}$ & 0.41 & 0.14 & 0.23 & 0.24 & 0.41 & 0.33 & 0.17 \\
\hline
\end{tabular}

The power differences between $\mathrm{T}_{0}$ and $\mathrm{T}_{25}, \mathrm{~T}_{20}$ and $\mathrm{T}_{45}$ were not significant for any of the lower frequency bands for left sternocleidomastoid muscle too. At 23-46 Hz frequency band, power at $\mathrm{T}_{45}$ was significantly different than at $\mathrm{T}_{0}$ and $\mathrm{T}_{25}$, for Rbio3.1 wavelet function. But, for the same wavelet the power decline from $T_{20}$ to $T_{25}$ and power growth from $T_{0}$ to $T_{20}$ was statistically not significant (Table 5.8 and Figure 5.8 c). At $12-23 \mathrm{~Hz}$ frequency band, power at $\mathrm{T}_{20}$ was significantly higher than $\mathrm{T}_{0}$, for Bior3.1 and Rbio3.1 wavelet functions. No significant difference in the power at $T_{25}$ and $T_{20}$ was observed for any wavelet function. At $T_{25}$ and $T_{45}$, Bior3.1, Rbio3.1, Coif5, Db2, and Sym4 wavelet functions showed significant power growth. 
Power at $\mathrm{T}_{45}$ was significantly higher than $\mathrm{T}_{0}$ for all wavelet functions except Db45 wavelet function (Table 5.8 and Figure $5.8 \mathrm{~b}$ ). At $6-12 \mathrm{~Hz}$ frequency band, power at $\mathrm{T}_{20}$ was significantly different than at $\mathrm{T}_{0}$, for Bior1.5, Rbio3.1, Coif5, and Db5 wavelet functions. Significant drop in the power at $\mathrm{T}_{25}$ and $\mathrm{T}_{20}$ was observed only for Db5 wavelet function. Both Bior3.1 and Rbio3.1 wavelet functions showed significant power changes between $T_{25}$ and $T_{45}$, and $T_{0}$ and $T_{45}$ (Table 5.8 and Figure 5.8 a).

\subsubsection{Comparison between the wavelet functions}

A scoring system based on the P-values of Turkey's multiple comparison tests, similar to the upper trapezius muscle, was used to evaluate performance of different wavelet functions (Table 5.9). Top 3 wavelet functions based on the overall score were Rbio3.1, Bior3.1, and Coif5, respectively (Table 5.9). Among these wavelet functions, Bior1.5 and Rbio3.1 wavelet functions showed more consistent and similar trend at the frequency band of 12-23 Hz (Table 5.9 and Figure 5.8 b). The Rbio3.1 wavelet function showed comparatively better increase and decline of power than Bior3.1 and Coif5 wavelet functions at the frequency band of 23-46 $\mathrm{Hz}$ with respect to different time instances (Table 5.9 and Figure 5.8 c). On the other hand, Coif5 and Bior3.1 wavelet functions exhibited better increase and decline of power than Rbio3.1 wavelet function at the frequency band of 6-12 $\mathrm{Hz}$ (Table 5.9 and Figure 5.8 a).

To comprehend additional insights on the performance of these top three wavelet functions, power contrast (\%) among statistically significant time instances were calculated and presented in Table 5.10. Progressively higher power contrasts were observed for lower frequency bands. Between $\mathrm{T}_{0}$ and $\mathrm{T}_{45}, \mathrm{~T}_{25}$ and $\mathrm{T}_{45}$, and $\mathrm{T}_{20}$ and $\mathrm{T}_{25}$ the highest power contrast was observed for Bior3.1 wavelet function at the frequency band of 6-12 Hz. The Rbio3.1 wavelet function showed the highest power contrast between $T_{0}$ and $T_{20}$. Between $T_{0}$ and $T_{20}, T_{25}$ 
and $\mathrm{T}_{45}$, and $\mathrm{T}_{0}$ and $\mathrm{T}_{45}$, the highest power contrast was observed for Rbio3.1 wavelet function at the frequency band of 12-23 Hz. Rbio3.1 wavelet function at the frequency bands of 23-46 Hz, showed highest power contrast between $\mathrm{T}_{0}$ and $\mathrm{T}_{45}, \mathrm{~T}_{25}$ and $\mathrm{T}_{45}$, and $\mathrm{T}_{20}$ and $\mathrm{T}_{25}$.

Table 5.9: Rank and scores based on the P-values of Turkey's multiple comparison and mixed model for the left sternocleidomastoid muscle. P-values of mixed model are denoted by 'Mixed'. Different times instances, $T_{0}, T_{20}, T_{25}$ and $T_{45}$ are symbolized as ' 1 ', ' 2 ', '3' and '4', respectively

\begin{tabular}{|c|c|c|c|c|c|c|c|c|c|c|c|}
\hline $\begin{array}{l}\text { Frequency } \\
\text { Band }(\mathrm{Hz})\end{array}$ & & $\begin{array}{l}\text { Bior } \\
1.5\end{array}$ & Bior3.1 & Rbio3.1 & Coif5 & $\mathrm{Db} 2$ & Db5 & $\mathrm{Db} 45$ & Haar & Sym4 & Sym5 \\
\hline \multirow[t]{7}{*}{$6-12$} & Mixed & 0 & 1 & 1 & 0 & 0 & 0 & 0 & 0 & 0 & 0 \\
\hline & 1 vs 2 & 1 & 0 & 1 & 1 & 0 & 1 & 0 & 0 & 0 & 0 \\
\hline & 1 vs 3 & 0 & 0 & 0 & 0 & 0 & 0 & 0 & 0 & 0 & 0 \\
\hline & 1 vs 4 & 0 & 1 & 1 & 0 & 0 & 0 & 0 & 0 & 0 & 0 \\
\hline & 2 vs 3 & 0 & 0 & 0 & 0 & 0 & 1 & 0 & 0 & 0 & 0 \\
\hline & 2 vs 4 & 0 & 0 & 0 & 0 & 0 & 0 & 0 & 0 & 0 & 0 \\
\hline & 3 vs 4 & 0 & 1 & 1 & 0 & 0 & 0 & 0 & 0 & 0 & 0 \\
\hline \multirow[t]{7}{*}{$12-23$} & Mixed & 0 & 1 & 1 & 1 & 1 & 0 & 0 & 0 & 1 & 0 \\
\hline & 1 vs 2 & 0 & 1 & 1 & 0 & 0 & 0 & 0 & 0 & 0 & 0 \\
\hline & 1 vs 3 & 0 & 0 & 0 & 0 & 0 & 0 & 0 & 0 & 0 & 0 \\
\hline & 1 vs 4 & 1 & 1 & 1 & 1 & 1 & 1 & 0 & 1 & 1 & 1 \\
\hline & 2 vs 3 & 0 & 0 & 0 & 0 & 0 & 0 & 0 & 0 & 0 & 0 \\
\hline & 2 vs 4 & 0 & 0 & 0 & 0 & 0 & 0 & 0 & 0 & 0 & 0 \\
\hline & 3 vs 4 & 0 & 1 & 1 & 1 & 1 & 0 & 0 & 0 & 1 & 0 \\
\hline \multirow[t]{9}{*}{$23-46$} & Mixed & 0 & 0 & 1 & 0 & 0 & 0 & 0 & 0 & 0 & 0 \\
\hline & 1 vs 2 & 0 & 0 & 0 & 0 & 0 & 0 & 0 & 0 & 0 & 0 \\
\hline & 1 vs 3 & 0 & 0 & 0 & 0 & 0 & 0 & 0 & 0 & 0 & 0 \\
\hline & 1 vs 4 & 0 & 0 & 1 & 0 & 0 & 0 & 0 & 0 & 0 & 0 \\
\hline & 2 vs 3 & 0 & 0 & 0 & 0 & 0 & 0 & 0 & 0 & 0 & 0 \\
\hline & 2 vs 4 & 0 & 0 & 0 & 0 & 0 & 0 & 0 & 0 & 0 & 0 \\
\hline & 3 vs 4 & 0 & 0 & 1 & 0 & 0 & 0 & 0 & 0 & 0 & 0 \\
\hline & Overall & 2 & 7 & 11 & 4 & 3 & 3 & 0 & 1 & 3 & 1 \\
\hline & Rank & 5 & 2 & 1 & 3 & 4 & 4 & 7 & 6 & 4 & 6 \\
\hline
\end{tabular}

Table 5.10: Power contrast $(\%)$ at the lower frequency bands: $6-12 \mathrm{~Hz}, 12-23 \mathrm{~Hz}$ and $23-46 \mathrm{~Hz}$ for the top 3 wavelet function for left sternocleidomastoid muscle. Different times instances, $T_{0}, T_{20}, T_{25}$ and $T_{45}$ are symbolized as ' 1 ', ' 2 ', '3' and ' 4 ', respectively

\begin{tabular}{l|l|llll}
\hline $\begin{array}{l}\text { Frequency Band } \\
(\mathrm{Hz})\end{array}$ & $\begin{array}{l}\text { Wavelet } \\
\text { Function }\end{array}$ & 1 vs & 2 vs 3 & 3 vs 4 & 1 vs 4 \\
\hline $6-12$ & Bior3.1 & 61.29 & 48.27 & 275.14 & 212.99 \\
& Rbio3.1 & 127.42 & 41.32 & 38.36 & 84.65 \\
& Coif5 & 122.99 & 35.10 & -2.97 & 40.41 \\
\hline $12-23$ & Bior3.1 & 95.86 & 33.88 & 90.46 & 146.64 \\
& Rbio3.1 & 141.69 & 36.48 & 87.32 & 232.85 \\
& Coif5 & 87.74 & 14.65 & 56.33 & 150.51 \\
\hline $23-46$ & Bior3.1 & 72.70 & 20.33 & 53.46 & 111.13 \\
& Rbio3.1 & 51.01 & 14.78 & 74.16 & 124.12 \\
& Coif5 & 31.64 & 2.46 & 31.65 & 69.04 \\
\hline
\end{tabular}




\section{Chapter 6: Discussion and Conclusions}

In this study, DWT analysis was used to quantitatively assess the neuromuscular fatigue of neck and shoulder muscles generated by dynamic arm and neck exertion. SEMG data from right upper trapezius and left sternocleidomastoid muscles were analyzed by using ten most commonly used wavelet functions. The power of different frequency sub-bands of SEMG signal was computed by using 7 levels of decomposition. In addition, subjective discomfort ratings in the regions of neck and shoulder corresponding to the locations of the above two muscles were recorded. With the increased in the duration of the repetitive exertions, progressively higher discomfort was reported by the participants indicating that the muscles were fatigued.

Onset and development of fatigue showed characteristics changes in the power of SEMG signal at lower frequency bands. The power of these bands increased significantly with the development of fatigue. At lower decomposition levels, some increase in power with the increase in fatigue was observed. However, this increase was statistically not significant. Increased power of lower frequency bands with the onset of fatigue were previously observed in a number of studies. Kumar et al [18] found significant increase in the power of 6-24 Hz frequency band when SEMG signal from fatigued and non-fatigued bicep-brachii muscle were compared. Sparto et al., [64] also quantified changes in the power of SEMG from medial and lateral erector spinae, and latissimus dorsi locations using STFT and wavelet transform. They found that development of fatigue produced an increase in the power of 7-88 Hz frequency band. Dolan et al., [100] also investigated fatigue-induced changes in the frequency content of SEMG from erector spinae

muscle by calculating power changes during fatigue within ten equal frequency bands in the range 5-300 Hz. An increase in the power of 5-30 Hz frequency band was observed with the development of fatigue. 
The observed increment of power at lower frequency bands with the development of fatigue is primarily due to the increased firing rate of motor units [79, 101-102]. The SEMG signal typically consist of spatio-temporal superposition of the action potential trains of the recruited motor units [79]. The changes in the power spectrum of the SEMG signal during dynamic contractions could be attributed to the modifications of shape of the motor unit action potential, firing rate and muscle fiber conduction velocity [103-106]. When a muscle becomes fatigued, it leads to decline in the conduction velocity of muscle fibers, further reducing excitation-contraction coupling and the force production [100, 107-110]. This reduced excitation-contraction coupling is primarily due to the lack of calcium $\left(\mathrm{Ca}^{2+}\right)$ release from the sarcoplasmic reticulum and accumulation of lactic acid [102, 111]. Because of this reduced conduction velocity, additional motor units [112] are progressively recruited to maintain similar level of force production increasing firing rate of motor units [79, 101-102]. This increased the firing rate of motor unit has been associated with the increase in the low frequency signal.

In this study, ten most popular wavelet functions were used for the fatigue assessment of neck and shoulder muscles using DWT. The result of this study seems to indicate that appropriate selection of the wavelet function is necessary to accurately estimate spectral changes of SMEG signal caused by neuromuscular fatigue. Based on the overall results, "Reverse Biorthogonal with 3.1 scales (Rbio3.1)" wavelet function was found to estimate the changes in the spectral content of the SEMG signal more preciously. This wavelet function also demonstrated a high power contrast between the non-fatigued and fatigued conditions. Previously, Kumar et al [18], studied power contrasts between non-fatigue and fatigued SEMG signals from biceps-bracii muscle using seven wavelet functions: haar, db2, db3, db4, db5, sym4 and sym5. Results of their study identified sym4 and sym5 as the most appropriate wavelet 
functions to study spectral changes due to the fatigue. This may suggest that different wavelet functions could be better suited for the fatigue assessment of different muscle groups. The power characterization of SEMG signal based on the DWT coefficients is primarily governed by matching of wavelet function with the trains of action potential from the recruited motor units. A higher amplitude of detailed coefficients signify better matching, whereas mismatch produces a lower amplitude [113]. In this study the highest overall power observed for the Rbio3.1 wavelet function could be due the closely matched shape of this wavelet function with the SEMG signal recorded from the fatigued neck and shoulder muscles.

A comparison between the two muscles investigated in this study showed higher power values for right upper trapezius muscle than the left sternocleidomastoid muscle. This may be due the nature of the task investigated in this study. Participants repetitively exerted upper trapezius muscle during the material handling tasks. Although, some rotation of head was required to complete the task, it is likely that participants may have compensated for their head motion using the eye motion during these tasks.

The changes in ionic concentrations such as accumulation of $\mathrm{Ca}^{2+}$ and lactic acid only represent transient alterations rather than permanent damage or injury and are completely reversible if muscles are allowed to rest and recover $[102,111]$. In this study between the two sessions of 20 minutes, a rest period of 5 minutes was provided. The spectral changes, in terms of power of different frequency bands, subsequent to the rest period showed almost full recovery. Exertions similar to the ones evaluated in this study were not investigated before. However, subsequent to the sustained driving task of 1 hour, a complete recovery of the power of lower frequency bands was observed by Hostens et al [12] after a rest period of 5 minutes for the trapezius and deltoid muscles. 


\subsection{Limitation and future works}

Study participants were graduate students with minimal or no manual material handling experience. It is likely that this group may have used different muscle recruitment strategies. Future study should look at working population with manual materials handling experience to determine how well the trends observed in the current study could be applied to the working population.

Physical motion during the repetitive task was not studied. A better understanding of the actual motion during sub-maximal repetitive tasks could provide additional cues about the fatigue development process. This will further assist in the validation of objective fatigue assessment methods. Future study using motion capture data in addition to the EMG data should be performed to investigate motion patterns during sustained repetitive exertions.

A full recovery from the neuromuscular fatigue was observed after 5 minutes of rest period following twenty minutes of repetitive exertion. Workers at the real material handling workstations perform manual material handling tasks over an 8 hour shift. Such longer durations may require higher recovery time. Future study should look at longer durations of exertions to more accurately estimate the optimal rest time.

For standardization purpose, weight of the boxes was controlled in this study. In real life scenarios, workers handle weights of different magnitudes. Handling of variables loads may require different muscle recruitment strategies and may exhibit different fatigue development patterns. Future study should look at the effect of variable weights on the fatigue development process. 
In this study, only male participants were used. Higher risk of neck and should MSD among females participants is reported in a few studies. Future study should look at both male and female populations.

\subsection{Occupational application}

Traditionally, sub-maximal repetitive exertions by the upper extremity and neck muscles have been the hallmark of work at various industries. Neuromuscular fatigue caused by such exertion is known to lead to work-related musculoskeletal disorder. Quantitative methods for the objective assessment of neuromuscular fatigue produced by such exertions are not well documented in the literature. This study establishes DWT as the appropriate method to study neck and shoulder muscle fatigue caused by repetitive sub-maximal exertions. The best wavelet function and the suitable frequency bands that should be used for performing DWT are identified in this study. These results could be very useful to the ergonomists to automate the process of localized muscle fatigue estimation, which could have applications related to improving working environment.

\subsection{Conclusions}

The finding of this study demonstrates that DWT could be used as an appropriate method for the assessment of neck and should muscle fatigue generated by the sub-maximal dynamic repetitive exertions. This study further confirmed that lower frequency bands of 6-12 Hz and 12$23 \mathrm{~Hz}$, represent better spectral and power contrast trends. Rbio3.1 was identified as the best wavelet function for the objective assessment of muscle fatigue. This wavelet function estimated the highest power in comparison with other commonly used wavelet functions for the two neck and shoulder muscles investigated in this study. Very high scores based on the statistical significance test were also observed for the Rbio3.1 wavelet function. Moreover, Rbio3.1 
wavelet function also exhibited better power contrast between fatigued and non-fatigued muscle condition at lower frequency bands than other wavelet functions for the two neck and shoulder muscles investigated in this study. 


\section{References}

1. BLS. Musculoskeletal disorders and days away from work in 2007. 20082009 [cited 2011 May 30]; Available from:

http://www.bls.gov/news.release/archives/osh2_11202008.pdf.

2. Côté, P., van der Velde, G., David Cassidy, J., Carroll, L.J., Hogg-Johnson, S., Holm, L.W., Carragee, E.J., Haldeman, S., Nordin, M., Hurwitz, E.L. The burden and determinants of neck pain in workers. European Spine Journal, 2008. 17: p. 60-74.

3. Barbara Silverstein, P., MPH and B. Darrin Adams. Work-related Musculoskeletal Disorders of the Neck, Back, and Upper Extremity in Washington State, 1996-2004. 2006 [cited 2011 May 23]; Available from:

http://www.Ini.wa.gov/Safety/Research/Files/WmsdFinal.pdf.

4. Juul-Kristensen, B., Kadefors, R., Hansen, K., Byström, P., Sandsjö, L., Sjøgaard, G. Clinical signs and physical function in neck and upper extremities among elderly female computer users: the NEW study. European Journal of Applied Physiology, 2006. 96(2): p. 136-145.

5. Hogg-Johnson, S., van der Velde, G., Carroll, L.J., Holm, L.W., Cassidy, J.D., Guzman, J., Côté, P., Haldeman, S., Ammendolia, C., Carragee, E. The burden and determinants of neck pain in the general population. European Spine Journal, 2008. 17: p. 39-51.

6. Larsson, B., K. Sogaard, and L. Rosendal, Work related neck-shoulder pain: a review on magnitude, risk factors, biochemical characteristics, clinical picture and preventive interventions. Best Practice \& Research Clinical Rheumatology, 2007. 21(3): p. 447-463. 
7. Baikun, Wan, Lifeng, Xu, Yue, Ren, Lu, Wang, Shuang, Qiu, Xiaojia, Liu, Xiuyun, Liu, Hongzhi, Qi, Dong, Ming, Weijie, Wang Study on fatigue feature from forearm SEMG signal based on wavelet analysis. in Robotics and Biomimetics (ROBIO), 2010 IEEE International Conference on. 2010.

8. Buckle, P. and Devereux, J. Work-related neck and upper limb musculoskeletal disorders. 1999: Citeseer.

9. Karlsson, S., Y. Jun, and M. Akay. Spectral analysis of myoelectric signals by wavelet methods. in Bioelectromagnetism, 1998. Proceedings of the 2nd International Conference on. 1998.

10. Alejandro P, M.L. and M.G. Roberto. Decomposition of MES using wavelet transform and support vector machine. in Applied Sciences in Biomedical and Communication Technologies (ISABEL), 2010 3rd International Symposium on. 2010.

11. Bonato, P., G. Gagliati, and M. Knaflitz, Analysis of myoelectric signals recorded during dynamic contractions. Engineering in Medicine and Biology Magazine, IEEE, 1996. 15(6): p. 102-111.

12. Hostens, I., et al., Validation of the wavelet spectral estimation technique in biceps brachii and brachioradialis fatigue assessment during prolonged low-level static and dynamic contractions. Journal of Electromyography and Kinesiology, 2004. 14(2): p. 205-215.

13. Moshou, D., et al., Dynamic muscle fatigue detection using self-organizing maps. Applied soft computing, 2005. 5(4): p. 391-398. 
14. Khezri, M. and M. Jahed. Surface Electromyogram signal estimation based on wavelet thresholding technique. in Engineering in Medicine and Biology Society, 2008. EMBS 2008. 30th Annual International Conference of the IEEE. 2008.

15. Kanoun, S. and N. Ali. A new digital signal processing technique for the estimation of motor unit action potential templates. in Computer Engineering \& Systems, 2009. ICCES 2009. International Conference on. 2009.

16. Ranniger, C.U. and D. Akin. EMG mean power frequency determination using wavelet analysis. 1997: IEEE.

17. Hussain, M., et al., Electromyography signal analysis using wavelet transform and higher order statistics to determine muscle contraction. Expert Systems, 2009. 26(1): p. 35-48.

18. Kumar, D.K., N.D. Pah, and A. Bradley, Wavelet analysis of surface electromyography. Neural Systems and Rehabilitation Engineering, IEEE Transactions on, 2003. 11(4): p. 400-406.

19. Phinyomark, A. and C.L.P. Phukpattaranont. Evaluation of wavelet function based on robust emg feature extraction. 2009.

20. Kumar, S., Theories of musculoskeletal injury causation. Ergonomics, 2001. 44(1): p. 1747.

21. Kaergaard, A. and J.H. Andersen, Musculoskeletal disorders of the neck and shoulders in female sewing machine operators: prevalence, incidence, and prognosis. Occupational and environmental medicine, 2000. 57(8): p. 528.

22. Johnston, V., Souvlis, T., Jimmieson, N.L., Jull, G. Associations between individual and workplace risk factors for self-reported neck pain and disability among female office workers. Applied Ergonomics, 2008. 39(2): p. 171-182. 
23. Korhonen, T., et al., Work related and individual predictors for incident neck pain among office employees working with video display units. British Medical Journal, 2003. 60(7): p. 475.

24. Jensen, C., Ryholt, CU, Burr, H., Villadsen, E., Christensen, H. Work-related psychosocial, physical and individual factors associated with musculoskeletal symptoms in computer users. Work \& Stress, 2002. 16(2): p. 107-120.

25. Morse, T., et al., Musculoskeletal disorders of the neck and shoulder in dental hygienists and dental hygiene students. Journal of Dental Hygiene, 2007. 81(1): p. 10-10.

26. Sivak-Callcott, J.A., et al., A Survey Study of Occupational Pain and Injury in Ophthalmic Plastic Surgeons. Ophthalmic Plastic \& Reconstructive Surgery, 2011. 27(1): p. 28.

27. Aublet-Cuvelier, A., M. Aptel, and H. Weber, The dynamic course of musculoskeletal disorders in an assembly line factory. International archives of occupational and environmental health, 2006. 79(7): p. 578-584.

28. Chee, H.L. and K.G. Rampal, Work-related musculoskeletal problems among women workers in the semiconductor industry in Peninsular Malaysia. International Journal of Occupational and Environmental Health, 2004. 10(1): p. 63-71.

29. Lipscomb, J., et al., Health Care System Changes and Reported Musculoskeletal Disorders Among Registered Nurses. American journal of public health, 2004. 94(8): p. $1431-1435$.

30. Rosecrance, J., G. Rodgers, and L. Merlino, Low back pain and musculoskeletal symptoms among Kansas farmers. American Journal of Industrial Medicine, 2006. 49(7): p. 547-556. 
31. Silverstein, B., E. Viikari-Juntura, and J. Kalat, Use of a prevention index to identify industries at high risk for work-related musculoskeletal disorders of the neck, back, and upper extremity in Washington state, 1990-1998. American Journal of Industrial Medicine, 2002. 41(3): p. 149-169.

32. Trinkoff, A.M., et al., Perceived physical demands and reported musculoskeletal problems in registered nurses. American Journal of Preventive Medicine, 2003. 24(3): p. 270-275.

33. Rohmert, W., Ermittlung von Erholungspausen für statische Arbeit des Menschen. European Journal of Applied Physiology and Occupational Physiology, 1960. 18(2): p. 123-164.

34. Chaffin, D.B., Localized muscle fatigue-definition and measurement. Journal of Occupational and Environmental Medicine, 1973. 15(4): p. 346.

35. Chiang, H.C., et al., Prevalence of shoulder and upper-limb disorders among workers in the fish-processing industry. Scandinavian journal of work, environment \& health, 1993. 19(2): p. 126-131.

36. NRC. Work-related musculoskeletal disorders: report, workshop summary, and workshop papers. 1999 [cited 201124 May]; Available from: http://www.nap.edu/openbook.php?isbn=0309063973.

37. 90/270/EEC, D. display screen equipment 1990 [cited 201126 May]; Available from: http://osha.europa.eu/en/legislation/directives/provisions-on-workload-ergonomical-andpsychosocial-risks/osh-directives/5.

38. Bartley, S.H. and E. Chute, Fatigue and impairment in man. 1947: New York, McGrawHill. 
39. Bigland-Ritchie, B., Donovan, EF, Roussos, CS Task-dependent factors in fatigue of human voluntary contractions. Advances in experimental medicine and biology, 1995. 384: p. 361.

40. Vøllestad, N.K., Measurement of human muscle fatigue. Journal of Neuroscience Methods, 1997. 74(2): p. 219-227.

41. Newham, D., T. McCarthy, and J. Turner, Voluntary activation of human quadriceps during and after isokinetic exercise. Journal of Applied Physiology, 1991. 71(6): p. 2122.

42. Garg, A., Hegmann, K. T., Schwoerer, B. J., Kapellusch, J. M. The effect of maximum voluntary contraction on endurance times for the shoulder girdle. International journal of Industrial ergonomics, 2002. 30(2): p. 103-113.

43. Sahlin, K. and J. Ren, Relationship of contraction capacity to metabolic changes during recovery from a fatiguing contraction. Journal of Applied Physiology, 1989. 67(2): p. 648.

44. Cady, EB, Jones, DA, Lynn, J., Newham, DJ Changes in force and intracellular metabolites during fatigue of human skeletal muscle. The Journal of physiology, 1989. 418(1): p. 311.

45. Westerblad, H., Lee, J.A., Lannergren, J., Allen, D.G.Cellular mechanisms offatigue in skeletal muscle. American Journal of Physiology-Cell Physiology, 1991. 261(2): p. C195.

46. Mancini, D.M., et al., Validation of near-infrared spectroscopy in humans. Journal of Applied Physiology, 1994. 77(6): p. 2740.

47. Yoshitake, Y., Ue, H., Miyazaki, M., Moritani, T. Assessment of lower-back muscle fatigue using electromyography, mechanomyography, and near-infrared spectroscopy. European journal of applied physiology, 2001. 84(3): p. 174-179. 
48. Hamaoka, T., et al., Noninvasive measures of oxidative metabolism on working human muscles by near-infrared spectroscopy. Journal of Applied Physiology, 1996. 81(3): p. 1410.

49. Sommerich, C.M., Joines, S., Hermans, V., Moon, S.D. Use of surface electromyography to estimate neck muscle activity. Journal of Electromyography and Kinesiology, 2000. 10(6): p. 377-398.

50. Basmajian, J.V. and C.J. De Luca, Muscles alive: their functions revealed by electromyography. 1985.

51. Sommerich, C.M., et al., Use of surface electromyography to estimate neck muscle activity. Journal of Electromyography and Kinesiology, 2000. 10(6): p. 377-98.

52. Nielsen, M., et al. Biomedical Signal Compression With Optimized Wavelets. in Acoustics, Speech and Signal Processing, 2006. ICASSP 2006 Proceedings. 2006 IEEE International Conference on. 2006.

53. Armstror, T.J., et al., A conceptual model for work-related neck and upper-limb musculoskeletal disorders. Scand J Work Environ Health, 1993. 19: p. 73-84.

54. Merletti, R. and P.A. Parker, Electromyography: Physiology, engineering, and noninvasive applications. 2004: Wiley-IEEE Press.

55. Sekulic, D., V. Medved, and N. Rausavljevi, EMG analysis of muscle load during simulation of characteristic postures in dinghy sailing. Journal of sports medicine and physical fitness, 2006. 46(1): p. 20-27.

56. Potvin, J., Effects of muscle kinematics on surface EMG amplitude and frequency during fatiguing dynamic contractions. Journal of Applied Physiology, 1997. 82(1): p. 144. 
57. Inbar, G., et al., Monitoring surface EMG spectral changes by the zero crossing rate. Medical and Biological Engineering and Computing, 1986. 24(1): p. 10-18.

58. Rice, S.O., Mathematical analysis of random noise-conclusion. Bell Systems Tech. J., Volume 24, p. 46-156, 1945. 24: p. 46-156.

59. Kilby, J. and G. Hosseini. Wavelet analysis of surface electromyography signals. 2004: IEEE.

60. Georgakis, A., L.K. Stergioulas, and G. Giakas, Fatigue analysis of the surface EMG signal in isometric constant force contractions using the averaged instantaneous frequency. Biomedical Engineering, IEEE Transactions on, 2003. 50(2): p. 262-265.

61. De Luca, C., Myoelectrical manifestations of localized muscular fatigue in humans. Critical reviews in biomedical engineering, 1984. 11(4): p. 251.

62. Merletti, R., A. Rainoldi, and D. Farina, Myoelectric manifestations of muscle fatigue. 2004.

63. Hägg, G.M., A. Luttmann, and M. Jäger, Methodologies for evaluating electromyographic field data in ergonomics. Journal of Electromyography and Kinesiology, 2000. 10(5): p. 301-312.

64. Sparto, P.J., et al., Wavelet and short-time Fourier transform analysis of electromyography for detection of back muscle fatigue. Rehabilitation Engineering, IEEE Transactions on, 2000. 8(3): p. 433-436.

65. Clancy, E.A., S. Bouchard, and D. Rancourt, Estimation and application of EMG amplitude during dynamic contractions. IEEE Engineering in Medicine and Biology, 2001. 20(6): p. 47-54. 
66. Hägg, G., Comparison of different estimators of electromyographic spectral shifts during work when applied on short test contractions. Medical and Biological Engineering and Computing, 1991. 29(5): p. 511-516.

67. Cifrek, M., et al., Surface EMG based muscle fatigue evaluation in biomechanics. Clinical Biomechanics, 2009. 24(4): p. 327-340.

68. Luttmann, A., M. Jäger, and W. Laurig, Electromyographical indication of muscular fatigue in occupational field studies. International journal of Industrial ergonomics, 2000. 25(6): p. 645-660.

69. Bigland-Ritchie, B., E. Donovan, and C. Roussos, Conduction velocity and EMG power spectrum changes in fatigue of sustained maximal efforts. Journal of Applied Physiology, 1981. 51(5): p. 1300.

70. Karlsson, S. and B. Gerdle, Mean frequency and signal amplitude of the surface EMG of the quadriceps muscles increase with increasing torque -- a study using the continuous wavelet transform. Journal of Electromyography and Kinesiology, 2001. 11(2): p. 131140.

71. Polikar, R., The wavelet tutorial. Internet Resources: http://engineering. rowan. edu/ polikar/WAVELETS/WTtutorial. html, 2006.

72. Mallat, S.G., A theory for multiresolution signal decomposition: The wavelet representation. Pattern Analysis and Machine Intelligence, IEEE Transactions on, 1989. 11(7): p. 674-693.

73. Misiti, M., et al., Wavelet toolbox for use with Matlab, the MathWorks. Inc., Natick, Massachusetts, 1997. 
74. Galli, A., G. Heydt, and P. Ribeiro, Exploring the power of wavelet analysis. Computer Applications in Power, IEEE, 1996. 9(4): p. 37-41.

75. Parameswariah, C. and M. Cox, Frequency characteristics of wavelets. Power Delivery, IEEE Transactions on, 2002. 17(3): p. 800-804.

76. Torrence, C. and G.P. Compo, A practical guide to wavelet analysis. Bulletin of the American Meteorological Society, 1998. 79(1): p. 61-78.

77. Samar, V.J., et al., Wavelet analysis of neuroelectric waveforms: a conceptual tutorial. Brain and Language, 1999. 66: p. 7-60.

78. Daubechies, I., The wavelet transform, time-frequency localization and signal analysis. Information Theory, IEEE Transactions on, 1990. 36(5): p. 961-1005.

79. Vukova, T., M. Vydevska-Chichova, and N. Radicheva, Fatigue-induced changes in muscle fiber action potentials estimated by wavelet analysis. Journal of Electromyography and Kinesiology, 2008. 18(3): p. 397-409.

80. Lindstrom, L., R. Kadefors, and I. Petersen, An electromyographic index for localized muscle fatigue. Journal of Applied Physiology, 1977. 43(4): p. 750.

81. Reaz, M.B.I., M.S. Hussain, and F. Mohd-Yasin. EMG analysis using wavelet functions to determine muscle contraction. in e-Health Networking, Applications and Services, 2006. HEALTHCOM 2006. 8th International Conference on. 2006.

82. Karlsson, S., J. Yu, and M. Akay, Time-frequency analysis of myoelectric signals during dynamic contractions: a comparative study. Biomedical Engineering, IEEE Transactions on, 2000. 47(2): p. 228-238. 
83. Georgakis, A., L. Stergioulas, and G. Giakas, Fatigue analysis of the surface EMG signal in isometric constant force contractions using the averaged instantaneous frequency. Biomedical Engineering, IEEE Transactions on, 2003. 50(2): p. 262-265.

84. Balasubramanian, V. and K. Adalarasu, EMG-based analysis of change in muscle activity during simulated driving. Journal of Bodywork and Movement Therapies, 2007. 11(2): p. $151-158$.

85. Recreation, U., PAR-Q. 2010.

86. Acierno, S.P., R.V. Baratta, and M. Solomonow, A practical guide to electromyography for biomechanics, in Louisiana State University. 1995.

87. Noraxon. http://www.noraxon.com/products/instruments/telemetrie_system.php3. Inc.

88. Nimbarte, A.D., et al., Neck disorders among construction workers: Understanding the physical loads on the cervical spine during static lifting tasks. Industrial health, 2010. 48(2): p. 145-153.

89. Farina, D., et al., Standardising surface electromyogram recordings for assessment of activity and fatigue in the human upper trapezius muscle. European Journal of Applied Physiology, 2002. 86(6): p. 469-478.

90. Vasavada, A., S. Li, and S. Delp, Influence of muscle morphometry and moment arms on the moment-generating capacity of human neck muscles. Spine, 1998. 23(4): p. 412.

91. Bosch, T. and M. de Looze, Development of fatigue and discomfort in the upper trapezius muscle during light manual work. Ergonomics, 2007. 50(2): p. 161.

92. Reaz, M., M. Hussain, and F. Mohd-Yasin. EMG analysis using wavelet functions to determine muscle contraction. 2006: IEEE. 
93. Khezri, M. and M. Jahed. Surface Electromyogram signal estimation based on wavelet thresholding technique. 2008: IEEE.

94. Ren, X., et al., MUAP extraction and classification based on wavelet transform and ICA for EMG decomposition. Medical and Biological Engineering and Computing, 2006. 44(5): p. 371-382.

95. Hussain, M., et al., Electromyography signal analysis using wavelet transform and higher order statistics to determine muscle contraction. Expert Systems, 2009. 26(1): p. 35-48.

96. Bousbia-Salah, A., M. Ait-Ameur, and M. Talha-Kedir. Biorthogonal wavelet for EEG signal compression. 2011: ACM.

97. Lauer, R., et al. Wavelet decomposition for the identification of EMG activity in the gait cycle. 2003: IEEE.

98. Phinyomark, A., C. Limsakul, and P. Phukpattaranont. An optimal wavelet function based on wavelet denoising for multifunction myoelectric control. 2009: IEEE.

99. Phinyomark, A., C. Limsakul, and P. Phukpattaranont. A comparative study of wavelet denoising for multifunction myoelectric control. 2009: IEEE.

100. Dolan, P., A. Mannion, and M. Adams, Fatigue of the erector spinae muscles: A quantitative assessment using" frequency banding" of the surface electromyography signal. Spine, 1995. 20(2): p. 149.

101. von Tscharner, V., B. Goepfert, and B.M. Nigg, Changes in EMG signals for the muscle tibialis anterior while running barefoot or with shoes resolved by non-linearly scaled wavelets. Journal of biomechanics, 2003. 36(8): p. 1169-1176.

102. Cairns, S.P., et al., Role of extracellular [Ca2+] in fatigue of isolated mammalian skeletal muscle. Journal of applied physiology, 1998. 84(4): p. 1395-1406. 
103. Moritani, T., A. Nagata, and M. Muro, Electromyographic manifestations of muscular fatigue. Medicine and science in sports and exercise, 1982. 14(3): p. 198.

104. Potvin, J., Effects of muscle kinematics on surface EMG amplitude and frequency during fatiguing dynamic contractions. Journal of applied physiology, 1997. 82(1): p. 144-151.

105. Vukova, T., et al., Intensity-dependent effects of microwave electromagnetic fields on acetylcholinesterase activity and protein conformation in frog skeletal muscles. Medical science monitor: international medical journal of experimental and clinical research, 2005. 11(2): p. BR50.

106. Broman, H., G. Bilotto, and C. De Luca, Myoelectric signal conduction velocity and spectral parameters: influence of force and time. Journal of applied physiology, 1985. 58(5): p. 1428-1437.

107. Allen, D., Skeletal muscle function: role of ionic changes in fatigue, damage and disease. Clinical and experimental pharmacology and physiology, 2004. 31(8): p. 485-493.

108. Bigland-Ritchie, B., et al., Central and peripheral fatigue in sustained maximum voluntary contractions of human quadriceps muscle. Clinical science and molecular medicine, 1978. 54(6): p. 609.

109. Colliander, E.B., G.A. Dudley, and P.A. Tesch, Skeletal muscle fiber type composition and performance during repeated bouts of maximal, concentric contractions. European journal of applied physiology and occupational physiology, 1988. 58(1): p. 81-86.

110. Brody, L., et al., pH-induced effects on median frequency and conduction velocity of the myoelectric signal. Journal of applied physiology, 1991. 71(5): p. 1878-1885. 
111. Kurebayashi, N. and Y. Ogawa, Depletion of Ca2+ in the sarcoplasmic reticulum stimulates Ca2 + entry into mouse skeletal muscle fibres. The Journal of physiology, 2001. 533(1): p. 185-199.

112. Mahaphonchaikul, K., et al. EMG signal feature extraction based on wavelet transform. in Electrical Engineering/Electronics Computer Telecommunications and Information Technology (ECTI-CON), 2010 International Conference on. 2010.

113. Samar, V.J., et al., Wavelet analysis of neuroelectric waveforms: a conceptual tutorial. Brain and language, 1999. 66(1): p. 7-60. 


\section{Appendix A: Physical Activity Readiness Questionnaire (PAR-Q)}

Figure A.1: Physical Activity Readiness Questionnaire (PAR-Q) of British Columbia Ministry of Health

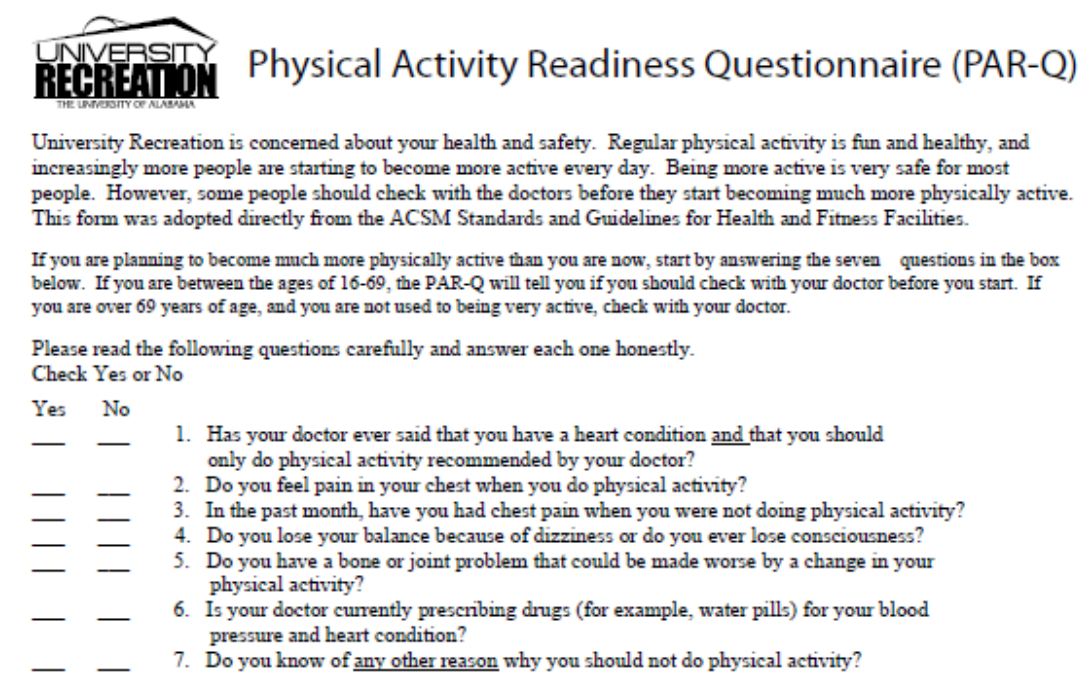

If $\quad$ YES to one or more questions

If Talk to your doctor by phone or in person BEFORE you start becoming much more physically You active or BEFORE you have a fitness appraisal. Tell your doctor about the PAR-Q and which Answered questions you answered YES.

- You may be able to do any activity you want- as long as you start slowly and build up gradually. Or, you may need to restrict your activities to those that are safe for you. Talk with your doctor about the kinds of activities you wish to participate in and follow his/her advice.

- Find out which community programs are safe and helpful for you.

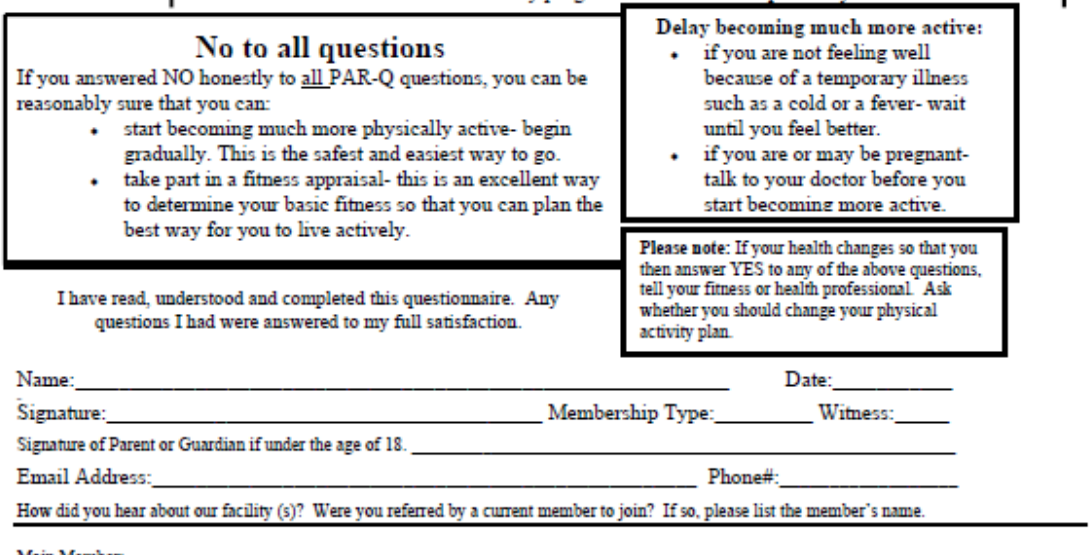




\section{Appendix B: Institutional Review Board (IRB) approval form}

Figure B.1: Snap shot of Institutional Review Board (IRB) approval of this study

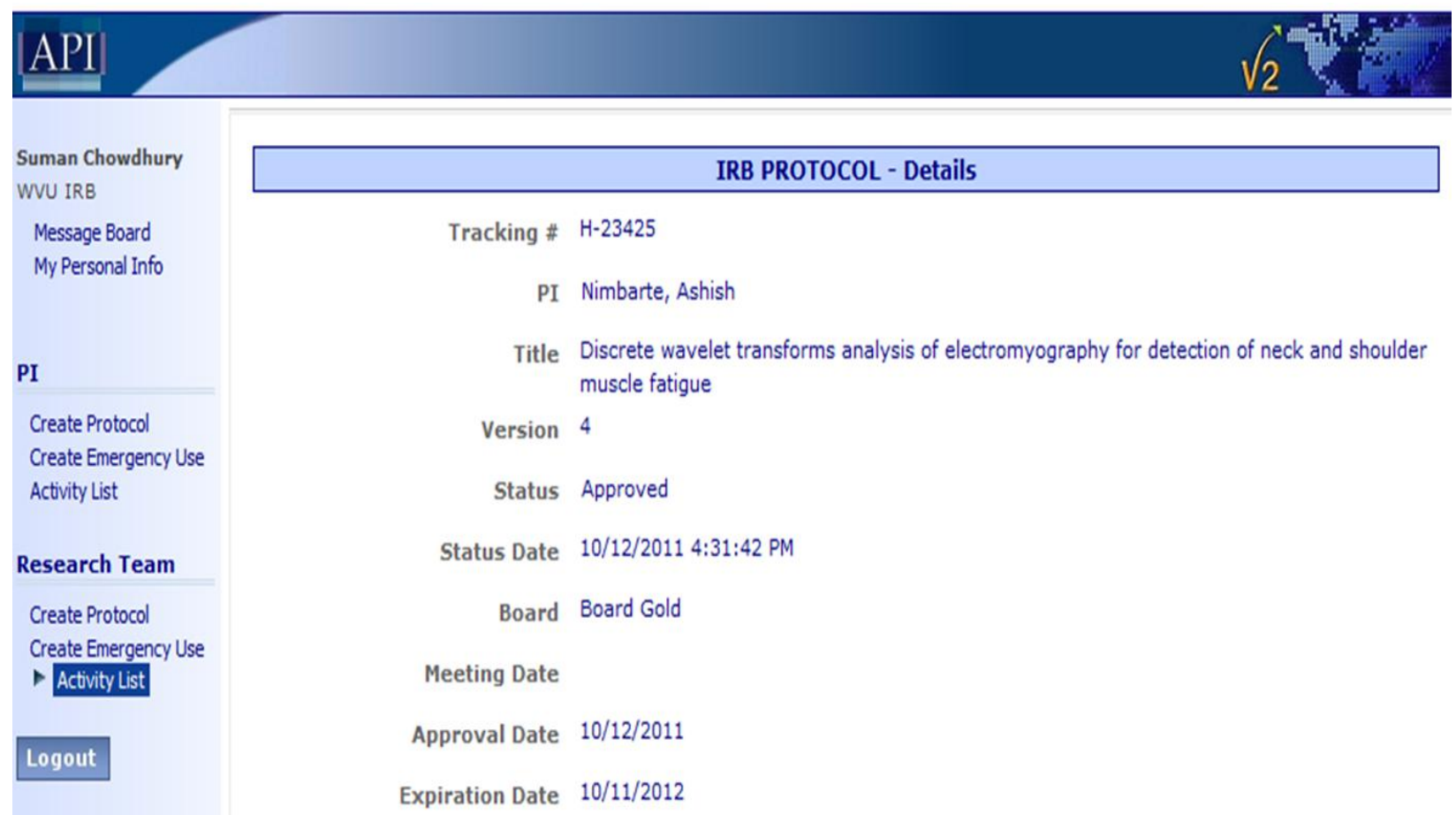




\section{Appendix C: Borg's scale}

Table C.1: Borg's scale of subjective discomfort rating

\begin{tabular}{ll}
\hline Number & Severity \\
\hline 1 & Nothing at all \\
2 & Just Noticeable \\
3 & Very Slight \\
4 & Slight \\
5 & Slight Moderate \\
6 & Moderate \\
7 & Some difficulty \\
8 & Moderate Severe \\
9 & Severe \\
10 & Very Severe \\
\hline
\end{tabular}




\section{Appendix D: Matlab codes for discrete wavelet transform (DWT)}

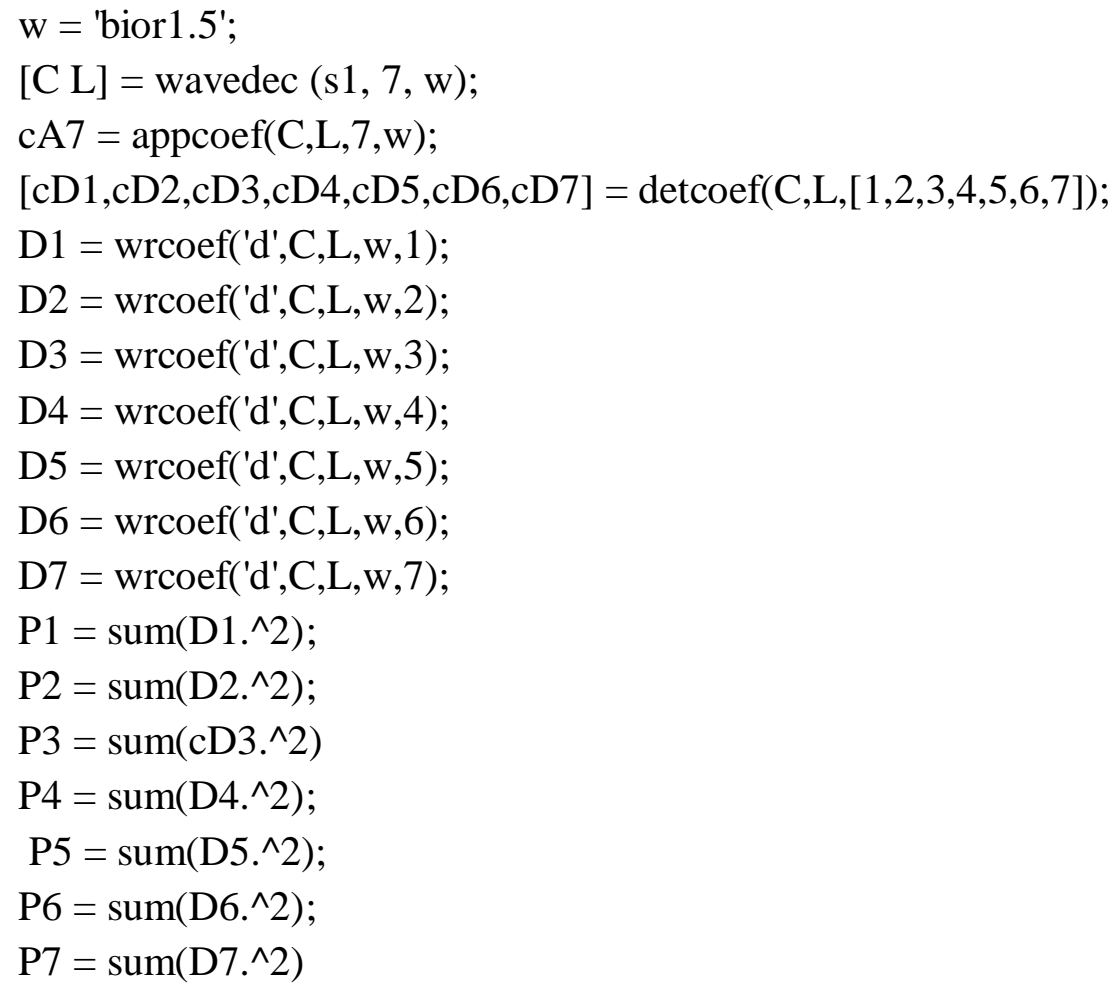




\section{Appendix E: SAS code for statistical tests}

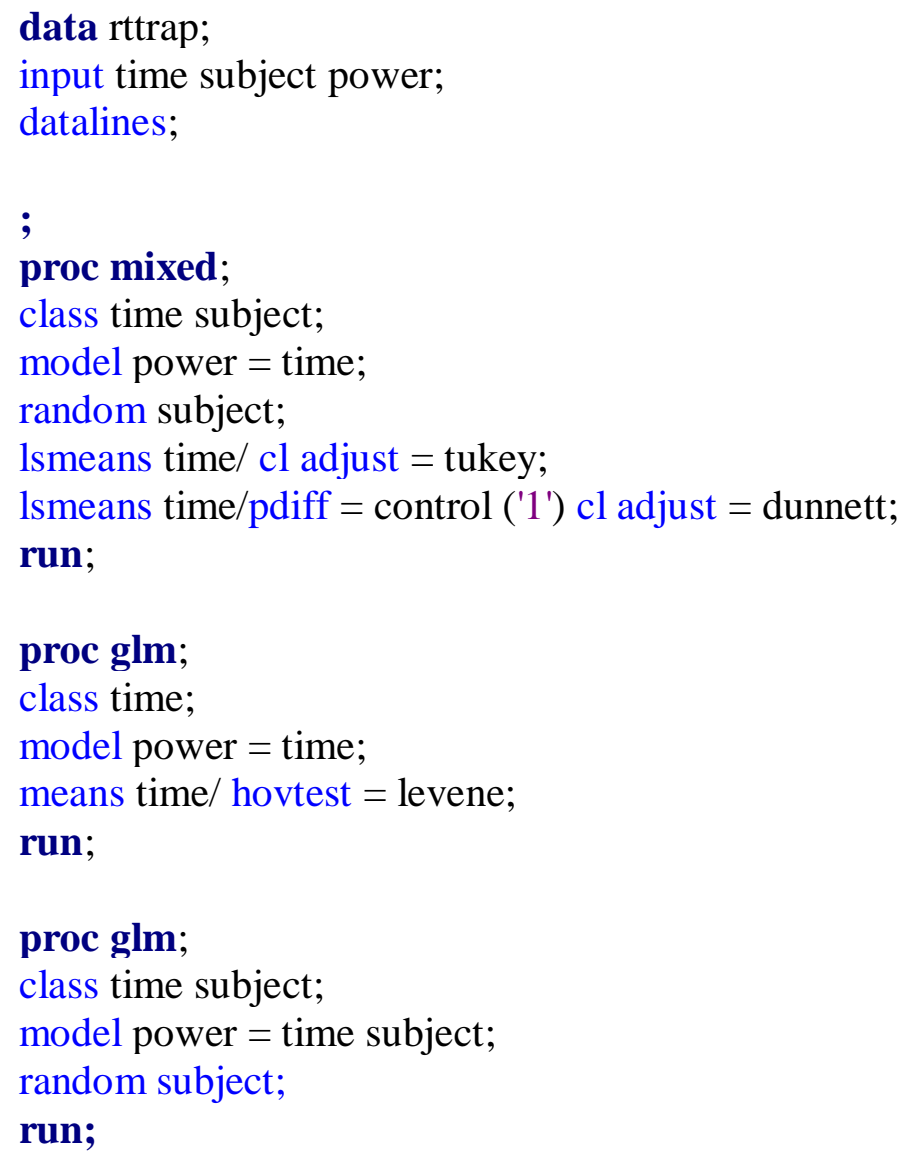




\section{Appendix F: Participants demographic and anthropometric data}

Table F.1: Demographic and anthropometric data of the participants

\begin{tabular}{cccc}
\hline $\begin{array}{c}\text { Subject } \\
\text { Number }\end{array}$ & $\begin{array}{c}\text { Weight } \\
(\text { Kg) }\end{array}$ & $\begin{array}{c}\text { Height } \\
\text { (cm) }\end{array}$ & $\begin{array}{c}\text { Age } \\
\text { (years) }\end{array}$ \\
\hline 1 & 70 & 172 & 24 \\
2 & 65 & 181 & 24 \\
3 & 68 & 168 & 26 \\
4 & 64 & 167 & 25 \\
5 & 95 & 183 & 42 \\
6 & 75 & 170 & 34 \\
7 & 65 & 176 & 28 \\
8 & 67 & 175 & 24 \\
9 & 67 & 167 & 25 \\
10 & 75 & 143 & 28 \\
Average & 71.12 & 170.2 & 28 \\
STD & 9.30 & 11.083521 & 5.792716 \\
\hline
\end{tabular}




\section{Appendix G: Exertion period}

Table G.1: Task completion durations and total number of cycles for the individual participants

\begin{tabular}{|c|c|c|c|c|c|c|c|c|}
\hline \multicolumn{3}{|c|}{ Trials } & \multicolumn{2}{|c|}{$\begin{array}{l}\text { Total Time } \\
\text { (minutes) }\end{array}$} & \multicolumn{2}{|c|}{$\begin{array}{l}\text { Average Trial time } \\
\text { (seconds) }\end{array}$} & \multicolumn{2}{|c|}{$\begin{array}{l}\text { Actual loading time } \\
\text { (Seconds) }\end{array}$} \\
\hline Subject & $1^{\mathrm{st}}$ & $2^{\text {nd }}$ & $1^{\text {st }}$ & $2^{\text {nd }}$ & $1^{\text {st }}$ & $2^{\text {nd }}$ session & $1^{\text {st }}$ & $2^{\text {nd }}$ session \\
\hline Number & session & session & session & session & session & & session & \\
\hline 1 & 19 & 20 & 20.001 & 20.000 & 63.16 & 60.00 & 2.11 & 2.00 \\
\hline 2 & 19 & 19 & 20.001 & 20.001 & 63.16 & 63.16 & 2.11 & 2.11 \\
\hline 3 & 18 & 19 & 20.001 & 20.001 & 66.67 & 63.16 & 2.22 & 2.11 \\
\hline 4 & 20 & 20 & 20.000 & 20.000 & 60.00 & 60.00 & 2.00 & 2.00 \\
\hline 5 & 20 & 21 & 20.000 & 19.999 & 60.00 & 57.14 & 2.00 & 1.90 \\
\hline 6 & 19 & 19 & 20.001 & 20.001 & 63.16 & 63.16 & 2.11 & 2.11 \\
\hline 7 & 20 & 20 & 20.000 & 20.000 & 60.00 & 60.00 & 2.00 & 2.00 \\
\hline 8 & 20 & 20 & 20.000 & 20.000 & 60.00 & 60.00 & 2.00 & 2.00 \\
\hline 9 & 20 & 21 & 20.000 & 19.999 & 60.00 & 57.14 & 2.00 & 1.90 \\
\hline 10 & 20 & 19 & 20.000 & 20.001 & 60.00 & 63.16 & 2.00 & 2.11 \\
\hline
\end{tabular}




\section{Appendix H: Individual subjective discomfort data}

Table H.1: Subjective discomfort ratings

\begin{tabular}{lllllll}
\hline & $\begin{array}{l}\text { Right } \\
\text { upper } \\
\text { trapezius }\end{array}$ & & & $\begin{array}{l}\text { Left } \\
\text { sternocleidomastoid }\end{array}$ & \\
\hline $\begin{array}{l}\text { Subject } \\
\text { Number }\end{array}$ & $\mathrm{T}=0$ & $\mathrm{~T}=20$ & $\mathrm{~T}=45$ & $\mathrm{~T}=0$ & $\mathrm{~T}=20$ & $\mathrm{~T}=45$ \\
1 & 1 & 4 & 7 & 1 & 4 & 6 \\
2 & 1 & 6 & 7 & 1 & 4 & 5 \\
3 & 1 & 7 & 8 & 1 & 2 & 6 \\
4 & 1 & 4 & 7 & 1 & 4 & 4 \\
5 & 1 & 3 & 5 & 1 & 5 & 5 \\
6 & 1 & 6 & 8 & 1 & 3 & 4 \\
7 & 1 & 5 & 6 & 1 & 4 & 5 \\
8 & 1 & 4 & 7 & 1 & 3 & 5 \\
9 & 1 & 4 & 7 & 1 & 5 & 5 \\
10 & 1 & 5 & 7 & 1 & 4 & 4 \\
Average & 1 & 4.8 & 6.9 & 1 & 3.8 & 4.9 \\
STD & 0 & 1.23 & 0.88 & 0 & 0.92 & 0.74 \\
\hline
\end{tabular}




\section{Appendix I: Power data $\left(\mathrm{mV}^{2}\right)$ for individual participants}

Table I.1: Power data for the $1^{\text {st }}$ participant

\begin{tabular}{|c|c|c|c|c|c|c|c|c|c|c|c|c|c|c|c|c|c|c|c|c|}
\hline $\mathrm{T}=0$ & \multicolumn{10}{|c|}{ Upper Trapezius } & \multicolumn{10}{|c|}{ Sternocleidomastoid } \\
\hline $\begin{array}{l}\text { Frequency } \\
\text { Band, } \mathbf{H z}\end{array}$ & Bior1.5 & Bior3.1 & Rbio3.1 & Coif5 & Db2 & Db5 & Db45 & Haar & Sym4 & Sym5 & Bior1.5 & Bior3.1 & Rbio3.1 & Coif5 & Db2 & Db5 & Db45 & Haar & Sym4 & Sym5 \\
\hline 375-750 & 3.24 & 0.17 & 20.40 & 0.10 & 0.66 & 0.15 & 0.08 & 3.07 & 0.20 & 0.16 & 0.057 & 0.008 & 0.281 & 0.005 & .02 & .007 & .005 & .053 & 0.008 & 0.007 \\
\hline $187-375$ & 12.78 & 3.04 & 154.51 & 2.38 & 5.45 & 3.18 & 2.09 & 10.59 & 3.19 & 3.03 & 0.207 & 0.106 & 1.282 & 0.087 & .122 & .097 & .079 & .162 & .099 & 0.009 \\
\hline $46-93$ & 62.05 & 97.38 & 692.63 & 51.33 & 44.37 & 48.77 & 47.06 & 42.91 & 51.01 & 47.92 & .396 & .737 & 2.597 & .304 & .291 & .263 & .317 & .238 & .266 & .302 \\
\hline $23-46$ & 57.85 & 128.66 & 808.81 & 44.35 & 38.96 & 43.07 & 47.76 & 36.24 & 40.60 & 41.76 & .085 & .667 & 1.024 & .076 & .094 & .089 & .059 & .059 & .073 & .091 \\
\hline $12-23$ & 14.44 & 125.89 & 278.03 & 10.69 & 15.99 & 14.62 & 13.79 & 8.89 & 11.47 & 15.87 & .027 & .405 & .852 & .019 & .023 & .023 & .022 & .013 & .027 & .024 \\
\hline 6-12 & 2.69 & 130.53 & 131.24 & 3.62 & 2.89 & 2.09 & 1.77 & 3.78 & 4.61 & 2.02 & .013 & .245 & 1.873 & .002 & .009 & .006 & .003 & .004 & .006 & .012 \\
\hline $375-750$ & 3.81 & .24 & 23.65 & .12 & .82 & .21 & .09 & 3.61 & .25 & .19 & .114 & .016 & .590 & .011 & .036 & .014 & .010 & .106 & .016 & .013 \\
\hline 187-375 & 15.15 & 4.12 & 177.22 & 3.26 & 6.49 & 4.09 & 2.81 & 12.49 & 4.28 & 4.10 & .368 & .167 & 2.972 & .122 & .255 & .174 & .127 & .297 & .161 & .140 \\
\hline 93-187 & 44.62 & 34.74 & 527.43 & 21.61 & 27.32 & 22.69 & 23.29 & 29.81 & 23.80 & 22.10 & 1.195 & 1.107 & 4.931 & .698 & .810 & .607 & .686 & .540 & .612 & .806 \\
\hline $46-93$ & 74.14 & 103.34 & 883.31 & 57.45 & 53.39 & 57.40 & 52.51 & 47.76 & 55.72 & 58.06 & .753 & 2.357 & 5.683 & .856 & .537 & .835 & .884 & .762 & .949 & .668 \\
\hline 23-46 & 69.80 & 186.37 & 954.34 & 59.70 & 48.82 & 54.61 & 63.34 & 48.16 & 56.63 & 53.38 & .325 & 2.114 & 2.346 & .244 & .326 & .313 & .262 & .173 & .237 & .342 \\
\hline $12-23$ & 19.87 & 198.12 & 365.42 & 16.46 & 21.45 & 18.84 & 16.01 & 14.94 & 18.28 & 20.99 & .101 & 3.424 & 2.203 & .084 & .046 & .074 & .039 & .132 & .030 & .043 \\
\hline 6-12 & 5.21 & 208.25 & 197.89 & 3.68 & 3.80 & 4.48 & 4.01 & 4.18 & 3.28 & 3.46 & .008 & 4.071 & .992 & .009 & .009 & .005 & .008 & .021 & .012 & .006 \\
\hline \multicolumn{21}{|l|}{$\mathrm{T}=25$} \\
\hline $375-750$ & 4.25 & .25 & 25.76 & .14 & .96 & .22 & .11 & 4.02 & .29 & .24 & .127 & .022 & .638 & .015 & .043 & .019 & .013 & .118 & .021 & .018 \\
\hline 93-187 & 47.82 & 40.24 & 512.99 & 26.58 & 31.05 & 27.68 & 26.47 & 32.83 & 27.64 & 27.76 & .989 & 1.140 & 5.943 & .795 & .732 & .828 & .793 & .722 & .795 & .728 \\
\hline $46-93$ & 72.52 & 103.50 & 769.45 & 55.45 & 52.97 & 55.49 & 54.95 & 47.01 & 55.26 & 55.44 & 1.100 & 2.069 & 5.743 & .889 & .851 & .830 & .877 & .621 & .835 & .907 \\
\hline $23-46$ & 63.49 & 175.67 & 793.52 & 54.77 & 46.60 & 52.39 & 56.79 & 41.18 & 52.39 & 51.49 & .376 & 1.983 & 3.719 & .285 & .291 & .295 & .328 & .301 & .294 & .293 \\
\hline $12-23$ & 16.75 & 135.98 & 392.57 & 14.49 & 14.94 & 13.94 & 13.24 & 14.12 & 14.56 & 14.75 & .079 & 2.592 & 1.346 & .058 & .074 & .075 & .05 & .082 & .052 & .072 \\
\hline 6-12 & 3.77 & 184.45 & 109.15 & 1.90 & 4.67 & 3.80 & 2.53 & 4.55 & 2.01 & 3.89 & .007 & 2.322 & .772 & .008 & .015 & .007 & .010 & .013 & .012 & .012 \\
\hline \multicolumn{21}{|l|}{$\mathrm{T}=45$} \\
\hline $375-750$ & 4.60 & .24 & 28.81 & .11 & .94 & .21 & .08 & 4.35 & .26 & .18 & .235 & .037 & 1.193 & .032 & .074 & .036 & .029 & .220 & .043 & .036 \\
\hline 187-375 & 17.88 & 4.27 & 207.06 & 3.27 & 8.51 & 4.95 & 2.96 & 14.75 & 4.67 & 4.29 & .753 & .360 & 6.614 & .246 & .442 & .278 & .232 & .608 & .336 & .278 \\
\hline 93-187 & 51.03 & 45.27 & 604.33 & 31.65 & 32.02 & 32.38 & 30.16 & 39.26 & 33.73 & 31.78 & 2.024 & 2.153 & 12.47 & 1.475 & 1.41 & 1.48 & 1.587 & 1.443 & 1.476 & 1.458 \\
\hline 46-93 & 88.23 & 124.45 & 1001.3 & 63.09 & 60.52 & 58.60 & 62.85 & 56.14 & 62.86 & 60.51 & 2.296 & 4.694 & 15.871 & 1.758 & 1.59 & 1.68 & 1.84 & 1.486 & 1.689 & 1.721 \\
\hline $23-46$ & 71.30 & 185.88 & 971.64 & 59.86 & 57.63 & 61.11 & 66.72 & 43.48 & 59.43 & 63.22 & .875 & 5.428 & 13.021 & .901 & .866 & .910 & .770 & .613 & .877 & .939 \\
\hline $12-23$ & 71.30 & 185.88 & 609.06 & 21.97 & 19.69 & 22.29 & 15.47 & 20.60 & 18.28 & 19.33 & .309 & 8.316 & 10.366 & .265 & .268 & .283 & .174 & .242 & .236 & .242 \\
\hline $6-12$ & 6.91 & 191.23 & 292.50 & 5.35 & 6.63 & 5.91 & 6.58 & 6.09 & 5.73 & 6.27 & .030 & 6.498 & 2.077 & .0266 & .030 & .028 & .023 & .042 & .032 & .024 \\
\hline
\end{tabular}


Table I.2: Power data for the $2^{\text {nd }}$ participant

\begin{tabular}{|c|c|c|c|c|c|c|c|c|c|c|c|c|c|c|c|c|c|c|c|c|}
\hline $\mathrm{T}=0$ & \multicolumn{10}{|c|}{ Upper Trapezius } & \multicolumn{10}{|c|}{ Sternocleidomastoid } \\
\hline $\begin{array}{l}\text { Frequency } \\
\text { Band, } \mathrm{Hz}\end{array}$ & Bior1.5 & Bior3.1 & Rbio3.1 & Coif5 & Db2 & Db5 & Db45 & Haar & Sym4 & Sym5 & Bior1.5 & Bior3.1 & Rbio3.1 & Coif5 & Db2 & Db5 & Db45 & Haar & Sym4 & Sym5 \\
\hline 375-750 & 2.11 & 0.08 & 14.24 & 0.05 & 0.35 & 0.07 & 0.04 & 2.02 & 0.10 & 0.08 & 0.089 & 0.007 & 0.529 & 0.005 & 0.022 & 0.006 & 0.005 & 0.084 & 0.008 & 0.008 \\
\hline $187-375$ & 8.59 & 1.46 & 119.23 & 1.11 & 3.17 & 1.46 & 0.97 & 7.23 & 1.57 & 1.43 & 0.338 & 0.090 & 3.528 & 0.067 & 0.154 & 0.087 & 0.060 & 0.275 & 0.092 & 0.085 \\
\hline 93-187 & 25.41 & 18.21 & 342.14 & 13.15 & 15.57 & 14.9 & 12.26 & 21.33 & 15.71 & 13.55 & 0.989 & 0.889 & 6.652 & 0.681 & 0.680 & 0.689 & 0.649 & 0.669 & 0.689 & 0.672 \\
\hline 46-93 & 55.99 & 72.44 & 497.78 & 43.82 & 42.26 & 44.0 & 42.63 & 30.76 & 39.41 & 45.46 & 1.288 & 2.452 & 7.500 & 1.084 & 0.987 & 1.069 & 1.150 & 0.817 & 1.020 & 1.079 \\
\hline $23-46$ & 35.92 & 106.42 & 500.90 & 30.39 & 23.78 & 25.4 & 31.80 & 28.43 & 31.50 & 24.98 & 0.326 & 1.868 & 3.746 & 0.312 & 0.257 & 0.277 & 0.282 & 0.277 & 0.339 & 0.273 \\
\hline $12-23$ & 9.58 & 86.98 & 216.29 & 7.79 & 10.68 & 9.89 & 8.77 & 5.85 & 7.90 & 10.71 & 0.087 & 2.449 & 1.684 & 0.060 & 0.124 & 0.081 & 0.058 & 0.069 & 0.051 & 0.100 \\
\hline $6-12$ & 0.49 & 128.02 & 136.55 & 0.75 & 1.78 & 0.89 & 0.46 & 1.18 & 1.21 & 1.55 & 0.012 & 4.381 & 1.439 & 0.007 & 0.019 & 0.010 & 0.009 & 0.017 & 0.007 & 0.013 \\
\hline 375-750 & 2.36 & 0.05 & 17.02 & 0.02 & 0.30 & 0.04 & 0.02 & 2.27 & 0.06 & 0.04 & 0.217 & 0.019 & 1.282 & 0.013 & 0.054 & 0.017 & 0.012 & 0.205 & 0.020 & 0.018 \\
\hline $187-375$ & 9.83 & 1.08 & 158.81 & 0.82 & 3.00 & 1.21 & 0.73 & 8.45 & 1.32 & 1.19 & 0.834 & 0.234 & 8.495 & 0.174 & 0.387 & 0.217 & 0.144 & 0.679 & 0.239 & 0.217 \\
\hline 93-187 & 33.30 & 17.09 & 524.56 & 13.8 & 19.20 & 15.3 & 12.2 & 24.99 & 16.30 & 15.15 & 2.138 & 2.263 & 18.57 & 1.577 & 1.460 & 1.662 & 1.479 & 1.773 & 1.687 & 1.510 \\
\hline $46-93$ & 79.13 & 92.23 & 907.74 & 53.6 & 56.03 & 54.6 & 54.8 & 45.42 & 50.84 & 55.54 & 3.037 & 5.345 & 19.28 & 2.854 & 2.479 & 2.685 & 2.867 & 1.843 & 2.647 & 2.787 \\
\hline 23-46 & 66.57 & 162.86 & 885.85 & 57.6 & 49.64 & 55.6 & 62.3 & 45.47 & 61.55 & 57.02 & 1.490 & 7.091 & 13.60 & 1.036 & 1.181 & 1.065 & 1.127 & 1.022 & 0.959 & 1.086 \\
\hline $12-23$ & 28.84 & 131.15 & 554.77 & 24.5 & 20.46 & 23.5 & 19.9 & 21.60 & 19.79 & 20.60 & 0.206 & 8.038 & 4.996 & 0.176 & 0.245 & 0.176 & 0.184 & 0.275 & 0.297 & 0.203 \\
\hline $6-12$ & 2.11 & 189.56 & 82.61 & 1.76 & 3.45 & 1.94 & 1.87 & 3.17 & 2.32 & 2.65 & 0.053 & 9.561 & 4.225 & 0.034 & 0.069 & 0.042 & 0.040 & 0.076 & 0.030 & 0.046 \\
\hline \multicolumn{21}{|l|}{$\mathrm{T}=25$} \\
\hline 375-750 & 0.052 & 10.911 & 0.028 & 0.237 & 0.04 & 0.02 & 1.507 & 0.057 & .044 & 0.017 & .002 & 0.097 & .002 & .005 & .002 & .002 & .016 & .002 & .002 & .002 \\
\hline 93-187 & 11.51 & 282.05 & 9.527 & 13.53 & 10.1 & 8.26 & 14.85 & 10.25 & 11.30 & 0.186 & .156 & 1.305 & .104 & .131 & .105 & .106 & .114 & .106 & .115 & .115 \\
\hline $46-93$ & 60.46 & 390.25 & 35.16 & 30.00 & 33.8 & 34.8 & 27.42 & 34.47 & 32.54 & 0.238 & .455 & 1.685 & .223 & .174 & .218 & .232 & .164 & .211 & .207 & .207 \\
\hline 23-46 & 78.22 & 363.01 & 27.82 & 27.00 & 28.9 & 28.7 & 21.50 & 25.39 & 28.94 & 0.081 & .423 & 1.059 & .065 & .066 & .065 & .053 & .060 & .066 & .064 & .064 \\
\hline $12-23$ & 114.1 & 140.91 & 6.490 & 6.016 & 5.71 & 7.01 & 7.873 & 8.283 & 5.779 & 0.026 & .354 & 0.773 & .020 & .025 & .024 & .021 & .021 & .023 & .023 & .023 \\
\hline 6-12 & 86.67 & 17.602 & 0.315 & 0.962 & 0.46 & 0.40 & 0.915 & 0.512 & 0.529 & 0.006 & .426 & 1.271 & .004 & .006 & .006 & .004 & .006 & .005 & .005 & .005 \\
\hline \multicolumn{21}{|l|}{$\mathrm{T}=45$} \\
\hline 375-750 & 1.69 & 0.03 & 12.43 & 0.02 & 0.19 & 0.03 & 0.01 & 1.63 & 0.04 & 0.03 & 0.205 & 0.020 & 1.275 & 0.014 & 0.04 & 0.01 & 0.012 & 0.195 & 0.019 & 0.016 \\
\hline $187-375$ & 6.85 & 0.70 & 120.79 & 0.48 & 2.01 & 0.65 & 0.39 & 5.96 & 0.84 & 0.68 & 0.819 & 0.195 & 9.353 & 0.144 & 0.32 & 0.16 & 0.131 & 0.676 & 0.200 & 0.186 \\
\hline 93-187 & 24.25 & 10.64 & 405.83 & 8.68 & 13.46 & 10.2 & 6.88 & 18.95 & 10.80 & 10.15 & 1.893 & 2.047 & 22.33 & 1.502 & 1.29 & 1.71 & 1.293 & 2.016 & 1.741 & 1.382 \\
\hline 46-93 & 49.81 & 68.19 & 549.29 & 46.65 & 37.93 & 41.6 & 49.0 & 36.67 & 48.66 & 40.89 & 4.337 & 5.850 & 25.72 & 3.139 & 3.19 & 3.00 & 3.681 & 2.218 & 2.769 & 3.298 \\
\hline $23-46$ & 53.17 & 130.9 & 588.44 & 40.77 & 40.12 & 42.4 & 41.0 & 32.03 & 38.65 & 43.03 & 1.311 & 6.281 & 21.46 & 1.410 & 1.31 & 1.27 & 1.076 & 1.058 & 1.501 & 1.332 \\
\hline $12-23$ & 15.43 & 133.3 & 260.03 & 12.51 & 14.24 & 13.5 & 11.2 & 11.80 & 10.06 & 13.80 & 0.355 & 10.133 & 28.00 & 0.305 & 0.31 & 0.309 & 0.251 & 0.234 & 0.280 & 0.276 \\
\hline 6-12 & 2.01 & 182.1 & 73.02 & 1.19 & 2.13 & 1.82 & 1.60 & 2.52 & 1.21 & 1.71 & 0.144 & 14.643 & 37.84 & 0.080 & 0.06 & 0.08 & 0.074 & 0.192 & 0.111 & 0.052 \\
\hline
\end{tabular}


Table I.3: Power data for the $3^{\text {rd }}$ participant

\begin{tabular}{|c|c|c|c|c|c|c|c|c|c|c|c|c|c|c|c|c|c|c|c|c|}
\hline $\mathrm{T}=0$ & \multicolumn{10}{|c|}{ Upper Trapezius } & \multicolumn{10}{|c|}{ Sternocleidomastoid } \\
\hline $\begin{array}{l}\text { Frequency } \\
\text { Band, } \mathbf{H z}\end{array}$ & Bior1.5 & Bior3.1 & Rbio3.1 & Coif5 & Db2 & Db5 & Db45 & Haar & Sym4 & Sym5 & Bior1.5 & Bior3.1 & Rbio3.1 & Coif5 & Db2 & Db5 & Db45 & Haar & Sym4 & Sym5 \\
\hline $375-750$ & 0.065 & 0.005 & 0.440 & 0.003 & 0.012 & 0.005 & 0.003 & 0.063 & 0.005 & 0.004 & 0.230 & 0.047 & 1.100 & 0.032 & 0.085 & 0.042 & 0.027 & 0.215 & 0.044 & 0.039 \\
\hline $187-375$ & 0.253 & 0.053 & 4.166 & 0.041 & 0.084 & 0.044 & 0.038 & 0.218 & 0.050 & 0.045 & 0.767 & 0.393 & 5.497 & 0.282 & 0.449 & 0.323 & 0.255 & 0.606 & 0.352 & 0.320 \\
\hline $46-93$ & 2.228 & 2.174 & 23.669 & 1.386 & 1.604 & 1.571 & 1.488 & 1.249 & 1.303 & 1.599 & 1.654 & 3.255 & 10.74 & 1.296 & 1.242 & 1.204 & 1.384 & 1.039 & 1.228 & 1.304 \\
\hline $23-46$ & 1.728 & 4.225 & 23.321 & 1.704 & 1.372 & 1.491 & 1.692 & 1.199 & 1.686 & 1.535 & 0.422 & 2.361 & 4.947 & 0.414 & 0.413 & 0.415 & 0.329 & 0.280 & 0.368 & 0.414 \\
\hline $12--23$ & 0.650 & 4.346 & 17.692 & 0.552 & 0.463 & 0.507 & 0.515 & 0.523 & 0.533 & 0.480 & 0.083 & 3.422 & 3.131 & 0.059 & 0.087 & 0.098 & 0.072 & 0.077 & 0.077 & 0.077 \\
\hline 6--12 & 0.102 & 5.933 & 13.359 & 0.103 & 0.091 & 0.075 & 0.100 & 0.154 & 0.126 & 0.085 & 0.042 & 5.425 & 12.75 & 0.007 & 0.030 & 0.049 & 0.008 & 0.019 & 0.010 & 0.025 \\
\hline $375-750$ & 0.104 & 0.007 & 0.716 & 0.004 & 0.018 & 0.006 & 0.003 & 0.100 & 0.007 & 0.006 & 0.344 & 0.057 & 1.748 & 0.041 & 0.112 & 0.053 & 0.033 & 0.322 & .061 & .048 \\
\hline $187-375$ & 0.411 & 0.076 & 6.718 & 0.055 & 0.134 & 0.062 & 0.052 & 0.353 & 0.072 & 0.064 & 1.214 & 0.564 & 9.574 & 0.418 & 0.674 & 0.479 & 0.405 & 0.960 & .502 & .487 \\
\hline 93-187 & 1.394 & 0.630 & 21.875 & 0.438 & 0.800 & 0.531 & 0.403 & 1.034 & 0.584 & 0.545 & 2.823 & 3.304 & 18.96 & 2.038 & 2.042 & 2.072 & 2.054 & 2.048 & .095 & .029 \\
\hline $46-93$ & 3.565 & 3.945 & 32.753 & 2.478 & 2.560 & 2.642 & 2.434 & 1.852 & 2.244 & 2.649 & 3.163 & 6.043 & 16.85 & 2.874 & 2.444 & 2.729 & 2.909 & 1.920 & 2.67 & 2.75 \\
\hline $23-46$ & 2.612 & 7.389 & 36.719 & 2.337 & 1.765 & 2.026 & 2.308 & 2.040 & 2.399 & 1.959 & 1.128 & 7.102 & 11.94 & 0.915 & 0.980 & 0.924 & 0.842 & 0.854 & .912 & .921 \\
\hline $12--23$ & 0.842 & 5.296 & 17.447 & 0.762 & 0.701 & 0.789 & 0.856 & 0.546 & 0.727 & 0.818 & 0.196 & 8.747 & 9.186 & 0.143 & 0.200 & 0.209 & 0.184 & 0.287 & .168 & .199 \\
\hline 6--12 & 0.115 & 10.048 & 3.426 & 0.079 & 0.180 & 0.097 & 0.081 & 0.189 & 0.115 & 0.120 & 0.057 & 11.62 & 20.50 & 0.016 & 0.091 & 0.076 & 0.012 & 0.063 & .038 & .070 \\
\hline \multicolumn{21}{|l|}{$\mathrm{T}=25$} \\
\hline $375-750$ & 0.100 & 0.006 & 0.671 & 0.004 & 0.018 & 0.005 & 0.003 & 0.096 & 0.007 & 0.006 & 0.166 & 0.027 & 0.868 & 0.019 & 0.053 & 0.024 & 0.016 & 0.156 & 0.028 & 0.023 \\
\hline 93-187 & 1.374 & 0.599 & 19.328 & 0.438 & 0.793 & 0.495 & 0.385 & 0.901 & 0.523 & 0.564 & 1.417 & 1.633 & 9.679 & 1.086 & 1.001 & 1.097 & 1.057 & 1.053 & 1.106 & 1.053 \\
\hline $46-93$ & 3.250 & 3.845 & 32.661 & 2.315 & 2.180 & 2.319 & 2.371 & 1.918 & 2.150 & 2.296 & 1.714 & 3.110 & 11.726 & 1.356 & 1.274 & 1.302 & 1.433 & 1.095 & 1.294 & 1.344 \\
\hline $23-46$ & 1.996 & 5.303 & 30.613 & 1.827 & 1.593 & 1.766 & 1.885 & 1.425 & 2.019 & 1.766 & 0.647 & 2.837 & 7.386 & 0.602 & 0.560 & 0.601 & 0.548 & 0.444 & 0.568 & 0.592 \\
\hline $12--23$ & 0.894 & 5.881 & 17.570 & 0.879 & 0.694 & 0.789 & 0.816 & 0.642 & 0.755 & 0.770 & 0.202 & 3.324 & 3.793 & 0.167 & 0.192 & 0.164 & 0.187 & 0.173 & 0.184 & 0.181 \\
\hline 6--12 & 0.242 & 8.274 & 8.444 & 0.127 & 0.221 & 0.206 & 0.126 & 0.286 & 0.122 & 0.182 & 0.015 & 3.775 & 0.797 & 0.011 & 0.025 & 0.015 & 0.010 & 0.031 & 0.016 & 0.017 \\
\hline \multicolumn{21}{|l|}{$\mathrm{T}=45$} \\
\hline $375-750$ & 0.169 & 0.009 & 1.162 & 0.006 & 0.028 & 0.009 & 0.005 & 0.163 & 0.010 & 0.008 & 0.592 & 0.101 & 3.033 & 0.069 & 0.197 & 0.090 & 0.062 & 0.555 & 0.100 & 0.086 \\
\hline $187-375$ & 0.680 & 0.121 & 10.868 & 0.086 & 0.220 & 0.105 & 0.081 & 0.581 & 0.118 & 0.104 & 2.114 & 0.949 & 16.920 & 0.718 & 1.117 & 0.788 & 0.647 & 1.685 & 0.869 & 0.820 \\
\hline 93-187 & 2.260 & 1.073 & 36.988 & 0.761 & 1.272 & 0.894 & 0.720 & 1.670 & 0.950 & 0.892 & 4.634 & 5.580 & 31.797 & 3.600 & 3.349 & 3.853 & 3.567 & 3.762 & 3.839 & 3.375 \\
\hline 46-93 & 4.657 & 5.992 & 56.236 & 4.039 & 3.307 & 3.602 & 3.930 & 3.391 & 4.192 & 3.591 & 5.646 & 9.192 & 36.698 & 4.880 & 4.414 & 4.487 & 4.839 & 3.359 & 4.288 & 4.870 \\
\hline $23-46$ & 5.104 & 11.298 & 59.544 & 3.994 & 3.910 & 4.223 & 4.221 & 3.014 & 3.652 & 4.275 & 2.176 & 14.259 & 35.264 & 1.796 & 1.948 & 1.829 & 1.864 & 1.521 & 1.803 & 1.940 \\
\hline $12--23$ & 1.304 & 9.980 & 24.873 & 1.153 & 1.129 & 1.114 & 1.001 & 1.036 & 1.087 & 1.079 & 0.863 & 24.444 & 44.084 & 0.689 & 1.054 & 0.687 & 0.627 & 0.720 & 0.797 & 0.791 \\
\hline 6--12 & 0.231 & 11.816 & 6.875 & 0.130 & 0.333 & 0.221 & 0.158 & 0.263 & 0.158 & 0.239 & 0.034 & 62.333 & 41.082 & 0.040 & 0.389 & 0.084 & 0.041 & 0.100 & 0.145 & 0.285 \\
\hline
\end{tabular}


Table I.4: Power data for the $4^{\text {th }}$ participant

\begin{tabular}{|c|c|c|c|c|c|c|c|c|c|c|c|c|c|c|c|c|c|c|c|c|}
\hline $\mathrm{T}=0$ & \multicolumn{10}{|c|}{ Upper Trapezius } & \multicolumn{10}{|c|}{ Sternocleidomastoid } \\
\hline $\begin{array}{l}\text { Frequency } \\
\text { Band, } \mathbf{H z}\end{array}$ & Bior1.5 & Bior3.1 & Rbio3.1 & Coif5 & Db2 & Db5 & Db45 & Haar & Sym4 & Sym5 & Bior1.5 & Bior3.1 & Rbio3.1 & Coif5 & Db2 & Db5 & Db45 & Haar & Sym4 & Sym5 \\
\hline $375-750$ & 2.07 & 0.05 & 14.48 & 0.03 & 0.29 & 0.05 & 0.02 & 1.98 & 0.06 & 0.04 & 0.08 & 0.01 & 0.46 & 0.01 & 0.02 & 0.01 & 0.01 & 0.08 & 0.01 & 0.01 \\
\hline $187-375$ & 8.42 & 1.20 & 125.85 & 0.85 & 2.81 & 1.11 & 0.66 & 7.16 & 1.43 & 1.21 & 0.29 & 0.09 & 3.24 & 0.06 & 0.13 & 0.07 & 0.06 & 0.24 & 0.09 & 0.08 \\
\hline $46-93$ & 61.16 & 86.11 & 465.42 & 47.42 & 43.83 & 46.37 & 51.51 & 34.69 & 43.96 & 46.72 & 1.27 & 2.27 & 8.30 & 1.14 & 0.92 & 1.08 & 1.22 & 0.86 & 1.12 & 1.04 \\
\hline $23-46$ & 30.18 & 107.63 & 372.26 & 27.33 & 25.62 & 26.42 & 25.19 & 21.52 & 26.90 & 26.80 & 0.47 & 2.05 & 4.02 & 0.40 & 0.42 & 0.44 & 0.35 & 0.31 & 0.36 & 0.43 \\
\hline $12--23$ & 9.86 & 130.60 & 222.04 & 8.34 & 7.41 & 8.13 & 8.23 & 9.64 & 8.79 & 7.81 & 0.08 & 2.60 & 2.30 & 0.07 & 0.07 & 0.06 & 0.07 & 0.12 & 0.10 & 0.06 \\
\hline $6--12$ & 1.17 & 113.31 & 62.90 & 1.08 & 1.63 & 1.13 & 1.03 & 1.45 & 1.52 & 1.35 & 0.02 & 2.14 & 2.64 & 0.01 & 0.02 & 0.01 & 0.01 & 0.02 & 0.01 & 0.01 \\
\hline $375-750$ & 1.62 & 0.03 & 11.67 & 0.02 & 0.20 & 0.03 & 0.01 & 1.56 & 0.04 & 0.02 & 0.046 & 0.006 & 0.263 & 0.005 & 0.013 & 0.006 & 0.004 & 0.044 & 0.006 & 0.006 \\
\hline $187-375$ & 6.59 & 0.75 & 106.13 & 0.52 & 2.13 & 0.76 & 0.40 & 5.67 & 0.93 & 0.76 & 0.173 & 0.059 & 1.778 & 0.043 & 0.076 & 0.048 & 0.037 & 0.141 & 0.056 & 0.052 \\
\hline 93-187 & 21.21 & 12.44 & 314.81 & 9.42 & 12.48 & 11.20 & 8.15 & 18.40 & 11.69 & 10.22 & 0.465 & 0.390 & 4.172 & 0.300 & 0.312 & 0.311 & 0.301 & 0.330 & 0.310 & 0.298 \\
\hline $46-93$ & 51.17 & 69.25 & 422.84 & 43.97 & 36.47 & 39.36 & 48.24 & 31.93 & 41.37 & 40.28 & 0.657 & 1.178 & 4.593 & 0.564 & 0.502 & 0.524 & 0.549 & 0.431 & 0.554 & 0.534 \\
\hline $23-46$ & 28.46 & 83.74 & 335.95 & 22.16 & 24.08 & 24.49 & 18.69 & 18.36 & 20.95 & 24.17 & 0.423 & 1.192 & 4.170 & 0.316 & 0.323 & 0.339 & 0.328 & 0.261 & 0.276 & 0.335 \\
\hline $12--23$ & 7.75 & 69.27 & 169.13 & 7.04 & 7.01 & 7.07 & 7.44 & 6.08 & 7.85 & 7.23 & 0.058 & 2.158 & 1.734 & 0.054 & 0.051 & 0.047 & 0.061 & 0.068 & 0.078 & 0.050 \\
\hline 6--12 & 1.64 & 78.09 & 63.28 & 1.18 & 1.80 & 1.40 & 1.24 & 1.96 & 1.44 & 1.62 & 0.009 & 1.543 & 1.037 & 0.005 & 0.009 & 0.010 & 0.009 & 0.011 & 0.009 & 0.010 \\
\hline \multicolumn{21}{|l|}{$\mathrm{T}=25$} \\
\hline 375-750 & 2.54 & 0.07 & 17.56 & 0.03 & 0.38 & 0.05 & 0.02 & 2.43 & 0.08 & 0.06 & 0.047 & 0.006 & 0.271 & 0.004 & 0.012 & 0.005 & 0.004 & 0.044 & 0.006 & 0.006 \\
\hline 93-187 & 33.86 & 22.00 & 350.81 & 16.88 & 21.47 & 18.68 & 15.36 & 25.12 & 19.39 & 18.68 & 0.436 & 0.401 & 5.299 & 0.277 & 0.281 & 0.306 & 0.264 & 0.393 & 0.320 & 0.269 \\
\hline $46-93$ & 65.50 & 102.86 & 420.03 & 58.38 & 48.52 & 55.13 & 59.01 & 36.92 & 52.60 & 55.27 & 0.859 & 1.266 & 6.334 & 0.690 & 0.630 & 0.651 & 0.743 & 0.540 & 0.643 & 0.678 \\
\hline $23-46$ & 25.27 & 131.48 & 286.91 & 19.28 & 19.75 & 19.45 & 21.14 & 21.98 & 22.37 & 19.53 & 0.424 & 1.411 & 3.986 & 0.387 & 0.399 & 0.387 & 0.361 & 0.262 & 0.385 & 0.402 \\
\hline $12--23$ & 6.64 & 135.56 & 125.56 & 5.28 & 6.71 & 6.21 & 4.44 & 5.28 & 4.49 & 5.84 & 0.074 & 1.326 & 1.437 & 0.070 & 0.059 & 0.064 & 0.055 & 0.072 & 0.062 & 0.059 \\
\hline 6--12 & 0.77 & 96.31 & 32.13 & 0.74 & 0.91 & 0.65 & 0.72 & 0.98 & 0.89 & 0.73 & 0.013 & 1.581 & 0.478 & 0.007 & 0.016 & 0.012 & 0.011 & 0.018 & 0.007 & 0.012 \\
\hline \multicolumn{21}{|l|}{$\mathrm{T}=45$} \\
\hline $375-750$ & 2.28 & 0.04 & 16.39 & 0.02 & 0.28 & 0.03 & 0.02 & 2.19 & 0.05 & 0.03 & 0.080 & 0.010 & 0.471 & 0.007 & 0.021 & 0.009 & 0.007 & 0.076 & 0.010 & 0.009 \\
\hline $187-375$ & 9.22 & 0.92 & 144.94 & 0.59 & 3.09 & 0.96 & 0.47 & 7.89 & 1.19 & 0.92 & 0.310 & 0.087 & 3.475 & 0.060 & 0.133 & 0.079 & 0.055 & 0.254 & 0.081 & 0.075 \\
\hline 93-187 & 30.58 & 19.65 & 401.93 & 15.89 & 18.19 & 18.10 & 14.78 & 25.44 & 18.80 & 15.67 & 0.889 & 0.666 & 8.376 & 0.469 & 0.571 & 0.492 & 0.417 & 0.601 & 0.489 & 0.507 \\
\hline $46-93$ & 66.26 & 90.04 & 568.10 & 54.57 & 48.33 & 50.58 & 59.45 & 41.83 & 51.13 & 52.69 & 1.519 & 2.386 & 9.077 & 1.262 & 1.124 & 1.230 & 1.426 & 0.927 & 1.215 & 1.219 \\
\hline $23-46$ & 36.20 & 111.79 & 456.93 & 31.23 & 32.30 & 33.20 & 27.48 & 23.55 & 29.56 & 33.82 & 0.624 & 2.565 & 7.817 & 0.615 & 0.558 & 0.610 & 0.499 & 0.437 & 0.608 & 0.614 \\
\hline $12--23$ & 11.99 & 131.80 & 283.58 & 10.59 & 9.44 & 9.43 & 10.12 & 10.32 & 11.94 & 8.99 & 0.153 & 7.445 & 6.332 & 0.114 & 0.118 & 0.113 & 0.112 & 0.210 & 0.123 & 0.112 \\
\hline 6--12 & 3.71 & 152.40 & 122.88 & 2.46 & 3.59 & 3.10 & 2.93 & 3.91 & 2.65 & 3.16 & 0.032 & 9.751 & 2.555 & 0.032 & 0.028 & 0.023 & 0.021 & 0.056 & 0.036 & 0.018 \\
\hline
\end{tabular}


Table I.5: Power data for the $5^{\text {th }}$ participant

\begin{tabular}{|c|c|c|c|c|c|c|c|c|c|c|c|c|c|c|c|c|c|c|c|c|}
\hline \multirow{2}{*}{$\begin{array}{l}\mathrm{T}=0 \\
\text { Frequency } \\
\text { Band, } \mathbf{H z}\end{array}$} & \multicolumn{10}{|c|}{ Upper Trapezius } & \multicolumn{10}{|c|}{ Sternocleidomastoid } \\
\hline & Bior1.5 & Bior3.1 & Rbio3.1 & Coif5 & Db2 & Db5 & Db45 & Haar & Sym4 & Sym5 & Bior1.5 & Bior3.1 & Rbio3.1 & Coif5 & Db2 & Db5 & Db45 & Haar & Sym4 & Sym5 \\
\hline $375-750$ & 2.85 & 0.13 & 17.80 & 0.06 & 0.58 & 0.11 & 0.05 & 2.69 & 0.15 & 0.11 & 0.023 & 0.003 & 0.132 & 0.002 & 0.006 & 0.002 & 0.002 & 0.022 & 0.003 & 0.003 \\
\hline $187-375$ & 11.37 & 2.91 & 121.06 & 2.20 & 4.90 & 2.59 & 1.80 & 9.27 & 3.16 & 2.85 & 0.084 & 0.023 & 0.969 & 0.017 & 0.036 & 0.022 & 0.017 & 0.069 & 0.021 & 0.021 \\
\hline 93-187 & 35.05 & 27.90 & 244.97 & 22.34 & 24.00 & 22.36 & 20.99 & 21.69 & 21.84 & 23.68 & 0.251 & 0.200 & 2.085 & 0.150 & 0.164 & 0.154 & 0.143 & 0.167 & 0.157 & 0.155 \\
\hline $46-93$ & 46.16 & 89.56 & 321.85 & 36.71 & 33.21 & 36.44 & 39.25 & 30.07 & 35.71 & 34.96 & 0.391 & 0.649 & 2.631 & 0.328 & 0.292 & 0.322 & 0.342 & 0.241 & 0.308 & 0.320 \\
\hline $23-46$ & 18.88 & 71.71 & 180.72 & 18.03 & 16.26 & 17.47 & 17.42 & 13.50 & 17.81 & 17.82 & 0.124 & 0.573 & 1.341 & 0.116 & 0.104 & 0.106 & 0.114 & 0.104 & 0.127 & 0.108 \\
\hline $12--23$ & 3.81 & 106.48 & 66.21 & 2.91 & 3.41 & 3.16 & 2.39 & 4.46 & 3.28 & 2.97 & 0.031 & 0.575 & 0.677 & 0.023 & 0.033 & 0.030 & 0.019 & 0.027 & 0.018 & 0.028 \\
\hline 6--12 & 0.19 & 90.47 & 15.67 & 0.19 & 0.42 & 0.22 & 0.21 & 0.48 & 0.28 & 0.32 & 0.004 & 0.644 & 0.851 & 0.003 & 0.006 & 0.003 & 0.002 & 0.007 & 0.003 & 0.002 \\
\hline \multicolumn{21}{|l|}{$\mathrm{T}=20$} \\
\hline $375-750$ & 3.77 & 0.15 & 24.05 & 0.06 & 0.72 & 0.13 & 0.04 & 3.57 & 0.18 & 0.13 & 0.014 & 0.002 & 0.082 & 0.002 & 0.004 & 0.002 & 0.001 & 0.014 & 0.002 & 0.002 \\
\hline $187-375$ & 14.97 & 3.80 & 174.90 & 2.80 & 6.16 & 3.18 & 2.36 & 12.33 & 4.05 & 3.48 & 0.046 & 0.018 & 0.613 & 0.013 & 0.023 & 0.014 & 0.013 & 0.039 & 0.017 & 0.014 \\
\hline $93-187$ & 47.49 & 35.45 & 382.93 & 25.60 & 31.82 & 26.91 & 25.18 & 30.34 & 26.78 & 27.62 & 0.160 & 0.095 & 1.599 & 0.078 & 0.101 & 0.077 & 0.066 & 0.098 & 0.078 & 0.094 \\
\hline $46-93$ & 66.53 & 119.18 & 438.33 & 60.64 & 50.54 & 59.83 & 62.17 & 44.18 & 59.03 & 58.11 & 0.229 & 0.462 & 2.870 & 0.189 & 0.136 & 0.169 & 0.219 & 0.226 & 0.221 & 0.149 \\
\hline $23-46$ & 30.55 & 127.73 & 334.57 & 25.57 & 23.65 & 24.01 & 24.54 & 22.41 & 23.97 & 24.50 & 0.174 & 0.432 & 1.724 & 0.167 & 0.175 & 0.184 & 0.151 & 0.072 & 0.134 & 0.190 \\
\hline $12--23$ & 5.87 & 155.95 & 111.08 & 4.79 & 6.17 & 5.31 & 5.05 & 5.55 & 5.37 & 5.63 & 0.050 & 0.543 & 1.891 & 0.039 & 0.039 & 0.039 & 0.028 & 0.036 & 0.033 & 0.032 \\
\hline 6--12 & 0.67 & 172.32 & 30.50 & 0.54 & 0.94 & 0.66 & 0.50 & 1.27 & 0.62 & 0.63 & 0.011 & 0.853 & 1.086 & 0.008 & 0.020 & 0.013 & 0.011 & 0.011 & 0.011 & 0.017 \\
\hline \multicolumn{21}{|l|}{$\mathrm{T}=25$} \\
\hline $375-750$ & 6.95 & 0.30 & 43.54 & 0.13 & 1.42 & 0.26 & 0.09 & 6.57 & 0.35 & 0.27 & 0.107 & 0.013 & 0.617 & 0.008 & 0.030 & 0.011 & 0.006 & 0.101 & 0.012 & 0.010 \\
\hline $187-375$ & 26.80 & 6.40 & 295.49 & 4.52 & 12.85 & 6.67 & 4.16 & 21.94 & 6.79 & 5.90 & 0.386 & 0.143 & 3.904 & 0.091 & 0.184 & 0.103 & 0.079 & 0.312 & 0.138 & 0.111 \\
\hline 93-187 & 77.07 & 78.73 & 614.47 & 51.28 & 52.33 & 55.50 & 49.24 & 60.57 & 57.35 & 50.75 & 1.006 & 1.088 & 7.253 & 0.834 & 0.693 & 0.901 & 0.776 & 0.857 & 0.882 & 0.772 \\
\hline $46-93$ & 124.37 & 195.61 & 761.70 & 96.63 & 89.82 & 91.59 & 103.64 & 69.47 & 87.21 & 97.45 & 1.473 & 2.458 & 7.283 & 1.040 & 1.133 & 1.011 & 1.196 & 0.785 & 0.938 & 1.122 \\
\hline $23-46$ & 35.00 & 176.55 & 369.60 & 36.24 & 29.00 & 33.60 & 30.45 & 27.03 & 34.96 & 32.67 & 0.320 & 1.775 & 3.458 & 0.383 & 0.307 & 0.325 & 0.300 & 0.279 & 0.386 & 0.340 \\
\hline $12--23$ & 7.59 & 215.84 & 135.79 & 5.92 & 8.89 & 7.09 & 6.92 & 7.37 & 7.84 & 7.77 & 0.067 & 2.408 & 1.378 & 0.057 & 0.058 & 0.057 & 0.050 & 0.064 & 0.055 & 0.053 \\
\hline 6--12 & 1.02 & 209.38 & 95.00 & 0.70 & 0.92 & 0.69 & 0.65 & 2.12 & 0.90 & 0.55 & 0.010 & 1.860 & 1.069 & 0.005 & 0.015 & 0.009 & 0.007 & 0.015 & 0.007 & 0.011 \\
\hline \multicolumn{21}{|l|}{$\mathrm{T}=45$} \\
\hline $375-750$ & 7.17 & 0.32 & 45.03 & 0.15 & 1.44 & 0.29 & 0.10 & 6.79 & 0.39 & 0.28 & 0.059 & 0.007 & 0.351 & 0.004 & 0.015 & 0.006 & 0.004 & 0.056 & 0.007 & 0.006 \\
\hline $187-375$ & 29.04 & 6.90 & 305.91 & 5.14 & 12.82 & 6.76 & 4.45 & 23.65 & 7.43 & 6.83 & 0.221 & 0.071 & 2.473 & 0.052 & 0.099 & 0.057 & 0.048 & 0.181 & 0.065 & 0.060 \\
\hline 93-187 & 80.69 & 73.18 & 609.68 & 56.96 & 55.15 & 59.51 & 54.08 & 60.63 & 60.23 & 56.67 & 0.639 & 0.545 & 5.607 & 0.381 & 0.427 & 0.403 & 0.356 & 0.449 & 0.403 & 0.395 \\
\hline $46-93$ & 118.44 & 224.11 & 704.50 & 102.49 & 87.87 & 91.92 & 101.26 & 69.43 & 94.98 & 95.24 & 1.018 & 1.729 & 7.645 & 0.787 & 0.720 & 0.781 & 0.877 & 0.662 & 0.763 & 0.779 \\
\hline $23-46$ & 42.81 & 190.94 & 397.32 & 29.68 & 36.59 & 35.45 & 34.22 & 29.39 & 31.06 & 35.38 & 0.451 & 1.855 & 7.817 & 0.458 & 0.413 & 0.426 & 0.384 & 0.342 & 0.458 & 0.433 \\
\hline $12--23$ & 9.61 & 255.98 & 215.98 & 7.86 & 7.75 & 8.02 & 7.33 & 10.04 & 7.38 & 7.33 & 0.190 & 2.144 & 8.051 & 0.158 & 0.150 & 0.169 & 0.159 & 0.117 & 0.126 & 0.161 \\
\hline $6--12$ & 1.35 & 257.84 & 174.83 & 1.18 & 0.98 & 0.78 & 1.47 & 2.84 & 1.63 & 0.89 & 0.020 & 2.207 & 2.990 & 0.024 & 0.031 & 0.019 & 0.029 & 0.024 & 0.036 & 0.028 \\
\hline
\end{tabular}


Table I.6: Power data for the $6^{\text {th }}$ participant

\begin{tabular}{|c|c|c|c|c|c|c|c|c|c|c|c|c|c|c|c|c|c|c|c|c|}
\hline \multirow{2}{*}{$\begin{array}{l}\mathrm{T}=0 \\
\text { Frequency } \\
\text { Band, } \mathbf{H z} \\
\end{array}$} & \multicolumn{10}{|c|}{ Upper Trapezius } & \multicolumn{10}{|c|}{ Sternocleidomastoid } \\
\hline & Bior1.5 & Bior3.1 & Rbio3.1 & Coif5 & Db2 & Db5 & Db45 & Haar & Sym4 & Sym5 & Bior1.5 & Bior3.1 & Rbio3.1 & Coif5 & Db2 & Db5 & Db45 & Haar & Sym4 & Sym5 \\
\hline $375-750$ & 2.04 & 0.18 & 12.88 & 0.12 & 0.45 & 0.16 & 0.10 & 1.95 & 0.18 & 0.16 & 0.268 & 0.026 & 1.632 & 0.018 & 0.063 & 0.024 & 0.015 & 0.254 & 0.026 & 0.022 \\
\hline $187-375$ & 7.90 & 1.79 & 100.06 & 1.21 & 3.14 & 1.53 & 0.98 & 6.57 & 1.87 & 1.61 & 0.021 & 0.005 & 0.227 & 0.003 & 0.010 & 0.005 & 0.003 & 0.017 & 0.005 & 0.004 \\
\hline 93-187 & 23.58 & 18.33 & 280.52 & 13.91 & 14.83 & 14.82 & 12.65 & 18.04 & 14.94 & 14.23 & 3.371 & 2.787 & 23.211 & 1.947 & 2.318 & 1.924 & 1.985 & 1.917 & 1.883 & 2.072 \\
\hline $46-93$ & 44.89 & 57.65 & 432.68 & 31.29 & 32.57 & 32.22 & 32.04 & 25.01 & 28.87 & 32.90 & 3.886 & 7.465 & 32.139 & 3.419 & 2.752 & 3.268 & 3.466 & 2.937 & 3.484 & 3.132 \\
\hline $23-46$ & 32.50 & 85.71 & 404.87 & 29.36 & 23.78 & 26.49 & 30.50 & 22.97 & 29.53 & 26.56 & 1.773 & 5.587 & 23.051 & 1.462 & 1.411 & 1.535 & 1.392 & 1.041 & 1.288 & 1.538 \\
\hline $12--23$ & 8.31 & 87.91 & 165.61 & 6.84 & 7.66 & 7.26 & 6.66 & 8.07 & 7.34 & 7.28 & 0.441 & 6.073 & 14.217 & 0.299 & 0.381 & 0.407 & 0.339 & 0.320 & 0.351 & 0.384 \\
\hline 6--12 & 1.10 & 79.91 & 44.41 & 1.09 & 1.46 & 1.19 & 0.97 & 1.01 & 1.02 & 1.10 & 0.160 & 10.160 & 25.687 & 0.131 & 0.113 & 0.104 & 0.089 & 0.179 & 0.169 & 0.092 \\
\hline \multicolumn{21}{|l|}{$\mathrm{T}=20$} \\
\hline $375-750$ & 1.06 & 0.08 & 7.04 & 0.05 & 0.20 & 0.07 & 0.04 & 1.01 & 0.08 & 0.07 & 0.232 & 0.011 & 1.478 & 0.007 & 0.045 & 0.010 & 0.005 & 0.220 & 0.013 & 0.010 \\
\hline 187-375 & 4.30 & 0.80 & 59.71 & 0.53 & 1.49 & 0.65 & 0.48 & 3.61 & 0.79 & 0.69 & 0.072 & 0.017 & 0.846 & 0.012 & 0.031 & 0.017 & 0.010 & 0.060 & 0.018 & 0.016 \\
\hline 93-187 & 14.41 & 8.03 & 163.81 & 6.45 & 8.99 & 6.79 & 6.32 & 9.32 & 7.01 & 7.32 & 2.743 & 2.354 & 20.877 & 1.925 & 1.856 & 1.987 & 1.780 & 1.992 & 1.964 & 1.933 \\
\hline $46-93$ & 25.10 & 38.85 & 270.83 & 21.23 & 16.87 & 19.17 & 21.30 & 18.06 & 21.45 & 18.72 & 3.800 & 6.876 & 28.106 & 3.243 & 2.908 & 3.090 & 3.296 & 2.378 & 3.074 & 3.127 \\
\hline $23-46$ & 18.90 & 47.54 & 197.41 & 14.68 & 16.31 & 16.65 & 16.30 & 10.90 & 14.37 & 17.34 & 1.646 & 6.821 & 19.050 & 1.272 & 1.291 & 1.287 & 1.364 & 1.128 & 1.251 & 1.266 \\
\hline $12--23$ & 6.91 & 48.55 & 138.45 & 5.99 & 4.84 & 5.57 & 4.51 & 5.19 & 5.13 & 4.77 & 0.528 & 10.458 & 33.888 & 0.369 & 0.506 & 0.443 & 0.419 & 0.472 & 0.421 & 0.458 \\
\hline 6--12 & 0.77 & 58.06 & 30.30 & 0.60 & 0.84 & 0.65 & 0.54 & 1.15 & 0.69 & 0.66 & 0.228 & 20.271 & 64.584 & 0.176 & 0.148 & 0.144 & 0.142 & 0.220 & 0.161 & 0.135 \\
\hline \multicolumn{21}{|l|}{$\mathrm{T}=25$} \\
\hline $375-750$ & 1.00 & 0.08 & 6.54 & 0.06 & 0.20 & 0.07 & 0.05 & 0.96 & 0.08 & 0.07 & 0.358 & 0.036 & 2.174 & 0.024 & 0.088 & 0.031 & 0.023 & 0.340 & 0.034 & 0.031 \\
\hline $187-375$ & 3.81 & 0.75 & 54.39 & 0.48 & 1.49 & 0.68 & 0.45 & 3.20 & 0.72 & 0.62 & 0.014 & 0.004 & 0.155 & 0.003 & 0.007 & 0.003 & 0.002 & 0.011 & 0.004 & 0.003 \\
\hline 93-187 & 12.96 & 7.80 & 147.48 & 6.70 & 7.97 & 6.98 & 5.44 & 8.89 & 7.07 & 7.45 & 3.822 & 3.548 & 32.982 & 2.756 & 2.587 & 2.858 & 2.485 & 2.964 & 2.956 & 2.786 \\
\hline $46-93$ & 23.01 & 34.59 & 219.77 & 18.13 & 17.03 & 18.33 & 20.26 & 14.79 & 18.08 & 17.69 & 6.183 & 10.810 & 38.922 & 4.246 & 4.722 & 4.381 & 4.918 & 3.315 & 4.013 & 4.505 \\
\hline $23-46$ & 14.37 & 49.06 & 194.55 & 13.50 & 11.62 & 12.54 & 13.91 & 10.76 & 14.72 & 13.17 & 3.020 & 13.335 & 39.664 & 3.108 & 2.206 & 2.634 & 2.445 & 2.355 & 2.826 & 2.461 \\
\hline $12--23$ & 6.88 & 60.59 & 151.27 & 4.87 & 5.58 & 5.79 & 3.69 & 5.26 & 3.00 & 5.00 & 0.794 & 13.347 & 32.762 & 0.491 & 0.700 & 0.755 & 0.733 & 0.805 & 0.544 & 0.752 \\
\hline 6--12 & 1.16 & 52.62 & 76.60 & 0.98 & 1.16 & 0.71 & 0.92 & 0.74 & 1.25 & 1.02 & 0.166 & 8.032 & 56.520 & 0.195 & 0.142 & 0.062 & 0.189 & 0.196 & 0.269 & 0.144 \\
\hline \multicolumn{21}{|l|}{$\mathrm{T}=45$} \\
\hline 375-750 & 0.86 & 0.07 & 5.70 & 0.04 & 0.16 & 0.06 & 0.03 & 0.82 & 0.06 & 0.05 & 0.119 & 0.007 & 0.754 & 0.004 & 0.024 & 0.006 & 0.004 & 0.113 & 0.007 & 0.006 \\
\hline 187-375 & 3.37 & 0.68 & 48.79 & 0.45 & 1.21 & 0.53 & 0.42 & 2.85 & 0.64 & 0.55 & 0.030 & 0.007 & 0.371 & 0.005 & 0.014 & 0.007 & 0.005 & 0.025 & 0.007 & 0.007 \\
\hline 93-187 & 11.45 & 6.94 & 131.57 & 4.69 & 7.14 & 5.24 & 4.82 & 7.72 & 5.59 & 5.36 & 1.559 & 1.464 & 12.166 & 0.839 & 1.073 & 0.849 & 1.016 & 0.929 & 0.843 & 0.839 \\
\hline $46-93$ & 21.08 & 31.23 & 217.53 & 17.60 & 14.26 & 16.30 & 18.52 & 14.94 & 17.32 & 16.17 & 1.675 & 2.877 & 12.750 & 1.705 & 1.294 & 1.629 & 1.475 & 1.292 & 1.701 & 1.640 \\
\hline $23-46$ & 12.96 & 38.03 & 159.58 & 11.19 & 11.37 & 11.87 & 10.77 & 7.90 & 11.25 & 12.12 & 1.115 & 3.029 & 14.785 & 0.910 & 0.870 & 0.935 & 0.981 & 0.701 & 0.878 & 0.943 \\
\hline $12--23$ & 5.82 & 45.97 & 106.56 & 5.12 & 4.80 & 5.08 & 4.59 & 4.19 & 4.18 & 4.93 & 0.292 & 4.399 & 13.468 & 0.212 & 0.298 & 0.250 & 0.182 & 0.269 & 0.200 & 0.242 \\
\hline $6--12$ & 0.99 & 51.28 & 43.25 & 0.71 & 0.84 & 0.76 & 0.54 & 1.20 & 0.74 & 0.63 & 0.109 & 3.059 & 21.035 & 0.060 & 0.048 & 0.058 & 0.045 & 0.124 & 0.051 & 0.047 \\
\hline
\end{tabular}


Table I.7: Power data for the $7^{\text {th }}$ participant

\begin{tabular}{|c|c|c|c|c|c|c|c|c|c|c|c|c|c|c|c|c|c|c|c|c|}
\hline $\mathrm{T}=0$ & \multicolumn{10}{|c|}{ Upper Trapezius } & \multicolumn{10}{|c|}{ Sternocleidomastoid } \\
\hline $\begin{array}{l}\text { Frequency } \\
\text { Band, Hz }\end{array}$ & Bior1.5 & Bior3.1 & Rbio3.1 & Coif5 & Db2 & Db5 & Db45 & Haar & Sym4 & Sym5 & Bior1.5 & Bior3.1 & Rbio3.1 & Coif5 & Db2 & Db5 & Db45 & Haar & Sym4 & Sym5 \\
\hline 375-750 & 1.93 & 0.03 & 13.82 & 0.01 & 0.25 & 0.03 & 0.01 & 1.86 & 0.04 & 0.03 & 0.135 & 0.011 & 0.888 & 0.008 & 0.026 & 0.010 & 0.007 & 0.129 & 0.011 & 0.009 \\
\hline $187-375$ & 7.96 & 0.97 & 124.70 & 0.72 & 2.59 & 1.02 & 0.53 & 6.81 & 1.20 & 1.06 & 0.527 & 0.096 & 7.271 & 0.066 & 0.201 & 0.084 & 0.058 & 0.442 & 0.099 & 0.086 \\
\hline 93-187 & 27.31 & 14.12 & 369.79 & 11.17 & 16.02 & 12.52 & 9.49 & 19.88 & 12.97 & 12.80 & 1.750 & 1.144 & 18.625 & 0.889 & 1.115 & 0.952 & 0.776 & 1.223 & 0.965 & 0.981 \\
\hline $46-93$ & 59.84 & 75.88 & 489.50 & 49.32 & 44.45 & 49.00 & 51.28 & 35.74 & 44.67 & 48.77 & 3.252 & 5.066 & 27.469 & 2.547 & 2.169 & 2.374 & 2.790 & 2.166 & 2.487 & 2.347 \\
\hline $23-46$ & 38.66 & 119.07 & 422.01 & 32.36 & 29.46 & 30.90 & 31.98 & 27.82 & 32.94 & 30.80 & 1.536 & 4.427 & 14.685 & 1.430 & 1.353 & 1.498 & 1.303 & 0.923 & 1.254 & 1.482 \\
\hline $12--23$ & 6.37 & 89.78 & 124.15 & 5.94 & 5.89 & 5.76 & 5.99 & 5.36 & 7.29 & 5.80 & 0.189 & 5.213 & 4.796 & 0.136 & 0.225 & 0.159 & 0.159 & 0.233 & 0.269 & 0.174 \\
\hline 6--12 & 0.84 & 123.65 & 41.25 & 0.54 & 1.18 & 0.66 & 0.40 & 2.04 & 0.67 & 0.62 & 0.050 & 3.142 & 7.312 & 0.030 & 0.029 & 0.027 & 0.019 & 0.046 & 0.033 & 0.027 \\
\hline \multicolumn{21}{|l|}{$\mathrm{T}=20$} \\
\hline $375-750$ & 1.92 & 0.03 & 14.01 & 0.01 & 0.23 & 0.03 & 0.01 & 1.85 & 0.03 & 0.02 & 0.123 & 0.009 & 0.812 & 0.007 & 0.023 & 0.009 & 0.006 & 0.118 & 0.010 & 0.008 \\
\hline $187-375$ & 7.81 & 0.91 & 130.66 & 0.58 & 2.33 & 0.73 & 0.41 & 6.74 & 1.13 & 0.87 & 0.475 & 0.098 & 6.825 & 0.064 & 0.165 & 0.068 & 0.054 & 0.401 & 0.095 & 0.080 \\
\hline 93-187 & 29.19 & 12.97 & 405.99 & 11.11 & 16.89 & 12.31 & 9.38 & 19.78 & 12.56 & 13.16 & 1.336 & 1.035 & 18.005 & 0.789 & 0.844 & 0.959 & 0.780 & 1.305 & 1.002 & 0.730 \\
\hline $46-93$ & 54.86 & 85.35 & 638.15 & 48.43 & 36.92 & 41.33 & 52.31 & 45.44 & 51.67 & 40.27 & 3.267 & 3.711 & 23.924 & 2.376 & 2.444 & 2.361 & 2.428 & 1.582 & 2.091 & 2.566 \\
\hline $23-46$ & 52.12 & 119.76 & 525.78 & 42.50 & 43.58 & 47.41 & 39.58 & 27.26 & 35.82 & 47.22 & 1.592 & 5.522 & 23.631 & 1.495 & 1.304 & 1.365 & 1.483 & 1.251 & 1.496 & 1.418 \\
\hline $12--23$ & 8.01 & 97.63 & 184.75 & 7.74 & 8.37 & 7.37 & 8.15 & 6.71 & 9.50 & 7.75 & 0.600 & 8.371 & 30.615 & 0.435 & 0.437 & 0.428 & 0.462 & 0.545 & 0.489 & 0.417 \\
\hline 6--12 & 2.86 & 177.61 & 84.52 & 1.60 & 3.61 & 2.62 & 1.74 & 3.97 & 1.17 & 2.53 & 0.272 & 7.872 & 59.078 & 0.213 & 0.128 & 0.160 & 0.149 & 0.212 & 0.195 & 0.138 \\
\hline \multicolumn{21}{|l|}{$\mathrm{T}=25$} \\
\hline $375-750$ & 1.43 & 0.02 & 10.50 & 0.01 & 0.17 & 0.02 & 0.01 & 1.38 & 0.03 & 0.02 & 0.033 & 0.003 & 0.211 & 0.002 & 0.007 & 0.003 & 0.002 & 0.032 & 0.003 & 0.003 \\
\hline $187-375$ & 5.96 & 0.53 & 98.69 & 0.37 & 1.81 & 0.60 & 0.32 & 5.15 & 0.66 & 0.57 & 0.131 & 0.029 & 1.673 & 0.021 & 0.054 & 0.030 & 0.020 & 0.109 & 0.029 & 0.026 \\
\hline 93-187 & 20.88 & 10.40 & 295.14 & 7.55 & 11.87 & 9.04 & 6.82 & 15.61 & 9.78 & 8.68 & 0.360 & 0.294 & 4.823 & 0.201 & 0.223 & 0.221 & 0.191 & 0.310 & 0.235 & 0.201 \\
\hline $46-93$ & 45.69 & 68.47 & 442.57 & 40.55 & 31.98 & 36.42 & 41.76 & 31.77 & 39.53 & 36.67 & 0.704 & 1.065 & 7.024 & 0.603 & 0.494 & 0.509 & 0.637 & 0.505 & 0.600 & 0.534 \\
\hline $23-46$ & 30.80 & 91.25 & 286.93 & 25.71 & 26.91 & 27.19 & 25.09 & 18.45 & 23.94 & 27.74 & 0.488 & 1.243 & 4.882 & 0.395 & 0.421 & 0.464 & 0.387 & 0.223 & 0.346 & 0.466 \\
\hline $12--23$ & 6.88 & 91.72 & 145.51 & 4.93 & 6.09 & 5.87 & 5.14 & 5.92 & 4.87 & 5.50 & 0.108 & 1.750 & 3.392 & 0.089 & 0.109 & 0.079 & 0.069 & 0.119 & 0.102 & 0.084 \\
\hline 6--12 & 0.64 & 100.20 & 49.16 & 0.78 & 1.10 & 0.61 & 0.53 & 1.26 & 1.07 & 0.82 & 0.017 & 2.217 & 2.462 & 0.012 & 0.056 & 0.021 & 0.012 & 0.019 & 0.020 & 0.037 \\
\hline \multicolumn{21}{|l|}{$\mathrm{T}=45$} \\
\hline $375-750$ & 1.58 & 0.02 & 11.72 & 0.01 & 0.17 & 0.02 & 0.01 & 1.53 & 0.02 & 0.02 & 0.076 & 0.007 & 0.461 & 0.006 & 0.018 & 0.007 & 0.005 & 0.072 & 0.008 & 0.008 \\
\hline $187-375$ & 6.68 & 0.54 & 111.57 & 0.35 & 1.86 & 0.55 & 0.24 & 5.76 & 0.70 & 0.59 & 0.277 & 0.074 & 3.581 & 0.051 & 0.120 & 0.065 & 0.046 & 0.231 & 0.067 & 0.061 \\
\hline 93-187 & 23.49 & 10.63 & 325.17 & 8.05 & 13.82 & 9.87 & 6.55 & 17.42 & 10.45 & 10.08 & 0.899 & 0.603 & 9.197 & 0.484 & 0.550 & 0.507 & 0.401 & 0.602 & 0.519 & 0.530 \\
\hline $46-93$ & 60.30 & 74.62 & 502.22 & 41.86 & 39.26 & 40.84 & 46.38 & 35.61 & 39.35 & 41.07 & 1.440 & 2.697 & 14.148 & 1.240 & 1.003 & 1.079 & 1.329 & 1.050 & 1.257 & 1.065 \\
\hline $23-46$ & 28.52 & 86.06 & 339.27 & 30.61 & 24.48 & 28.71 & 28.79 & 20.10 & 31.80 & 28.94 & 1.290 & 3.670 & 15.941 & 0.997 & 1.030 & 1.120 & 0.973 & 0.712 & 0.864 & 1.089 \\
\hline $12--23$ & 7.83 & 79.82 & 163.11 & 6.01 & 7.25 & 7.07 & 4.99 & 5.84 & 4.62 & 6.47 & 0.332 & 6.904 & 12.912 & 0.262 & 0.364 & 0.310 & 0.278 & 0.320 & 0.323 & 0.319 \\
\hline $6--12$ & 1.40 & 133.36 & 69.32 & 1.02 & 1.14 & 1.07 & 0.82 & 1.59 & 1.10 & 0.92 & 0.033 & 3.872 & 4.869 & 0.031 & 0.030 & 0.029 & 0.031 & 0.062 & 0.036 & 0.030 \\
\hline
\end{tabular}


Table I. 8: Power data for the $8^{\text {th }}$ participant

\begin{tabular}{|c|c|c|c|c|c|c|c|c|c|c|c|c|c|c|c|c|c|c|c|c|}
\hline $\mathrm{T}=0$ & \multicolumn{10}{|c|}{ Upper Trapezius } & \multicolumn{10}{|c|}{ Sternocleidomastoid } \\
\hline $\begin{array}{l}\text { Frequency } \\
\text { Band, Hz }\end{array}$ & Bior1.5 & Bior3.1 & Rbio3.1 & Coif5 & Db2 & Db5 & Db45 & Haar & Sym4 & Sym5 & Bior1.5 & Bior3.1 & Rbio3.1 & Coif5 & Db2 & Db5 & Db45 & Haar & Sym4 & Sym5 \\
\hline 375-750 & 2.47 & 0.07 & 17.32 & 0.04 & 0.35 & 0.06 & 0.03 & 2.37 & 0.07 & 0.06 & 0.029 & 0.001 & 0.187 & 0.001 & 0.005 & 0.001 & 0.001 & 0.027 & 0.002 & 0.001 \\
\hline 187-375 & 10.04 & 1.30 & 143.16 & 0.74 & 3.46 & 1.08 & 0.59 & 8.46 & 1.55 & 1.20 & 0.117 & 0.020 & 1.338 & 0.013 & 0.048 & 0.021 & 0.010 & 0.097 & 0.023 & 0.021 \\
\hline $46-93$ & 61.47 & 94.89 & 575.98 & 49.70 & 44.63 & 48.30 & 53.44 & 37.53 & 46.43 & 48.13 & 0.551 & 0.795 & 3.299 & 0.429 & 0.418 & 0.376 & 0.466 & 0.304 & 0.394 & 0.429 \\
\hline $23-46$ & 31.90 & 98.01 & 875.52 & 22.24 & 22.46 & 21.94 & 20.30 & 24.97 & 23.65 & 21.85 & 0.161 & 0.619 & 1.896 & 0.147 & 0.158 & 0.157 & 0.119 & 0.107 & 0.127 & 0.159 \\
\hline $12--23$ & 23.31 & 104.98 & 514.75 & 22.51 & 20.38 & 22.33 & 25.02 & 14.82 & 20.61 & 23.08 & 0.037 & 0.552 & 1.644 & 0.029 & 0.030 & 0.032 & 0.030 & 0.033 & 0.033 & 0.029 \\
\hline $6--12$ & 5.93 & 114.72 & 167.59 & 4.74 & 6.08 & 5.20 & 2.37 & 6.01 & 6.31 & 4.77 & 0.022 & 0.764 & 2.615 & 0.012 & 0.029 & 0.016 & 0.016 & 0.018 & 0.019 & 0.026 \\
\hline $375-750$ & 2.40 & 0.03 & 17.79 & 0.02 & 0.26 & 0.03 & 0.01 & 2.32 & 0.04 & 0.03 & 0.021 & 0.001 & 0.137 & 0.001 & 0.004 & 0.001 & 0.001 & 0.020 & 0.001 & 0.001 \\
\hline $187-375$ & 9.76 & 0.65 & 162.64 & 0.33 & 3.08 & 0.71 & 0.28 & 8.43 & 0.87 & 0.63 & 0.080 & 0.013 & 1.011 & 0.008 & 0.034 & 0.012 & 0.006 & 0.067 & 0.015 & 0.012 \\
\hline 93-187 & 37.32 & 18.22 & 435.65 & 15.64 & 22.53 & 17.24 & 13.59 & 25.57 & 18.26 & 18.28 & 0.294 & 0.206 & 2.164 & 0.158 & 0.203 & 0.155 & 0.150 & 0.168 & 0.155 & 0.184 \\
\hline $46-93$ & 75.42 & 115.42 & 764.01 & 63.48 & 53.97 & 61.73 & 67.75 & 47.84 & 59.22 & 60.81 & 0.374 & 0.732 & 3.348 & 0.318 & 0.254 & 0.313 & 0.346 & 0.284 & 0.325 & 0.285 \\
\hline $23-46$ & 38.53 & 123.62 & 979.22 & 29.57 & 27.26 & 28.41 & 27.07 & 29.86 & 32.28 & 27.54 & 0.196 & 0.593 & 3.012 & 0.176 & 0.163 & 0.180 & 0.158 & 0.122 & 0.160 & 0.180 \\
\hline $12--23$ & 31.69 & 196.83 & 638.78 & 30.84 & 29.30 & 30.32 & 32.84 & 20.72 & 27.28 & 31.41 & 0.074 & 1.005 & 2.333 & 0.065 & 0.071 & 0.065 & 0.067 & 0.063 & 0.074 & 0.071 \\
\hline 6--12 & 6.43 & 172.40 & 182.01 & 4.14 & 7.14 & 5.56 & 1.98 & 8.34 & 6.02 & 5.22 & 0.028 & 1.041 & 1.687 & 0.025 & 0.019 & 0.022 & 0.021 & 0.024 & 0.023 & 0.016 \\
\hline \multicolumn{21}{|l|}{$\mathrm{T}=25$} \\
\hline $375-750$ & 1.40 & 0.03 & 10.18 & 0.02 & 0.17 & 0.02 & 0.01 & 1.35 & 0.03 & 0.02 & 0.060 & & 0.392 & 0.002 & 0.011 & 0.003 & 0.002 & 0.057 & 0.004 & 0.003 \\
\hline 93-187 & 20.91 & 11.23 & 258.37 & 8.35 & 12.77 & 9.37 & 7.75 & 14.74 & 9.89 & 9.79 & 0.630 & 0.672 & 6.769 & 0.474 & 0.414 & 0.537 & 0.447 & 0.624 & 0.561 & 0.430 \\
\hline $46-93$ & 42.56 & 60.90 & 415.79 & 36.40 & 30.26 & 34.60 & 38.57 & 27.54 & 34.44 & 34.18 & 1.305 & 1.839 & 7.503 & 0.977 & 0.968 & 0.909 & 1.074 & 0.643 & 0.883 & 1.008 \\
\hline $23-46$ & 22.49 & 71.45 & 474.67 & 18.75 & 17.32 & 18.14 & 17.61 & 16.62 & 20.13 & 18.17 & 0.450 & 2.006 & 6.151 & 0.393 & 0.418 & 0.397 & 0.346 & 0.323 & 0.395 & 0.429 \\
\hline $12--23$ & 14.85 & 93.29 & 283.71 & 14.21 & 13.62 & 14.38 & 14.30 & 9.49 & 12.24 & 14.61 & 0.179 & 2.496 & 5.452 & 0.165 & 0.106 & 0.138 & 0.140 & 0.173 & 0.147 & 0.115 \\
\hline 6--12 & 2.76 & 119.84 & 72.76 & 1.54 & 3.34 & 2.50 & 0.94 & 4.08 & 2.19 & 2.28 & 0.069 & 2.027 & 5.434 & 0.035 & 0.062 & 0.053 & 0.037 & 0.071 & 0.037 & 0.049 \\
\hline \multicolumn{21}{|l|}{$\mathrm{T}=45$} \\
\hline $375-750$ & 1.87 & 0.03 & 13.86 & 0.02 & 0.21 & 0.02 & 0.01 & 1.81 & 0.03 & 0.03 & 0.029 & 0.002 & 0.189 & 0.001 & 0.006 & 0.002 & 0.001 & 0.028 & 0.002 & 0.002 \\
\hline 187-375 & 7.64 & 0.57 & 128.34 & 0.30 & 2.29 & 0.54 & 0.27 & 6.59 & 0.72 & 0.52 & 0.113 & 0.022 & 1.431 & 0.014 & 0.044 & 0.018 & 0.011 & 0.094 & 0.024 & 0.020 \\
\hline 93-187 & 31.45 & 13.82 & 351.40 & 9.99 & 19.39 & 11.18 & 9.31 & 18.34 & 11.79 & 13.45 & 0.361 & 0.270 & 3.009 & 0.218 & 0.242 & 0.233 & 0.195 & 0.262 & 0.237 & 0.229 \\
\hline $46-93$ & 62.36 & 88.68 & 716.78 & 47.12 & 41.43 & 48.96 & 52.62 & 39.90 & 44.67 & 46.62 & 0.583 & 0.948 & 3.743 & 0.498 & 0.436 & 0.464 & 0.527 & 0.362 & 0.470 & 0.470 \\
\hline $23-46$ & 37.20 & 92.71 & 948.96 & 30.74 & 28.15 & 28.61 & 23.94 & 26.18 & 28.62 & 28.06 & 0.285 & 1.158 & 3.833 & 0.224 & 0.232 & 0.244 & 0.226 & 0.184 & 0.217 & 0.244 \\
\hline 12--23 & 29.70 & 155.34 & 665.44 & 28.17 & 22.21 & 27.15 & 32.00 & 20.25 & 27.34 & 26.94 & 0.079 & 1.864 & 4.252 & 0.061 & 0.056 & 0.061 & 0.054 & 0.083 & 0.063 & 0.053 \\
\hline 6--12 & 4.15 & 158.97 & 111.02 & 3.80 & 6.14 & 3.63 & 1.78 & 6.37 & 6.87 & 4.47 & 0.017 & 2.004 & 1.906 & 0.019 & 0.024 & 0.015 & 0.016 & 0.021 & 0.023 & 0.020 \\
\hline
\end{tabular}


Table I.9: Power data for the $9^{\text {th }}$ participant

\begin{tabular}{|c|c|c|c|c|c|c|c|c|c|c|c|c|c|c|c|c|c|c|c|c|}
\hline $\mathrm{T}=0$ & \multicolumn{10}{|c|}{ Upper Trapezius } & \multicolumn{10}{|c|}{ Sternocleidomastoid } \\
\hline $\begin{array}{l}\text { Frequency } \\
\text { Band, } \mathbf{H z}\end{array}$ & Bior1.5 & Bior3.1 & Rbio3.1 & Coif5 & Db2 & Db5 & Db45 & Haar & Sym4 & Sym5 & Bior1.5 & Bior3.1 & Rbio3.1 & Coif5 & Db2 & Db5 & Db45 & Haar & Sym4 & Sym5 \\
\hline $375-750$ & 0.234 & 0.008 & 1.657 & 0.005 & 0.033 & 0.007 & 0.004 & 0.225 & 0.009 & 0.007 & 0.0055 & 0.0005 & 0.0335 & 0.0003 & 0.0012 & 0.0004 & 0.0003 & 0.0052 & 0.0005 & 0.0004 \\
\hline $187-375$ & 0.954 & 0.119 & 14.833 & 0.078 & 0.311 & 0.105 & 0.069 & 0.814 & 0.129 & 0.108 & 1.0606 & 0.2612 & 11.0765 & 0.1712 & 0.4582 & 0.2326 & 0.1530 & 0.8632 & 0.2644 & 0.2370 \\
\hline 93-187 & 3.238 & 1.813 & 43.017 & 1.509 & 1.958 & 1.687 & 1.303 & 2.443 & 1.735 & 1.667 & 0.0592 & 0.0623 & 0.5338 & 0.0404 & 0.0396 & 0.0428 & 0.0433 & 0.0462 & 0.0444 & 0.0381 \\
\hline $46-93$ & 6.802 & 9.327 & 65.766 & 5.411 & 4.922 & 5.190 & 5.520 & 4.153 & 5.145 & 5.223 & 0.0914 & 0.1424 & 0.6465 & 0.0681 & 0.0686 & 0.0689 & 0.0694 & 0.0538 & 0.0624 & 0.0733 \\
\hline $23-46$ & 4.744 & 12.844 & 64.313 & 3.919 & 3.485 & 3.774 & 4.152 & 3.265 & 4.093 & 3.832 & 0.0332 & 0.1270 & 0.4540 & 0.0351 & 0.0296 & 0.0314 & 0.0302 & 0.0248 & 0.0340 & 0.0319 \\
\hline $12--23$ & 1.695 & 13.075 & 32.425 & 1.316 & 1.503 & 1.523 & 1.194 & 1.171 & 1.047 & 1.414 & 0.0103 & 0.1478 & 0.3712 & 0.0092 & 0.0078 & 0.0081 & 0.0089 & 0.0089 & 0.0098 & 0.0074 \\
\hline 6--12 & 0.236 & 20.003 & 14.434 & 0.253 & 0.319 & 0.196 & 0.186 & 0.360 & 0.313 & 0.255 & 0.0030 & 0.1531 & 0.3682 & 0.0019 & 0.0041 & 0.0029 & 0.0026 & 0.0032 & 0.0025 & 0.0035 \\
\hline \multicolumn{21}{|l|}{$\mathrm{T}=20$} \\
\hline $375-750$ & 0.42 & 0.01 & 2.98 & 0.01 & 0.06 & 0.01 & 0.01 & 0.40 & 0.01 & 0.01 & 0.02 & 0.002 & 0.116 & 0.001 & 0.004 & 0.001 & 0.001 & 0.018 & 0.002 & 0.001 \\
\hline $187-375$ & 1.77 & 0.21 & 26.32 & 0.14 & 0.58 & 0.21 & 0.12 & 1.50 & 0.24 & 0.21 & 0.90 & 0.197 & 10.215 & 0.134 & 0.394 & 0.186 & 0.102 & 0.742 & 0.229 & 0.192 \\
\hline 93-187 & 5.90 & 3.46 & 79.66 & 2.87 & 3.60 & 3.04 & 2.61 & 4.26 & 3.13 & 3.17 & 0.22 & 0.170 & 2.166 & 0.123 & 0.143 & 0.126 & 0.122 & 0.150 & 0.128 & 0.129 \\
\hline $46-93$ & 12.19 & 16.32 & 143.95 & 8.65 & 8.50 & 8.70 & 9.16 & 7.55 & 8.42 & 8.61 & 0.34 & 0.547 & 2.529 & 0.299 & 0.264 & 0.291 & 0.277 & 0.203 & 0.282 & 0.290 \\
\hline $23-46$ & 9.31 & 20.27 & 136.65 & 8.09 & 7.37 & 7.91 & 7.75 & 6.35 & 7.98 & 7.81 & 0.22 & 0.709 & 3.818 & 0.156 & 0.148 & 0.150 & 0.181 & 0.169 & 0.167 & 0.150 \\
\hline $12--23$ & 4.69 & 27.74 & 92.22 & 4.24 & 3.85 & 4.11 & 4.50 & 3.55 & 4.19 & 4.25 & 0.07 & 0.892 & 6.807 & 0.056 & 0.052 & 0.058 & 0.053 & 0.056 & 0.050 & 0.057 \\
\hline $6--12$ & 0.72 & 18.78 & 33.26 & 0.55 & 0.54 & 0.58 & 0.38 & 0.83 & 0.59 & 0.47 & 0.04 & 0.882 & 13.857 & 0.025 & 0.038 & 0.030 & 0.025 & 0.030 & 0.028 & 0.036 \\
\hline \multicolumn{21}{|l|}{$\mathrm{T}=25$} \\
\hline $375-750$ & 0.60 & 0.02 & 4.15 & 0.01 & 0.09 & 0.02 & 0.01 & 0.57 & 0.02 & 0.02 & 0.0038 & 0.0004 & 0.0229 & 0.0003 & 0.0009 & 0.0004 & 0.0003 & 0.0036 & 0.0004 & 0.0004 \\
\hline $187-375$ & 2.33 & 0.37 & 35.87 & $\begin{array}{l}0.01 \\
0.21\end{array}$ & 0.81 & 0.27 & $\begin{array}{l}0.01 \\
0.18\end{array}$ & $\begin{array}{l}0.51 \\
1.98\end{array}$ & 0.39 & 0.29 & $\begin{array}{l}0.0030 \\
1.3745\end{array}$ & 0.3628 & 15.0574 & 0.2352 & 0.5924 & 0.3097 & 0.2124 & $\begin{array}{l}0.0050 \\
1.1241\end{array}$ & 0.3655 & 0.3179 \\
\hline 93-187 & 8.85 & 4.79 & 99.31 & 3.87 & 5.51 & 4.08 & 3.61 & 5.52 & 4.09 & 4.49 & 0.0469 & 0.0377 & 0.3309 & 0.0284 & 0.0314 & 0.0277 & 0.0303 & 0.0273 & 0.0269 & 0.0293 \\
\hline $46-93$ & 14.57 & 21.68 & 167.13 & 12.76 & 10.39 & 12.07 & 12.82 & 10.76 & 12.67 & 11.66 & 0.0544 & 0.1175 & 0.4928 & 0.0207 & 0.0416 & 0.0496 & 0.0468 & 0.0367 & 0.0494 & 0.0478 \\
\hline $23-46$ & 11.46 & 27.23 & 165.84 & 8.68 & 9.16 & 9.19 & 8.84 & 7.56 & 8.61 & 9.19 & 0.0278 & 0.1423 & 0.6809 & 0.0190 & 0.0230 & 0.0213 & 0.0208 & 0.0204 & 0.0213 & 0.0214 \\
\hline $12--23$ & 5.34 & 26.34 & 110.63 & 4.87 & 4.07 & 4.67 & 4.93 & 3.45 & 4.46 & 4.65 & 0.0196 & 0.1713 & 2.3906 & 0.0133 & 0.0086 & 0.0099 & 0.0108 & 0.0171 & 0.0132 & 0.0085 \\
\hline $6--12$ & 0.71 & 27.63 & 25.98 & 0.49 & 0.79 & 0.61 & 0.42 & 0.85 & 0.65 & 0.61 & 0.0229 & 0.3331 & 5.3169 & 0.0122 & 0.0179 & 0.0133 & 0.0139 & 0.0165 & 0.0118 & 0.0159 \\
\hline \multicolumn{21}{|l|}{$\mathrm{T}=45$} \\
\hline $375-750$ & 0.65 & 0.02 & 4.65 & 0.01 & 0.09 & 0.02 & 0.01 & 0.62 & 0.02 & 0.02 & 0.008 & 0.001 & 0.050 & 0.001 & 0.002 & 0.001 & 0.000 & 0.008 & 0.001 & 0.001 \\
\hline $187-375$ & 2.63 & 0.30 & 42.19 & 0.20 & 0.85 & 0.28 & 0.18 & 2.25 & 0.33 & 0.28 & 0.468 & 0.089 & 5.122 & 0.059 & 0.214 & 0.090 & 0.050 & 0.385 & 0.102 & 0.085 \\
\hline 93-187 & 9.55 & 4.90 & 119.47 & 3.63 & 5.76 & 4.15 & 3.29 & 6.57 & 4.40 & 4.35 & 0.089 & 0.076 & 1.029 & 0.055 & 0.059 & 0.057 & 0.050 & 0.070 & 0.057 & 0.056 \\
\hline $46-93$ & 19.56 & 26.56 & 170.93 & 16.50 & 14.12 & 15.76 & 16.49 & 11.74 & 15.39 & 15.61 & 0.159 & 0.210 & 1.450 & 0.117 & 0.120 & 0.124 & 0.124 & 0.092 & 0.108 & 0.124 \\
\hline $23-46$ & 11.81 & 38.37 & 131.17 & 10.25 & 9.79 & 10.42 & 10.74 & 8.28 & 10.93 & 10.57 & 0.121 & 0.358 & 3.682 & 0.108 & 0.089 & 0.097 & 0.100 & 0.088 & 0.097 & 0.095 \\
\hline $12--23$ & 4.73 & 54.52 & 95.02 & 3.62 & 3.51 & 3.70 & 3.48 & 4.34 & 3.00 & 3.42 & 0.050 & 0.588 & 8.017 & 0.035 & 0.045 & 0.033 & 0.042 & 0.048 & 0.056 & 0.041 \\
\hline 6--12 & 0.46 & 40.77 & 25.80 & 0.46 & 0.57 & 0.40 & 0.41 & 0.63 & 0.59 & 0.48 & 0.049 & 1.487 & 13.841 & 0.037 & 0.034 & 0.039 & 0.033 & 0.036 & 0.036 & 0.034 \\
\hline
\end{tabular}


Table I.10: Power data for the $10^{\text {th }}$ participant

\begin{tabular}{|c|c|c|c|c|c|c|c|c|c|c|c|c|c|c|c|c|c|c|c|c|}
\hline $\mathrm{T}=0$ & \multicolumn{10}{|c|}{ Upper Trapezius } & \multicolumn{10}{|c|}{ Sternocleidomastoid } \\
\hline $\begin{array}{l}\text { Frequency } \\
\text { Band, Hz } \\
\end{array}$ & Bior1.5 & Bior3.1 & Rbio3.1 & Coif5 & Db2 & Db5 & Db45 & Haar & Sym4 & Sym5 & Bior1.5 & Bior3.1 & Rbio3.1 & Coif5 & Db2 & Db5 & Db45 & Haar & Sym4 & Sym5 \\
\hline $375-750$ & 1.38 & 0.12 & 8.19 & 0.07 & 0.34 & 0.11 & 0.06 & 1.30 & 0.13 & 0.11 & 0.003 & 0.002 & 0.009 & 0.001 & 0.002 & 0.001 & 0.001 & 0.002 & 0.001 & 0.001 \\
\hline 187-375 & 5.18 & 1.65 & 57.12 & 1.23 & 2.43 & 1.41 & 1.20 & 4.22 & 1.52 & 1.40 & 0.008 & 0.007 & 0.032 & 0.005 & 0.005 & 0.005 & 0.005 & 0.006 & 0.006 & 0.006 \\
\hline 93-187 & 14.34 & 13.22 & 137.18 & 9.92 & 9.54 & 10.18 & 9.04 & 10.96 & 10.17 & 9.88 & 0.008 & 0.014 & 0.015 & 0.007 & 0.006 & 0.007 & 0.009 & 0.006 & 0.007 & 0.006 \\
\hline $46-93$ & 22.54 & 38.45 & 189.21 & 16.64 & 16.20 & 15.49 & 18.07 & 15.41 & 17.03 & 15.93 & 0.008 & 0.016 & 0.121 & 0.006 & 0.006 & 0.005 & 0.005 & 0.005 & 0.005 & 0.006 \\
\hline $23-46$ & 14.41 & 37.20 & 149.82 & 12.91 & 11.36 & 13.10 & 12.07 & 7.78 & 11.04 & 12.83 & 0.006 & 0.020 & 0.176 & 0.004 & 0.004 & 0.004 & 0.004 & 0.004 & 0.004 & 0.004 \\
\hline $12--23$ & 1.45 & 52.50 & 36.40 & 1.11 & 1.93 & 1.47 & 1.37 & 1.76 & 1.80 & 1.75 & 0.007 & 0.027 & 0.292 & 0.005 & 0.005 & 0.005 & 0.005 & 0.005 & 0.005 & 0.005 \\
\hline 6--12 & 0.29 & 54.88 & 33.18 & 0.31 & 0.63 & 0.36 & 0.25 & 0.43 & 0.39 & 0.49 & 0.002 & 0.028 & 0.221 & 0.001 & 0.002 & 0.002 & 0.002 & 0.001 & 0.001 & 0.002 \\
\hline \multicolumn{21}{|l|}{$\mathrm{T}=20$} \\
\hline $375-750$ & 1.37 & 0.10 & 8.78 & 0.06 & 0.28 & 0.09 & 0.05 & 1.30 & 0.10 & 0.08 & 0.003 & 0.001 & 0.011 & 0.001 & 0.002 & 0.001 & 0.001 & 0.003 & 0.001 & 0.001 \\
\hline $187-375$ & 5.53 & 1.31 & 68.87 & 1.01 & 2.14 & 1.11 & 0.92 & 4.58 & 1.30 & 1.20 & 0.008 & 0.006 & 0.042 & 0.005 & 0.006 & 0.005 & 0.005 & 0.006 & 0.005 & 0.005 \\
\hline 93-187 & 15.69 & 12.15 & 182.78 & 8.84 & 10.15 & 9.72 & 8.16 & 12.41 & 9.78 & 8.99 & 0.013 & 0.022 & 0.022 & 0.012 & 0.009 & 0.011 & 0.014 & 0.010 & 0.011 & 0.011 \\
\hline $46-93$ & 30.03 & 39.72 & 224.16 & 24.19 & 22.93 & 24.31 & 23.19 & 17.01 & 22.24 & 24.97 & 0.013 & 0.026 & 0.177 & 0.009 & 0.009 & 0.008 & 0.009 & 0.008 & 0.008 & 0.009 \\
\hline $23-46$ & 18.07 & 54.23 & 220.63 & 14.78 & 12.69 & 13.45 & 16.11 & 12.92 & 14.59 & 13.31 & 0.009 & 0.042 & 0.254 & 0.007 & 0.006 & 0.006 & 0.006 & 0.007 & 0.007 & 0.006 \\
\hline $12--23$ & 3.19 & 46.35 & 66.74 & 2.86 & 3.45 & 2.90 & 3.22 & 2.69 & 3.67 & 3.16 & 0.008 & 0.034 & 0.262 & 0.007 & 0.006 & 0.007 & 0.006 & 0.005 & 0.006 & 0.007 \\
\hline 6--12 & 0.95 & 100.20 & 32.96 & 0.69 & 0.75 & 0.83 & 0.70 & 1.23 & 0.73 & 0.72 & 0.002 & 0.033 & 0.143 & 0.002 & 0.002 & 0.002 & 0.003 & 0.002 & 0.002 & 0.002 \\
\hline \multicolumn{21}{|l|}{$\mathrm{T}=25$} \\
\hline $375-750$ & 1.31 & 0.14 & 7.62 & 0.09 & 0.34 & 0.13 & 0.07 & 1.24 & 0.15 & 0.11 & 0.013 & 0.003 & 0.058 & 0.003 & 0.005 & 0.003 & 0.002 & 0.012 & 0.003 & 0.003 \\
\hline $187-375$ & 5.38 & 1.79 & 52.01 & 1.30 & 2.20 & 1.46 & 1.14 & 4.30 & 1.68 & 1.63 & 0.039 & 0.023 & 0.295 & 0.016 & 0.024 & 0.017 & 0.015 & 0.031 & 0.020 & 0.017 \\
\hline 93-187 & 13.42 & 11.97 & 114.18 & 8.95 & 9.34 & 9.19 & 8.41 & 9.55 & 9.17 & 9.16 & 0.084 & 0.099 & 0.161 & 0.073 & 0.063 & 0.071 & 0.085 & 0.067 & 0.070 & 0.069 \\
\hline $46-93$ & 19.22 & 31.25 & 145.85 & 16.20 & 14.72 & 15.89 & 16.37 & 11.83 & 15.09 & 15.70 & 0.096 & 0.203 & 0.672 & 0.074 & 0.071 & 0.073 & 0.080 & 0.061 & 0.072 & 0.074 \\
\hline $23-46$ & 11.32 & 46.94 & 127.21 & 9.18 & 8.39 & 8.75 & 9.41 & 8.03 & 9.08 & 8.70 & 0.039 & 0.217 & 0.434 & 0.037 & 0.034 & 0.036 & 0.032 & 0.025 & 0.034 & 0.036 \\
\hline 12--23 & 1.63 & 42.66 & 62.99 & 1.17 & 2.09 & 1.40 & 1.51 & 1.63 & 1.71 & 1.73 & 0.010 & 0.271 & 0.278 & 0.008 & 0.010 & 0.008 & 0.008 & 0.011 & 0.009 & 0.009 \\
\hline 6--12 & 0.22 & 79.43 & 74.36 & 0.22 & 0.69 & 0.32 & 0.16 & 0.50 & 0.39 & 0.46 & 0.003 & 0.307 & 0.147 & 0.002 & 0.002 & 0.002 & 0.002 & 0.003 & 0.002 & 0.003 \\
\hline \multicolumn{21}{|l|}{$\mathrm{T}=45$} \\
\hline $375-750$ & 1.23 & 0.09 & 8.01 & 0.05 & 0.24 & 0.08 & 0.03 & 1.18 & 0.09 & 0.07 & 0.055 & 0.010 & 0.268 & 0.007 & 0.020 & 0.009 & 0.007 & 0.051 & 0.010 & 0.010 \\
\hline 187-375 & 4.90 & 1.06 & 66.92 & 0.86 & 1.95 & 1.09 & 0.87 & 4.10 & 1.00 & 1.00 & 0.187 & 0.094 & 1.460 & 0.068 & 0.097 & 0.070 & 0.058 & 0.149 & 0.085 & 0.077 \\
\hline 93-187 & 14.31 & 9.19 & 183.77 & 7.42 & 8.66 & 8.19 & 6.01 & 11.59 & 8.72 & 8.02 & 0.444 & 0.413 & 0.777 & 0.330 & 0.336 & 0.325 & 0.362 & 0.283 & 0.307 & 0.330 \\
\hline $46-93$ & 31.47 & 46.46 & 244.66 & 24.59 & 23.73 & 24.49 & 25.16 & 17.65 & 22.91 & 24.80 & 0.467 & 0.974 & 3.071 & 0.397 & 0.356 & 0.406 & 0.400 & 0.312 & 0.384 & 0.390 \\
\hline $23-46$ & 19.80 & 61.69 & 231.43 & 16.58 & 14.43 & 15.63 & 17.15 & 13.84 & 16.21 & 15.26 & 0.189 & 0.882 & 2.522 & 0.165 & 0.141 & 0.152 & 0.163 & 0.156 & 0.171 & 0.151 \\
\hline $12--23$ & 3.79 & 46.59 & 72.77 & 3.42 & 3.74 & 3.31 & 3.67 & 3.66 & 4.01 & 3.79 & 0.045 & 0.942 & 0.947 & 0.035 & 0.046 & 0.041 & 0.044 & 0.042 & 0.039 & 0.042 \\
\hline 6--12 & 0.94 & 49.69 & 34.56 & 0.61 & 0.73 & 0.74 & 0.57 & 1.35 & 0.60 & 0.59 & 0.007 & 1.298 & 0.365 & 0.009 & 0.010 & 0.006 & 0.004 & 0.011 & 0.010 & 0.007 \\
\hline
\end{tabular}




\section{Appendix J: Mean ( \pm standard deviation) of power (in $\mathbf{m V}^{2}$ ) calculated using ten wavelet for right upper trapezius muscle}

Table J.1: Power estimated using Bior1.5 wavelet function as an effect of time for right upper trapezius muscle

\begin{tabular}{lllll}
\hline $\begin{array}{l}\text { Frequency } \\
\text { Band, Hz }\end{array}$ & $\mathrm{T}=0$ & $\mathrm{~T}=20$ & $\mathrm{~T}=25$ & $\mathrm{~T}=45$ \\
\hline $375-750$ & $1.84(1.03)$ & $1.88(1.25)$ & $2.12(2.04)$ & $2.21(2.12)$ \\
$187-375$ & $7.34(4.11)$ & $7.61(4.98)$ & $8.32(7.85)$ & $8.89(8.50)$ \\
$93-187$ & $23.03(12.99)$ & $25.05(15.86)$ & $25.95(22.21)$ & $27.91(23.15)$ \\
$46-93$ & $42.31(23.30)$ & $47.21(27.69)$ & $44.98(35.49)$ & $52.22(34.61)$ \\
$23-46$ & $26.68(16.96)$ & $33.49(23.11)$ & $25.14(17.44)$ & $31.89(20.57)$ \\
$12-23$ & $7.95(6.98)$ & $11.77(10.98)$ & $7.51(4.99)$ & $11.74(9.73)$ \\
$6-12$ & $1.30(1.80)$ & $2.15(2.11)$ & $1.18(1.17)$ & $2.21(2.10)$ \\
\hline
\end{tabular}

Table J.2: Power estimated using Bior3.1 wavelet function as an effect of time for right upper trapezius muscle

\begin{tabular}{lllll}
\hline $\begin{array}{l}\text { Frequency } \\
\text { Band, Hz }\end{array}$ & $\mathrm{T}=0$ & $\mathrm{~T}=20$ & $\mathrm{~T}=25$ & $\mathrm{~T}=45$ \\
\hline $375-750$ & $0.09(0.06)$ & $0.07(0.07)$ & $0.10(0.10)$ & $0.09(0.11)$ \\
$187-375$ & $1.45(0.99)$ & $1.37(1.41)$ & $1.79(2.16)$ & $1.61(2.20)$ \\
$93-187$ & $16.12(9.46)$ & $15.52(11.67)$ & $19.93(23.39)$ & $19.53(22.49)$ \\
$46-93$ & $62.39(34.80)$ & $68.36(41.41)$ & $68.32(55.37)$ & $78.03(62.26)$ \\
$23-46$ & $77.15(44.45)$ & $93.35(60.31)$ & $85.32(59.12)$ & $94.77(61.18)$ \\
$12-23$ & $80.25(43.66)$ & $117.69(69.70)$ & $92.20(62.19)$ & $129.43(75.67)$ \\
$6-12$ & $86.14(45.37)$ & $128.53(74.33)$ & $96.48(63.14)$ & $132.95(80.45)$ \\
\hline
\end{tabular}

Table J.3: Power estimated using Rbio3.1 wavelet function as an effect of time for right upper trapezius muscle

\begin{tabular}{lllll}
\hline $\begin{array}{l}\text { Frequency } \\
\text { Band, Hz }\end{array}$ & $\mathrm{T}=0$ & $\mathrm{~T}=20$ & $\mathrm{~T}=25$ & $\mathrm{~T}=45$ \\
\hline $375-750$ & $12.12(6.69)$ & $12.77(8.04)$ & $13.74(12.61)$ & $14.78(13.11)$ \\
$187-375$ & $96.47(52.79)$ & $107.20(63.36)$ & $105.82(84.45)$ & $118.74(87.40)$ \\
$93-187$ & $256.23(144.80)$ & $303.95(181.63)$ & $269.41(187.50)$ & $317.01(198.36)$ \\
$46-93$ & $375.45(220.45)$ & $472.61(312.32)$ & $376.52(247.34)$ & $473.16(296.31)$ \\
$23-46$ & $380.26(291.75)$ & $529.82(356.02)$ & $309.28(214.45)$ & $509.69(322.64)$ \\
$12-23$ & $167.36(152.09)$ & $268.96(213.40)$ & $156.65(107.41)$ & $287.09(220.64)$ \\
$6-12$ & $66.06(57.43)$ & $85.19(66.20)$ & $56.12(34.39)$ & $109.72(85.92)$ \\
\hline
\end{tabular}


Table J.4: Power estimated using Coif5 wavelet function as an effect of time for right upper trapezius muscle

\begin{tabular}{lllll}
\hline $\begin{array}{l}\text { Frequency } \\
\text { Band, Hz }\end{array}$ & $\mathrm{T}=0$ & $\mathrm{~T}=20$ & $\mathrm{~T}=25$ & $\mathrm{~T}=45$ \\
\hline $375-750$ & $0.05(0.04)$ & $0.04(0.04)$ & $0.05(0.05)$ & $0.04(0.05)$ \\
$187-375$ & $1.06(0.77)$ & $1.00(1.11)$ & $1.27(1.56)$ & $1.17(1.67)$ \\
$93-187$ & $12.51(7.36)$ & $11.58(7.87)$ & $14.01(14.96)$ & $14.77(17.15)$ \\
$46-93$ & $33.30(19.00)$ & $38.41(22.42)$ & $37.20(27.79)$ & $41.85(28.48)$ \\
$23-46$ & $22.26(13.32)$ & $27.70(19.84)$ & $21.58(15.50)$ & $26.49(16.62)$ \\
$12-23$ & $6.80(6.52)$ & $10.52(10.06)$ & $6.31(4.63)$ & $10.04(8.73)$ \\
$6-12$ & $1.27(1.60)$ & $1.48(1.38)$ & $0.78(0.57)$ & $1.69(1.68)$ \\
\hline
\end{tabular}

Table J.5: Power estimated using Db2 wavelet function as an effect of time for right upper trapezius muscle

\begin{tabular}{lllll}
\hline $\begin{array}{l}\text { Frequency } \\
\text { Band, Hz }\end{array}$ & $\mathrm{T}=0$ & $\mathrm{~T}=20$ & $\mathrm{~T}=25$ & $\mathrm{~T}=45$ \\
\hline $375-750$ & $0.33(0.21)$ & $0.31(0.26)$ & $0.40(0.44)$ & $0.38(0.45)$ \\
$187-375$ & $2.84(1.70)$ & $2.75(2.10)$ & $3.42(3.83)$ & $3.48(4.00)$ \\
$93-187$ & $14.54(8.39)$ & $15.38(10.05)$ & $16.66(15.11)$ & $17.49(15.81)$ \\
$46-93$ & $30.80(17.02)$ & $33.82(20.01)$ & $32.79(25.68)$ & $37.08(25.05)$ \\
$23-46$ & $19.65(11.65)$ & $25.52(17.00)$ & $19.73(13.14)$ & $25.88(16.52)$ \\
$12-23$ & $7.53(6.53)$ & $10.56(9.60)$ & $6.87(4.55)$ & $9.38(7.13)$ \\
$6-12$ & $1.65(1.77)$ & $2.31(2.18)$ & $1.48(1.39)$ & $2.31(2.35)$ \\
\hline
\end{tabular}

Table J.6: Power estimated using Db5 wavelet function as an effect of time for right upper trapezius muscle

\begin{tabular}{lllll}
\hline $\begin{array}{l}\text { Frequency } \\
\text { Band, Hz }\end{array}$ & $\mathrm{T}=0$ & $\mathrm{~T}=20$ & $\mathrm{~T}=25$ & $\mathrm{~T}=45$ \\
\hline $375-750$ & $0.07(0.06)$ & $0.06(0.06)$ & $0.08(0.09)$ & $0.08(0.09)$ \\
$187-375$ & $1.35(0.97)$ & $1.27(1.31)$ & $1.68(2.10)$ & $1.64(2.28)$ \\
$93-187$ & $13.34(7.57)$ & $12.57(8.28)$ & $15.11(16.10)$ & $15.98(17.65)$ \\
$46-93$ & $32.74(18.61)$ & $36.91(21.97)$ & $35.57(26.38)$ & $39.27(25.70)$ \\
$23-46$ & $21.01(12.55)$ & $27.46(19.13)$ & $21.20(14.86)$ & $27.16(17.22)$ \\
$12-23$ & $7.47(6.83)$ & $10.58(9.99)$ & $6.58(4.49)$ & $10.07(8.55)$ \\
$6-12$ & $1.20(1.53)$ & $1.88(1.83)$ & $1.06(1.16)$ & $1.84(1.83)$ \\
\hline
\end{tabular}

Table J.7: Power estimated using Db45 wavelet function as an effect of time for right upper trapezius muscle

\begin{tabular}{lllll}
\hline $\begin{array}{l}\text { Frequency } \\
\text { Band, Hz }\end{array}$ & $\mathrm{T}=0$ & $\mathrm{~T}=20$ & $\mathrm{~T}=25$ & $\mathrm{~T}=45$ \\
\hline $375-750$ & $0.04(0.03)$ & $0.03(0.03)$ & $0.04(0.04)$ & $0.03(0.03)$ \\
$187-375$ & $0.89(0.67)$ & $0.86(0.95)$ & $1.09(1.36)$ & $1.03(1.47)$ \\
$93-187$ & $11.50(7.00)$ & $10.93(8.05)$ & $13.18(14.58)$ & $13.66(16.45)$ \\
$46-93$ & $34.23(19.38)$ & $39.39(23.21)$ & $38.46(29.34)$ & $43.57(28.56)$ \\
$23-46$ & $22.29(14.12)$ & $27.80(21.11)$ & $21.39(15.47)$ & $26.51(18.20)$ \\
$12-23$ & $7.39(7.48)$ & $10.26(9.89)$ & $6.20(4.46)$ & $9.39(9.05)$ \\
$6-12$ & $0.77(0.76)$ & $1.30(1.17)$ & $0.74(0.69)$ & $1.68(1.91)$ \\
\hline
\end{tabular}


Table J.8: Power estimated using Haar wavelet function as an effect of time for right upper trapezius muscle

\begin{tabular}{lllll}
\hline $\begin{array}{l}\text { Frequency } \\
\text { Band, Hz }\end{array}$ & $\mathrm{T}=0$ & $\mathrm{~T}=20$ & $\mathrm{~T}=25$ & $\mathrm{~T}=45$ \\
\hline $375-750$ & $1.75(0.98)$ & $1.80(1.19)$ & $2.01(1.93)$ & $2.11(2.00)$ \\
$187-375$ & $6.13(3.41)$ & $6.42(4.12)$ & $6.92(6.41)$ & $7.44(6.90)$ \\
$93-187$ & $16.75(9.03)$ & $17.59(10.45)$ & $18.86(17.33)$ & $20.76(17.62)$ \\
$46-93$ & $25.75(14.26)$ & $30.70(18.00)$ & $27.94(19.97)$ & $32.73(20.81)$ \\
$23-46$ & $18.77(11.75)$ & $22.37(15.58)$ & $17.45(11.46)$ & $20.78(12.65)$ \\
$12-23$ & $6.06(4.44)$ & $8.76(7.54)$ & $6.10(3.93)$ & $9.21(6.82)$ \\
$6-12$ & $1.69(1.86)$ & $2.63(2.42)$ & $1.63(1.50)$ & $2.68(2.16)$ \\
\hline
\end{tabular}

Table J.9: Power estimated using Sym4 wavelet function as an effect of time for right upper trapezius muscle

\begin{tabular}{lllll}
\hline $\begin{array}{l}\text { Frequency } \\
\text { Band, Hz }\end{array}$ & $\mathrm{T}=0$ & $\mathrm{~T}=20$ & $\mathrm{~T}=25$ & $\mathrm{~T}=45$ \\
\hline $375-750$ & $0.10(0.07)$ & $0.08(0.08)$ & $0.11(0.12)$ & $0.10(0.13)$ \\
$187-375$ & $1.57(1.04)$ & $1.50(1.46)$ & $1.90(2.26)$ & $1.76(2.37)$ \\
$93-187$ & $13.57(7.62)$ & $12.99(8.46)$ & $15.52(16.57)$ & $16.55(17.87)$ \\
$46-93$ & $31.35(17.75)$ & $37.22(21.70)$ & $35.15(25.23)$ & $40.15(26.79)$ \\
$23-46$ & $21.97(12.95)$ & $27.06(19.73)$ & $21.36(14.55)$ & $26.12(16.32)$ \\
$12-23$ & $7.01(6.03)$ & $10.18(8.65)$ & $6.22(4.49)$ & $9.19(8.17)$ \\
$6-12$ & $1.65(2.10)$ & $1.70(1.79)$ & $1.00(0.67)$ & $2.13(2.32)$ \\
\hline
\end{tabular}

Table J.10: Power estimated using Sym5 wavelet function as an effect of time for right upper trapezius muscle

\begin{tabular}{lllll}
\hline $\begin{array}{l}\text { Frequency } \\
\text { Band, Hz }\end{array}$ & $\mathrm{T}=0$ & $\mathrm{~T}=20$ & $\mathrm{~T}=25$ & $\mathrm{~T}=45$ \\
\hline $375-750$ & $0.08(0.06)$ & $0.06(0.06)$ & $0.09(0.09)$ & $0.07(0.09)$ \\
$187-375$ & $1.39(0.97)$ & $1.32(1.36)$ & $1.65(1.97)$ & $1.58(2.20)$ \\
$93-187$ & $13.30(7.85)$ & $12.65(8.41)$ & $14.87(14.70)$ & $15.64(16.73)$ \\
$46-93$ & $32.76(18.55)$ & $36.80(21.82)$ & $35.89(27.92)$ & $39.72(26.66)$ \\
$23-46$ & $20.88(12.29)$ & $27.43(19.13)$ & $21.14(14.55)$ & $27.47(17.74)$ \\
$12-23$ & $7.72(7.19)$ & $10.66(10.06)$ & $6.64(4.70)$ & $9.61(8.13)$ \\
$6-12$ & $1.25(1.39)$ & $1.81(1.64)$ & $1.11(1.13)$ & $1.93(2.04)$ \\
\hline
\end{tabular}




\title{
Appendix K: Output of Turkey's test of multiple comparisons for right upper trapezius muscle
}

\author{
Frequency Band 23-46 Hz
}

\section{Bior1.5}

$\begin{array}{lrrrr} & \text { Num } & \text { Den } & & \\ \text { Effect } & \text { DF } & \text { DF } & \text { F Value } & \text { Pr > F } \\ \text { time } & 3 & 27 & 2.92 & 0.0522\end{array}$

Least Squares Means

\begin{tabular}{llrrrrrrrr} 
& \multicolumn{9}{c}{ Standard } \\
Effect & time & Estimate & Error & DF & t Value & Pr $>|t|$ & Alpha & Lower & Upper \\
time & 1 & 26676846 & 6223645 & 27 & 4.29 & 0.0002 & 0.05 & 13906982 & 39446710 \\
time & 2 & 33491320 & 6223645 & 27 & 5.38 & $<.0001$ & 0.05 & 20721456 & 46261184 \\
time & 3 & 25140507 & 6223645 & 27 & 4.04 & 0.0004 & 0.05 & 12370643 & 37910370 \\
time & 4 & 31886860 & 6223645 & 27 & 5.12 & $<.0001$ & 0.05 & 19116996 & 44656724
\end{tabular}

Differences of Least Squares Means

$\begin{array}{lllrrrrrrrr}\text { Effect } & \text { time } & \text { _time } & \text { Estimate } & \begin{array}{r}\text { Standard } \\ \text { Error }\end{array} & \text { DF } & \text { t Value } & \text { Pr }>|t| & \text { Adjustment } & \text { Adj P } & \text { Alpha } \\ \text { time } & 1 & 2 & -6814474 & 3326674 & 27 & -2.02 & 0.0554 & \text { Tukey-Kramer } & 0.1958 & 0.05 \\ \text { time } & 1 & 3 & 1536339 & 3326674 & 27 & 0.46 & 0.6479 & \text { Tukey-Kramer } & 0.9667 & 0.05 \\ \text { time } & 1 & 4 & -5210014 & 3326674 & 27 & -1.57 & 0.1290 & \text { Tukey-Kramer } & 0.4141 & 0.05 \\ \text { time } & 2 & 3 & 8350814 & 3326674 & 27 & 2.51 & 0.0184 & \text { Tukey-Kramer } & 0.0809 & 0.05 \\ \text { time } & 2 & 4 & 1604461 & 3326674 & 27 & 0.48 & 0.6335 & \text { Tukey-Kramer } & 0.9624 & 0.05 \\ \text { time } & 3 & 4 & -6746353 & 3326674 & 27 & -2.07 & 0.0501 & \text { Tukey-Kramer } & 0.2029 & 0.05\end{array}$

\section{Bior3.1}

$\begin{array}{lccrl} & \text { Num } & \text { Den } & & \\ \text { Effect } & \text { DF } & \text { DF } & \text { F Value } & \text { Pr > F } \\ \text { time } & 3 & 27 & 0.97 & 0.4202\end{array}$

Least Squares Means

$\begin{array}{llrrrrrrrr}\text { Effect } & \text { time } & \text { Estimate } & \begin{array}{r}\text { Standard } \\ \text { Error }\end{array} & \text { DF } & \mathrm{t} \text { Value } & \mathrm{Pr}>|\mathrm{t}| & \text { Alpha } & \text { Lower } & \text { Upper } \\ \text { time } & 1 & 77147082 & 17924515 & 27 & 4.30 & 0.0002 & 0.05 & 40369015 & 1.1393 \mathrm{E} 8 \\ \text { time } & 2 & 93350478 & 17924515 & 27 & 5.21 & <.0001 & 0.05 & 56572411 & 1.3013 \mathrm{E} 8 \\ \text { time } & 3 & 85316979 & 17924515 & 27 & 4.76 & <.0001 & 0.05 & 48538912 & 1.221 \mathrm{E8} \\ \text { time } & 4 & 94767983 & 17924515 & 27 & 5.29 & <.0001 & 0.05 & 57989916 & 1.3155 \mathrm{E} 8\end{array}$

Differences of Least Squares Means

$\begin{array}{lllrrrrrrrr}\text { Effect } & \text { time } & \text { time } & \text { Estimate } & \begin{array}{r}\text { Standard } \\ \text { Error }\end{array} & \text { DF } & \text { t Value } & \operatorname{Pr}>|\mathrm{t}| & \text { Adjustment } & \text { Adj P } & \text { Alpha } \\ \text { time } & 1 & 2 & -1.62 \mathrm{E} 7 & 11678357 & 27 & -1.39 & 0.1766 & \text { Tukey-Kramer } & 0.5177 & 0.05 \\ \text { time } & 1 & 3 & -8169897 & 11678357 & 27 & -0.70 & 0.4902 & \text { Tukey-Kramer } & 0.8963 & 0.05 \\ \text { time } & 1 & 4 & -1.762 \mathrm{E} 7 & 11678357 & 27 & -1.51 & 0.1430 & \text { Tukey-Kramer } & 0.4463 & 0.05 \\ \text { time } & 2 & 3 & 8033499 & 11678357 & 27 & 0.69 & 0.4974 & \text { Tukey-Kramer } & 0.9008 & 0.05 \\ \text { time } & 2 & 4 & -1417505 & 11678357 & 27 & -0.12 & 0.9043 & \text { Tukey-Kramer } & 0.9993 & 0.05 \\ \text { time } & 3 & 4 & -9451004 & 11678357 & 27 & -0.81 & 0.4254 & \text { Tukey-Kramer } & 0.8495 & 0.05\end{array}$




\section{Rbio 3.1}

$\begin{array}{lrrrl} & \text { Num } & \text { Den } & & \\ \text { Effect } & \text { DF } & \text { DF } & \text { F Value } & \text { Pr }>F \\ \text { time } & 3 & 27 & 3.49 & 0.0293\end{array}$

Least Squares Means

\begin{tabular}{|c|c|c|c|c|c|c|c|c|c|}
\hline Effect & time & Estimate & $\begin{array}{r}\text { Standard } \\
\text { Error }\end{array}$ & DF & t value & $P r>|t|$ & Alpha & Lower & Upper \\
\hline ime & 1 & $3.8026 \mathrm{E} 8$ & 95125355 & 27 & 4.00 & 0.0004 & 0.05 & 1.8507E8 & $5.7544 \mathrm{E} 8$ \\
\hline & 2 & $5.6071 \mathrm{E} 8$ & 95125355 & 27 & 4.84 & $<.0001$ & 0.05 & $2.6553 \mathrm{E} 8$ & $6.5589 \mathrm{E} 8$ \\
\hline & 3 & $3.0928 \mathrm{E} 8$ & 95125355 & 27 & 3.25 & 0.0031 & 0.05 & $1.141 \mathrm{E} 8$ & $5.0447 \mathrm{E} 8$ \\
\hline me & 4 & $5.2843 \mathrm{E} 8$ & 95125355 & 27 & 4.50 & 0.0001 & 0.05 & $2.3325 \mathrm{E} 8$ & $6.2361 \mathrm{E} 8$ \\
\hline
\end{tabular}

Differences of Least Squares Means

\begin{tabular}{|c|c|c|c|c|c|c|c|c|c|c|}
\hline & & & & Standard & & & & & & \\
\hline & time & time & Estimate & Error & DF & t Value & $\operatorname{Pr}>|t|$ & Adjustment & Adj $P$ & Alpha \\
\hline $\mathrm{me}$ & 1 & 2 & $-10.046 \mathrm{E} 7$ & 49851385 & 27 & -2.31 & 0.0312 & Tukey-Kramer & 0.3880 & 0.05 \\
\hline me & 1 & 3 & 70970889 & 49851385 & 27 & 1.42 & 0.1660 & Tukey-Kramer & 0.4961 & 0.05 \\
\hline & 1 & 4 & $-4.817 \mathrm{E} 7$ & 49851385 & 27 & -2.27 & 0.03425 & Tukey-Kramer & 0.7694 & 0.05 \\
\hline & 2 & 3 & $1.5143 \mathrm{E} 8$ & 49851385 & 27 & 3.04 & 0.0052 & Tukey-Kramer & 0.0254 & 0.05 \\
\hline & 2 & 4 & 32286074 & 49851385 & 27 & 0.65 & 0.5227 & Tukey-Kramer & 0.9154 & 0.05 \\
\hline & 3 & 4 & $-1.191 \mathrm{E} 8$ & 49851385 & 27 & -2.39 & 0.0241 & Tukey-Kramer & 0.1032 & 0.05 \\
\hline
\end{tabular}

\section{Coif5}

$\begin{array}{lrrrr} & \text { Num } & \text { Den } & & \\ \text { Effect } & \text { DF } & \text { DF } & \text { F Value } & \text { Pr }>F \\ \text { time } & 3 & 27 & 2.09 & 0.1255\end{array}$

Least Squares Means

\begin{tabular}{|c|c|c|c|c|c|c|c|c|c|}
\hline Effect & time & Estimate & $\begin{array}{r}\text { Standard } \\
\text { Error }\end{array}$ & DF & t Value & $P r>|t|$ & Alpha & Lower & Upper \\
\hline time & 1 & 22259676 & 5214299 & 27 & 4.27 & 0.0002 & 0.05 & 11560818 & 32958534 \\
\hline ime & 2 & 27703763 & 5214299 & 27 & 5.31 & $<.0001$ & 0.05 & 17004905 & 38402620 \\
\hline me & 3 & 21577214 & 5214299 & 27 & 4.14 & 0.0003 & 0.05 & 10878357 & 32276072 \\
\hline me & 4 & 26490861 & 5214299 & 27 & 5.08 & $<.0001$ & 0.05 & 15792003 & 37189719 \\
\hline
\end{tabular}

Differences of Least Squares Means

$\begin{array}{lllrrrrrrrr}\text { Effect } & \text { time } & \text { time } & \text { Estimate } & \begin{array}{r}\text { Standard } \\ \text { Error }\end{array} & \text { DF } & \text { t Value } & \text { Pr }>|t| & \text { Adjustment } & \text { Adj P } & \text { Alpha } \\ \text { time } & 1 & 2 & -5444087 & 2979929 & 27 & -1.83 & 0.0788 & \text { Tukey-Kramer } & 0.2831 & 0.05 \\ \text { time } & 1 & 3 & 682462 & 2979929 & 27 & 0.23 & 0.8206 & \text { Tukey-Kramer } & 0.9957 & 0.05 \\ \text { time } & 1 & 4 & -4231185 & 2979929 & 27 & -1.42 & 0.1671 & \text { Tukey-Kramer } & 0.4983 & 0.05 \\ \text { time } & 2 & 3 & 6126549 & 2979929 & 27 & 2.06 & 0.0496 & \text { Tukey-Kramer } & 0.1932 & 0.05 \\ \text { time } & 2 & 4 & 1212902 & 2979929 & 27 & 0.41 & 0.6872 & \text { Tukey-Kramer } & 0.9768 & 0.05 \\ \text { time } & 3 & 4 & -4913647 & 2979929 & 27 & -1.65 & 0.1108 & \text { Tukey-Kramer } & 0.3695 & 0.05\end{array}$




\section{Db2}

$\begin{array}{lrrrl} & \text { Num } & \text { Den } & & \\ \text { Effect } & \text { DF } & \text { DF } & \text { F Value } & \text { Pr > F } \\ \text { time } & 3 & 27 & 3.28 & 0.0362\end{array}$

Least Squares Means

\begin{tabular}{|c|c|c|c|c|c|c|c|c|c|}
\hline Effect & time & Estimate & $\begin{array}{r}\text { Standard } \\
\text { Error }\end{array}$ & DF & t Value & $\mathrm{Pr}>|\mathrm{t}|$ & Alpha & Lower & Upper \\
\hline time & 1 & 19653271 & 4665005 & 27 & 4.21 & 0.0003 & 0.05 & 10081471 & 29225071 \\
\hline time & 2 & 25515854 & 4665005 & 27 & 5.47 & $<.0001$ & 0.05 & 15944054 & 35087654 \\
\hline time & 3 & 19734624 & 4665005 & 27 & 4.23 & 0.0002 & 0.05 & 10162825 & 2930642 \\
\hline time & 4 & 25877223 & 4665005 & 27 & 5.55 & $<.0001$ & 0.05 & 16305423 & 35449023 \\
\hline
\end{tabular}

Differences of Least Squares Means

\begin{tabular}{|c|c|c|c|c|c|c|c|c|c|c|}
\hline & & & & Standard & & & & & & Alpha \\
\hline $\begin{array}{l}\text { Effect } \\
\text { time }\end{array}$ & $\begin{array}{l}\text { time } \\
1\end{array}$ & $\frac{1}{2}^{\text {time }}$ & $\begin{array}{l}\text { Estimate } \\
-5862583\end{array}$ & $\begin{array}{r}\text { Error } \\
2710414\end{array}$ & $\begin{array}{l}\mathrm{DF} \\
27\end{array}$ & $\begin{array}{r}\text { t Value } \\
-2.16\end{array}$ & $\begin{array}{r}\operatorname{Pr}>|t| \\
0.0396\end{array}$ & $\begin{array}{l}\text { Adjustment } \\
\text { Tukey-Kramer }\end{array}$ & $\begin{array}{r}\text { Adj P } \\
0.1594\end{array}$ & $\begin{array}{r}\text { Alpha } \\
0.05\end{array}$ \\
\hline time & 1 & 3 & -81354 & 2710414 & 27 & -0.03 & 0.9763 & Tukey-Kramer & 1.0000 & 0.05 \\
\hline time & 1 & 4 & -6223952 & 2710414 & 27 & -2.30 & 0.0296 & Tukey-Kramer & 0.1240 & 0.05 \\
\hline time & 2 & 3 & 5781230 & 2710414 & 27 & 2.13 & 0.0422 & Tukey-Kramer & 0.1684 & 0.05 \\
\hline time & 2 & 4 & -361369 & 2710414 & 27 & -0.13 & 0.8949 & Tukey-Kramer & 0.9991 & 0.05 \\
\hline time & 3 & 4 & -6142599 & 2710414 & 27 & -2.27 & 0.0317 & Tukey-Kramer & 0.1313 & 0.05 \\
\hline
\end{tabular}

\section{Db5}

$\begin{array}{lrrrr} & \text { Num } & \text { Den } & & \\ \text { Effect } & \text { DF } & \text { DF } & F \text { Value } & \text { Pr }>F \\ \text { time } & 3 & 27 & 2.91 & 0.0527\end{array}$

Least Squares Means

\begin{tabular}{|c|c|c|c|c|c|c|c|c|c|}
\hline & & & Standard & & & & & & \\
\hline Effec & time & Estimate & Error & DF & t Value & $\operatorname{Pr}>|\mathrm{t}|$ & Alpha & Lower & Upper \\
\hline time & 1 & 21014020 & 5100290 & 27 & 4.12 & 0.0003 & 0.05 & 10549090 & 31478951 \\
\hline time & 2 & 27458845 & 5100290 & 27 & 5.38 & $<.0001$ & 0.05 & 16993915 & 37923776 \\
\hline time & 3 & 21196556 & 5100290 & 27 & 4.16 & 0.0003 & 0.05 & 10731625 & 31661486 \\
\hline ime & 4 & 27163292 & 5100290 & 27 & 5.33 & $<.0001$ & 0.05 & 16698361 & 37628222 \\
\hline
\end{tabular}

Differences of Least Squares Means

$\begin{array}{lllrrrrrrrr}\text { Effect } & \text { time } & \text { time } & \text { Estimate } & \begin{array}{r}\text { Standard } \\ \text { Error }\end{array} & \text { DF } & \text { t Value } & \text { Pr }>|t| & \text { Adjustment } & \text { Adj P } & \text { Alpha } \\ \text { time } & 1 & 2 & -6444825 & 2973204 & 27 & -2.17 & 0.0392 & \text { Tukey-Kramer } & 0.1580 & 0.05 \\ \text { time } & 1 & 3 & -182535 & 2973204 & 27 & -0.06 & 0.9515 & \text { Tukey-Kramer } & 0.9999 & 0.05 \\ \text { time } & 1 & 4 & -6149271 & 2973204 & 27 & -2.07 & 0.0483 & \text { Tukey-Kramer } & 0.1891 & 0.05 \\ \text { time } & 2 & 3 & 6262290 & 2973204 & 27 & 2.11 & 0.0446 & \text { Tukey-Kramer } & 0.1767 & 0.05 \\ \text { time } & 2 & 4 & 295554 & 2973204 & 27 & 0.10 & 0.9216 & \text { Tukey-Kramer } & 0.9996 & 0.05 \\ \text { time } & 3 & 4 & -5966736 & 2973204 & 27 & -2.21 & 0.0449 & \text { Tukey-Kramer } & 0.2105 & 0.05\end{array}$




\section{Db45}

$\begin{array}{lrrrl} & \text { Num } & \text { Den } & & \\ \text { Effect } & \text { DF } & \text { DF } & \text { F Value } & \text { Pr > F } \\ \text { time } & 3 & 27 & 2.09 & 0.1252\end{array}$

Least Squares Means

\begin{tabular}{llrrrrrrrr} 
& \multicolumn{9}{c}{ Standard } \\
Effect & time & Estimate & Error & DF & t Value & Pr $>|t|$ & Alpha & Lower & Upper \\
time & 1 & 22286431 & 5512882 & 27 & 4.04 & 0.0004 & 0.05 & 10974933 & 33597930 \\
time & 2 & 27804484 & 5512882 & 27 & 5.04 & $<.0001$ & 0.05 & 16492985 & 39115982 \\
time & 3 & 21387769 & 5512882 & 27 & 3.88 & 0.0006 & 0.05 & 10076270 & 32699267 \\
time & 4 & 26505487 & 5512882 & 27 & 4.81 & $<.0001$ & 0.05 & 15193988 & 37816985
\end{tabular}

Differences of Least Squares Means

\begin{tabular}{|c|c|c|c|c|c|c|c|c|c|c|}
\hline Effect & time & _time & Estimate & $\begin{array}{r}\text { Standard } \\
\text { Error }\end{array}$ & DF & t Value & $\operatorname{Pr}>|t|$ & Adjustment & Adj $\mathrm{P}$ & Alpha \\
\hline time & 1 & $\overline{2}$ & -5518053 & 3070013 & 27 & -1.80 & 0.0835 & Tukey-Kramer & 0.2965 & 0.05 \\
\hline time & 1 & 3 & 898662 & 3070013 & 27 & 0.29 & 0.7720 & Tukey-Kramer & 0.9911 & 0.05 \\
\hline time & 1 & 4 & -4219055 & 3070013 & 27 & -1.37 & 0.1807 & Tukey-Kramer & 0.5257 & 0.05 \\
\hline time & 2 & 3 & 6416715 & 3070013 & 27 & 2.09 & 0.0462 & Tukey-Kramer & 0.1819 & 0.05 \\
\hline time & 2 & 4 & 1298997 & 3070013 & 27 & 0.42 & 0.6756 & Tukey-Kramer & 0.9740 & 0.05 \\
\hline time & 3 & 4 & -5117718 & 3070013 & 27 & -1.67 & 0.1071 & Tukey-Kramer & 0.3601 & 0.05 \\
\hline
\end{tabular}

\section{Haar}

$\begin{array}{lrrrr}\text { Effect } & \text { DF } & \text { DF } & \text { F Value } & \text { Pr > F } \\ \text { time } & 3 & 27 & 1.71 & 0.1887\end{array}$

Least Squares Means

\begin{tabular}{|c|c|c|c|c|c|c|c|c|c|}
\hline Effec & time & Estimate & $\begin{array}{r}\text { Standard } \\
\text { Error }\end{array}$ & DF & t Value & $P r>|t|$ & Alpha & Lower & Upper \\
\hline time & 1 & 18769674 & 4098994 & 27 & 4.58 & $<.0001$ & 0.05 & 10359233 & 27180115 \\
\hline time & 2 & 22373077 & 4098994 & 27 & 5.46 & $<.0001$ & 0.05 & 13962636 & 30783518 \\
\hline ime & 3 & 17453098 & 4098994 & 27 & 4.26 & 0.0002 & 0.05 & 9042656 & 25863539 \\
\hline & 4 & 20776325 & 4098994 & 27 & 5.07 & $<.0001$ & 0.05 & 12365884 & 29186766 \\
\hline
\end{tabular}

Differences of Least Squares Means

$\begin{array}{lllrrrrrrrr}\text { Effect } & \text { time } & \text { _time } & \text { Estimate } & \begin{array}{c}\text { Standard } \\ \text { Error }\end{array} & \text { DF } & \text { t Value } & \mathrm{Pr}>|\mathrm{t}| & \text { Adjustment } & \text { Adj P } & \text { Alpha } \\ \text { time } & 1 & 2 & -3603403 & 2347992 & 27 & -1.53 & 0.1365 & \text { Tukey-Kramer } & 0.4316 & 0.05 \\ \text { time } & 1 & 3 & 1316577 & 2347992 & 27 & 0.56 & 0.5796 & \text { Tukey-Kramer } & 0.9428 & 0.05 \\ \text { time } & 1 & 4 & -2006651 & 2347992 & 27 & -0.85 & 0.4003 & \text { Tukey-Kramer } & 0.8278 & 0.05 \\ \text { time } & 2 & 3 & 4919979 & 2347992 & 27 & 2.10 & 0.0456 & \text { Tukey-Kramer } & 0.1802 & 0.05 \\ \text { time } & 2 & 4 & 1596752 & 2347992 & 27 & 0.68 & 0.5023 & \text { Tukey-Kramer } & 0.9038 & 0.05 \\ \text { time } & 3 & 4 & -3323227 & 2347992 & 27 & -1.42 & 0.1684 & \text { Tukey-Kramer } & 0.5010 & 0.05\end{array}$




\section{Sym4}

$\begin{array}{lrrrl} & \text { Num } & \text { Den } & & \\ \text { Effect } & \text { DF } & \text { DF } & \text { F Value } & \text { Pr }>\text { F } \\ \text { time } & 3 & 27 & 1.65 & 0.2011\end{array}$

Least Squares Means

$\begin{array}{llrrrrrrrr}\text { Effect } & \text { time } & \text { Estimate } & \begin{array}{r}\text { Standard } \\ \text { Error }\end{array} & \text { DF } & t \text { Value } & \text { Pr > |t| } & \text { Alpha } & \text { Lower } & \text { Upper } \\ \text { time } & 1 & 21973787 & 5086614 & 27 & 4.32 & 0.0002 & 0.05 & 11536917 & 32410658 \\ \text { time } & 2 & 27055124 & 5086614 & 27 & 5.32 & <.0001 & 0.05 & 16618254 & 37491994 \\ \text { time } & 3 & 21362531 & 5086614 & 27 & 4.20 & 0.0003 & 0.05 & 10925661 & 31799402 \\ \text { time } & 4 & 26115192 & 5086614 & 27 & 5.13 & <.0001 & 0.05 & 15678322 & 36552063\end{array}$

Differences of Least Squares Means

$\begin{array}{lllrrrrrrrr}\text { Effect } & \text { time } & \text { time } & \text { Estimate } & \begin{array}{c}\text { Standard } \\ \text { Error }\end{array} & \text { DF } & \text { t Value } & \text { Pr }>|t| & \text { Adjustment } & \text { Adj P } & \text { Alpha } \\ \text { time } & 1 & 2 & -5081337 & 3165301 & 27 & -1.61 & 0.1201 & \text { Tukey-Kramer } & 0.3926 & 0.05 \\ \text { time } & 1 & 3 & 611256 & 3165301 & 27 & 0.19 & 0.8483 & \text { Tukey-Kramer } & 0.9974 & 0.05 \\ \text { time } & 1 & 4 & -4141405 & 3165301 & 27 & -1.31 & 0.2018 & \text { Tukey-Kramer } & 0.5657 & 0.05 \\ \text { time } & 2 & 3 & 5692593 & 3165301 & 27 & 1.80 & 0.0833 & \text { Tukey-Kramer } & 0.2960 & 0.05 \\ \text { time } & 2 & 4 & 939932 & 3165301 & 27 & 0.30 & 0.7688 & \text { Tukey-Kramer } & 0.9907 & 0.05 \\ \text { time } & 3 & 4 & -4752661 & 3165301 & 27 & -1.50 & 0.1448 & \text { Tukey-Kramer } & 0.4505 & 0.05\end{array}$

\section{Sym5}

$\begin{array}{lrrrr} & \text { Num } & \text { Den } & & \\ \text { Effect } & \text { DF } & \text { DF } & \text { F Value } & \text { Pr }>\text { F } \\ \text { time } & 3 & 27 & 2.98 & 0.0489\end{array}$

Least Squares Means

\begin{tabular}{|c|c|c|c|c|c|c|c|c|c|}
\hline Effec & time & Estimate & $\begin{array}{r}\text { Standard } \\
\text { Error }\end{array}$ & DF & t Value & $P r>|t|$ & Alpha & Lower & Upper \\
\hline time & 1 & 20877296 & 5107964 & 27 & 4.09 & 0.0004 & 0.05 & 10396620 & 31357971 \\
\hline time & 2 & 27425145 & 5107964 & 27 & 5.37 & $<.0001$ & 0.05 & 16944469 & 37905820 \\
\hline ime & 3 & 21136174 & 5107964 & 27 & 4.14 & 0.0003 & 0.05 & 10655499 & 31616850 \\
\hline me & 4 & 27467965 & 5107964 & 27 & 5.38 & $<.0001$ & 0.05 & 16987289 & 37948641 \\
\hline
\end{tabular}

Differences of Least Squares Means

\begin{tabular}{lllrcrrrrrr} 
& & \multicolumn{7}{c}{ Standard } \\
Effect & time & time & Estimate & Error & DF & t Value & Pr > $|t|$ & Adjustment & Adj P & Alpha \\
time & 1 & 2 & -6547849 & 3045877 & 27 & -2.15 & 0.0407 & Tukey-Kramer & 0.1633 & 0.05 \\
time & 1 & 3 & -258879 & 3045877 & 27 & -0.08 & 0.9329 & Tukey-Kramer & 0.9998 & 0.05 \\
time & 1 & 4 & -6590670 & 3045877 & 27 & -2.16 & 0.0395 & Tukey-Kramer & 0.1592 & 0.05 \\
time & 2 & 3 & 6288970 & 3045877 & 27 & 2.06 & 0.0487 & Tukey-Kramer & 0.1903 & 0.05 \\
time & 2 & 4 & -42820 & 3045877 & 27 & -0.01 & 0.9889 & Tukey-Kramer & 1.0000 & 0.05 \\
time & 3 & 4 & -6331791 & 3045877 & 27 & -2.08 & 0.0473 & Tukey-Kramer & 0.1856 & 0.05
\end{tabular}




\section{Frequency Band 12-23 Hz}

\section{Bior 1.5}

$\begin{array}{lrrrl} & \text { Num } & \text { Den } & & \\ \text { Effect } & \text { DF } & \text { DF } & \text { F Value } & \text { Pr > F } \\ \text { time } & 3 & 27 & 3.42 & 0.0314\end{array}$

Least Squares Means

$\begin{array}{llrrrrrrrr}\text { Effect } & \text { time } & \text { Estimate } & \begin{array}{r}\text { Standard } \\ \text { Error }\end{array} & \text { DF } & \text { t Value } & \operatorname{Pr}>|t| & \text { Alpha } & \text { Lower } & \text { Upper } \\ \text { time } & 1 & 7947403 & 2687150 & 27 & 2.96 & 0.0064 & 0.05 & 2433827 & 13460978 \\ \text { time } & 2 & 11765665 & 2687150 & 27 & 4.38 & 0.0002 & 0.05 & 6252090 & 17279241 \\ \text { time } & 3 & 7512342 & 2687150 & 27 & 2.80 & 0.0094 & 0.05 & 1998767 & 13025918 \\ \text { time } & 4 & 11740516 & 2687150 & 27 & 4.37 & 0.0002 & 0.05 & 6226940 & 17254091\end{array}$

Differences of Least Squares Means

$\begin{array}{lllrrrrrrrr}\text { Effect } & \text { time } & \text { time } & \text { Estimate } & \begin{array}{r}\text { Standard } \\ \text { Error }\end{array} & \text { DF } & \text { t Value } & \text { Pr }>|t| & \text { Adjustment } & \text { Adj P } & \text { Alpha } \\ \text { time } & 1 & 2 & -3818262 & 1782193 & 27 & -2.14 & 0.0413 & \text { Tukey-Kramer } & 0.1655 & 0.05 \\ \text { time } & 1 & 3 & 435060 & 1782193 & 27 & 0.24 & 0.8090 & \text { Tukey-Kramer } & 0.9948 & 0.05 \\ \text { time } & 1 & 4 & -3793113 & 1782193 & 27 & -2.13 & 0.0426 & \text { Tukey-Kramer } & 0.1698 & 0.05 \\ \text { time } & 2 & 3 & 4253323 & 1782193 & 27 & 2.39 & 0.0243 & \text { Tukey-Kramer } & 0.1039 & 0.05 \\ \text { time } & 2 & 4 & 25149 & 1782193 & 27 & 0.01 & 0.9888 & \text { Tukey-Kramer } & 1.0000 & 0.05 \\ \text { time } & 3 & 4 & -4228174 & 1782193 & 27 & -2.37 & 0.0251 & \text { Tukey-Kramer } & 0.1068 & 0.05\end{array}$

\section{Bior 3.1}

$\begin{array}{lrrrl} & \text { Num } & \text { Den } & & \\ \text { Effect } & \text { DF } & \text { DF } & \text { F Value } & \text { Pr > F } \\ \text { time } & 3 & 27 & 2.74 & 0.02\end{array}$

Least Squares Means

\begin{tabular}{|c|c|c|c|c|c|c|c|c|c|}
\hline Effect & time & Estimate & $\begin{array}{r}\text { Standard } \\
\text { Error }\end{array}$ & DF & t Value & $\operatorname{Pr}>|t|$ & Alpha & Lower & Upper \\
\hline time & 1 & 80254484 & 20222366 & 27 & 3.97 & 0.0005 & 0.05 & 38761615 & $1.2175 \mathrm{E} 8$ \\
\hline time & 2 & 97689002 & 20222366 & 27 & 4.83 & $<.0001$ & 0.05 & 56196133 & 1.3918E8 \\
\hline time & 3 & 92204039 & 20222366 & 27 & 4.56 & $<.0001$ & 0.05 & 50711170 & $1.337 \mathrm{E} 8$ \\
\hline ime & 4 & $1.0943 \mathrm{E} 8$ & 20222366 & 27 & 5.41 & $<.0001$ & 0.05 & 67939008 & $1.5092 \mathrm{E}$ \\
\hline
\end{tabular}

Differences of Least Squares Means

$\begin{array}{lllrlrrrrrr}\text { Effect } & \text { time } & \text { time } & \text { Estimate } & \begin{array}{r}\text { Standard } \\ \text { Error }\end{array} & \text { DF } & \text { t Value } & \mathrm{Pr}>|\mathrm{t}| & \text { Adjustment } & \text { Adj P } & \text { Alpha } \\ \text { time } & 1 & 2 & -1.743 E 7 & 13800632 & 27 & -2.26 & 0.0363 & \text { Tukey-Kramer } & 0.5933 & 0.05 \\ \text { time } & 1 & 3 & -1.195 \mathrm{E} 7 & 13800632 & 27 & -0.87 & 0.3942 & \text { Tukey-Kramer } & 0.8222 & 0.05 \\ \text { time } & 1 & 4 & -2.918 \mathrm{E} 7 & 13800632 & 27 & -2.11 & 0.0139 & \text { Tukey-Kramer } & 0.1742 & 0.05 \\ \text { time } & 2 & 3 & 5484963 & 13800632 & 27 & 2.10 & 0.0412 & \text { Tukey-Kramer } & 0.9783 & 0.05 \\ \text { time } & 2 & 4 & -1.174 \mathrm{E} 7 & 13800632 & 27 & -0.85 & 0.4023 & \text { Tukey-Kramer } & 0.8296 & 0.05 \\ \text { time } & 3 & 4 & -1.823 \mathrm{E} 7 & 13800632 & 27 & -2.25 & 0.0222 & \text { Tukey-Kramer } & 0.6025 & 0.05\end{array}$




\section{Rbio 3.1}

$\begin{array}{lrrrl} & \text { Num } & \text { Den } & & \\ \text { Effect } & \text { DF } & \text { DF } & \text { F Value } & \text { Pr > F } \\ \text { time } & 3 & 27 & 2.91 & 0.0421\end{array}$

Least Squares Means

$\begin{array}{llrrrrrrrr}\text { Effect } & \text { time } & \text { Estimate } & \begin{array}{r}\text { Standard } \\ \text { Error }\end{array} & \text { DF } & \mathrm{t} \text { Value } & \operatorname{Pr}>|\mathrm{t}| & \text { Alpha } & \text { Lower } & \text { Upper } \\ \text { time } & 1 & 1.6736 \mathrm{E} 8 & 56764537 & 27 & 2.95 & 0.0065 & 0.05 & 50887849 & 2.8383 \mathrm{E} 8 \\ \text { time } & 2 & 3.3388 \mathrm{E} 8 & 56764537 & 27 & 4.12 & 0.0003 & 0.05 & 1.1741 \mathrm{E} 8 & 3.5035 \mathrm{E} 8 \\ \text { time } & 3 & 1.5665 \mathrm{E} 8 & 56764537 & 27 & 2.76 & 0.0103 & 0.05 & 40180312 & 2.7312 \mathrm{E} 8 \\ \text { time } & 4 & 3.4964 \mathrm{E} 8 & 56764537 & 27 & 4.40 & 0.0002 & 0.05 & 1.3317 \mathrm{E} 8 & 3.6611 \mathrm{E} 8\end{array}$

Differences of Least Squares Means

$\begin{array}{lllrrrrrrrr}\text { Effect } & \text { time } & \text { time } & \text { Estimate } & \begin{array}{r}\text { Standard } \\ \text { Error }\end{array} & \text { DF } & \text { t Value } & \operatorname{Pr}>|t| & \text { Adjustment } & \text { Adj P } & \text { Alpha } \\ \text { time } & 1 & 2 & -8.652 E 7 & 40145102 & 27 & -3.66 & 0.0109 & \text { Tukey-Kramer } & 0.3653 & 0.05 \\ \text { time } & 1 & 3 & 10707537 & 40145102 & 27 & 0.27 & 0.7917 & \text { Tukey-Kramer } & 0.9932 & 0.05 \\ \text { time } & 1 & 4 & -8.228 E 7 & 40145102 & 27 & -2.18 & 0.0262 & \text { Tukey-Kramer } & 0.1954 & 0.05 \\ \text { time } & 2 & 3 & 77226663 & 40145102 & 27 & 2.09 & 0.0440 & \text { Tukey-Kramer } & 0.2422 & 0.05 \\ \text { time } & 2 & 4 & -1.577 E 7 & 40145102 & 27 & -0.39 & 0.6976 & \text { Tukey-Kramer } & 0.9790 & 0.05 \\ \text { time } & 3 & 4 & -9.299 E 7 & 40145102 & 27 & -2.32 & 0.0284 & \text { Tukey-Kramer } & 0.1193 & 0.05\end{array}$

\section{Coif5}

$\begin{array}{lrrrl} & \text { Num } & \text { Den } & & \\ \text { Effect } & \text { DF } & \text { DF } & \text { F Value } & \text { Pr > F } \\ \text { time } & 3 & 27 & 3.80 & 0.0216\end{array}$

Least Squares Means

\begin{tabular}{|c|c|c|c|c|c|c|c|c|c|}
\hline & & & Standard & & & & & & \\
\hline Effect & time & Estimate & Error & DF & t Value & $\operatorname{Pr}>|t|$ & Alpha & Lower & Upper \\
\hline time & 1 & 6800407 & 2456224 & 27 & 2.77 & 0.0100 & 0.05 & 1760653 & 11840162 \\
\hline ime & 2 & 10522563 & 2456224 & 27 & 4.28 & 0.0002 & 0.05 & 5482808 & 15562317 \\
\hline & 3 & 6310796 & 2456224 & 27 & 2.57 & 0.0160 & 0.05 & 1271041 & 11350550 \\
\hline ime & 4 & 10042332 & 2456224 & 27 & 4.09 & 0.0004 & 0.05 & 5002577 & 15082086 \\
\hline
\end{tabular}

Differences of Least Squares Means

$\begin{array}{lllrrrrrrrr}\text { Effect } & \text { time } & \text { time } & \text { Estimate } & \begin{array}{r}\text { Standard } \\ \text { Error }\end{array} & \text { DF } & \text { t Value } & \operatorname{Pr}>|t| & \text { Adjustment } & \text { Adj P } & \text { Alpha } \\ \text { time } & 1 & 2 & -3722156 & 1575110 & 27 & -2.36 & 0.0256 & \text { Tukey-Kramer } & 0.1088 & 0.05 \\ \text { time } & 1 & 3 & 489612 & 1575110 & 27 & 0.31 & 0.7583 & \text { Tukey-Kramer } & 0.9894 & 0.05 \\ \text { time } & 1 & 4 & -3241924 & 1575110 & 27 & -2.06 & 0.0493 & \text { Tukey-Kramer } & 0.1925 & 0.05 \\ \text { time } & 2 & 3 & 4211767 & 1575110 & 27 & 2.67 & 0.0126 & \text { Tukey-Kramer } & 0.0573 & 0.05 \\ \text { time } & 2 & 4 & 480231 & 1575110 & 27 & 0.30 & 0.7628 & \text { Tukey-Kramer } & 0.9899 & 0.05 \\ \text { time } & 3 & 4 & -3731536 & 1575110 & 27 & -2.37 & 0.0252 & \text { Tukey-Kramer } & 0.1076 & 0.05\end{array}$




\section{Db2}

$\begin{array}{lrrrl} & \text { Num } & \text { Den } & & \\ \text { Effect } & \text { DF } & \text { DF } & \text { F Value } & \text { Pr > F } \\ \text { time } & 3 & 27 & 3.57 & 0.0270\end{array}$

Least Squares Means

\begin{tabular}{llrrrrrrrr} 
& \multicolumn{9}{c}{ Standard } \\
Effect & time & Estimate & Error & DF & t Value & Pr > |t| & Alpha & Lower \\
time & 1 & 7532497 & 2271978 & 27 & 3.32 & 0.0026 & 0.05 & 2870783 & 12194211 \\
time & 2 & 10559141 & 2271978 & 27 & 4.65 & $<.0001$ & 0.05 & 5897427 & 15220855 \\
time & 3 & 6869888 & 2271978 & 27 & 3.02 & 0.0054 & 0.05 & 2208174 & 11531602 \\
time & 4 & 9375427 & 2271978 & 27 & 4.13 & 0.0003 & 0.05 & 4713713 & 14037141
\end{tabular}

Differences of Least Squares Means

$\begin{array}{lllrrrrrrrr}\text { Effect } & \text { time } & \text { _time } & \text { Estimate } & \begin{array}{r}\text { Standard } \\ \text { Error }\end{array} & \text { DF } & \text { t Value } & \text { Pr }>|t| & \text { Adjustment } & \text { Adj P } & \text { Alpha } \\ \text { time } & 1 & 2 & -3026644 & 1265508 & 27 & -2.39 & 0.0240 & \text { Tukey-Kramer } & 0.1029 & 0.05 \\ \text { time } & 1 & 3 & 662609 & 1265508 & 27 & 0.52 & 0.6048 & \text { Tukey-Kramer } & 0.9527 & 0.05 \\ \text { time } & 1 & 4 & -1842930 & 1265508 & 27 & -1.46 & 0.1568 & \text { Tukey-Kramer } & 0.4768 & 0.05 \\ \text { time } & 2 & 3 & 3689253 & 1265508 & 27 & 2.92 & 0.0071 & \text { Tukey-Kramer } & 0.0336 & 0.05 \\ \text { time } & 2 & 4 & 1183714 & 1265508 & 27 & 0.94 & 0.3579 & \text { Tukey-Kramer } & 0.7862 & 0.05 \\ \text { time } & 3 & 4 & -2505539 & 1265508 & 27 & -1.98 & 0.0580 & \text { Tukey-Kramer } & 0.2204 & 0.05\end{array}$

\section{Db5}

$\begin{array}{lrrrl} & \text { Num } & \text { Den } & & \\ \text { Effect } & \text { DF } & \text { DF } & \text { F Value } & \text { Pr > F } \\ \text { time } & 3 & 27 & 3.63 & 0.0254\end{array}$

Least Squares Means

\begin{tabular}{|c|c|c|c|c|c|c|c|c|c|}
\hline Effect & time & Estimate & $\begin{array}{r}\text { Standard } \\
\text { Error }\end{array}$ & DF & t Value & $\operatorname{Pr}>|t|$ & Alpha & Lower & Upper \\
\hline time & 2 & 10582607 & 2447374 & 27 & 4.32 & 0.0002 & 0.05 & 5561011 & 15604203 \\
\hline time & 4 & 10067070 & 2447374 & 27 & 4.11 & 0.0003 & 0.05 & 5045474 & 15088666 \\
\hline
\end{tabular}

Differences of Least Squares Means

$\begin{array}{lllrrrrrrrr}\text { Effect } & \text { time } & \text { time } & \text { Estimate } & \begin{array}{r}\text { Standard } \\ \text { Error }\end{array} & \text { DF } & \text { t Value } & \text { Pr }>|t| & \text { Adjustment } & \text { Adj P } & \text { Alpha } \\ \text { time } & 1 & 2 & -3117504 & 1447222 & 27 & -2.15 & 0.0403 & \text { Tukey-Kramer } & 0.1620 & 0.05 \\ \text { time } & 1 & 3 & 880915 & 1447222 & 27 & 0.61 & 0.5478 & \text { Tukey-Kramer } & 0.9284 & 0.05 \\ \text { time } & 1 & 4 & -2601967 & 1447222 & 27 & -1.80 & 0.0834 & \text { Tukey-Kramer } & 0.2962 & 0.05 \\ \text { time } & 2 & 3 & 3998419 & 1447222 & 27 & 2.76 & 0.0102 & \text { Tukey-Kramer } & 0.0472 & 0.05 \\ \text { time } & 2 & 4 & 515537 & 1447222 & 27 & 0.36 & 0.7244 & \text { Tukey-Kramer } & 0.9842 & 0.05 \\ \text { time } & 3 & 4 & -3482882 & 1447222 & 27 & -2.41 & 0.0232 & \text { Tukey-Kramer } & 0.0998 & 0.05\end{array}$




\section{Db45}

$\begin{array}{lrrrl} & \text { Num } & \text { Den } & & \\ \text { Effect } & \text { DF } & \text { DF } & \text { F Value } & \text { Pr > F } \\ \text { time } & 3 & 27 & 3.31 & 0.0351\end{array}$

Least Squares Means

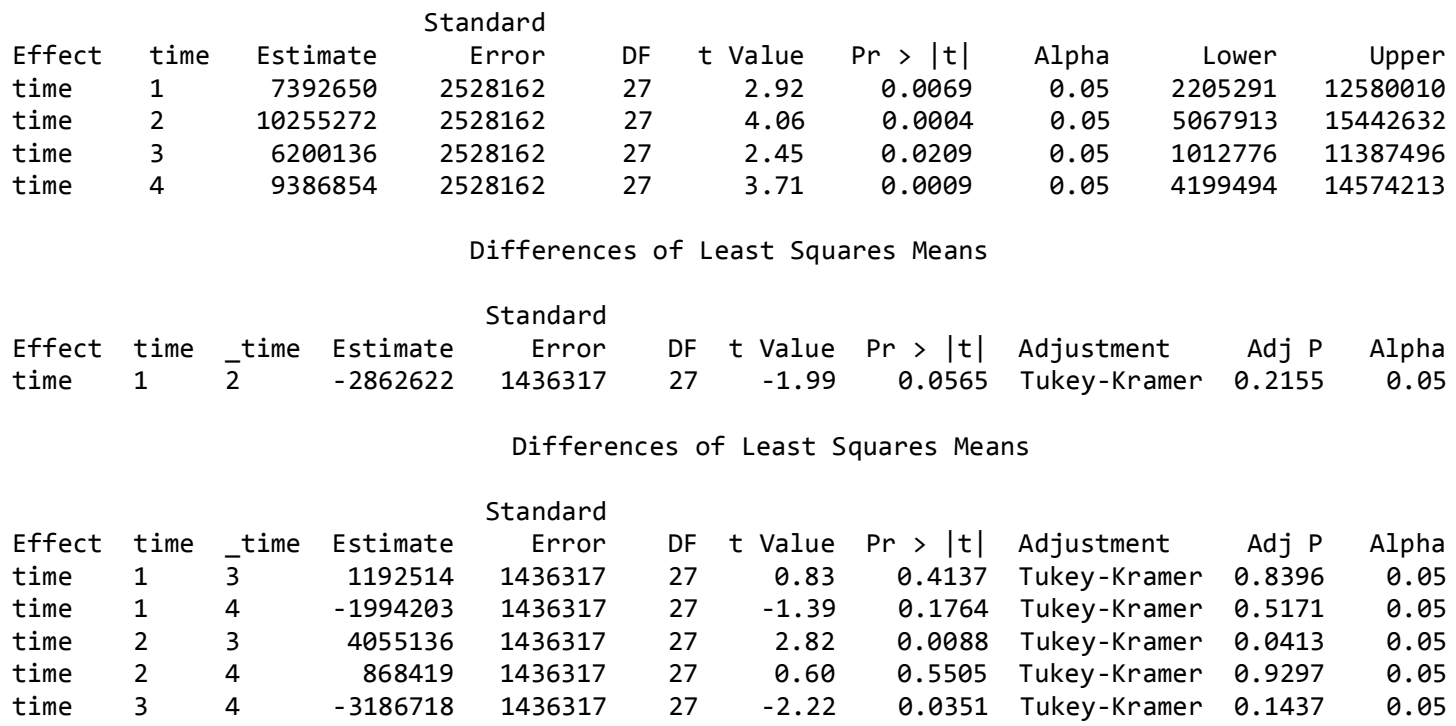

\section{Haar}

$\begin{array}{lrrrl} & \text { Num } & \text { Den } & & \\ \text { Effect } & \text { DF } & \text { DF } & \text { F Value } & \text { Pr > F } \\ \text { time } & 3 & 27 & 2.96 & 0.0426\end{array}$

Least Squares Means

\begin{tabular}{|c|c|c|c|c|c|c|c|c|c|}
\hline & & & Standard & & & & & & \\
\hline Effect & time & Estimate & Error & DF & t Value & $\operatorname{Pr}>|t|$ & Alpha & Lower & Upper \\
\hline time & 1 & 6055205 & 1860753 & 27 & 3.25 & 0.0031 & 0.05 & 2237257 & 9873154 \\
\hline time & 2 & 8756833 & 1860753 & 27 & 4.71 & $<.0001$ & 0.05 & 4938884 & 12574782 \\
\hline =ime & 3 & 6104191 & 1860753 & 27 & 3.28 & 0.0029 & 0.05 & 2286242 & 9922140 \\
\hline ime & 4 & 9207961 & 1860753 & 27 & 4.95 & $<.0001$ & 0.05 & 5390012 & 13025910 \\
\hline
\end{tabular}

Differences of Least Squares Means

$\begin{array}{lllrrrrrrrr}\text { Effect } & \text { time } & \text { _time } & \text { Estimate } & \begin{array}{r}\text { Standard } \\ \text { Error }\end{array} & \text { DF } & \text { t Value } & \text { Pr }>|t| & \text { Adjustment } & \text { Adj P } & \text { Alpha } \\ \text { time } & 1 & 2 & -2701627 & 1410464 & 27 & -1.92 & 0.0661 & \text { Tukey-Kramer } & 0.2455 & 0.05 \\ \text { time } & 1 & 3 & -48986 & 1410464 & 27 & -0.03 & 0.9726 & \text { Tukey-Kramer } & 1.0000 & 0.05 \\ \text { time } & 1 & 4 & -3152756 & 1410464 & 27 & -2.24 & 0.0339 & \text { Tukey-Kramer } & 0.1393 & 0.05 \\ \text { time } & 2 & 3 & 2652642 & 1410464 & 27 & 1.88 & 0.0708 & \text { Tukey-Kramer } & 0.2598 & 0.05 \\ \text { time } & 2 & 4 & -451128 & 1410464 & 27 & -0.32 & 0.7515 & \text { Tukey-Kramer } & 0.9884 & 0.05 \\ \text { time } & 3 & 4 & -3103770 & 1410464 & 27 & -2.20 & 0.0365 & \text { Tukey-Kramer } & 0.1487 & 0.05\end{array}$




\section{Sym4}

$\begin{array}{lrrrl} & \text { Num } & \text { Den } & & \\ \text { Effect } & \text { DF } & \text { DF } & \text { F Value } & \text { Pr }>\text { F } \\ \text { time } & 3 & 27 & 3.58 & 0.0267\end{array}$

Least Squares Means

\begin{tabular}{|c|c|c|c|c|c|c|c|c|c|}
\hline & & & Standard & & & & & & \\
\hline Effect & time & Estimate & Error & DF & $t$ Value & $\operatorname{Pr}>|t|$ & Alpha & Lower & Upper \\
\hline time & 1 & 7006607 & 2224774 & 27 & 3.15 & 0.0040 & 0.05 & 2441748 & 11571467 \\
\hline time & 2 & 10178931 & 2224774 & 27 & 4.58 & $<.0001$ & 0.05 & 5614071 & 14743790 \\
\hline time & 3 & 6222807 & 2224774 & 27 & 2.80 & 0.0094 & 0.05 & 1657948 & 10787667 \\
\hline time & 4 & 9190853 & 2224774 & 27 & 4.13 & 0.0003 & 0.05 & 4625994 & 13755713 \\
\hline
\end{tabular}

Differences of Least Squares Means

$\begin{array}{lllrrrrrrrr}\text { Effect } & \text { time } & \text { time } & \text { Estimate } & \begin{array}{r}\text { Standard } \\ \text { Error }\end{array} & \text { DF } & \text { t Value } & \operatorname{Pr}>|\mathrm{t}| & \text { Adjustment } & \text { Adj P } & \text { Alpha } \\ \text { time } & 1 & 2 & -3172323 & 1379351 & 27 & -2.30 & 0.0294 & \text { Tukey-Kramer } & 0.1231 & 0.05 \\ \text { time } & 1 & 3 & 783800 & 1379351 & 27 & 0.57 & 0.5746 & \text { Tukey-Kramer } & 0.9407 & 0.05 \\ \text { time } & 1 & 4 & -2184246 & 1379351 & 27 & -1.58 & 0.1249 & \text { Tukey-Kramer } & 0.4045 & 0.05 \\ \text { time } & 2 & 3 & 3956124 & 1379351 & 27 & 2.87 & 0.0079 & \text { Tukey-Kramer } & 0.0374 & 0.05 \\ \text { time } & 2 & 4 & 988078 & 1379351 & 27 & 0.72 & 0.4799 & \text { Tukey-Kramer } & 0.8897 & 0.05 \\ \text { time } & 3 & 4 & -2968046 & 1379351 & 27 & -2.15 & 0.0405 & \text { Tukey-Kramer } & 0.1627 & 0.05\end{array}$

\section{Sym5}

$\begin{array}{lrrrr} & \text { Num } & \text { Den } & & \\ \text { Effect } & \text { DF } & \text { DF } & \text { F Value } & \text { Pr > F } \\ \text { time } & 3 & 27 & 3.84 & 0.0206\end{array}$

Least Squares Means

$\begin{array}{llrrrrrrrr} & & & & & & \\ \text { Effect } & \text { time } & \text { Estimate } & \text { Error } & \text { DF } & \mathrm{t} \text { Value } & \operatorname{Pr}>|\mathrm{t}| & \text { Alpha } & \text { Lower } & \text { Upper } \\ \text { time } & 1 & 7717379 & 2454832 & 27 & 3.14 & 0.0040 & 0.05 & 2680479 & 12754278 \\ \text { time } & 2 & 10661270 & 2454832 & 27 & 4.34 & 0.0002 & 0.05 & 5624371 & 15698170 \\ \text { time } & 3 & 6639208 & 2454832 & 27 & 2.70 & 0.0117 & 0.05 & 1602309 & 11676108 \\ \text { time } & 4 & 9607692 & 2454832 & 27 & 3.91 & 0.0006 & 0.05 & 4570793 & 14644592\end{array}$

Differences of Least Squares Means

$\begin{array}{lllrrrrrrrr}\text { Effect } & \text { time } & \text { time } & \text { Estimate } & \begin{array}{r}\text { Standard } \\ \text { Error }\end{array} & \text { DF } & \text { t Value } & \text { Pr }>|t| & \text { Adjustment } & \text { Adj P } & \text { Alpha } \\ \text { time } & 1 & 2 & -2943892 & 1308668 & 27 & -2.25 & 0.0328 & \text { Tukey-Kramer } & 0.1356 & 0.05 \\ \text { time } & 1 & 3 & 1078170 & 1308668 & 27 & 0.82 & 0.4172 & \text { Tukey-Kramer } & 0.8427 & 0.05 \\ \text { time } & 1 & 4 & -1890314 & 1308668 & 27 & -1.44 & 0.1601 & \text { Tukey-Kramer } & 0.4838 & 0.05 \\ \text { time } & 2 & 3 & 4022062 & 1308668 & 27 & 3.07 & 0.0048 & \text { Tukey-Kramer } & 0.0233 & 0.05 \\ \text { time } & 2 & 4 & 1053578 & 1308668 & 27 & 0.81 & 0.4278 & \text { Tukey-Kramer } & 0.8515 & 0.05 \\ \text { time } & 3 & 4 & -2968484 & 1308668 & 27 & -2.27 & 0.0315 & \text { Tukey-Kramer } & 0.1308 & 0.05\end{array}$


Frequency Band 6-12 Hz

\section{Bior 1.5}

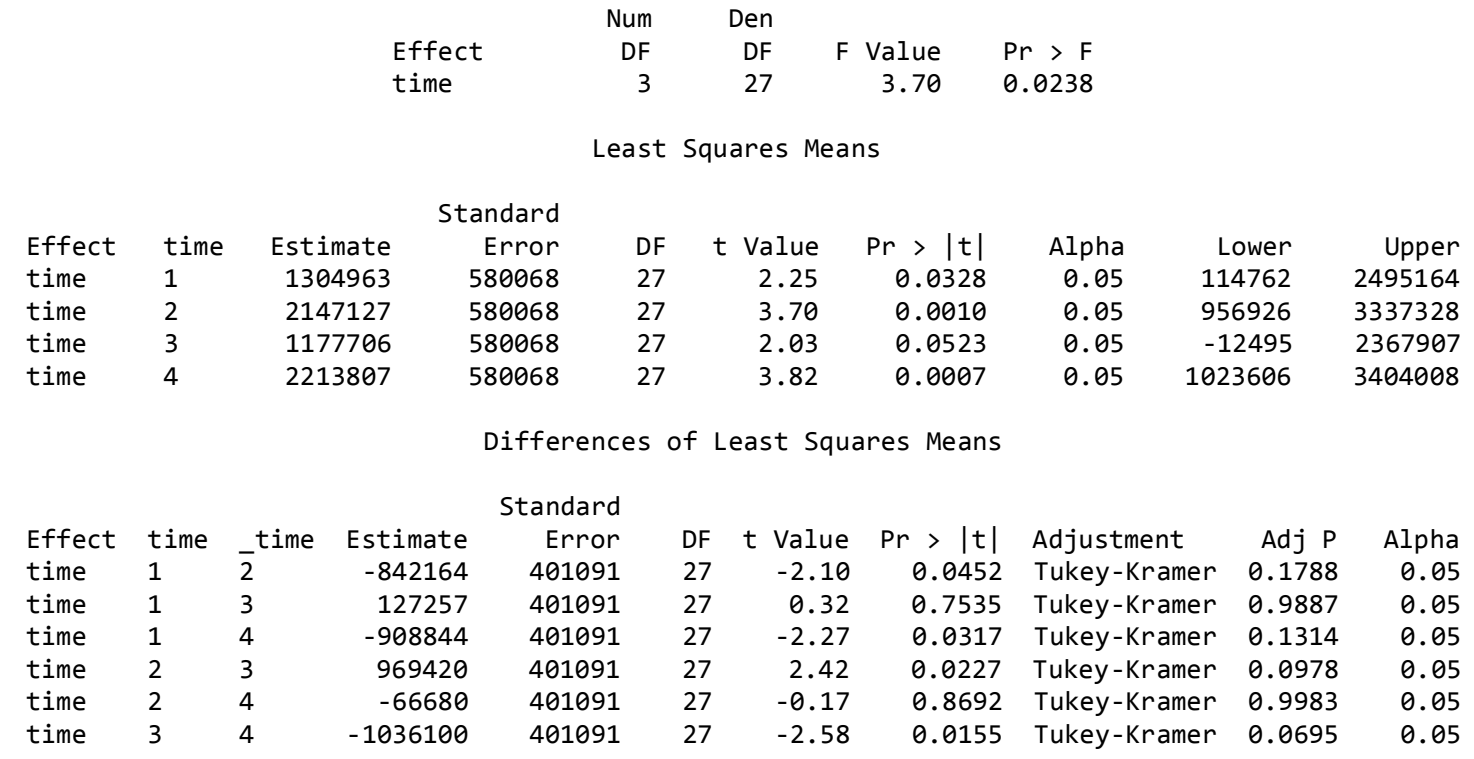

\section{Bior 3.1}

$\begin{array}{lrrrl} & \text { Num } & \text { Den } & & \\ \text { Effect } & \text { DF } & \text { DF } & \text { F Value } & \text { Pr > F } \\ \text { time } & 3 & 27 & 3.07 & 0.0445\end{array}$

Least Squares Means

$\begin{array}{llrrrrrrrr}\text { Effect } & \text { time } & \text { Estimate } & \begin{array}{r}\text { Standard } \\ \text { Error }\end{array} & \text { DF } & \text { t Value } & \text { Pr }>|t| & \text { Alpha } & \text { Lower } & \text { Upper } \\ \text { time } & 1 & 86142556 & 21237806 & 27 & 4.06 & 0.0004 & 0.05 & 42566178 & 1.2972 \mathrm{E} 8 \\ \text { time } & 2 & 1.1853 \mathrm{E} 8 & 21237806 & 27 & 5.58 & <.0001 & 0.05 & 74954023 & 1.6211 \mathrm{E} 8 \\ \text { time } & 3 & 96481543 & 21237806 & 27 & 4.54 & 0.0001 & 0.05 & 52905165 & 1.4006 \mathrm{E} 8 \\ \text { time } & 4 & 1.2295 \mathrm{E} 8 & 21237806 & 27 & 5.79 & <.0001 & 0.05 & 79376628 & 1.6653 \mathrm{E} 8\end{array}$

Differences of Least Squares Means

$\begin{array}{lllrlrrrrrr}\text { Effect } & \text { time } & \text { time } & \text { Estimate } & \begin{array}{r}\text { Standard } \\ \text { Error }\end{array} & \text { DF } & \text { t Value } & \operatorname{Pr}>|t| & \text { Adjustment } & \text { Adj P } & \text { Alpha } \\ \text { time } & 1 & 2 & -3.239 E 7 & 14198062 & 27 & -2.28 & 0.0306 & \text { Tukey-Kramer } & 0.1277 & 0.05 \\ \text { time } & 1 & 3 & -1.034 E 7 & 14198062 & 27 & -0.73 & 0.4728 & \text { Tukey-Kramer } & 0.8849 & 0.05 \\ \text { time } & 1 & 4 & -3.681 E 7 & 14198062 & 27 & -2.59 & 0.0152 & \text { Tukey-Kramer } & 0.0681 & 0.05 \\ \text { time } & 2 & 3 & 22048858 & 14198062 & 27 & 1.55 & 0.1321 & \text { Tukey-Kramer } & 0.4214 & 0.05 \\ \text { time } & 2 & 4 & -4422606 & 14198062 & 27 & -0.31 & 0.7578 & \text { Tukey-Kramer } & 0.9893 & 0.05 \\ \text { time } & 3 & 4 & -2.647 E 7 & 14198062 & 27 & -2.33 & 0.0321 & \text { Tukey-Kramer } & 0.2667 & 0.05\end{array}$




\section{Rbio 3.1}

$\begin{array}{lrrrr} & \text { Num } & \text { Den } & & \\ \text { Effect } & \text { DF } & \text { DF } & \text { F Value } & \text { Pr > F } \\ \text { time } & 3 & 27 & 2.90 & 0.0531\end{array}$

Least Squares Means

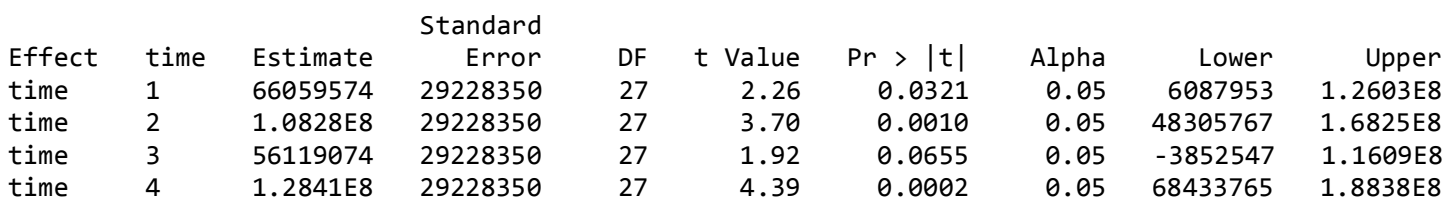

Differences of Least Squares Means

$\begin{array}{lllrrrrrrrr}\text { Effect } & \text { time } & \text { time } & \text { Estimate } & \begin{array}{r}\text { Standard } \\ \text { Error }\end{array} & \text { DF } & \text { t Value } & \text { Pr > |t| } & \text { Adjustment } & \text { Adj P } & \text { Alpha } \\ \text { time } & 1 & 2 & -4.222 E 7 & 28478717 & 27 & -1.48 & 0.1498 & \text { Tukey-Kramer } & 0.4615 & 0.05 \\ \text { time } & 1 & 3 & 9940500 & 28478717 & 27 & 0.35 & 0.7298 & \text { Tukey-Kramer } & 0.9851 & 0.05 \\ \text { time } & 1 & 4 & -6.235 E 7 & 28478717 & 27 & -2.19 & 0.0374 & \text { Tukey-Kramer } & 0.1519 & 0.05 \\ \text { time } & 2 & 3 & 52158313 & 28478717 & 27 & 2.13 & 0.0381 & \text { Tukey-Kramer } & 0.2811 & 0.05 \\ \text { time } & 2 & 4 & -2.013 E 7 & 28478717 & 27 & -0.71 & 0.4858 & \text { Tukey-Kramer } & 0.8935 & 0.05 \\ \text { time } & 3 & 4 & -7.229 E 7 & 28478717 & 27 & -2.84 & 0.0172 & \text { Tukey-Kramer } & 0.0763 & 0.05\end{array}$

Coif 5

$\begin{array}{lrrrr} & \text { Num } & \text { Den } & & \\ \text { Effect } & \text { DF } & \text { DF } & \text { F Value } & \text { Pr }>F \\ \text { time } & 3 & 27 & 3.56 & 0.0274\end{array}$

Least Squares Means

$\begin{array}{llrrrrrrrr} & & & & & & \\ \text { Effect } & \text { time } & \text { Estimate } & \text { Error } & \text { DF } & \text { t Value } & \text { Pr > |t| } & \text { Alpha } & \text { Lower } & \text { Upper } \\ \text { time } & 1 & 1266345 & 436341 & 27 & 2.90 & 0.0073 & 0.05 & 371047 & 2161643 \\ \text { time } & 2 & 1482973 & 436341 & 27 & 3.40 & 0.0021 & 0.05 & 587675 & 2378271 \\ \text { time } & 3 & 779748 & 436341 & 27 & 1.79 & 0.0852 & 0.05 & -115550 & 1675046 \\ \text { time } & 4 & 1690376 & 436341 & 27 & 3.87 & 0.0006 & 0.05 & 795078 & 2585674\end{array}$

Differences of Least Squares Means

$\begin{array}{lllrrrrrrrr}\text { Effect } & \text { time } & \text { time } & \text { Estimate } & \begin{array}{r}\text { Standard } \\ \text { Error }\end{array} & \text { DF } & \text { t Value } & \text { Pr }>|t| & \text { Adjustment } & \text { Adj P } & \text { Alpha } \\ \text { time } & 1 & 2 & -216628 & 292901 & 27 & -0.74 & 0.4659 & \text { Tukey-Kramer } & 0.8802 & 0.05 \\ \text { time } & 1 & 3 & 486597 & 292901 & 27 & 1.66 & 0.1082 & \text { Tukey-Kramer } & 0.3630 & 0.05 \\ \text { time } & 1 & 4 & -424031 & 292901 & 27 & -1.45 & 0.1592 & \text { Tukey-Kramer } & 0.4819 & 0.05 \\ \text { time } & 2 & 3 & 703225 & 292901 & 27 & 2.40 & 0.0235 & \text { Tukey-Kramer } & 0.1010 & 0.05 \\ \text { time } & 2 & 4 & -207403 & 292901 & 27 & -0.71 & 0.4850 & \text { Tukey-Kramer } & 0.8930 & 0.05 \\ \text { time } & 3 & 4 & -910628 & 292901 & 27 & -3.11 & 0.0044 & \text { Tukey-Kramer } & 0.0215 & 0.05\end{array}$




\section{Db2}

$\begin{array}{lrrrr} & \text { Num } & \text { Den } & & \\ \text { Effect } & \text { DF } & \text { DF } & \text { F Value } & \text { Pr > F } \\ \text { time } & 3 & 27 & 2.30 & 0.0998\end{array}$

Least Squares Means

\begin{tabular}{|c|c|c|c|c|c|c|c|c|c|}
\hline & & & tandard & & & & & & \\
\hline time & 2 & 2305125 & 619915 & 27 & 3.72 & 0.0009 & 0.05 & 1033166 & 3577085 \\
\hline time & 4 & 2307257 & 619915 & 27 & 3.72 & 0.0009 & 0.05 & 1035298 & 3579217 \\
\hline
\end{tabular}

Differences of Least Squares Means

$\begin{array}{lllrrrrrrrr}\text { Effect } & \text { time } & \text { _time } & \text { Estimate } & \begin{array}{r}\text { Standard } \\ \text { Error }\end{array} & \text { DF } & \text { t Value } & \text { Pr }>|t| & \text { Adjustment } & \text { Adj P } & \text { Alpha } \\ \text { time } & 1 & 2 & -655881 & 405824 & 27 & -1.62 & 0.1177 & \text { Tukey-Kramer } & 0.3868 & 0.05 \\ \text { time } & 1 & 3 & 173783 & 405824 & 27 & 0.43 & 0.6719 & \text { Tukey-Kramer } & 0.9731 & 0.05 \\ \text { time } & 1 & 4 & -658013 & 405824 & 27 & -1.62 & 0.1165 & \text { Tukey-Kramer } & 0.3840 & 0.05 \\ \text { time } & 2 & 3 & 829664 & 405824 & 27 & 2.04 & 0.0508 & \text { Tukey-Kramer } & 0.1972 & 0.05 \\ \text { time } & 2 & 4 & -2132.23 & 405824 & 27 & -0.01 & 0.9958 & \text { Tukey-Kramer } & 1.0000 & 0.05 \\ \text { time } & 3 & 4 & -831796 & 405824 & 27 & -2.05 & 0.0502 & \text { Tukey-Kramer } & 0.1954 & 0.05\end{array}$

Db5

$\begin{array}{lrccc}\text { Effect } & \text { DF } & \text { DF } & \text { F Value } & \text { Pr > F } \\ \text { time } & 3 & 27 & 3.01 & 0.0477\end{array}$

Least Squares Means

$\begin{array}{lcccccccc}\text { time } & \text { Estimate } & \begin{array}{c}\text { Standard } \\ \text { Error }\end{array} & \text { DF } & t \text { Value } & \mathrm{Pr}>|\mathrm{t}| & \text { Alpha } & \text { Lower } & \text { Upper } \\ 1 & 1202013 & 509077 & 27 & 2.36 & 0.0257 & 0.05 & 157474 & 2246552 \\ 2 & 1880909 & 509077 & 27 & 3.69 & 0.0010 & 0.05 & 836370 & 2925448 \\ 3 & 1056633 & 509077 & 27 & 2.08 & 0.0476 & 0.05 & 12094 & 2101172 \\ 4 & 1843134 & 509077 & 27 & 3.62 & 0.0012 & 0.05 & 798596 & 2887673\end{array}$

Differences of Least Squares Means

\begin{tabular}{|c|c|c|c|c|c|c|c|c|}
\hline $\begin{array}{l}\text { Standard Effect: } \\
\text { time }\end{array}$ & Estimate & $\begin{array}{l}\text { Standard } \\
\text { Error }\end{array}$ & DF & t Value & $\operatorname{Pr}>|t|$ & Adjustment & Adj $P$ & Alpha \\
\hline 1 vs 2 & -678897 & 348650 & 27 & -1.95 & 0.0620 & Tukey-Kramer & 0.2329 & 0.05 \\
\hline 1 vs 3 & 145380 & 348650 & 27 & 0.42 & 0.6800 & Tukey-Kramer & 0.9751 & 0.05 \\
\hline 1 vs 4 & -641122 & 348650 & 27 & -1.84 & 0.0770 & Tukey-Kramer & 0.2778 & 0.05 \\
\hline 2 vs 3 & 824277 & 348650 & 27 & 2.36 & 0.0255 & Tukey-Kramer & 0.1086 & 0.05 \\
\hline 2 vs 4 & 37775 & 348650 & 27 & 0.11 & 0.9145 & Tukey-Kramer & 0.9995 & 0.05 \\
\hline 3 vs 4 & -786502 & 348650 & 27 & -2.26 & 0.0324 & Tukey-Kramer & 0.1340 & 0.05 \\
\hline
\end{tabular}




\section{Db45}

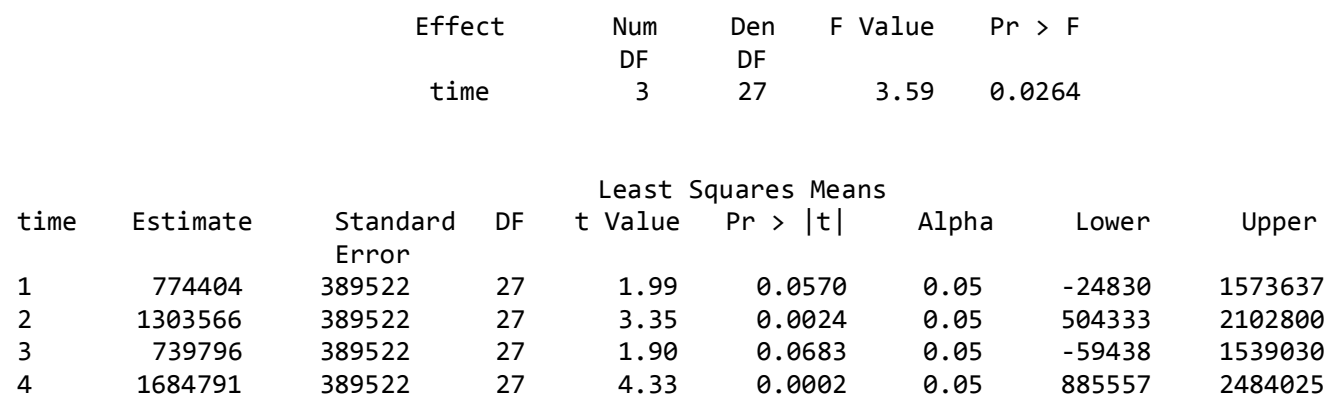

Differences of Least Squares Means

\begin{tabular}{|c|c|c|c|c|c|c|c|c|}
\hline $\begin{array}{l}\text { Standard Effect: } \\
\text { time }\end{array}$ & Estimate & $\begin{array}{l}\text { Standard } \\
\text { Error }\end{array}$ & DF & $\begin{array}{l}\mathrm{t} \\
\text { Value }\end{array}$ & $\operatorname{Pr}>|t|$ & Adjustment & Adj $P$ & Alpha \\
\hline 1 vs 2 & -529163 & 338357 & 27 & -1.56 & 0.1295 & Tukey-Kramer & 0.4153 & 0.05 \\
\hline 1 vs 3 & 34608 & 338357 & 27 & 0.10 & 0.9193 & Tukey-Kramer & 0.9996 & 0.05 \\
\hline 1 vs 4 & -910388 & 338357 & 27 & -2.69 & 0.0121 & Tukey-Kramer & 0.0552 & 0.05 \\
\hline 2 vs 3 & 563771 & 338357 & 27 & 1.67 & 0.1072 & Tukey-Kramer & 0.3605 & 0.05 \\
\hline 2 vs 4 & -381225 & 338357 & 27 & -1.13 & 0.2698 & Tukey-Kramer & 0.6766 & 0.05 \\
\hline 3 vs 4 & -944995 & 338357 & 27 & -2.79 & 0.0095 & Tukey-Kramer & 0.0442 & 0.05 \\
\hline
\end{tabular}

\section{Haar}

$\begin{array}{lccccrr}\text { Effect } & \text { Num } & \text { DF } & \text { Den } & \text { DF } & \text { F Value } & \text { Pr }>F \\ \text { time } & 3 & & 27 & & 4.63 & 0.0097\end{array}$

Least Squares Means

$\begin{array}{lllllrrrrr}\text { Effect } & \text { time } & \text { Estimate } & \begin{array}{c}\text { Standard } \\ \text { Error }\end{array} & \text { DF } & t \text { Value } & \text { Pr }>|t| & \text { Alpha } & \text { Lower } & \text { Upper } \\ \text { time } & 1 & 1689280 & 637183 & 27 & 2.65 & 0.0133 & 0.05 & 381887 & 2996672 \\ \text { time } & 2 & 2629553 & 637183 & 27 & 4.13 & 0.0003 & 0.05 & 1322160 & 3936945 \\ \text { time } & 3 & 1627994 & 637183 & 27 & 2.55 & 0.0166 & 0.05 & 320601 & 2935386 \\ \text { time } & 4 & 2675553 & 637183 & 27 & 4.20 & 0.0003 & 0.05 & 1368160 & 3982945\end{array}$

Differences of Least Squares Means

\begin{tabular}{|c|c|c|c|c|c|c|c|c|}
\hline $\begin{array}{l}\text { Standard } \\
\text { Effect: time }\end{array}$ & Estimate & $\begin{array}{l}\text { Standar } \\
\text { d Error }\end{array}$ & DF & t Value & $\operatorname{Pr}>|t|$ & Adjustment & Adj $P$ & Alpha \\
\hline 1 vs 2 & -940273 & 377622 & 27 & -2.49 & 0.0192 & Tukey-Kramer & 0.0843 & 0.05 \\
\hline 1 vs 3 & 61286 & 377622 & 27 & 0.16 & 0.8723 & Tukey-Kramer & 0.9984 & 0.05 \\
\hline 1 vs 4 & -986273 & 377622 & 27 & -2.61 & 0.0145 & Tukey-Kramer & 0.0654 & 0.05 \\
\hline 2 vs 3 & 1001559 & 377622 & 27 & 2.65 & 0.0132 & Tukey-Kramer & 0.0600 & 0.05 \\
\hline 2 vs 4 & -46000 & 377622 & 27 & -0.12 & 0.9039 & Tukey-Kramer & 0.9993 & 0.05 \\
\hline 3 vs 4 & -1047559 & 377622 & 27 & -2.77 & 0.0099 & Tukey-Kramer & 0.0460 & 0.05 \\
\hline
\end{tabular}




\section{Sym4}

$\begin{array}{lcccccc}\text { Effect } & \text { Num } & \text { DF } & \text { Den } & \text { DF } & \text { F Value } & \text { Pr }>F \\ \text { time } & 3 & & 27 & & 2.96 & 0.0502\end{array}$

Least Squares Means

\begin{tabular}{|c|c|c|c|c|c|c|c|c|c|c|c|}
\hline & time & Estimate & $\begin{array}{l}\text { Standard } \\
\text { Error }\end{array}$ & DF & t Value & $\operatorname{Pr}>|t|$ & Alpha & \multicolumn{2}{|c|}{ Lower } & \multicolumn{2}{|c|}{ Upper } \\
\hline & 1 & 1645269 & 579032 & 27 & 2.84 & 0.0084 & 0.05 & \multicolumn{2}{|c|}{457194} & \multicolumn{2}{|c|}{2833345} \\
\hline & 2 & 1697056 & 579032 & 27 & 2.93 & 0.0068 & 0.05 & \multicolumn{2}{|c|}{508980} & \multicolumn{2}{|c|}{2885131} \\
\hline & 3 & 997955 & 579032 & 27 & 1.72 & 0.0962 & 0.05 & \multicolumn{2}{|c|}{-190121} & \multicolumn{2}{|c|}{2186030} \\
\hline & 4 & 2125632 & 579032 & 27 & 3.67 & 0.0010 & 0.05 & \multicolumn{2}{|c|}{937557} & \multicolumn{2}{|c|}{3313707} \\
\hline $\begin{array}{l}\text { Stan } \\
\text { Effe } \\
\text { time }\end{array}$ & $\begin{array}{l}\text { dard } \\
\text { ct: }\end{array}$ & Estimate & $\begin{array}{l}\text { Standard } \\
\text { Error }\end{array}$ & DF & $\begin{array}{l}\mathrm{t} \\
\text { Value }\end{array}$ & $\operatorname{Pr}>|t|$ & \multicolumn{2}{|c|}{ Adjustment } & Adj & $\mathrm{P}$ & Alph \\
\hline $1 \mathrm{vs}$ & 2 & -51786 & 382649 & 27 & -0.14 & 0.8934 & \multirow{2}{*}{\multicolumn{2}{|c|}{$\begin{array}{l}\text { Tukey-Kramer } \\
\text { Tukey-Kramer }\end{array}$}} & 0.99 & 91 & 0.05 \\
\hline $1 \mathrm{vs}$ & 3 & 647315 & 382649 & 27 & 1.69 & 0.1022 & & & 0.34 & 175 & 0.05 \\
\hline $1 \mathrm{vs}$ & 4 & -480362 & 382649 & 27 & -1.26 & 0.2201 & \multicolumn{2}{|c|}{ Tukey-Kramer } & 0.59 & 982 & 0.05 \\
\hline 2 vs & 3 & 699101 & 382649 & 27 & 1.83 & 0.0788 & \multicolumn{2}{|c|}{ Tukey-Kramer } & 0.28 & 331 & 0.05 \\
\hline 2 vs & 4 & -428576 & 382649 & 27 & -1.12 & 0.2726 & \multicolumn{2}{|c|}{ Tukey-Kramer } & 0.68 & 306 & 0.05 \\
\hline 3 vs & 4 & -1127677 & 382649 & 27 & -2.95 & 0.0065 & \multicolumn{2}{|c|}{ Tukey-Kramer } & 0.03 & 312 & 0.05 \\
\hline
\end{tabular}

\section{Sym5}

$\begin{array}{lclccc}\text { Effect } & \text { Num DF } & \text { Den } & \text { DF } & \text { F Value } & \text { Pr }>F \\ \text { time } & 3 & 27 & & 2.52 & 0.0790\end{array}$

$\begin{array}{lcccccccc}\text { time } & \text { Estimate } & \begin{array}{l}\text { Standard } \\ \text { Error }\end{array} & \text { DF } & \mathrm{t} \text { Value } & \mathrm{Pr}>|\mathrm{t}| & \text { Alpha } & \text { Lower } & \text { Upper } \\ 1 & 1254482 & 500899 & 27 & 2.50 & 0.0186 & 0.05 & 226722 & 2282241 \\ 2 & 1808585 & 500899 & 27 & 3.61 & 0.0012 & 0.05 & 780826 & 2836345 \\ 3 & 1106275 & 500899 & 27 & 2.21 & 0.0359 & 0.05 & 78515 & 2134035 \\ 4 & 1934359 & 500899 & 27 & 3.86 & 0.0006 & 0.05 & 906600 & 2962119\end{array}$

Differences of Least Squares Means

\begin{tabular}{lrlllllll} 
Standard & Estimate & Error & DF & \multicolumn{1}{c}{ V } & Pr $>|t|$ & Adjustment & Adj $P$ & Alpha \\
Effect: time & & & & Value & & & & \\
1 vs 2 & -554104 & 362354 & 27 & -1.53 & 0.1379 & Tukey-Kramer & 0.4348 & 0.05 \\
1 vs 3 & 148207 & 362354 & 27 & 0.41 & 0.6858 & Tukey-Kramer & 0.9764 & 0.05 \\
1 vs 4 & -679878 & 362354 & 27 & -1.88 & 0.0715 & Tukey-Kramer & 0.2617 & 0.05 \\
2 vs 3 & 702311 & 362354 & 27 & 1.94 & 0.0631 & Tukey-Kramer & 0.2364 & 0.05 \\
2 vs 4 & -125774 & 362354 & 27 & -0.35 & 0.7312 & Tukey-Kramer & 0.9853 & 0.05 \\
3 vs 4 & -828085 & 362354 & 27 & -2.29 & 0.0304 & Tukey-Kramer & 0.1267 & 0.05
\end{tabular}




\section{Appendix L: Mean ( \pm standard deviation) of power (in $\mathbf{m V}^{2}$ ) using ten wavelet functions for left sternocleidomastoid muscle}

Table L.1: Power estimated using Bior1.5 wavelet function as an effect of time for left sternocleidomastoid muscle

\begin{tabular}{cllll}
\hline $\begin{array}{l}\text { Frequency } \\
\text { Band, Hz }\end{array}$ & $\mathrm{T}=0$ & $\mathrm{~T}=20$ & $\mathrm{~T}=25$ & $\mathrm{~T}=45$ \\
\hline $375-750$ & $0.10(0.09)$ & $0.13(0.12)$ & $0.10(0.11)$ & $0.16(0.18)$ \\
$187-375$ & $0.38(0.35)$ & $0.46(0.43)$ & $0.38(0.42)$ & $0.57(0.64)$ \\
$93-187$ & $1.08(1.06)$ & $1.26(1.08)$ & $0.99(1.15)$ & $1.44(1.37)$ \\
$46-93$ & $1.42(1.33)$ & $1.74(1.52)$ & $1.51(1.83)$ & $2.07(1.80)$ \\
$23-46$ & $0.55(0.65)$ & $0.80(0.65)$ & $0.65(0.91)$ & $0.92(0.64)$ \\
$12-23$ & $0.11(0.14)$ & $0.18(0.21)$ & $0.17(0.24)$ & $0.23(0.24)$ \\
$6-12$ & $0.04(0.05)$ & $0.07(0.10)$ & $0.04(0.05)$ & $0.04(0.04)$ \\
\hline
\end{tabular}

Table L.2: Power estimated using Bior3.1 wavelet function as an effect of time for left sternocleidomastoid muscle

\begin{tabular}{ccccc}
\hline $\begin{array}{l}\text { Frequency } \\
\text { Band, Hz }\end{array}$ & $\mathrm{T}=0$ & $\mathrm{~T}=20$ & $\mathrm{~T}=25$ & $\mathrm{~T}=45$ \\
\hline $375-750$ & $0.01(0.01)$ & $0.01(0.02)$ & $0.01(0.01)$ & $0.02(0.03)$ \\
$187-375$ & $0.12(0.13)$ & $0.15(0.18)$ & $0.13(0.13)$ & $0.21(0.30)$ \\
$93-187$ & $0.98(0.93)$ & $1.21(1.16)$ & $1.00(1.09)$ & $1.49(1.71)$ \\
$46-93$ & $2.54(2.42)$ & $3.03(2.54)$ & $2.58(3.23)$ & $3.40(2.78)$ \\
$23-46$ & $2.03(1.88)$ & $3.51(3.04)$ & $2.79(4.04)$ & $4.29(4.19)$ \\
$12-23$ & $2.38(2.19)$ & $4.67(3.47)$ & $3.09(3.99)$ & $5.88(5.95)$ \\
$6-12$ & $3.01(3.28)$ & $4.85(5.76)$ & $2.51(2.31)$ & $9.41(19.45)$ \\
\hline
\end{tabular}

Table L.3: Power estimated using Rbio3.1 wavelet function as an effect of time for left sternocleidomastoid muscle

\begin{tabular}{lllll}
\hline $\begin{array}{l}\text { Frequency } \\
\text { Band, Hz }\end{array}$ & $\mathrm{T}=0$ & $\mathrm{~T}=20$ & $\mathrm{~T}=25$ & $\mathrm{~T}=45$ \\
\hline $375-750$ & $0.58(0.53)$ & $0.72(0.64)$ & $0.59(0.66)$ & $0.86(0.91)$ \\
$187-375$ & $3.83(3.56)$ & $4.70(4.03)$ & $3.86(4.47)$ & $5.48(5.08)$ \\
$93-187$ & $8.08(7.88)$ & $10.16(8.58)$ & $8.26(9.71)$ & $11.78(9.76)$ \\
$46-93$ & $10.59(11.42)$ & $11.91(10.13)$ & $9.63(11.47)$ & $14.12(11.10)$ \\
$23-46$ & $6.13(7.67)$ & $9.26(8.12)$ & $7.89(12.11)$ & $13.74(9.99)$ \\
$12-23$ & $3.30(4.32)$ & $7.97(11.02)$ & $5.86(10.20)$ & $10.97(10.68)$ \\
$6-12$ & $6.17(8.32)$ & $14.03(22.16)$ & $8.24(18.21)$ & $11.40(15.71)$ \\
\hline
\end{tabular}


Table L.4: Power estimated using Coif5 wavelet function as an effect of time for left sternocleidomastoid muscle

\begin{tabular}{ccccc}
\hline $\begin{array}{l}\text { Frequency } \\
\text { Band, Hz }\end{array}$ & $\mathrm{T}=0$ & $\mathrm{~T}=20$ & $\mathrm{~T}=25$ & $\mathrm{~T}=45$ \\
\hline $375-750$ & $0.01(0.01)$ & $0.01(0.01)$ & $0.01(0.01)$ & $0.02(0.02)$ \\
$187-375$ & $0.09(0.09)$ & $0.11(0.13)$ & $0.09(0.09)$ & $0.15(0.23)$ \\
$93-187$ & $0.69(0.63)$ & $0.85(0.79)$ & $0.73(0.84)$ & $1.00(1.10)$ \\
$46-93$ & $1.18(1.13)$ & $1.51(1.29)$ & $1.12(1.24)$ & $1.71(1.47)$ \\
$23-46$ & $0.49(0.56)$ & $0.64(0.54)$ & $0.63(0.95)$ & $0.82(0.55)$ \\
$12-23$ & $0.08(0.09)$ & $0.15(0.15)$ & $0.13(0.15)$ & $0.20(0.19)$ \\
$6-12$ & $0.02(0.04)$ & $0.05(0.08)$ & $0.03(0.06)$ & $0.03(0.02)$ \\
\hline
\end{tabular}

Table L.5: Power estimated using Db2 wavelet function as an effect of time for left sternocleidomastoid muscle

\begin{tabular}{ccccc}
\hline $\begin{array}{l}\text { Frequency } \\
\text { Band, Hz }\end{array}$ & $\mathrm{T}=0$ & $\mathrm{~T}=20$ & $\mathrm{~T}=25$ & $\mathrm{~T}=45$ \\
\hline $375-750$ & $0.03(0.03)$ & $0.03(0.04)$ & $0.03(0.03)$ & $0.04(0.06)$ \\
$187-375$ & $0.18(0.17)$ & $0.23(0.22)$ & $0.18(0.19)$ & $0.28(0.34)$ \\
$93-187$ & $0.74(0.73)$ & $0.86(0.76)$ & $0.68(0.78)$ & $1.00(1.00)$ \\
$46-93$ & $1.02(0.92)$ & $1.33(1.19)$ & $1.14(1.40)$ & $1.55(1.39)$ \\
$23-46$ & $0.47(0.53)$ & $0.65(0.52)$ & $0.52(0.65)$ & $0.81(0.58)$ \\
$12-23$ & $0.11(0.12)$ & $0.16(0.18)$ & $0.15(0.21)$ & $0.24(0.31)$ \\
$6-12$ & $0.03(0.03)$ & $0.05(0.05)$ & $0.04(0.04)$ & $0.06(0.12)$ \\
\hline
\end{tabular}

Table L.6: Power estimated using Db5 wavelet function as an effect of time for left sternocleidomastoid muscle

\begin{tabular}{ccccc}
\hline $\begin{array}{l}\text { Frequency } \\
\text { Band, Hz }\end{array}$ & $\mathrm{T}=0$ & $\mathrm{~T}=20$ & $\mathrm{~T}=25$ & $\mathrm{~T}=45$ \\
\hline $375-750$ & $0.01(0.01)$ & $0.01(0.02)$ & $0.01(0.01)$ & $0.02(0.03)$ \\
$187-375$ & $0.11(0.11)$ & $0.14(0.15)$ & $0.11(0.11)$ & $0.17(0.25)$ \\
$93-187$ & $0.70(0.63)$ & $0.88(0.82)$ & $0.76(0.87)$ & $1.07(1.18)$ \\
$46-93$ & $1.11(1.07)$ & $1.44(1.23)$ & $1.10(1.29)$ & $1.61(1.36)$ \\
$23-46$ & $0.51(0.59)$ & $0.65(0.51)$ & $0.58(0.79)$ & $0.83(0.55)$ \\
$12-23$ & $0.10(0.12)$ & $0.15(0.16)$ & $0.15(0.23)$ & $0.20(0.20)$ \\
$6-12$ & $0.03(0.03)$ & $0.05(0.06)$ & $0.02(0.02)$ & $0.03(0.03)$ \\
\hline
\end{tabular}


Table L.7: Power estimated using Db45 wavelet function as an effect of time for left sternocleidomastoid muscle

\begin{tabular}{cllll}
\hline $\begin{array}{l}\text { Frequency } \\
\text { Band, Hz }\end{array}$ & $\mathrm{T}=0$ & $\mathrm{~T}=20$ & $\mathrm{~T}=25$ & $\mathrm{~T}=45$ \\
\hline $375-750$ & $0.01(0.01)$ & $0.01(0.01)$ & $0.01(0.01)$ & $0.01(0.02)$ \\
$187-375$ & $0.08(0.08)$ & $0.10(0.13)$ & $0.08(0.08)$ & $0.14(0.20)$ \\
$93-187$ & $0.67(0.65)$ & $0.82(0.76)$ & $0.68(0.76)$ & $0.99(1.10)$ \\
$46-93$ & $1.24(1.17)$ & $1.53(1.31)$ & $1.24(1.45)$ & $1.79(1.52)$ \\
$23-46$ & $0.44(0.53)$ & $0.66(0.55)$ & $0.53(0.74)$ & $0.76(0.54)$ \\
$12-23$ & $0.09(0.10)$ & $0.14(0.17)$ & $0.15(0.23)$ & $0.17(0.18)$ \\
$6-12$ & $0.02(0.03)$ & $0.04(0.06)$ & $0.03(0.06)$ & $0.03(0.02)$ \\
\hline
\end{tabular}

Table L.8: Power estimated using Haar wavelet function as an effect of time for left sternocleidomastoid muscle

\begin{tabular}{cllll}
\hline $\begin{array}{l}\text { Frequency } \\
\text { Band, Hz }\end{array}$ & $\mathrm{T}=0$ & $\mathrm{~T}=20$ & $\mathrm{~T}=25$ & $\mathrm{~T}=45$ \\
\hline $375-750$ & $0.10(0.09)$ & $0.12(0.11)$ & $0.10(0.10)$ & $0.15(0.17)$ \\
$187-375$ & $0.31(0.28)$ & $0.38(0.34)$ & $0.31(0.34)$ & $0.46(0.51)$ \\
$93-187$ & $0.72(0.63)$ & $0.93(0.84)$ & $0.79(0.88)$ & $1.13(1.16)$ \\
$46-93$ & $0.96(0.98)$ & $1.07(0.86)$ & $0.86(0.97)$ & $1.27(1.00)$ \\
$23-46$ & $0.35(0.38)$ & $0.56(0.49)$ & $0.47(0.72)$ & $0.63(0.45)$ \\
$12-23$ & $0.10(0.11)$ & $0.19(0.19)$ & $0.17(0.24)$ & $0.20(0.20)$ \\
$6-12$ & $0.04(0.06)$ & $0.06(0.08)$ & $0.04(0.06)$ & $0.06(0.06)$ \\
\hline
\end{tabular}

Table L.9: Power estimated using Sym4 wavelet function as an effect of time for left sternocleidomastoid muscle

\begin{tabular}{cllll}
\hline $\begin{array}{l}\text { Frequency } \\
\text { Band, Hz }\end{array}$ & $\mathrm{T}=0$ & $\mathrm{~T}=20$ & $\mathrm{~T}=25$ & $\mathrm{~T}=45$ \\
\hline $375-750$ & $0.01(0.01)$ & $0.01(0.02)$ & $0.01(0.01)$ & $0.02(0.03)$ \\
$187-375$ & $0.12(0.12)$ & $0.15(0.16)$ & $0.12(0.12)$ & $0.19(0.27)$ \\
$93-187$ & $0.70(0.62)$ & $0.89(0.83)$ & $0.78(0.90)$ & $1.07(1.18)$ \\
$46-93$ & $1.15(1.15)$ & $1.42(1.18)$ & $1.05(1.17)$ & $1.58(1.28)$ \\
$23-46$ & $0.44(0.49)$ & $0.62(0.53)$ & $0.59(0.86)$ & $0.81(0.56)$ \\
$12-23$ & $0.10(0.12)$ & $0.16(0.18)$ & $0.13(0.16)$ & $0.20(0.23)$ \\
$6-12$ & $0.03(0.05)$ & $0.05(0.07)$ & $0.04(0.09)$ & $0.04(0.04)$ \\
\hline
\end{tabular}


Table L.10: Power estimated using Sym5 wavelet function as an effect of time for left sternocleidomastoid muscle

\begin{tabular}{lllll}
\hline $\begin{array}{l}\text { Frequency } \\
\text { Band, Hz }\end{array}$ & $\mathrm{T}=0$ & $\mathrm{~T}=20$ & $\mathrm{~T}=25$ & $\mathrm{~T}=45$ \\
\hline $375-750$ & $0.01(0.01)$ & $0.01(0.01)$ & $0.01(0.01)$ & $0.02(0.03)$ \\
$187-375$ & $0.11(0.11)$ & $0.13(0.15)$ & $0.11(0.11)$ & $0.18(0.26)$ \\
$93-187$ & $0.70(0.66)$ & $0.86(0.78)$ & $0.71(0.85)$ & $0.97(1.02)$ \\
$46-93$ & $1.11(1.03)$ & $1.46(1.29)$ & $1.15(1.33)$ & $1.69(1.50)$ \\
$23-46$ & $0.50(0.59)$ & $0.65(0.51)$ & $0.56(0.74)$ & $0.85(0.58)$ \\
$12-23$ & $0.10(0.12)$ & $0.15(0.17)$ & $0.15(0.23)$ & $0.20(0.23)$ \\
$6-12$ & $0.02(0.03)$ & $0.05(0.05)$ & $0.03(0.04)$ & $0.05(0.09)$ \\
\hline
\end{tabular}




\section{Appendix M: Output of Turkey's test of multiple comparisons for left sternocleidomastoid muscle}

Frequency Band 23-46 Hz

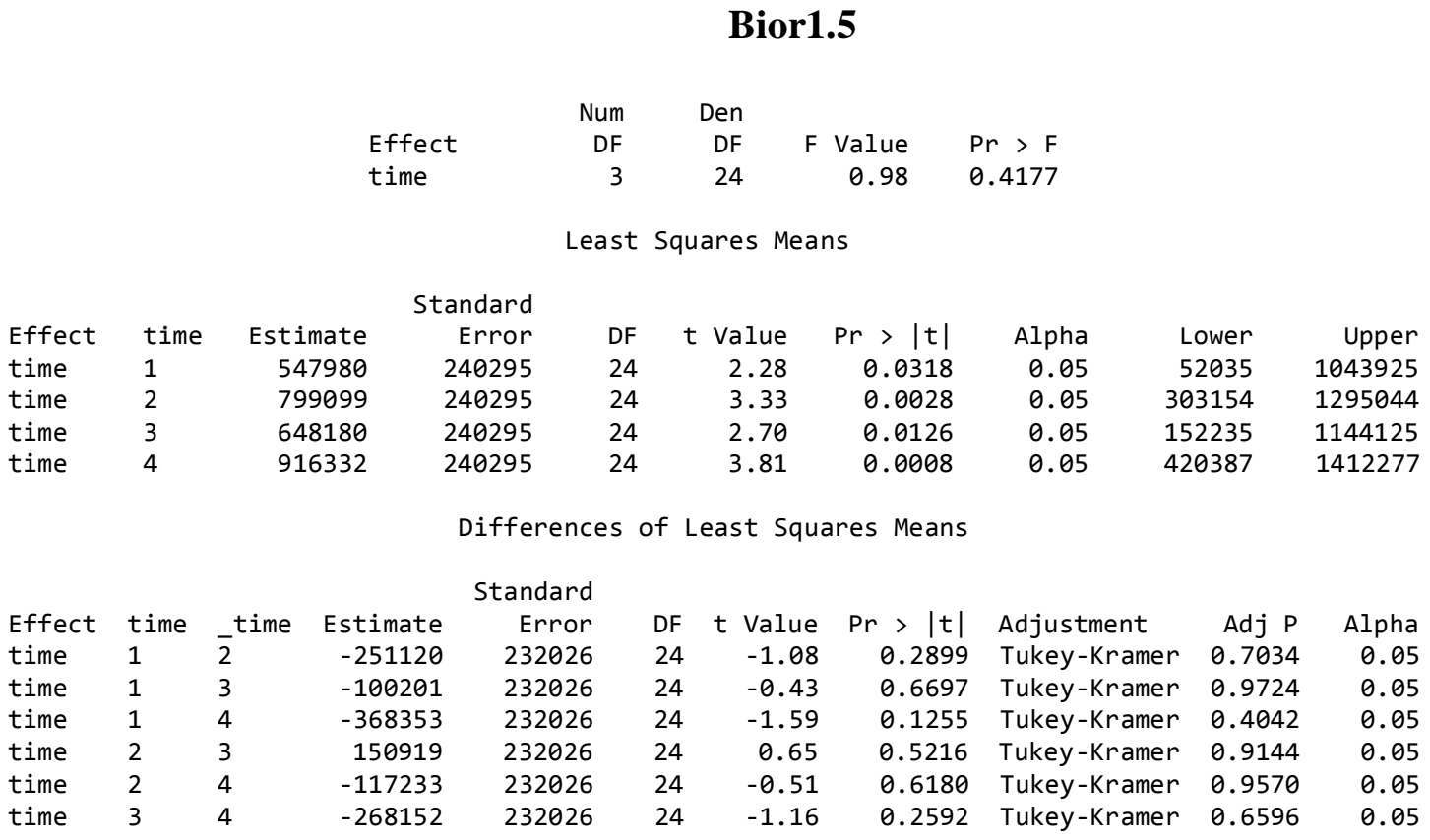

\section{Bior3.1}

$\begin{array}{lrrrl} & \text { Num } & \text { Den } & & \\ \text { Effect } & \text { DF } & \text { DF } & \text { F Value } & \text { Pr }>F \\ \text { time } & 3 & 24 & 1.11 & 0.3656\end{array}$

Least Squares Means

$\begin{array}{llrrrrrrrr}\text { Effect } & \text { time } & \text { Estimate } & \begin{array}{r}\text { Standard } \\ \text { Error }\end{array} & \text { DF } & t \text { Value } & \text { Pr > }|t| & \text { Alpha } & \text { Lower } & \text { Upper } \\ \text { time } & 1 & 2031534 & 1138340 & 24 & 1.78 & 0.0870 & 0.05 & -317883 & 4380952 \\ \text { time } & 2 & 3508366 & 1138340 & 24 & 3.08 & 0.0051 & 0.05 & 1158949 & 5857783 \\ \text { time } & 3 & 2794951 & 1138340 & 24 & 2.46 & 0.0217 & 0.05 & 445534 & 5144369 \\ \text { time } & 4 & 4289227 & 1138340 & 24 & 3.77 & 0.0009 & 0.05 & 1939810 & 6638645\end{array}$

Differences of Least Squares Means

$\begin{array}{lllrrrrrrrr}\text { Effect } & \text { time } & \text { time } & \text { Estimate } & \begin{array}{r}\text { Standard } \\ \text { Error }\end{array} & \text { DF } & \text { t Value } & \operatorname{Pr}>|t| & \text { Adjustment } & \text { Adj P } & \text { Alpha } \\ \text { time } & 1 & 2 & -1476832 & 1299254 & 24 & -1.14 & 0.2669 & \text { Tukey-Kramer } & 0.6710 & 0.05 \\ \text { time } & 1 & 3 & -763417 & 1299254 & 24 & -0.59 & 0.5623 & \text { Tukey-Kramer } & 0.9349 & 0.05 \\ \text { time } & 1 & 4 & -2257693 & 1299254 & 24 & -1.74 & 0.0951 & \text { Tukey-Kramer } & 0.3271 & 0.05 \\ \text { time } & 2 & 3 & 713415 & 1299254 & 24 & 0.55 & 0.5880 & \text { Tukey-Kramer } & 0.9459 & 0.05 \\ \text { time } & 2 & 4 & -780861 & 1299254 & 24 & -0.60 & 0.5535 & \text { Tukey-Kramer } & 0.9307 & 0.05 \\ \text { time } & 3 & 4 & -1494276 & 1299254 & 24 & -1.15 & 0.2614 & \text { Tukey-Kramer } & 0.6630 & 0.05\end{array}$




\section{Rbio3.1}

$\begin{array}{lrrrl} & \text { Num } & \text { Den } & & \\ \text { Effect } & \text { DF } & \text { DF } & \text { F Value } & \text { Pr }>F \\ \text { time } & 3 & 24 & 5.75 & 0.00041\end{array}$

Least Squares Means

$\begin{array}{llrrrrrrrr}\text { Effect } & \text { time } & \text { Estimate } & \begin{array}{r}\text { Standard } \\ \text { Error }\end{array} & \text { DF } & t \text { Value } & \text { Pr }>|t| & \text { Alpha } & \text { Lower } & \text { Upper } \\ \text { time } & 1 & 6128879 & 5309548 & 24 & 1.15 & 0.2597 & 0.05 & -4829489 & 17087247 \\ \text { time } & 2 & 16144226 & 5309548 & 24 & 3.04 & 0.0056 & 0.05 & 5185858 & 27102593 \\ \text { time } & 3 & 8109581 & 5309548 & 24 & 1.53 & 0.1397 & 0.05 & -2848787 & 19067949 \\ \text { time } & 4 & 27402967 & 5309548 & 24 & 5.16 & <.0001 & 0.05 & 16444599 & 38361335\end{array}$

Differences of Least Squares Means

$\begin{array}{lllrrrrrrrr}\text { Effect } & \text { time } & \text { _time } & \text { Estimate } & \begin{array}{r}\text { Standard } \\ \text { Error }\end{array} & \text { DF } & \text { t Value } & \operatorname{Pr}>|t| & \text { Adjustment } & \text { Adj P } & \text { Alpha } \\ \text { time } & 1 & 2 & -1.002 E 7 & 5697683 & 24 & -1.76 & 0.0915 & \text { Tukey-Kramer } & 0.3175 & 0.05 \\ \text { time } & 1 & 3 & -1980702 & 5697683 & 24 & -0.35 & 0.7311 & \text { Tukey-Kramer } & 0.9852 & 0.05 \\ \text { time } & 1 & 4 & -2.127 E 7 & 5697683 & 24 & -3.73 & 0.0010 & \text { Tukey-Kramer } & 0.0053 & 0.05 \\ \text { time } & 2 & 3 & 8034645 & 5697683 & 24 & 1.41 & 0.1713 & \text { Tukey-Kramer } & 0.5055 & 0.05 \\ \text { time } & 2 & 4 & -1.126 \mathrm{E} 7 & 5697683 & 24 & -1.98 & 0.0598 & \text { Tukey-Kramer } & 0.2248 & 0.05 \\ \text { time } & 3 & 4 & -1.929 \mathrm{E} 7 & 5697683 & 24 & -3.39 & 0.0024 & \text { Tukey-Kramer } & 0.0122 & 0.05\end{array}$

\section{Coif5}

$\begin{array}{lrrrl} & \text { Num } & \text { Den } & & \\ \text { Effect } & \text { DF } & \text { DF } & \text { F Value } & \text { Pr > F } \\ \text { time } & 3 & 24 & 0.69 & 0.5664\end{array}$

Least Squares Means

$\begin{array}{llrrrrrrrr} & & & & & & \\ \text { Effect } & \text { time } & \text { Estimate } & \text { Error } & \text { DF } & \mathrm{t} \text { Value } & \mathrm{Pr}>|\mathrm{t}| & \text { Alpha } & \text { Lower } & \text { Upper } \\ \text { time } & 1 & 487670 & 223429 & 24 & 2.18 & 0.0391 & 0.05 & 26536 & 948805 \\ \text { time } & 2 & 641957 & 223429 & 24 & 2.87 & 0.0084 & 0.05 & 180823 & 1103092 \\ \text { time } & 3 & 626174 & 223429 & 24 & 2.80 & 0.0099 & 0.05 & 165039 & 1087308 \\ \text { time } & 4 & 824368 & 223429 & 24 & 3.69 & 0.0011 & 0.05 & 363233 & 1285502\end{array}$

Differences of Least Squares Means

\begin{tabular}{|c|c|c|c|c|c|c|c|c|c|c|}
\hline Effect & time & _time & Estimate & $\begin{array}{r}\text { Standard } \\
\text { Error }\end{array}$ & DF & t Value & $\operatorname{Pr}>|t|$ & Adjustment & Adj $P$ & Alpha \\
\hline me & 1 & 2 & -154287 & 235091 & 24 & -0.66 & 0.5179 & Tukey-Kramer & 0.9123 & 0.05 \\
\hline ime & 1 & 3 & -138503 & 235091 & 24 & -0.59 & 0.5613 & Tukey-Kramer & 0.9344 & 0.05 \\
\hline ime & 1 & 4 & -336698 & 235091 & 24 & -1.43 & 0.1650 & Tukey-Kramer & 0.4924 & 0.05 \\
\hline & 2 & 3 & 15784 & 235091 & 24 & 0.07 & 0.9470 & Tukey-Kramer & 0.9999 & 0.05 \\
\hline ne & 2 & 4 & -182411 & 235091 & 24 & -0.78 & 0.4454 & Tukey-Kramer & 0.8645 & 0.05 \\
\hline ne & 3 & 4 & -198194 & 235091 & 24 & -0.84 & 0.4075 & Tukey-Kramer & 0.8334 & 0.05 \\
\hline
\end{tabular}




\section{Db2}

$\begin{array}{lrrrr} & \text { Num } & \text { Den } & & \\ \text { Effect } & \text { DF } & \text { DF } & \text { F Value } & \text { Pr > F } \\ \text { time } & 3 & 24 & 1.28 & 0.3050\end{array}$

Least Squares Means

\begin{tabular}{|c|c|c|c|c|c|c|c|c|c|}
\hline & & & tandard & & & & & & \\
\hline Effect & time & Estimate & Error & DF & t Value & $\operatorname{Pr}>|t|$ & Alpha & Lower & Upper \\
\hline time & 1 & 471329 & 191332 & 24 & 2.46 & 0.0213 & 0.05 & 76439 & 866218 \\
\hline time & 2 & 654672 & 191332 & 24 & 3.42 & 0.0022 & 0.05 & 259783 & 1049561 \\
\hline ime & 3 & 521174 & 191332 & 24 & 2.72 & 0.0118 & 0.05 & 126285 & 916063 \\
\hline ime & 4 & 812831 & 191332 & 24 & 4.25 & 0.0003 & 0.05 & 417941 & 1207720 \\
\hline
\end{tabular}

Differences of Least Squares Means

$\begin{array}{lllrrrrrrrr}\text { Effect } & \text { time } & \text { time } & \text { Estimate } & \begin{aligned} \text { Standard } \\ \text { Error }\end{aligned} & \text { DF } & \text { t Value } & \text { Pr }>|t| & \text { Adjustment } & \text { Adj P } & \text { Alpha } \\ \text { time } & 1 & 2 & -183343 & 191432 & 24 & -0.96 & 0.3477 & \text { Tukey-Kramer } & 0.7742 & 0.05 \\ \text { time } & 1 & 3 & -49845 & 191432 & 24 & -0.26 & 0.7968 & \text { Tukey-Kramer } & 0.9936 & 0.05 \\ \text { time } & 1 & 4 & -341502 & 191432 & 24 & -1.78 & 0.0871 & \text { Tukey-Kramer } & 0.3052 & 0.05 \\ \text { time } & 2 & 3 & 133498 & 191432 & 24 & 0.70 & 0.4923 & \text { Tukey-Kramer } & 0.8971 & 0.05 \\ \text { time } & 2 & 4 & -158159 & 191432 & 24 & -0.83 & 0.4168 & \text { Tukey-Kramer } & 0.8415 & 0.05 \\ \text { time } & 3 & 4 & -291657 & 191432 & 24 & -1.52 & 0.1407 & \text { Tukey-Kramer } & 0.4397 & 0.05\end{array}$

\section{Db5}

$\begin{array}{lrrrr} & \text { Num } & \text { Den } & & \\ \text { Effect } & \text { DF } & \text { DF } & F \text { Value } & \text { Pr > F } \\ \text { time } & 3 & 24 & 0.92 & 0.4456\end{array}$

Least Squares Means

\begin{tabular}{|c|c|c|c|c|c|c|c|c|c|}
\hline & & & tandard & & & & & & \\
\hline Effect & time & Estimate & Error & DF & t Value & $\operatorname{Pr}>|t|$ & Alpha & Lower & Upper \\
\hline time & 1 & 505078 & 206392 & 24 & 2.45 & 0.0221 & 0.05 & 79107 & 931050 \\
\hline time & 2 & 645040 & 206392 & 24 & 3.13 & 0.0046 & 0.05 & 219068 & 1071011 \\
\hline time & 3 & 576620 & 206392 & 24 & 2.79 & 0.0101 & 0.05 & 150649 & 1002591 \\
\hline me & 4 & 827175 & 206392 & 24 & 4.01 & 0.0005 & 0.05 & 401203 & 1253146 \\
\hline
\end{tabular}

Differences of Least Squares Means

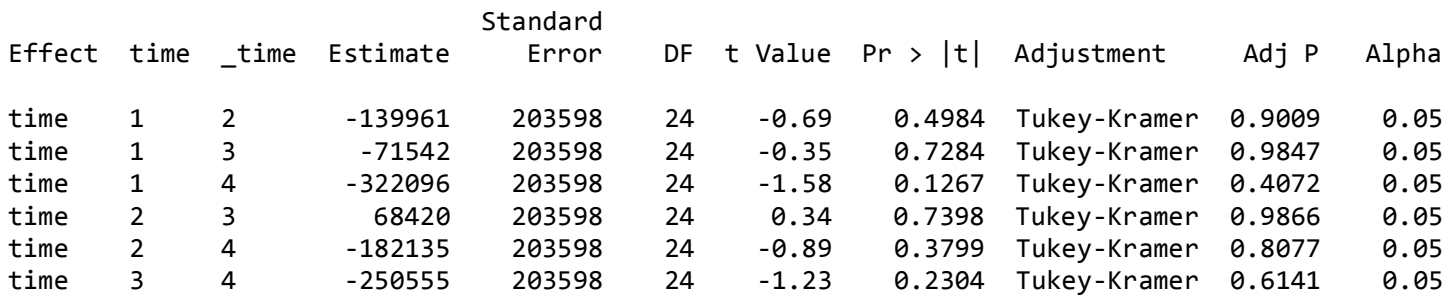




\section{Db45}

$\begin{array}{lrrrl} & \text { Num } & \text { Den } & & \\ \text { Effect } & \text { DF } & \text { DF } & \text { F Value } & \text { Pr > F } \\ \text { time } & 3 & 24 & 1.07 & 0.3815\end{array}$

Least Squares Means

\begin{tabular}{|c|c|c|c|c|c|c|c|c|c|}
\hline Effect & time & Estimate & $\begin{array}{c}\text { tandard } \\
\text { Error }\end{array}$ & DF & t Value & $\operatorname{Pr}>|t|$ & Alpha & Lower & Upper \\
\hline time & 2 & 655342 & 198305 & 24 & 3.30 & 0.0030 & 0.05 & 246059 & 1064624 \\
\hline time & 4 & 763600 & 198305 & 24 & 3.85 & 0.0008 & 0.05 & 354317 & 1172882 \\
\hline
\end{tabular}

Differences of Least Squares Means

$\begin{array}{lllrrrrrrrrr}\text { Effect } & \text { time } & \text { _time } & \text { Estimate } & \begin{array}{c}\text { Standard } \\ \text { Error }\end{array} & \text { DF } & t \text { Value } & \text { Pr }>|t| & \text { Adjustment } & \text { Adj P Alpha } \\ \text { time } & 1 & 2 & -213440 & 192684 & 24 & -1.11 & 0.2790 & \text { Tukey-Kramer } & 0.6884 & 0.05 \\ \text { time } & 1 & 3 & -90075 & 192684 & 24 & -0.47 & 0.6444 & \text { Tukey-Kramer } & 0.9655 & 0.05 \\ \text { time } & 1 & 4 & -321698 & 192684 & 24 & -1.67 & 0.1080 & \text { Tukey-Kramer } & 0.3610 & 0.05 \\ \text { time } & 2 & 3 & 123365 & 192684 & 24 & 0.64 & 0.5281 & \text { Tukey-Kramer } & 0.9179 & 0.05 \\ \text { time } & 2 & 4 & -108258 & 192684 & 24 & -0.56 & 0.5794 & \text { Tukey-Kramer } & 0.9424 & 0.05 \\ \text { time } & 3 & 4 & -231623 & 192684 & 24 & -1.20 & 0.2411 & \text { Tukey-Kramer } & 0.6315 & 0.05\end{array}$

\section{Haar}

$\begin{array}{lrrrl} & \text { Num } & \text { Den } & & \\ \text { Effect } & \text { DF } & \text { DF } & \text { F Value } & \text { Pr > F } \\ \text { time } & 3 & 24 & 0.86 & 0.4772\end{array}$

Least Squares Means

\begin{tabular}{|c|c|c|c|c|c|c|c|c|c|}
\hline Effect & time & Estimate & $\begin{array}{r}\text { tandard } \\
\text { Error }\end{array}$ & DF & t Value & $\operatorname{Pr}>|t|$ & Alpha & Lower & Upper \\
\hline time & 2 & 561368 & 174455 & 24 & 3.22 & 0.0037 & 0.05 & 201312 & 921425 \\
\hline time & 4 & 628510 & 174455 & 24 & 3.60 & 0.0014 & 0.05 & 268453 & 988566 \\
\hline
\end{tabular}

Differences of Least Squares Means

$\begin{array}{lllrrrrrrrr}\text { Effect } & \text { time } & \text { _time } & \text { Estimate } & \begin{array}{c}\text { Standard } \\ \text { Error }\end{array} & \text { DF } & \text { t Value } & \text { Pr }>|t| & \text { Adjustment } & \text { Adj P Alpha } \\ \text { time } & 1 & 2 & -213871 & 185468 & 24 & -1.15 & 0.2602 & \text { Tukey-Kramer } & 0.6611 & 0.05 \\ \text { time } & 1 & 3 & -126590 & 185468 & 24 & -0.68 & 0.5014 & \text { Tukey-Kramer } & 0.9027 & 0.05 \\ \text { time } & 1 & 4 & -281012 & 185468 & 24 & -1.52 & 0.1428 & \text { Tukey-Kramer } & 0.4444 & 0.05 \\ \text { time } & 2 & 3 & 87281 & 185468 & 24 & 0.47 & 0.6422 & \text { Tukey-Kramer } & 0.9648 & 0.05 \\ \text { time } & 2 & 4 & -67142 & 185468 & 24 & -0.36 & 0.7205 & \text { Tukey-Kramer } & 0.9834 & 0.05 \\ \text { time } & 3 & 4 & -154423 & 185468 & 24 & -0.83 & 0.4133 & \text { Tukey-Kramer } & 0.8385 & 0.05\end{array}$




\section{Sym4}

$\begin{array}{lrrrl} & \text { Num } & \text { Den } & & \\ \text { Effect } & \text { DF } & \text { DF } & F \text { Value } & \text { Pr > F } \\ \text { time } & 3 & 24 & 0.93 & 0.4411\end{array}$

Least Squares Means

$\begin{array}{llrrrrrrrr}\text { Effect } & \text { time } & \text { Estimate } & \begin{array}{r}\text { Standard } \\ \text { Error }\end{array} & \text { DF } & t \text { Value } & \text { Pr > |t| } & \text { Alpha } & \text { Lower } & \text { Upper } \\ \text { time } & 1 & 441088 & 208756 & 24 & 2.11 & 0.0452 & 0.05 & 10237 & 871939 \\ \text { time } & 2 & 621173 & 208756 & 24 & 2.98 & 0.0066 & 0.05 & 190322 & 1052024 \\ \text { time } & 3 & 587616 & 208756 & 24 & 2.81 & 0.0096 & 0.05 & 156765 & 1018468 \\ \text { time } & 4 & 811523 & 208756 & 24 & 3.89 & 0.0007 & 0.05 & 380672 & 1242374\end{array}$

Differences of Least Squares Means

\begin{tabular}{|c|c|c|c|c|c|c|c|c|c|c|}
\hline Effect & time & time & Estimate & $\begin{array}{l}\text { Standard } \\
\text { Error }\end{array}$ & DF & t Value & $\mathrm{Pr}>|\mathrm{t}|$ & Adjustment & Adj $P$ & Alpha \\
\hline time & 1 & $\overline{2}^{-2116}$ & -180085 & 223381 & 24 & -0.81 & 0.4281 & Tukey-Kramer & 0.8509 & 0.05 \\
\hline time & 1 & 3 & -146528 & 223381 & 24 & -0.66 & 0.5181 & Tukey-Kramer & 0.9124 & 0.05 \\
\hline time & 1 & 4 & -370435 & 223381 & 24 & -1.66 & 0.1103 & Tukey-Kramer & 0.3667 & 0.05 \\
\hline time & 2 & 3 & 33557 & 223381 & 24 & 0.15 & 0.8818 & Tukey-Kramer & 0.9988 & 0.05 \\
\hline time & 2 & 4 & -190350 & 223381 & 24 & -0.85 & 0.4026 & Tukey-Kramer & 0.8290 & 0.05 \\
\hline time & 3 & 4 & -223907 & 223381 & 24 & -1.00 & 0.3262 & Tukey-Kramer & 0.7495 & 0.05 \\
\hline
\end{tabular}

\section{Sym5}

$\begin{array}{lrrrl} & \text { Num } & \text { Den } & & \\ \text { Effect } & \text { DF } & \text { DF } & \text { F Value } & \text { Pr }>F \\ \text { time } & 3 & 24 & 1.11 & 0.3661\end{array}$

Least Squares Means

\begin{tabular}{|c|c|c|c|c|c|c|c|c|c|}
\hline & & & tandard & & & & & & \\
\hline Effect & time & Estimate & Error & DF & t Value & $P r>|t|$ & Alpha & Lower & Upper \\
\hline time & 1 & 503490 & 202876 & 24 & 2.48 & 0.0205 & 0.05 & 84775 & 922205 \\
\hline time & 2 & 654343 & 202876 & 24 & 3.23 & 0.0036 & 0.05 & 235628 & 1073058 \\
\hline time & 3 & 563222 & 202876 & 24 & 2.78 & 0.0105 & 0.05 & 144507 & 981938 \\
\hline time & 4 & 847394 & 202876 & 24 & 4.18 & 0.0003 & 0.05 & 428679 & 1266109 \\
\hline
\end{tabular}

Differences of Least Squares Means

$\begin{array}{lllrrrrrrrr}\text { Effect } & \text { time } & \text { _time } & \text { Estimate } & \begin{array}{r}\text { Standard } \\ \text { Error }\end{array} & \text { DF } & \text { t Value } & \text { Pr }>|t| & \text { Adjustment } & \text { Adj P } & \text { Alpha } \\ \text { time } & 1 & 2 & -150853 & 202073 & 24 & -0.75 & 0.4626 & \text { Tukey-Kramer } & 0.8772 & 0.05 \\ \text { time } & 1 & 3 & -258879 & 3045877 & 27 & -0.08 & 0.9329 & \text { Tukey-Kramer } & 0.9998 & 0.05 \\ \text { time } & 1 & 4 & -6590670 & 3045877 & 27 & -2.16 & 0.0395 & \text { Tukey-Kramer } & 0.1592 & 0.05 \\ \text { time } & 2 & 3 & 6288970 & 3045877 & 27 & 2.06 & 0.0487 & \text { Tukey-Kramer } & 0.1903 & 0.05 \\ \text { time } & 2 & 4 & -42820 & 3045877 & 27 & -0.01 & 0.9889 & \text { Tukey-Kramer } & 1.0000 & 0.05 \\ \text { time } & 3 & 4 & -6331791 & 3045877 & 27 & -2.08 & 0.0473 & \text { Tukey-Kramer } & 0.1856 & 0.05\end{array}$




\section{Bior1.5}

\begin{tabular}{|c|c|c|c|c|c|c|c|c|c|c|c|}
\hline & & & \multicolumn{2}{|c|}{$\begin{array}{l}\text { Effect } \\
\text { time }\end{array}$} & \multicolumn{2}{|c|}{$\begin{array}{r}\text { DF } \\
3\end{array}$} & $\begin{array}{r}\text { Den } \\
\text { DF } \\
24\end{array}$ & $\begin{array}{r}\text { Value } \\
1.94\end{array}$ & \multicolumn{3}{|l|}{$\begin{array}{l}\mathrm{Pr}>\mathrm{F} \\
0.1508\end{array}$} \\
\hline \multicolumn{12}{|c|}{ Least Squares Means } \\
\hline \multicolumn{12}{|c|}{ Standard } \\
\hline Effect & time & Esti & nate & Error & & & t Value & $\operatorname{Pr}>|t|$ & Alpha & Lower & Upper \\
\hline time & 1 & & 0064 & 70497 & & & 1.56 & 0.1316 & 0.05 & -35434 & 255563 \\
\hline time & 2 & & 8637 & 70497 & & & 2.96 & 0.0068 & 0.05 & 63139 & 354136 \\
\hline time & 3 & & 1955 & 70497 & & & 2.44 & 0.0225 & 0.05 & 26456 & 317454 \\
\hline time & 4 & & 1411 & 70497 & & & 4.13 & 0.0004 & 0.05 & 45912 & 436910 \\
\hline \multicolumn{12}{|c|}{ Differences of Least Squares Means } \\
\hline \multicolumn{12}{|c|}{ Standard } \\
\hline time & 1 & $\overline{2}$ & -98573 & & & 24 & -1.28 & 0.2129 & Tukey-Kramer & 0.5841 & 0.05 \\
\hline time & 1 & 3 & -61891 & & & 24 & -0.80 & 0.4296 & Tukey-Kramer & 0.8521 & 0.05 \\
\hline time & 1 & 4 & -181346 & & & 24 & -2.35 & 0.0271 & Tukey-Kramer & 0.1137 & 0.05 \\
\hline time & 2 & 3 & 36682 & & & 24 & 0.48 & 0.6382 & Tukey-Kramer & 0.9636 & 0.05 \\
\hline time & 2 & 4 & -82774 & & & 24 & -1.07 & 0.2932 & Tukey-Kramer & 0.7079 & 0.05 \\
\hline time & 3 & 4 & -119456 & & & 24 & -1.55 & 0.1340 & Tukey-Kramer & 0.4244 & 0.05 \\
\hline
\end{tabular}

\section{Bior3.1}

$\begin{array}{lrrrl} & \text { Num } & \text { Den } & & \\ \text { Effect } & \text { DF } & \text { DF } & \text { F Value } & \text { Pr > F } \\ \text { time } & 3 & 24 & 2.97 & 0.0501\end{array}$

Least Squares Means

\begin{tabular}{|c|c|c|c|c|c|c|c|c|c|}
\hline Effect & time & Estimate & $\begin{array}{r}\text { Standard } \\
\text { Error }\end{array}$ & DF & t Value & $\operatorname{Pr}>|t|$ & Alpha & Lower & Upper \\
\hline time & 2 & 4848410 & 1565382 & 24 & 3.10 & 0.0049 & 0.05 & 1617621 & 8079198 \\
\hline time & 4 & 7359662 & 1565382 & 24 & 4.70 & $<.0001$ & 0.05 & 4128874 & 10590451 \\
\hline
\end{tabular}

Differences of Least Squares Means

$\begin{array}{lllrrrrrrrr}\text { Effect } & \text { time } & \text { time } & \text { Estimate } & \begin{array}{r}\text { Standard } \\ \text { Error }\end{array} & \text { DF } & \text { t Value } & \text { Pr }>|t| & \text { Adjustment } & \text { Adj P } & \text { Alpha } \\ \text { time } & 1 & 2 & -2466016 & 1838239 & 24 & -2.34 & 0.0323 & \text { Tukey-Kramer } & 0.5466 & 0.05 \\ \text { time } & 1 & 3 & -702818 & 1838239 & 24 & -0.38 & 0.7056 & \text { Tukey-Kramer } & 0.9805 & 0.05 \\ \text { time } & 1 & 4 & -4977269 & 1838239 & 24 & -2.71 & 0.0123 & \text { Tukey-Kramer } & 0.0557 & 0.05 \\ \text { time } & 2 & 3 & 1763198 & 1838239 & 24 & 0.96 & 0.3470 & \text { Tukey-Kramer } & 0.7734 & 0.05 \\ \text { time } & 2 & 4 & -2511253 & 1838239 & 24 & -1.37 & 0.1846 & \text { Tukey-Kramer } & 0.5318 & 0.05 \\ \text { time } & 3 & 4 & -4274451 & 1838239 & 24 & -2.33 & 0.0288 & \text { Tukey-Kramer } & 0.1202 & 0.05\end{array}$




\section{Rbio3.1}

$\begin{array}{lrrrl} & \text { Num } & \text { Den } & & \\ \text { Effect } & \text { DF } & \text { DF } & \text { F Value } & \text { Pr }>F \\ \text { time } & 3 & 24 & 3.61 & 0.03\end{array}$

Least Squares Means

\begin{tabular}{|c|c|c|c|c|c|c|c|c|c|}
\hline Effect & time & Estimate & $\begin{array}{r}\text { Standard } \\
\text { Error }\end{array}$ & DF & t Value & $\operatorname{Pr}>|t|$ & Alpha & Lower & Upper \\
\hline time & 2 & 10405850 & 3533538 & 24 & 2.94 & 0.0071 & 0.05 & 3112987 & 17698713 \\
\hline time & 4 & 15053734 & 3533538 & 24 & 4.26 & 0.0003 & 0.05 & 7760870 & 22346597 \\
\hline
\end{tabular}

Differences of Least Squares Means

$\begin{array}{lllrrrrrrrr}\text { Effect } & \text { time } & \text {-time } & \text { Estimate } & \begin{array}{r}\text { Standard } \\ \text { Error }\end{array} & \text { DF } & \text { t Value } & \text { Pr }>|t| & \text { Adjustment } & \text { Adj P } & \text { Alpha } \\ \text { time } & 1 & 2 & -7108979 & 4226186 & 24 & -2.08 & 0.0455 & \text { Tukey-Kramer } & 0.3546 & 0.05 \\ \text { time } & 1 & 3 & -2561293 & 4226186 & 24 & -0.61 & 0.5502 & \text { Tukey-Kramer } & 0.9292 & 0.05 \\ \text { time } & 1 & 4 & -1.176 E 7 & 4226186 & 24 & -2.78 & 0.0104 & \text { Tukey-Kramer } & 0.0476 & 0.05 \\ \text { time } & 2 & 3 & 4547686 & 4226186 & 24 & 1.08 & 0.2926 & \text { Tukey-Kramer } & 0.7071 & 0.05 \\ \text { time } & 2 & 4 & -4647884 & 4226186 & 24 & -1.10 & 0.2823 & \text { Tukey-Kramer } & 0.6931 & 0.05 \\ \text { time } & 3 & 4 & -9195569 & 4226186 & 24 & -2.18 & 0.0396 & \text { Tukey-Kramer } & 0.1587 & 0.05\end{array}$

\section{Coif5}

$\begin{array}{lrrrl} & \text { Num } & \text { Den } & & \\ \text { Effect } & \text { DF } & \text { DF } & \text { F Value } & \text { Pr > F } \\ \text { time } & 3 & 24 & 3.27 & 0.04\end{array}$

Least Squares Means

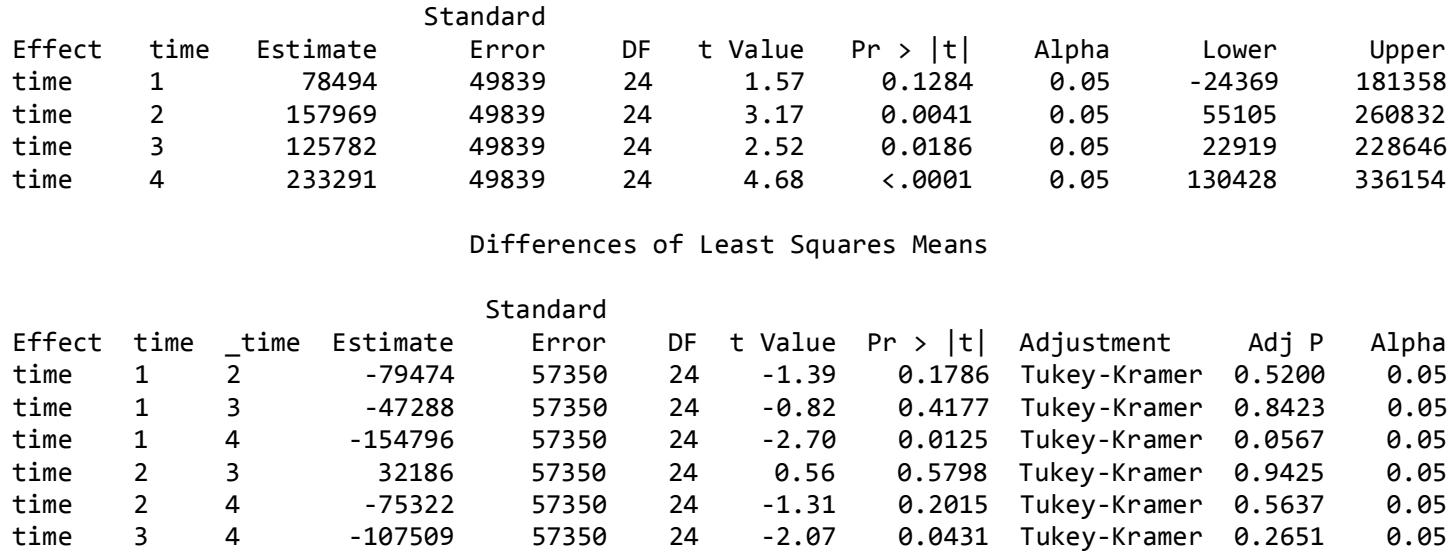




\section{Db2}

$\begin{array}{lrrrr} & \text { Num } & \text { Den } & & \\ \text { Effect } & \text { DF } & \text { DF } & \text { F Value } & \text { Pr }>F \\ \text { time } & 3 & 24 & 2.05 & 0.1339\end{array}$

Least Squares Means

\begin{tabular}{|c|c|c|c|c|c|c|c|c|c|c|c|c|}
\hline \multirow{2}{*}{ Effect } & \multirow[b]{2}{*}{ time } & \multicolumn{3}{|c|}{ Standard } & & & \multirow[b]{2}{*}{$\operatorname{Pr}>|t|$} & \multirow[b]{2}{*}{ Alpha } & \multirow{2}{*}{\multicolumn{2}{|c|}{ Lower }} & \multirow[b]{2}{*}{ Upper } \\
\hline & & \multicolumn{2}{|c|}{ Estimate } & Error & \multicolumn{2}{|c|}{ DF } & t Value & & & & & \\
\hline time & 1 & \multicolumn{2}{|c|}{108848} & 72147 & \multicolumn{2}{|c|}{24} & 1.51 & 0.1444 & 0.05 & -40056 & Lower & 257752 \\
\hline ime & 2 & \multicolumn{2}{|c|}{183041} & 72147 & \multicolumn{2}{|c|}{24} & 2.54 & 0.0181 & 0.05 & \multicolumn{2}{|c|}{34137} & 331946 \\
\hline ime & 3 & \multicolumn{2}{|c|}{147818} & 72147 & \multicolumn{2}{|c|}{24} & 2.05 & 0.0516 & 0.05 & \multicolumn{2}{|c|}{-1086.83} & 296722 \\
\hline \multirow[t]{3}{*}{ time } & 4 & & 5714 & 72147 & & & 4.11 & 0.0004 & 0.05 & & 809 & 445618 \\
\hline & \multicolumn{12}{|c|}{ Differences of Least Squares Means } \\
\hline & & & & Stanc & & & & & & & & \\
\hline ffect & time & _time & Estimate & & & DF & t Value & $P r>|t|$ & Adjustme & & Adj $P$ & Alpha \\
\hline ime & 1 & $\overline{2}$ & -74193 & & & 24 & -0.93 & 0.3630 & Tukey-Kr & amer & 0.7906 & 0.05 \\
\hline ime & 1 & 3 & -38969 & & & 24 & -0.49 & 0.6306 & Tukey-Kr & amer & 0.9612 & 0.05 \\
\hline ime & 1 & 4 & -187865 & & & 24 & -2.35 & 0.0274 & Tukey-Kr & amer & 0.1151 & 0.05 \\
\hline me & 2 & 3 & 35224 & & & 24 & 0.44 & 0.6637 & Tukey-Kr & amer & 0.9708 & 0.05 \\
\hline & 2 & 4 & -113672 & & & 24 & -1.42 & 0.1682 & Tukey-Kr & amer & 0.4991 & 0.05 \\
\hline me & 3 & 4 & -148896 & & & 24 & -1.96 & 0.0540 & Tukey-Kr & amer & 0.2709 & 0.05 \\
\hline
\end{tabular}

\section{Db5}

$\begin{array}{lrrrl} & \text { Num } & \text { Den } & & \\ \text { Effect } & \text { DF } & \text { DF } & \text { F Value } & \text { Pr > F } \\ \text { time } & 3 & 24 & 1.83 & 0.1692\end{array}$

Least Squares Means

\begin{tabular}{llrrrrrrrr} 
& \multicolumn{7}{c}{ Standard } & & \\
Effect & time & Estimate & Error & DF & t Value & Pr $>|t|$ & Alpha & Lower & Upper \\
time & 1 & 99718 & 60885 & 24 & 1.64 & 0.1145 & 0.05 & -25942 & 225377 \\
time & 2 & 171002 & 60885 & 24 & 2.81 & 0.0097 & 0.05 & 45342 & 296661 \\
time & 3 & 151876 & 60885 & 24 & 2.49 & 0.0199 & 0.05 & 26216 & 277536 \\
time & 4 & 246085 & 60885 & 24 & 4.04 & 0.0005 & 0.05 & 120426 & 371745
\end{tabular}

Differences of Least Squares Means

$\begin{array}{lllrrrrrrrr}\text { Effect } & \text { time } & \text { time } & \text { Estimate } & \begin{array}{r}\text { Standard } \\ \text { Error }\end{array} & \text { DF } & \text { t Value } & \text { Pr }>|t| & \text { Adjustment } & \text { Adj P } & \text { Alpha } \\ \text { time } & 1 & 2 & -71284 & 63432 & 24 & -1.12 & 0.2722 & \text { Tukey-Kramer } & 0.6788 & 0.05 \\ \text { time } & 1 & 3 & -52158 & 63432 & 24 & -0.82 & 0.4190 & \text { Tukey-Kramer } & 0.8434 & 0.05 \\ \text { time } & 1 & 4 & -146368 & 63432 & 24 & -2.31 & 0.0300 & \text { Tukey-Kramer } & 0.1244 & 0.05 \\ \text { time } & 2 & 3 & 19126 & 63432 & 24 & 0.30 & 0.7656 & \text { Tukey-Kramer } & 0.9902 & 0.05 \\ \text { time } & 2 & 4 & -75084 & 63432 & 24 & -1.18 & 0.2481 & \text { Tukey-Kramer } & 0.6427 & 0.05 \\ \text { time } & 3 & 4 & -94210 & 63432 & 24 & -1.49 & 0.1505 & \text { Tukey-Kramer } & 0.4615 & 0.05\end{array}$




\section{Db45}

$\begin{array}{lrrrl} & \text { Num } & \text { Den } & & \\ \text { Effect } & \text { DF } & \text { DF } & \text { F Value } & \text { Pr }>F \\ \text { time } & 3 & 24 & 1.28 & 0.3035\end{array}$

Least Squares Means

$\begin{array}{llrrrrrrrr} & & & & & \\ \text { Effect } & \text { time } & \text { Estimate } & \text { Error } & \text { DF } & \mathrm{t} \text { Value } & \operatorname{Pr}>|\mathrm{t}| & \text { Alpha } & \text { Lower } & \text { Upper } \\ \text { time } & 1 & 86938 & 58026 & 24 & 1.50 & 0.1471 & 0.05 & -32821 & 206697 \\ \text { time } & 2 & 166187 & 58026 & 24 & 2.86 & 0.0086 & 0.05 & 46428 & 285946 \\ \text { time } & 3 & 146262 & 58026 & 24 & 2.52 & 0.0188 & 0.05 & 26503 & 266021 \\ \text { time } & 4 & 208660 & 58026 & 24 & 3.60 & 0.0015 & 0.05 & 88901 & 328419\end{array}$

Differences of Least Squares Means

$\begin{array}{lllrrrrrrrr}\text { Effect } & \text { time } & \text { time } & \text { Estimate } & \begin{array}{r}\text { Standard } \\ \text { Error }\end{array} & \text { DF } & \text { t Value } & \operatorname{Pr}>|\mathrm{t}| & \text { Adjustment } & \text { Adj P } & \text { Alpha } \\ \text { time } & 1 & 2 & -79249 & 63217 & 24 & -1.25 & 0.2221 & \text { Tukey-Kramer } & 0.6001 & 0.05 \\ \text { time } & 1 & 3 & -59325 & 63217 & 24 & -0.94 & 0.3574 & \text { Tukey-Kramer } & 0.7847 & 0.05 \\ \text { time } & 1 & 4 & -121722 & 63217 & 24 & -1.93 & 0.0661 & \text { Tukey-Kramer } & 0.2443 & 0.05 \\ \text { time } & 2 & 3 & 19925 & 63217 & 24 & 0.32 & 0.7553 & \text { Tukey-Kramer } & 0.9889 & 0.05 \\ \text { time } & 2 & 4 & -42473 & 63217 & 24 & -0.67 & 0.5081 & \text { Tukey-Kramer } & 0.9067 & 0.05 \\ \text { time } & 3 & 4 & -62397 & 63217 & 24 & -0.99 & 0.3335 & \text { Tukey-Kramer } & 0.7581 & 0.05\end{array}$

\section{Haar}

$\begin{array}{lrrrl} & \text { Num } & \text { Den } & & \\ \text { Effect } & \text { DF } & \text { DF } & F \text { Value } & \text { Pr }>F \\ \text { time } & 3 & 24 & 1.78 & 0.1772\end{array}$

Least Squares Means

$\begin{array}{llrrrrrrrr} & & & \text { Standard } & & & \\ \text { Effect } & \text { time } & \text { Estimate } & \text { Error } & \text { DF } & t \text { Value } & \operatorname{Pr}>|t| & \text { Alpha } & \text { Lower } & \text { Upper } \\ \text { time } & 1 & 99689 & 64044 & 24 & 1.56 & 0.1327 & 0.05 & -32493 & 231870 \\ \text { time } & 2 & 214936 & 64044 & 24 & 3.36 & 0.0026 & 0.05 & 82755 & 347118 \\ \text { time } & 3 & 169315 & 64044 & 24 & 2.64 & 0.0142 & 0.05 & 37134 & 301496 \\ \text { time } & 4 & 249204 & 64044 & 24 & 3.89 & 0.0007 & 0.05 & 117022 & 381385\end{array}$

Differences of Least Squares Means

$\begin{array}{lllrrrrrrrr}\text { Effect } & \text { time } & \text { time } & \text { Estimate } & \begin{array}{r}\text { Standard } \\ \text { Error }\end{array} & \text { DF } & \text { t Value } & \operatorname{Pr}>|t| & \text { Adjustment } & \text { Adj P } & \text { Alpha } \\ \text { time } & 1 & 2 & -115248 & 68440 & 24 & -1.68 & 0.1052 & \text { Tukey-Kramer } & 0.3537 & 0.05 \\ \text { time } & 1 & 3 & -69626 & 68440 & 24 & -1.02 & 0.3191 & \text { Tukey-Kramer } & 0.7410 & 0.05 \\ \text { time } & 1 & 4 & -149515 & 68440 & 24 & -2.18 & 0.0389 & \text { Tukey-Kramer } & 0.1562 & 0.05 \\ \text { time } & 2 & 3 & 45622 & 68440 & 24 & 0.67 & 0.5114 & \text { Tukey-Kramer } & 0.9086 & 0.05 \\ \text { time } & 2 & 4 & -34267 & 68440 & 24 & -0.50 & 0.6211 & \text { Tukey-Kramer } & 0.9581 & 0.05 \\ \text { time } & 3 & 4 & -79889 & 68440 & 24 & -1.17 & 0.2546 & \text { Tukey-Kramer } & 0.6526 & 0.05\end{array}$




\section{Sym4}

$\begin{array}{lrrrl} & \text { Num } & \text { Den } & & \\ \text { Effect } & \text { DF } & \text { DF } & \text { F Value } & \text { Pr > F } \\ \text { time } & 3 & 24 & 1.76 & 0.1810\end{array}$

Least Squares Means

\begin{tabular}{|c|c|c|c|c|c|c|c|c|c|}
\hline & & & andard & & & & & & \\
\hline Effect & time & Estimate & Error & DF & t Value & $\operatorname{Pr}>|t|$ & Alpha & Lower & Upper \\
\hline time & 1 & 103588 & 58874 & 24 & 1.76 & 0.0912 & 0.05 & -17923 & 225098 \\
\hline time & 2 & 182262 & 58874 & 24 & 3.10 & 0.0049 & 0.05 & 60751 & 303773 \\
\hline ime & 3 & 131484 & 58874 & 24 & 2.23 & 0.0351 & 0.05 & 9973.75 & 252995 \\
\hline ime & 4 & 244987 & 58874 & 24 & 4.16 & 0.0004 & 0.05 & 123476 & 366497 \\
\hline
\end{tabular}

Differences of Least Squares Means

\begin{tabular}{|c|c|c|c|c|c|c|c|c|c|c|}
\hline Effect & time & time & Estimate & $\begin{array}{r}\text { Standard } \\
\text { Error }\end{array}$ & DF & t Value & $\mathrm{Pr}>|\mathrm{t}|$ & Adjustment & Adj $P$ & Alpha \\
\hline time & 1 & $\overline{2}$ & -78674 & 66193 & 24 & -1.19 & 0.2462 & Tukey-Kramer & 0.6397 & 0.05 \\
\hline time & 1 & 3 & -27897 & 66193 & 24 & -0.42 & 0.6772 & Tukey-Kramer & 0.9743 & 0.05 \\
\hline time & 1 & 4 & -141399 & 66193 & 24 & -2.14 & 0.0431 & Tukey-Kramer & 0.1705 & 0.05 \\
\hline time & 2 & 3 & 50778 & 66193 & 24 & 0.77 & 0.4505 & Tukey-Kramer & 0.8684 & 0.05 \\
\hline time & 2 & 4 & -62725 & 66193 & 24 & -0.95 & 0.3528 & Tukey-Kramer & 0.7797 & 0.05 \\
\hline :ime & 3 & 4 & -113502 & 66193 & 24 & -1.71 & 0.0993 & Tukey-Kramer & 0.3383 & 0.05 \\
\hline
\end{tabular}

\section{Sym5}

$\begin{array}{lrrrl} & \text { Num } & \text { Den } & & \\ \text { Effect } & \text { DF } & \text { DF } & F \text { Value } & \text { Pr }>F \\ \text { time } & 3 & 24 & 1.68 & 0.1987\end{array}$

Least Squares Means

$\begin{array}{llrrrrrrrr}\text { Effect } & \text { time } & \text { Estimate } & \begin{array}{r}\text { Standard } \\ \text { Error }\end{array} & \text { DF } & t \text { Value } & \operatorname{Pr}>|t| & \text { Alpha } & \text { Lower } & \text { Upper } \\ \text { time } & 1 & 98454 & 63656 & 24 & 1.55 & 0.1350 & 0.05 & -32926 & 229833 \\ \text { time } & 2 & 169820 & 63656 & 24 & 2.67 & 0.0135 & 0.05 & 38440 & 301199 \\ \text { time } & 3 & 149753 & 63656 & 24 & 2.35 & 0.0272 & 0.05 & 18373 & 281132 \\ \text { time } & 4 & 248582 & 63656 & 24 & 3.91 & 0.0007 & 0.05 & 117202 & 379961\end{array}$

Differences of Least Squares Means

$\begin{array}{lllrrrrrrrr}\text { Effect } & \text { time } & \text { time } & \text { Estimate } & \begin{aligned} \text { Standard } \\ \text { Error }\end{aligned} & \text { DF } & \text { t Value } & \text { Pr }>|t| & \text { Adjustment } & \text { Adj P } & \text { Alpha } \\ \text { time } & 1 & 2 & -71366 & 68100 & 24 & -1.05 & 0.3051 & \text { Tukey-Kramer } & 0.7234 & 0.05 \\ \text { time } & 1 & 3 & -51299 & 68100 & 24 & -0.75 & 0.4586 & \text { Tukey-Kramer } & 0.8744 & 0.05 \\ \text { time } & 1 & 4 & -150128 & 68100 & 24 & -2.20 & 0.0373 & \text { Tukey-Kramer } & 0.1507 & 0.05 \\ \text { time } & 2 & 3 & 20067 & 68100 & 24 & 0.29 & 0.7708 & \text { Tukey-Kramer } & 0.9909 & 0.05 \\ \text { time } & 2 & 4 & -78762 & 68100 & 24 & -1.16 & 0.2588 & \text { Tukey-Kramer } & 0.6591 & 0.05 \\ \text { time } & 3 & 4 & -98829 & 68100 & 24 & -1.45 & 0.1597 & \text { Tukey-Kramer } & 0.4812 & 0.05\end{array}$


Frequency Band, 6-12 Hz

\section{Bior1.5}

$\begin{array}{lrrrl} & \text { Num } & \text { Den } & & \\ \text { Effect } & \text { DF } & \text { DF } & \text { F Value } & \text { Pr }>F \\ \text { time } & 3 & 24 & 1.55 & 0.2264\end{array}$

Least Squares Means

$\begin{array}{llrrrrrrrr}\text { Effect } & \text { time } & \text { Estimate } & \begin{array}{r}\text { Standard } \\ \text { Error }\end{array} & \text { DF } & t \text { Value } & \text { Pr }>|t| & \text { Alpha } & \text { Lower } & \text { Upper } \\ \text { time } & 1 & 35966 & 21732 & 24 & 1.65 & 0.1109 & 0.05 & -8886.64 & 80818 \\ \text { time } & 2 & 78786 & 21732 & 24 & 3.63 & 0.0013 & 0.05 & 33934 & 123638 \\ \text { time } & 3 & 36355 & 21732 & 24 & 1.67 & 0.1073 & 0.05 & -8497.43 & 81207 \\ \text { time } & 4 & 51938 & 21732 & 24 & 2.39 & 0.0251 & 0.05 & 7085.56 & 96790\end{array}$

Differences of Least Squares Means

$\begin{array}{lllrrrrrrrr}\text { Effect } & \text { time } & \text { time } & \text { Estimate } & \begin{array}{r}\text { Standard } \\ \text { Error }\end{array} & \text { DF } & \text { t Value } & \operatorname{Pr}>|\mathrm{t}| & \text { Adjustment } & \text { Adj P } & \text { Alpha } \\ \text { time } & 1 & 2 & -42821 & 22814 & 24 & -2.11 & 0.0427 & \text { Tukey-Kramer } & 0.2142 & 0.05 \\ \text { time } & 1 & 3 & -389.21 & 22814 & 24 & -0.02 & 0.9865 & \text { Tukey-Kramer } & 1.0000 & 0.05 \\ \text { time } & 1 & 4 & -15972 & 22814 & 24 & -0.70 & 0.4906 & \text { Tukey-Kramer } & 0.8960 & 0.05 \\ \text { time } & 2 & 3 & 42431 & 22814 & 24 & 1.86 & 0.0752 & \text { Tukey-Kramer } & 0.2714 & 0.05 \\ \text { time } & 2 & 4 & 26848 & 22814 & 24 & 1.18 & 0.2508 & \text { Tukey-Kramer } & 0.6468 & 0.05 \\ \text { time } & 3 & 4 & -15583 & 22814 & 24 & -0.68 & 0.5011 & \text { Tukey-Kramer } & 0.9025 & 0.05\end{array}$

\section{Bior3.1}

$\begin{array}{lrrrl} & \text { Num } & \text { Den } & & \\ \text { Effect } & \text { DF } & \text { DF } & F \text { Value } & \text { Pr }>F \\ \text { time } & 3 & 24 & 2.78 & 0.03\end{array}$

Least Squares Means

$\begin{array}{llrrrrrrrr}\text { Effect } & \text { time } & \text { Estimate } & \begin{array}{r}\text { Standard } \\ \text { Error }\end{array} & \text { DF } & t \text { Value } & \text { Pr > }|t| & \text { Alpha } & \text { Lower } & \text { Upper } \\ \text { time } & 1 & 3006251 & 3489671 & 24 & 0.86 & 0.3975 & 0.05 & -4196075 & 10208577 \\ \text { time } & 2 & 6412599 & 3489671 & 24 & 1.84 & 0.0785 & 0.05 & -789728 & 13614925 \\ \text { time } & 3 & 2508198 & 3489671 & 24 & 0.72 & 0.4792 & 0.05 & -4694128 & 9710524 \\ \text { time } & 4 & 11761572 & 3489671 & 24 & 3.37 & 0.0025 & 0.05 & 4559246 & 18963898\end{array}$

Differences of Least Squares Means

\begin{tabular}{|c|c|c|c|c|c|c|c|c|c|c|}
\hline & time & _time & Estimate & $\begin{array}{r}\text { Standard } \\
\text { Error }\end{array}$ & DF & t Value & $P r>|t|$ & Adjustment & $\mathrm{Ad}$ & Alph \\
\hline & 1 & $\overline{2}$ & -3406348 & 4522446 & 24 & -0.75 & 0.4586 & Tukey-Kramer & 0.8744 & 0.05 \\
\hline Lme & 1 & 3 & 498053 & 4522446 & 24 & 0.11 & 0.9132 & Tukey-Kramer & 0.9995 & 0.05 \\
\hline & 1 & 4 & -8755321 & 4522446 & 24 & -2.10 & 0.0447 & Tukey-Kramer & 0.2402 & 0.05 \\
\hline & 2 & 3 & 3904401 & 4522446 & 24 & 0.86 & 0.3965 & Tukey-Kramer & 0.8235 & 0.05 \\
\hline & 2 & 4 & -5348973 & 4522446 & 24 & -1.18 & 0.2485 & Tukey-Kramer & 0.6432 & 0.05 \\
\hline & 3 & 4 & -9253374 & 4522446 & 24 & -2.08 & 0.0480 & Tukey-Kramer & 0.1996 & 0.05 \\
\hline
\end{tabular}




\section{Rbio3.1}

$\begin{array}{lrrrr} & \text { Num } & \text { Den } & & \\ \text { Effect } & \text { DF } & \text { DF } & F \text { Value } & \text { Pr > F } \\ \text { time } & 3 & 24 & 3.16 & 0.0205\end{array}$

Least Squares Means

\begin{tabular}{|c|c|c|c|c|c|c|c|c|c|}
\hline Effect & time & Estimate & $\begin{array}{r}\text { Standard } \\
\text { Error }\end{array}$ & DF & t Value & $\operatorname{Pr}>|t|$ & Alpha & Lower & Upper \\
\hline time & 2 & 18560756 & 6002733 & 24 & 3.09 & 0.0050 & 0.05 & 6171724 & 30949788 \\
\hline time & 4 & 14243979 & 6002733 & 24 & 2.37 & 0.0260 & 0.05 & 1854947 & 26633011 \\
\hline
\end{tabular}

Differences of Least Squares Means

$\begin{array}{lllrrrrrrrr}\text { Effect } & \text { time } & \text { time } & \text { Estimate } & \begin{array}{r}\text { Etandard } \\ \text { Error }\end{array} & \text { DF } & \text { t Value } & \text { Pr }>|t| & \text { Adjustment } & \text { Adj P } & \text { Alpha } \\ \text { time } & 1 & 2 & -1.239 E 7 & 6624210 & 24 & -2.13 & 0.0427 & \text { Tukey-Kramer } & 0.2169 & 0.05 \\ \text { time } & 1 & 3 & -2064468 & 6624210 & 24 & -0.31 & 0.7580 & \text { Tukey-Kramer } & 0.9892 & 0.05 \\ \text { time } & 1 & 4 & -8072844 & 6624210 & 24 & -2.62 & 0.0148 & \text { Tukey-Kramer } & 0.4214 & 0.05 \\ \text { time } & 2 & 3 & 10325152 & 6624210 & 24 & 1.56 & 0.1322 & \text { Tukey-Kramer } & 0.4200 & 0.05 \\ \text { time } & 2 & 4 & 4316776 & 6624210 & 24 & 0.65 & 0.5208 & \text { Tukey-Kramer } & 0.9139 & 0.05 \\ \text { time } & 3 & 4 & -6008376 & 6624210 & 24 & -2.31 & 0.0234 & \text { Tukey-Kramer } & 0.2013 & 0.05\end{array}$

\section{Coif5}

$\begin{array}{lrrrl} & \text { Num } & \text { Den } & & \\ \text { Effect } & \text { DF } & \text { DF } & F \text { Value } & \text { Pr }>F \\ \text { time } & 3 & 24 & 1.21 & 0.3290\end{array}$

Least Squares Means

\begin{tabular}{|c|c|c|c|c|c|c|c|c|c|}
\hline & & & andard & & & & & & \\
\hline Effect & time & Estimate & Error & DF & t Value & $\mathrm{Pr}>|\mathrm{t}|$ & Alpha & Lower & Upper \\
\hline time & 1 & 22179 & 18371 & 24 & 1.21 & 0.2391 & 0.05 & -15737 & 60094 \\
\hline time & 2 & 56875 & 18371 & 24 & 3.10 & 0.0049 & 0.05 & 18960 & 94790 \\
\hline time & 3 & 32096 & 18371 & 24 & 1.75 & 0.0934 & 0.05 & -5819.46 & 70011 \\
\hline :ime & 4 & 38926 & 18371 & 24 & 2.12 & 0.0446 & 0.05 & 1011.17 & 76842 \\
\hline
\end{tabular}

Differences of Least Squares Means

\begin{tabular}{|c|c|c|c|c|c|c|c|c|c|c|}
\hline & & & & tandard & & & & & & \\
\hline $\begin{array}{l}\text { Effect } \\
\text { time }\end{array}$ & $\begin{array}{l}\text { time } \\
1\end{array}$ & $\frac{2}{2}^{\text {time }}$ & $\begin{array}{r}\text { Estimate } \\
-34696\end{array}$ & $\begin{array}{l}\text { Error } \\
18831\end{array}$ & $\begin{array}{l}\text { DF } \\
24\end{array}$ & $\begin{array}{r}\text { t Value } \\
-2.05\end{array}$ & $\begin{array}{r}\operatorname{Pr}>|t| \\
0.0510\end{array}$ & $\begin{array}{l}\text { Adjustment } \\
\text { Tukey-Kramer }\end{array}$ & $\begin{array}{r}\text { Adj P } \\
0.2789\end{array}$ & $\begin{array}{r}\text { Alpha } \\
0.05\end{array}$ \\
\hline time & 1 & 3 & -9917.20 & 18831 & 24 & -0.53 & 0.6033 & Tukey-Kramer & 0.9518 & 0.05 \\
\hline time & 1 & 4 & -16748 & 18831 & 24 & -0.89 & 0.3826 & Tukey-Kramer & 0.8104 & 0.05 \\
\hline time & 2 & 3 & 24779 & 18831 & 24 & 1.32 & 0.2007 & Tukey-Kramer & 0.5622 & 0.05 \\
\hline time & 2 & 4 & 17949 & 18831 & 24 & 0.95 & 0.3500 & Tukey-Kramer & 0.7767 & 0.05 \\
\hline ime & 3 & 4 & -6830.63 & 18831 & 24 & -0.36 & 0.7200 & Tukey-Kramer & 0.9833 & 0.05 \\
\hline
\end{tabular}




\section{Db2}

$\begin{array}{lrrrr} & \text { Num } & \text { Den } & & \\ \text { Effect } & \text { DF } & \text { DF } & F \text { Value } & \text { Pr }>F \\ \text { time } & 3 & 24 & 0.98 & 0.4198\end{array}$

Least Squares Means

$\begin{array}{llrrrrrrrr}\text { Effect } & \text { time } & \text { Estimate } & \begin{array}{r}\text { Standard } \\ \text { Error }\end{array} & \text { DF } & t \text { Value } & \operatorname{Pr}>|t| & \text { Alpha } & \text { Lower } & \text { Upper } \\ \text { time } & 1 & 28781 & 23416 & 24 & 1.23 & 0.2309 & 0.05 & -19548 & 77110 \\ \text { time } & 2 & 58911 & 23416 & 24 & 2.52 & 0.0190 & 0.05 & 10582 & 107240 \\ \text { time } & 3 & 39335 & 23416 & 24 & 1.68 & 0.1060 & 0.05 & -8993.53 & 87664 \\ \text { time } & 4 & 75888 & 23416 & 24 & 3.24 & 0.0035 & 0.05 & 27559 & 124217\end{array}$

Differences of Least Squares Means

$\begin{array}{lllrrrrrrrr}\text { Effect } & \text { time } & \text { _time } & \text { Estimate } & \begin{array}{c}\text { Standard } \\ \text { Error }\end{array} & \text { DF } & t \text { Value } & \text { Pr }>|t| & \text { Adjustment } & \text { Adj } P & \text { Alpha } \\ \text { time } & 1 & 2 & -30130 & 29909 & 24 & -1.01 & 0.3238 & \text { Tukey-Kramer } & 0.7467 & 0.05 \\ \text { time } & 1 & 3 & -10554 & 29909 & 24 & -0.35 & 0.7273 & \text { Tukey-Kramer } & 0.9846 & 0.05 \\ \text { time } & 1 & 4 & -47107 & 29909 & 24 & -1.58 & 0.1283 & \text { Tukey-Kramer } & 0.4111 & 0.05 \\ \text { time } & 2 & 3 & 19576 & 29909 & 24 & 0.65 & 0.5190 & \text { Tukey-Kramer } & 0.9129 & 0.05 \\ \text { time } & 2 & 4 & -16977 & 29909 & 24 & -0.57 & 0.5756 & \text { Tukey-Kramer } & 0.9407 & 0.05 \\ \text { time } & 3 & 4 & -36552 & 29909 & 24 & -1.22 & 0.2335 & \text { Tukey-Kramer } & 0.6193 & 0.05\end{array}$

\section{Db5}

$\begin{array}{lrrrr} & \text { Num } & \text { Den } & & \\ \text { Effect } & \text { DF } & \text { DF } & \text { F Value } & \text { Pr }>F \\ \text { time } & 3 & 24 & 2.48 & 0.0858\end{array}$

Least Squares Means

$\begin{array}{llrrrrrrrr}\text { Effect } & \text { time } & \text { Estimate } & \begin{array}{r}\text { Standard } \\ \text { Error }\end{array} & \text { DF } & t \text { Value } & \text { Pr }>|t| & \text { Alpha } & \text { Lower } & \text { Upper } \\ \text { time } & 1 & 25907 & 12543 & 24 & 2.07 & 0.0498 & 0.05 & 19.4541 & 51795 \\ \text { time } & 2 & 55790 & 12543 & 24 & 4.45 & 0.0002 & 0.05 & 29902 & 81678 \\ \text { time } & 3 & 21952 & 12543 & 24 & 1.75 & 0.0929 & 0.05 & -3935.39 & 47840 \\ \text { time } & 4 & 41983 & 12543 & 24 & 3.35 & 0.0027 & 0.05 & 16095 & 67871\end{array}$

Differences of Least Squares Means

\begin{tabular}{|c|c|c|c|c|c|c|c|c|c|c|}
\hline Effect & time & _time & Estimate & $\begin{array}{r}\text { Standard } \\
\text { Error }\end{array}$ & DF & t Value & $\operatorname{Pr}>|t|$ & Adjustment & Adj $P$ & Alpha \\
\hline & 1 & 2 & -29883 & 13982 & 24 & -2.14 & 0.0430 & Tukey-Kramer & 0.1702 & 0.05 \\
\hline & 1 & 3 & 3954.85 & 13982 & 24 & 0.28 & 0.7797 & Tukey-Kramer & 0.9919 & 0.05 \\
\hline & 1 & 4 & -16076 & 13982 & 24 & -1.15 & 0.2616 & Tukey-Kramer & 0.6632 & 0.05 \\
\hline & 2 & 3 & 33838 & 13982 & 24 & 2.42 & 0.0235 & Tukey-Kramer & 0.1001 & 0.05 \\
\hline & 2 & 4 & 13807 & 13982 & 24 & 0.99 & 0.3333 & Tukey-Kramer & 0.7578 & 0.05 \\
\hline & 3 & 4 & -20031 & 13982 & 24 & -1.43 & 0.1649 & Tukey-Kramer & 0.4922 & 0.05 \\
\hline
\end{tabular}




\section{Db45}

$\begin{array}{lrrrl} & \text { Num } & \text { Den } & & \\ \text { Effect } & \text { DF } & \text { DF } & \text { F Value } & \text { Pr }>F \\ \text { time } & 3 & 24 & 1.17 & 0.3415\end{array}$

Least Squares Means

$\begin{array}{llr}\text { Effect } & \text { time } & \text { Estimate } \\ \text { time } & 1 & 17530 \\ \text { time } & 2 & 46380 \\ \text { time } & 3 & 32574 \\ \text { time } & 4 & 34759\end{array}$

Standard

$\begin{array}{rrrrrrr}\text { Error } & \text { DF } & \mathrm{t} \text { Value } & \text { Pr }>|\mathrm{t}| & \text { Alpha } & \text { Lower } & \text { Upper } \\ 14789 & 24 & 1.19 & 0.2475 & 0.05 & -12993 & 48053 \\ 14789 & 24 & 3.14 & 0.0045 & 0.05 & 15857 & 76903 \\ 14789 & 24 & 2.20 & 0.0375 & 0.05 & 2051.21 & 63097 \\ 14789 & 24 & 2.35 & 0.0273 & 0.05 & 4235.66 & 65282\end{array}$

Differences of Least Squares Means

$\begin{array}{lllrrrrrrrr}\text { Effect } & \text { time } & \text { time } & \text { Estimate } & \begin{array}{r}\text { Standard } \\ \text { Error }\end{array} & \text { DF } & \text { t Value } & \text { Pr }>|t| & \text { Adjustment } & \text { Adj P } & \text { Alpha } \\ \text { time } & 1 & 2 & -28851 & 15492 & 24 & -1.86 & 0.0749 & \text { Tukey-Kramer } & 0.2704 & 0.05 \\ \text { time } & 1 & 3 & -15044 & 15492 & 24 & -0.97 & 0.3412 & \text { Tukey-Kramer } & 0.7669 & 0.05 \\ \text { time } & 1 & 4 & -17229 & 15492 & 24 & -1.11 & 0.2771 & \text { Tukey-Kramer } & 0.6857 & 0.05 \\ \text { time } & 2 & 3 & 13806 & 15492 & 24 & 0.89 & 0.3817 & \text { Tukey-Kramer } & 0.8094 & 0.05 \\ \text { time } & 2 & 4 & 11622 & 15492 & 24 & 0.75 & 0.4604 & \text { Tukey-Kramer } & 0.8757 & 0.05 \\ \text { time } & 3 & 4 & -2184.46 & 15492 & 24 & -0.14 & 0.8890 & \text { Tukey-Kramer } & 0.9990 & 0.05\end{array}$

\section{Haar}

$\begin{array}{lrrrl} & \text { Num } & \text { Den } & & \\ \text { Effect } & \text { DF } & \text { DF } & \text { F Value } & \text { Pr }>F \\ \text { time } & 3 & 24 & 1.88 & 0.1593\end{array}$

Least Squares Means

\begin{tabular}{|c|c|c|c|c|c|c|c|c|c|}
\hline & & & andard & & & & & & \\
\hline time & 2 & 74230 & 21638 & 24 & 3.43 & 0.0022 & 0.05 & 29571 & 118889 \\
\hline time & 4 & 73170 & 21638 & 24 & 3.38 & 0.0025 & 0.05 & 28511 & 117829 \\
\hline
\end{tabular}

Differences of Least Squares Means

$\begin{array}{lllrrrrrrrr}\text { Effect } & \text { time } & \text { _time } & \text { Estimate } & \begin{array}{r}\text { Standard } \\ \text { Error }\end{array} & \text { DF } & \text { t Value } & \text { Pr > }|t| & \text { Adjustment } & \text { Adj P Alpha } \\ \text { time } & 1 & 2 & -38954 & 20849 & 24 & -1.87 & 0.0740 & \text { Tukey-Kramer } & 0.2678 & 0.05 \\ \text { time } & 1 & 3 & -7602.92 & 20849 & 24 & -0.36 & 0.7186 & \text { Tukey-Kramer } & 0.9830 & 0.05 \\ \text { time } & 1 & 4 & -37894 & 20849 & 24 & -1.82 & 0.0816 & \text { Tukey-Kramer } & 0.2899 & 0.05 \\ \text { time } & 2 & 3 & 31351 & 20849 & 24 & 1.50 & 0.1457 & \text { Tukey-Kramer } & 0.4509 & 0.05 \\ \text { time } & 2 & 4 & 1060.38 & 20849 & 24 & 0.05 & 0.9599 & \text { Tukey-Kramer } & 1.0000 & 0.05 \\ \text { time } & 3 & 4 & -30291 & 20849 & 24 & -1.45 & 0.1592 & \text { Tukey-Kramer } & 0.4803 & 0.05\end{array}$




\section{Sym4}

$\begin{array}{lrrrr} & \text { Num } & \text { Den } & & \\ \text { Effect } & \text { DF } & \text { DF } & \text { F Value } & \text { Pr > F } \\ \text { time } & 3 & 24 & 0.62 & 0.6096\end{array}$

Least Squares Means

\begin{tabular}{|c|c|c|c|c|c|c|c|c|c|}
\hline Effect & time & Estimate & $\begin{array}{l}\text { andard } \\
\text { Error }\end{array}$ & DF & t Value & $\operatorname{Pr}>|t|$ & Alpha & Lower & Upper \\
\hline time & 2 & 56270 & 21649 & 24 & 2.60 & 0.0157 & 0.05 & 11588 & 100952 \\
\hline time & 4 & 56237 & 21649 & 24 & 2.60 & 0.0158 & 0.05 & 11555 & 100919 \\
\hline
\end{tabular}

Differences of Least Squares Means

$\begin{array}{lllrrrrrrrr}\text { Effect } & \text { time } & \text { time } & \text { Estimate } & \begin{array}{r}\text { Standard } \\ \text { Error }\end{array} & \text { DF } & \text { t Value } & \text { Pr }>|t| & \text { Adjustment } & \text { Adj P } & \text { Alpha } \\ \text { time } & 1 & 2 & -27829 & 23879 & 24 & -1.17 & 0.2553 & \text { Tukey-Kramer } & 0.6537 & 0.05 \\ \text { time } & 1 & 3 & -14268 & 23879 & 24 & -0.60 & 0.5558 & \text { Tukey-Kramer } & 0.9318 & 0.05 \\ \text { time } & 1 & 4 & -27795 & 23879 & 24 & -1.16 & 0.2559 & \text { Tukey-Kramer } & 0.6546 & 0.05 \\ \text { time } & 2 & 3 & 13560 & 23879 & 24 & 0.57 & 0.5754 & \text { Tukey-Kramer } & 0.9407 & 0.05 \\ \text { time } & 2 & 4 & 33.4274 & 23879 & 24 & 0.00 & 0.9989 & \text { Tukey-Kramer } & 1.0000 & 0.05 \\ \text { time } & 3 & 4 & -13527 & 23879 & 24 & -0.57 & 0.5763 & \text { Tukey-Kramer } & 0.9411 & 0.05\end{array}$

\section{Sym5}

$\begin{array}{lrrrl} & \text { Num } & \text { Den } & & \\ \text { Effect } & \text { DF } & \text { DF } & \text { F Value } & \text { Pr }>\text { F } \\ \text { time } & 3 & 24 & 1.03 & 0.3958\end{array}$

Least Squares Means

$\begin{array}{llrrrrrrrr}\text { Effect } & \text { time } & \text { Estimate } & \begin{array}{r}\text { Standard } \\ \text { Error }\end{array} & \text { DF } & t \text { Value } & \text { Pr }>|t| & \text { Alpha } & \text { Lower } & \text { Upper } \\ \text { time } & 1 & 23701 & 18715 & 24 & 1.27 & 0.2175 & 0.05 & -14924 & 62326 \\ \text { time } & 2 & 52904 & 18715 & 24 & 2.83 & 0.0093 & 0.05 & 14279 & 91529 \\ \text { time } & 3 & 33871 & 18715 & 24 & 1.81 & 0.0829 & 0.05 & -4754.26 & 72496 \\ \text { time } & 4 & 59839 & 18715 & 24 & 3.20 & 0.0039 & 0.05 & 21214 & 98464\end{array}$

Differences of Least Squares Means

$\begin{array}{lllrrrrrrrr}\text { Effect } & \text { time } & \text {-time } & \text { Estimate } & \begin{array}{r}\text { Standard } \\ \text { Error }\end{array} & \text { DF } & \text { t Value } & \text { Pr }>|t| & \text { Adjustment } & \text { Adj P Alpha } \\ \text { time } & 1 & 2 & -29204 & 23241 & 24 & -1.26 & 0.2210 & \text { Tukey-Kramer } & 0.5983 & 0.05 \\ \text { time } & 1 & 3 & -10170 & 23241 & 24 & -0.44 & 0.6656 & \text { Tukey-Kramer } & 0.9714 & 0.05 \\ \text { time } & 1 & 4 & -36139 & 23241 & 24 & -1.55 & 0.1330 & \text { Tukey-Kramer } & 0.4221 & 0.05 \\ \text { time } & 2 & 3 & 19034 & 23241 & 24 & 0.82 & 0.4209 & \text { Tukey-Kramer } & 0.8449 & 0.05 \\ \text { time } & 2 & 4 & -6934.99 & 23241 & 24 & -0.30 & 0.7680 & \text { Tukey-Kramer } & 0.9905 & 0.05 \\ \text { time } & 3 & 4 & -25969 & 23241 & 24 & -1.12 & 0.2749 & \text { Tukey-Kramer } & 0.6826 & 0.05\end{array}$

